\title{
NOVEL SLURRY PHASE DIESEL CATALYSTS FOR COAL-DERIVED SYNGAS
}

\author{
Final Report \\ Period: 6/22/99-8/31/01 \\ Submitted by \\ Dr. Dragomir B. Bukur (Professor) \\ Department of Chemical Engineering \\ Texas A\&M University \\ College Station, TX 77843-3122 \\ Contributors:
Texas A\&M University: Dr. Ketil Hanssen (Research Associate)
Alec Klinghoffer (Graduate Student)
Dr. Lech Nowicki (Research Associate)
Patricia O'Dowd (Graduate Student)
University of New Mexico: Dr. Hien Pham (Research Associate)
Brigham Young University: Jian Xu (Graduate Student)

January 7, 2001

\author{
Prepared for \\ University of New Mexico \\ Under DOE Grant No. DE-FG26-98FT40110 \\ Co-Investigators
}

Abhaya K. Datye (Professor)

University of New Mexico

Department of Chemical Engr. and

Director, Center for Micro-engineered

Materials

Albuquerque, NM 87131
Calvin Bartholomew (Professor)

Brigham Young University

Department of Chemical Engr.

Provo, UT 84602 


\section{Disclaimer}

This report was prepared as an account of work sponsored by an agency of the United States Government. Neither the United States Government nor any agency thereof, nor any of their employees, makes any warranty, express or implied, or assumes any legal liability or responsibility for the accuracy, completeness, or usefulness of any information, apparatus, product or process disclosed, or represents that its use would not infringe privately owned rights. Reference herein to any specific commercial product, process, or service by trade name, trademark, manufacturer, or otherwise does not necessarily constitute or imply its endorsement, recommendation, or favoring by the United States Government or any agency thereof. The views and opinions of authors expressed herein do not necessarily state or reflect those of the United States Government or any agency thereof. 


\begin{abstract}
This report describes research conducted to support the DOE program in novel slurry phase catalysts for converting coal-derived synthesis gas to diesel fuels. The primary objective of this research program is to develop attrition resistant catalysts that exhibit high activities for conversion of coal-derived syngas. Three partner institutions, University of New Mexico (UNM), Texas A\&M University (TAMU) and Brigham Young University (BYU) have actively worked together to develop these novel catalysts.

Specifically, at TAMU we have synthesized several alumina (from Condea) and silica (Davison 948) supported iron Fischer-Tropsch (F-T) catalysts, determined their attrition properties (in collaboration with the UNM) under both reactive and non-reactive conditions, and evaluated their performance during F-T synthesis in a stirred tank slurry reactor (STSR). Also, we have determined attrition properties of a precipitated iron F-T catalyst with nominal composition $100 \mathrm{Fe} / 3 \mathrm{Cu} / 4 \mathrm{~K} / 16 \mathrm{SiO}_{2}$ (in parts by weight) in a STSR under both reactive and non-reactive conditions. This catalyst was developed at TAMU under DOE sponsorship (Contracts DE-AC22-89PC89968 and DE-AC22-94PC93069) and has excellent performance characteristics: high activity and productivity, excellent stability with time and high selectivity to liquid hydrocarbons and wax.

During extended F-T synthesis tests in the STSR we found that the alumina supported catalysts showed formation of fine particles (about $15 \mathrm{wt} \%$ ) in the size range of $1-10 \mu \mathrm{m}$. The silica supported catalyst was more resistant to erosion than the alumina supports. Attrition resistance behavior of the precipitated TAMU catalyst was comparable to or better than that of Davison 948 silica in both types of attrition tests (ultrasound fragmentation and STSR tests). Its attrition resistance could be further improved by preparing the catalyst in form of micro-spherical particles (e.g. by spray drying).
\end{abstract}

Alumina supported catalyst (20wt\% Fe/ $\gamma$-alumina; promoted with $1.6 \mathrm{wt} \%$ of $\mathrm{Cu}$ and $\mathrm{K}$ ) had higher initial activity and better selectivity to $\mathrm{C}_{5}+$ hydrocarbons than the silica supported catalyst $(20 \mathrm{wt} \% \mathrm{Fe} /$ silica; promoted with $1.6 \mathrm{wt} \%$ of $\mathrm{Cu}$ and $\mathrm{K}$ ) but it deactivated more severely. Further work is needed to improve stability and selectivity of supported catalysts. 


\section{TABLE OF CONTENTS}

Disclaimer

Abstract

Executive Summary

Technical Objectives

Task 1. Project Orientation and Equipment Testing

Task 2. Catalyst Synthesis and Characterization 8

Experimental

Results and Discussion

Conclusions

Task 3. Attrition Resistance Tests

Results and Discussion

Conclusions

Task 4. Catalyst Testing and Data Analysis $\quad 15$

Experimental

Results and Discussion

Conclusions

Acknowledgements

References

Figures 1-22

Appendix A. Collaborative F-T Paper

Appendix C. Progress Report submitted by BYU 


\section{Executive Summary}

This report covers a three year period of cooperative research grant under the University Coal Research program. This research program involves a partnership between three institutions, University of New Mexico (UNM), Texas A\&M University (TAMU) and Brigham Young University (BYU). The three partner institutions have actively worked together to develop novel catalysts for converting coal-derived synthesis gas to diesel fuels. The catalysts were designed for slurry phase Fischer-Tropsch synthesis, which is recognized as the preferred mode for operation of F-T reactors. Slurry phase catalysts based on Fe tend to break down into fine particles leading to severe operational difficulties in separating the hydrocarbon products from the catalyst. The primary objective of this research program has been to develop attrition resistant catalysts that exhibit high activities for conversion of coal derived syngas $\left(\mathrm{H}_{2} / \mathrm{CO}\right.$ feed ratio of $\left.\sim 2 / 3\right)$.

Studies conducted at TAMU were focused on synthesis of supported Fe catalysts, evaluation of their attrition properties in a stirred tank slurry reactor (STSR) under both reactive and non-reactive conditions, F-T synthesis reaction studies in STSR to determine activity, selectivity and stability of supported catalysts. Also, we have determined attrition properties of a precipitated iron F-T catalyst with nominal composition $100 \mathrm{Fe} / 3 \mathrm{Cu} / 4 \mathrm{~K} / 16 \mathrm{SiO}_{2}$ (in parts by weight) in a STSR under both reactive and non-reactive conditions. This catalyst was developed at TAMU under DOE sponsorship (Contracts DE-AC22-89PC89968 and DEAC22-94PC93069) and has excellent performance characteristics: high activity and productivity, excellent stability with time and high selectivity to liquid hydrocarbons and wax. However, its attrition properties have not been determined yet. Here we briefly summarize the major accomplishments and results.

\section{Catalyst Synthesis}

Several catalysts were prepared by aqueous incipient wetness impregnation (IWI) of commercially available alumina (Condea HP 14 and Condea HP 14-150) and silica (Davison 948) supports. All synthesized catalysts had iron loading of $20 \mathrm{wt} \%$. Copper $(\mathrm{Cu})$ and potassium $(\mathrm{K})$ were used as standard promoters, in the following proportions relative to iron: $100 \mathrm{Fe} / 8 \mathrm{Cu} / 8 \mathrm{~K}$ (in parts per weight), which corresponds to $1.6 \mathrm{wt} \%$ loading for each of the two promoters. With the Davison 948 silica support catalysts were prepared by both aqueous and organic (methanol as solvent) impregnation to study the effect of preparation procedure on catalytic performance.

\section{Attrition Properties of Supported and Precipitated Catalysts}

Commercially available supports were tested first for their attrition resistance using the ultrasonic fragmentation test at the UNM. The more promising supports were tested then by TAMU in a STSR, where either $\mathrm{N}_{2}$ gas or syngas was bubbled during stirring to simulate the mechanical forces that would be encountered during slurry phase reactor operation. Subsequently, UNM performed particle size and SEM tests of these supports and/or catalysts to correlate the ultrasonic test results with those from the more extended testing in a STSR. 
Alumina supports (Condea HP 14 and Condea HP 14-150) showed evidence of significant fracture, and some break-up due to erosion, during the ultrasonic fragmentation tests. Davison 948 silica and precipitated TAMU catalyst were resistant to ultrasonic fragmentation, and showed very little erosion. Several of these supports were then tested in a stirred tank reactor under simulating F-T synthesis reaction conditions for 168 hours. We found that the STSR testing may be more severe to erosion in terms of its effect on the breakup of the support particles. However, both the alumina and Davison 948 silica supports were found to be sufficiently strong for further testing under reaction conditions. In the next step, the synthesized F-T catalysts were tested under actual F-T reaction conditions for extended times (up to 318 hours). With the alumina supported catalysts fine particles in the size range of 1-10 $\mu \mathrm{m}$ were generated (about $15 \mathrm{wt} \%$ ). The silica supported catalyst (Davison 948) is more resistant to erosion than the alumina supported catalysts. Attrition resistance behavior of the precipitated TAMU catalyst was comparable to or better than that of Davison 948 silica in both types of tests (ultrasound fragmentation and STSR tests). Its attrition resistance could be further improved by preparing the catalyst in form of micro-spherical particles (e.g. by spray drying).

\section{Catalyst Testing in a STSR}

Results from tests with $\mathrm{Cu}$ and $\mathrm{K}$ promoted $\mathrm{Fe}$ catalysts prepared by aqueous IWI of supports, showed that calcined $\gamma$-alumina (HP 14-150) is a more promising support than boehmite alumina (HP 14) for F-T synthesis. Calcination of $\gamma$-alumina is an important step, and the catalyst prepared by IWI of calcined support (at $500^{\circ} \mathrm{C}$ for 5 hours) was superior to the one prepared by IWI of uncalcined (as received) support. Silica supported catalyst had both lower initial activity and selectivity to $\mathrm{C}_{5}+$ hydrocarbons than the calcined $\gamma$-alumina supported catalyst, but it deactivated less severely. Improvements in stability are needed for both silica and alumina supported catalysts.

With $\mathrm{Cu}$ and $\mathrm{K}$ promoted $20 \% \mathrm{Fe} / \mathrm{SiO}_{2}$ catalysts, the catalyst prepared from methanol solution had better activity maintenance than the catalyst prepared from aqueous solution. However, the initial catalyst activity was the same for both catalysts. Hydrocarbon selectivity of the catalyst prepared by organic IWI was inferior (more methane and less $\mathrm{C}_{5}+$ products) compared to the catalyst prepared by aqueous IWI. The expected promotional effects of $\mathrm{K}$ (increase in molecular weight of hydrocarbon products, increased olefinicity, increase in WGS activity) were observed to a relatively small extent on the catalyst prepared by aqueous impregnation, but were less evident on the catalyst prepared by organic impregnation. F-T activity was not significantly affected by addition of $\mathrm{Cu}$ and $\mathrm{K}$ promoters. The amount of $\mathrm{K}$ promoter used is rather high ( 8 parts per 100 parts of $\mathrm{Fe}$ on weight basis) compared to Fe precipitated catalysts, but its promotional effect was small. This is indicative of promoter-support interactions and/or decreased Fe-K contact.

Silica and alumina supported catalysts produced significantly more methane (4-8 \% on carbon atom basis) than the precipitated TAMU catalyst ( $2.5 \%)$. Also, both their activity and stability were inferior in comparison to that of the precipitated catalyst. Further work is needed to develop basic understanding of underlying causes for differences in the reaction behaviors and to synthesize improved supported Fe catalysts for slurry phase F-T synthesis. 


\section{Technical Objectives}

The objective of this research project is to develop attrition resistant catalysts that exhibit high activities for conversion of coal-derived syngas to produce diesel fuels. The overall program is divided into the following tasks:

Task 1. Project Orientation and Equipment Testing

Task 2. Catalyst Synthesis and Characterization

Task 3. Attrition Resistance Tests

Task 4. Catalyst Testing and Data Analysis

In task 1, TAMU will prepare their fixed-bed and slurry reactors, and get their analytical system including gas chromatographs ready for product analysis. Shakedown runs with reactors will be conducted, and standard mixtures representative of F-T products (aqueous phase, organic phase and wax) will be analyzed.

In task 2, synthesis and characterization of precipitated and supported Fe catalysts will be performed collaboratively at BYU, TAMU and UNM. Characterization of these catalysts includes $\mathrm{H}_{2}$ chemisorption, BET surface area measurements, SEM, TEM, XRD and Mössbauer studies to map out the microstructure of the prepared catalysts. Temperature programmed reduction (TPR) as well as isothermal reduction studies in a TGA will measure the reducibility of the catalysts synthesized.

In task 3, attrition tests at the micro-scale will be performed at UNM using the ultrasonic fragmentation approach. In addition, attrition tests will be performed in a stirred tank slurry reactor (STSR) at TAMU. Particle size distributions will be measured at UNM by a sedigraph particle size analyzer after extraction of the wax from the powder. Both TEM and SEM will be used at UNM to investigate the mechanism of attrition - erosion vs. fracture.

In task 4, selected catalysts will be evaluated in a STSR (TAMU) or a fixed bed reactor (BYU). Slurry samples from the STSR runs will be periodically withdrawn from the reactor in an inert atmosphere for particle size distribution measurements and catalyst characterization at UNM and/or BYU. 


\section{Description of Technical Progress}

\section{Task 1. Project Orientation and Equipment Testing}

Shakedown tests in fixed bed and slurry reactors were successfully completed to test the equipment for reaction studies. Graduate students and postdoctoral fellows were trained in the use of gas chromatographs for product quantification, as well as the existing software for data analysis.

\section{Task 2. Catalyst Synthesis and Characterization}

Catalysts synthesized at TAMU were prepared by incipient wetness impregnation (IWI) of commercially available alumina and silica supports. All synthesized catalysts had iron (Fe) loading of $20 \mathrm{wt} \%$. Copper $(\mathrm{Cu})$ and potassium $(\mathrm{K})$ were used as standard promoters, in the following proportions relative to iron: $100 \mathrm{Fe} / 8 \mathrm{Cu} / 8 \mathrm{~K}$ (in parts per weight).

\section{Experimental}

2.1a Preparation of Catalysts by Aqueous Incipient Wetness Impregnation

Commercial supports were first dried for 2 hours at $110^{\circ} \mathrm{C}$ in a vacuum, then sieved to 325140 mesh $(45-106 \mu \mathrm{m})$. The sieved support was calcined for 5 hours at $500^{\circ} \mathrm{C}$ (heating rate of $5^{\circ} \mathrm{C} / \mathrm{min}$ ) without gas flow, and then cooled down to a room temperature.

Catalysts were prepared by co-impregnation with aqueous solutions containing desired amounts of iron nitrate, copper nitrate and potassium bicarbonate in one (silica supported catalysts) or two (alumina supported catalysts) steps using the incipient wetness method. Impregnation was conducted by placing the desired amounts of support and aqueous solution of iron and promoter salts in small Teflon coated container $6.5 \mathrm{~cm}$ in diameter, $8 \mathrm{~cm}$ in height) and its content was stirred with a Teflon bar.

After each impregnation, the resulting mixture was transferred into a rotating shaft evaporator and the water was partially removed by creating a vacuum for 2.5 hours in a water bath at $50^{\circ} \mathrm{C}$. The catalyst precursor was then transferred into a glass tube and dried in flowing air $(100 \mathrm{ml} / \mathrm{min})$ at $105-110^{\circ} \mathrm{C}$ for $5 \mathrm{~h}$.

After the final impregnation/drying step the catalyst precursor was heated in flowing air (3 $\mathrm{Nl} / \mathrm{g}$-cat/h) from room temperature to $180^{\circ} \mathrm{C}$ at $1{ }^{\circ} \mathrm{C} / \mathrm{min}$, held for 2 hours at $180^{\circ} \mathrm{C}$ to decompose any remaining nitrates. After this the air temperature was increased to $300^{\circ} \mathrm{C} \mathrm{(at}$ $1{ }^{\circ} \mathrm{C} / \mathrm{min}$ ) and held at $300^{\circ} \mathrm{C}$ for another $5 \mathrm{~h}$. After cooling in air, the catalyst was crushed (alumina supported catalysts only) and sieved to 325-140 mesh (45-106 $\mu \mathrm{m})$.

\section{1b Preparation of Catalysts by Organic Incipient Wetness Impregnation}

Preparation of unpromoted $20 \% \mathrm{Fe}$, and $100 \mathrm{Fe} / 8 \mathrm{Cu} / 8 \mathrm{Na}$ on Davison 948 silica catalysts by organic IWI was identical to that described for aqueous IWI, except that methanol was used as a solvent, instead of water. The impregnation was completed in four steps due to lower solubility of $\mathrm{Fe}, \mathrm{Cu}$ and $\mathrm{Na}$ nitrate salts in methanol relative to water. Preparation procedure 
for catalysts containing $20 \mathrm{wt} \% \mathrm{Fe}$ and $\mathrm{Cu}$ and $\mathrm{K}$ as promoters was slightly different, due to low solubility of potassium salts in methanol. This catalyst was first impregnated with $\mathrm{Fe}$ and $\mathrm{Cu}$ salts, and then with potassium acetate dissolved in methanol. Davison 948 silica was first co-impregnated with nitrate salts of $\mathrm{Fe}$ and $\mathrm{Cu}$ dissolved in methanol. This was accomplished in four steps with drying between each step as described above for catalysts prepared by aqueous impregnation. After the final impregnation the catalyst was calcined in flowing air (see above). Following this the catalyst was impregnated with the desired amount of potassium acetate salt dissolved in methanol in one step. The impregnated catalyst was placed in the evaporator, followed by drying in air, and finally heated and calcined at $300^{\circ} \mathrm{C}$ for 5 hours.

\section{1c Synthesis of Precipitated Iron Catalyst $\left(100 \mathrm{Fe} / 3 \mathrm{Cu} / 4 \mathrm{~K} / 16 \mathrm{SiO}_{2}, 59.7 \mathrm{wt} \% \mathrm{Fe}\right)$}

Catalyst preparation consisted of three distinct steps: preparation of the iron-copper precursor, incorporation of silica binder, and impregnation by potassium. The constant - $\mathrm{pH}$ precipitation technique used to prepare the $\mathrm{Fe} / \mathrm{Cu}$ catalyst precursor was described in detail previously (Bukur et al., 1989, 1990a). In brief, the catalyst precursor was continuously precipitated at $82^{\circ} \mathrm{C}$ from a flowing aqueous solution containing iron and copper nitrates at the desired $\mathrm{Fe} / \mathrm{Cu}$ ratio, using aqueous ammonia. The precipitate was then thoroughly washed with distilled water by vacuum filtration. Silicon oxide was incorporated by addition of an appropriate amount of dilute $(26 \mathrm{wt} \%) \mathrm{K}_{2} \mathrm{SiO}_{3}$ solution to undried, reslurried $\mathrm{Fe} / \mathrm{Cu}$ coprecipitate, followed by adjustment of $\mathrm{pH}$ to $\leq 6$ to ensure complete deposition of the silicate.

After a vacuum drying step, the potassium promoter was added as aqueous $\mathrm{KHCO}_{3}$ solution via an incipient wetness pore filling technique. The final step was to dry the catalyst at $120^{\circ} \mathrm{C}$ for 16 hours in a vacuum oven. The dried catalyst was calcined in air at $300^{\circ} \mathrm{C}$ for 5 $\mathrm{h}$, and then crushed and sieved to $45-106 \mu \mathrm{m}$ size range (140/325 mesh sieves).

\subsection{Isothermal Reduction by Thermal Gravimetric Analysis}

Isothermal reduction in thermogravimetric analysis (TGA) experiments was conducted using approximately $20 \mathrm{mg}$ catalyst samples in a simultaneous TGA/DTA apparatus (TA Instruments, Model SDT 2960). The catalyst sample was purged with helium $\left(40 \mathrm{~cm}^{3} / \mathrm{min}\right)$ and temperature was ramped at a rate of $5^{\circ} \mathrm{C} / \mathrm{min}$ from room temperature to a desired reduction temperature $\left(280^{\circ} \mathrm{C}\right)$ and then held at this temperature for 30 minutes to remove adsorbed moisture from the sample. The sample weight at the end of the heating period in helium is taken as a reference weight of the sample. After that, the flow was switched to pure $\mathrm{H}_{2}$, and weight loss of sample was recorded as a function of time. The observed weight loss is related to the degree of reduction of $\mathrm{Fe}_{2} \mathrm{O}_{3}$. The degree of reduction is calculated by dividing the observed weight loss with the theoretical weight loss corresponding to the complete reduction of $\mathrm{Fe}_{2} \mathrm{O}_{3}$ to metallic $\mathrm{Fe}$. Contribution from reduction of $\mathrm{CuO}$ to $\mathrm{Cu}$ has been neglected, whereas the other oxides in a sample are assumed to remain in the oxide form. 


\section{Results and Discussion}

Table 1 summarizes properties of support materials used to synthesize catalysts at TAMU. Surface areas and pore volumes of uncalcined (as received) supports were reported by suppliers (W. R. Grace - silica supports, Condea Vista- alumina supports) whereas particle density measurements and surface areas of calcined supports were made at the UNM.

Table 1. Selected Support Properties

\begin{tabular}{|l|c|c|c|c|c|c|c|c|}
\hline Designation & $\begin{array}{c}\text { Davison } \\
952\end{array}$ & \multicolumn{2}{|c|}{ Davison 948} & \multicolumn{2}{c|}{$\begin{array}{c}\text { Condea } \\
\text { HP 14-150 }\end{array}$} & \multicolumn{2}{c|}{$\begin{array}{c}\text { Condea } \\
\text { HP } 14\end{array}$} & $\begin{array}{c}\text { Condea } \\
\text { Vista B }\end{array}$ \\
\hline Type & \multicolumn{2}{|c|}{ Silica gel } & \multicolumn{2}{c|}{$\gamma$-Alumina } & \multicolumn{3}{c|}{ Boehmite } \\
\hline & uncalc. & uncalc. & calcined $^{\mathrm{a}}$ & uncalc. & calcined & uncalc. & calcined & uncalc. \\
\hline $\begin{array}{l}\text { Density } \\
\left(\mathrm{g} / \mathrm{cm}^{3}\right)\end{array}$ & 2.22 & 2.09 & 2.08 & 3.07 & 3.07 & 2.71 & 2.68 & 2.24 \\
\hline $\begin{array}{l}\text { Pore volume } \\
\left(\mathrm{cm}^{3} / \mathrm{g}\right)\end{array}$ & 1.61 & 1.62 & & 0.97 & & 0.94 & & 0.47 \\
\hline $\begin{array}{l}\text { Surface area } \\
\left(\mathrm{m}^{2} / \mathrm{g}\right)\end{array}$ & 309 & 279 & 304 & 153 & 157 & 150 & 156 & 243 \\
\hline
\end{tabular}

${ }^{\text {a }}$ Calcined in air at $500^{\circ} \mathrm{C}$ for 5 hours

Condea HP 14 and HP 14-150 microspherical particles (prepared by spray drying)

Davison 952 and Condea Vista B were used as catalyst supports at TAMU during the DOE contract (DE-AC22-94PC93069) and their attrition properties were evaluated at the UNM. Silica supports have higher surface areas and pore volumes than the alumina supports used in our studies. Calcination at $500^{\circ} \mathrm{C}$ for 5 hours does not have significant effect on physical properties of support materials. Calcined (at $300^{\circ} \mathrm{C}$ for 5 hours) precipitated iron catalyst $\left(100 \mathrm{Fe} / 3 \mathrm{Cu} / 4 \mathrm{~K} / 16 \mathrm{SiO}_{2}\right)$ has the BET surface area of $291 \mathrm{~m}^{2} / \mathrm{g}$ and the pore volume of $0.43 \mathrm{~cm}^{3} / \mathrm{g}$.

Reduction behavior of alumina and silica supported catalysts $(100 \mathrm{Fe} / 8 \mathrm{Cu} / 8 \mathrm{~K}, 20 \mathrm{wt} \% \mathrm{Fe})$ prepared by aqueous impregnation is shown in Figure 1. As can be seen from this figure reducibility of iron decreases in the order: $\mathrm{SiO}_{2}>\gamma-\mathrm{Al}_{2} \mathrm{O}_{3}$ (HP 14-150 uncalcined) $>\gamma$ alumina (HP 14-150 calcined) $>$ Boehmite $\mathrm{Al}_{2} \mathrm{O}_{3}$ (HP 14 calcined). Reduction of iron is complete after about 3 hours with the silica supported catalyst, and nearly complete $(95 \%$ reduction) with uncalcined HP 14-150 supported catalyst after 8 hours. Final degree of reduction of iron on boehmite alumina type support (HP 14) was only $54 \%$ after 8 hours. 
The effect of preparation method (aqueous vs. organic impregnation) and promoters (unpromoted catalyst vs. $100 \mathrm{Fe} / 8 \mathrm{Cu} / 8 \mathrm{~K}$, both with $20 \mathrm{wt} \% \mathrm{Fe}$ loading) on the reduction behavior is shown in Figure 2. It can be seen that the presence of promoters (primarily $\mathrm{Cu}$ ) improves reduction of iron regardless of the preparation method. Reducibility of iron was improved with organic impregnation for the unpromoted catalyst, whereas in the presence of promoters the rate of reduction was slightly higher with the catalyst prepared by aqueous impregnation (up to 6 hours). Calculated degrees of reduction with promoted silica catalysts in Figures 1 and 2 exceed $100 \%$ after 3-4 hours of reduction, due to experimental errors in measured weights and/or catalyst compositions.

Samples of synthesized catalysts, as well as samples withdrawn from a stirred tank slurry reactor tests (under both reactive and non-reactive conditions) were sent to our collaborators at the UNM and BYU for characterization studies by SEM/TEM, XRD and/or Mössbauer spectroscopy. Results from these characterization studies can be found in sections of the report prepared by the UNM and BYU.

\section{Conclusions}

Several catalysts were prepared by aqueous incipient wetness impregnation (IWI) of commercially available alumina (Condea HP 14 and Condea HP 14-150) and silica (Davison 948) supports. All synthesized catalysts had iron loading of $20 \mathrm{wt} \%$. Copper $(\mathrm{Cu})$ and potassium $(\mathrm{K})$ were used as standard promoters, in the following proportions relative to iron: $100 \mathrm{Fe} / 8 \mathrm{Cu} / 8 \mathrm{~K}$ (in parts per weight), which corresponds to $1.6 \mathrm{wt} \%$ loading for each of the two promoters. With the Davison 948 silica support catalysts were prepared by both aqueous and organic (methanol as solvent) impregnation to study the effect of preparation procedure on catalytic performance. Also, $\mathrm{Na}$ was used as a promoter instead of $\mathrm{K}$, for the catalyst prepared from methanol solution (organic IWI). Two unpromoted silica supported catalysts (20 wt\% Fe loading) were synthesized from both aqueous and methanol solutions for catalytic studies of the effect of promoters on activity and selectivity.

Reduction behavior of synthesized catalysts was studied in a TGA unit using pure $\mathrm{H}_{2}$ as reducing gas at $280^{\circ} \mathrm{C}$. For promoted catalysts prepared from aqueous solutions reducibility of iron decreases in the order: $\mathrm{SiO}_{2}>\gamma-\mathrm{Al}_{2} \mathrm{O}_{3}$ (HP 14-150 uncalcined) $>\gamma-\mathrm{Al}_{2} \mathrm{O}_{3}$ (HP 14-150 calcined) $>$ Boehmite $\mathrm{Al}_{2} \mathrm{O}_{3}$ ( $\mathrm{HP} 14$ calcined). Presence of $\mathrm{Cu}$ improves reduction of iron regardless of the preparation method (aqueous vs. organic impregnation). Reducibility of iron was improved with organic impregnation for the unpromoted catalyst.

\section{Task 3. Attrition Resistance Tests}

We have examined several commercially available silica and alumina supports (Table 1) to determine their suitability for preparing attrition-resistant Fe catalysts. Two types of tests were conducted to assess the attrition resistance of various support materials as well as that of a precipitated iron catalyst $\left(100 \mathrm{Fe} / 3 \mathrm{Cu} / 4 \mathrm{~K} / 16 \mathrm{SiO}_{2}\right)$. In ultrasonic fragmentation tests, conducted at the UNM, catalyst (or support) particles were subjected to ultrasound energy over different time periods, and particle size distribution was measured after different 
exposures to ultrasonic fragmentation (Kalakkad et al., 1995; Pham et al., 1999, 2000). Attrition properties were also studied under reactive and nonreactive conditions in a stirred tank slurry reactor (STSR) at TAMU. Under non-reacting conditions, nitrogen was used as the feed gas, while under reacting F-T conditions; syngas was used as the feed gas. Slurry samples were withdrawn from the STSR and particle size distributions were subsequently measured at UNM after extraction of slurry liquid from the powder. A brief description of experimental procedures employed is provided here, followed by description of results from tests with supports and catalysts conducted at TAMU. More comprehensive information on attrition testing, including a wider range of supports and catalysts can be found in a section of the report prepared by the UNM.

\section{Experimental}

\subsection{Ultrasound Fragmentation Testing}

In a typical run, $1 \mathrm{~g}$ of catalyst or support was added to $50 \mathrm{ml}$ of a $0.05 \mathrm{wt} . \%$ sodium hexametaphosphate solution which was used as a dispersing agent. A Micromeritics Sedigraph 5100 analyzer was used to measure the particle size distribution at time 0 min. The suspension was then subjected to ultrasonic energy at an amplitude setting of 20 (100 W) at 5 min intervals using a Tekmar 501 ultrasonic disrupter equipped with a V1A horn and a $12.7 \mathrm{~mm}(1 / 2 ")$ probe tip $(20 \mathrm{kHz} \pm 50 \mathrm{~Hz})$. After different extents of ultrasonic irradiation, the particle size distribution was analyzed to detect the mode of particle break-up.

\subsection{Attrition Testing in a Stirred Tank Slurry Reactor}

Experiments were conducted in a $1 \mathrm{dm}^{3}$ reactor (Autoclave Engineers, Erie, Pennsylvania). A standard six-blade turbine impeller of $3.2 \mathrm{~cm}$ in diameter and a stirrer speed of $1200 \mathrm{rpm}$ were used in all experiments. In a typical experiment the reactor was charged with $25 \mathrm{~g}$ of support (or catalyst) dispersed in 450-470 $\mathrm{g}$ of Durasyn-164 (hydrogenated 1-decene homopolymer). Nitrogen at $260^{\circ} \mathrm{C}, 1.48 \mathrm{MPa}(200 \mathrm{psig})$ and $3 \mathrm{Nl} / \mathrm{g} / \mathrm{h}$ was used as the feed gas in experiments under nonreactive conditions $(\mathrm{Nl}=$ Normal liter at standard temperature, $0^{\circ} \mathrm{C}$, and pressure, 1 bar). Slurry samples were withdrawn from the STSR at $0,8,24$ and 168 $\mathrm{h}$ of stirring, and Durasyn-164 was removed by filtration aided by addition of a commercial solvent Varsol (mixture of liquid hydrocarbons and oxygenates). Washing with Varsol was done to remove Durasyn-164 (or wax in the case of experiments under reactive conditions) from catalyst (support) porous structure. Dry particles were sent to UNM for particle size distribution measurements (Micromeritics Sedigraph 5100 analyzer).

Slurry samples were also withdrawn from the STSR during F-T synthesis at $260^{\circ} \mathrm{C}, 1.48$ 2.17 MPa, 0.8-1.2 Nl/g-cat/h using syngas feed with $\mathrm{H}_{2} / \mathrm{CO}$ molar feed ratio of $\sim 2 / 3$. After removal of slurry liquid and wax from pores a dry catalyst powder was shipped to UNM for particle size distribution measurements. This provides information on the combined effect of phase transformations, which occur during F-T synthesis and physical break-up of particles (due to particle collisions and shearing effects), on attrition properties of the catalyst. 


\section{Results and Discussion}

Figure 3 shows a cumulative particle size distribution plot of mass finer (\%) vs. equivalent spherical diameters for representative support materials used for preparation of catalysts by IWI at TAMU, and of precipitated iron catalyst (uncalcined form) during ultrasound fragmentation tests. Fracture of particles is seen for two alumina supports (Figs. 3a and 3b), as indicated by the shift in curves to the right with time, i.e., towards smaller size particles. However, more fine particles are seen with Condea HP 14-150 ( $\gamma$-alumina) than with Condea HP 14 (boehmite) during ultrasonic irradiation. Nevertheless, very little generation of fine particles due to erosion (as indicated by an increase in the percentage of fines for a particular particle size) is seen below $6 \mu \mathrm{m}$ for Condea HP 14 and $3 \mu \mathrm{m}$ for Condea HP 14-150. The median particle sizes for Condea HP 14 and HP 140/150 are $37 \mu \mathrm{m}$ and $32 \mu \mathrm{m}$, respectively. SEM images (not shown) showed that Condea HP 14 and HP 14-150 particles are roughly spherical in shape, suggesting that these alumina particles came from a spray-drying process. For Davison 948 (Figure 3c) very little attrition of particles due to fracture is seen after 25 min of ultrasonic irradiation. The median particle size is $34 \mu \mathrm{m}$. There is very little generation of fine particles due to erosion below $6 \mu \mathrm{m}$. SEM images showed that Davison 948 particles are roughly spherical. Uncalcined precipitated iron catalyst $(100 \mathrm{Fe} / 3 \mathrm{Cu} / 4$ $\mathrm{K} / 16 \mathrm{SiO}_{2}$ ) showed very little fragmentation and erosion during ultrasound fragmentation test (Figure 3d). Similar results (not shown) were obtained after calcination at $300^{\circ} \mathrm{C}$ for $5 \mathrm{~h}$. Precipitated catalyst particles are irregularly shaped (as indicated by SEM) and its median size was $13 \mu \mathrm{m}$ (uncalcined catalyst) and $16 \mu \mathrm{m}$ (calcined catalyst).

Results from attrition tests in a STSR under non-reacting conditions are shown in Figure 4. In this case, Condea HP 14 and HP 14-150 supports do not show significant fracture, but there is generation of fine particles in the $1-10 \mu \mathrm{m}$ range after use in the STSR after $8 \mathrm{~h}$ of stirring (Figures $4 \mathrm{a}$ and $4 \mathrm{~b}$ ). The amount of fines does not increase with time (up to $168 \mathrm{~h}$ ). Davison 948 silica shows some fragmentation (distribution shifts to the right) after 8 hours in the STSR (Fig. 4c). Some erosion is evident after 24 and 168 hours of testing, but the production of fines is lower in comparison to the two alumina supports. The erosion of supports was more pronounced during the STSR tests of supported catalysts than during the ultrasonic irradiation tests.

Precipitated TAMU catalyst $\left(100 \mathrm{Fe} / 3 \mathrm{Cu} / 4 \mathrm{~K} / 16 \mathrm{SiO}_{2}\right)$ calcined at $300^{\circ} \mathrm{C}$ for 5 hours showed very little change in particle size distribution (high attrition strength) during 161 hours of testing in $\mathrm{N}_{2}$ atmosphere (Figure $4 \mathrm{~d}$ ). Very little erosion is observed in 5-6 $\mu \mathrm{m}$ range. After $161 \mathrm{~h}$ of testing in $\mathrm{N}_{2}$ the catalyst was reduced in pure $\mathrm{CO}$ at $0.8 \mathrm{MPa}(100$ psig), $280^{\circ} \mathrm{C}$ and space velocity of $3 \mathrm{Nl} / \mathrm{g}$-cat $/ \mathrm{h}$ for 8 hours. Following the reduction with $\mathrm{CO}$ the flow was switched to $\mathrm{N}_{2}$ at $260^{\circ} \mathrm{C}, 1.48 \mathrm{MPa}$ and $3 \mathrm{Nl} / \mathrm{g}$-cat/h to assess the attrition resistance of the $\mathrm{CO}$ reduced catalyst. Particle size distribution (PSD) determined by Sedigraph analyzer shows shift to the left, which is indicative of particle agglomeration (the fraction of particles finer than a given particle size decreases relative to TOS $=161$ hours). This is believed to be due to experimental artifacts and errors. For example, this could result from a loss of small particles during slurry filtration and/or errors in particle density measurements. The same trend, i.e. shift of PSD to the left, was also observed with some of the supported catalyst samples withdrawn from the STSR during F-T synthesis (Figure 5). 
Figure 5 shows results of PSD measurements of catalyst samples withdrawn from the STSR during F-T synthesis reaction studies. The first sample (TOS $=0 \mathrm{hr}$ ) was withdrawn from the reactor prior to $\mathrm{CO}$ reduction (calcined catalyst in oxide form). All catalysts were reduced in $\mathrm{CO}$ at $280^{\circ} \mathrm{C}, 0.8 \mathrm{MPa}$ and $3 \mathrm{Nl} / \mathrm{g}$-cat/h for 8 hours prior to introduction of syngas $\left(\mathrm{H}_{2} / \mathrm{CO}=\right.$ $2 / 3$ ). Initially, all catalysts were tested at $260^{\circ} \mathrm{C}, 1.48 \mathrm{MPa}$ and $4 \mathrm{Nl} / \mathrm{g}-\mathrm{Fe} / \mathrm{h}$. In some runs the catalysts were also tested at $2.17 \mathrm{MPa}(300 \mathrm{psig})$ and $5.9 \mathrm{Nl} / \mathrm{g}-\mathrm{Fe} / \mathrm{h}$.

PSD shifted to the left with time in all cases, which is indicative of particle agglomeration. For $20 \% \mathrm{Fe} / \mathrm{HP} 14 \mathrm{Al}_{2} \mathrm{O}_{3}$ catalyst (run SB-1250), this trend was observed for particles greater than $10 \mu \mathrm{m}$, whereas for particles smaller than $10 \mu \mathrm{m}$ there was apparently some erosion with time (Figure 5a). Similar, but less pronounced, trend was observed in run SB1640 with $20 \% \mathrm{Fe}$ /uncalcined HP $14-150 \mathrm{Al}_{2} \mathrm{O}_{3}$ catalyst (Figure 5b). On the other hand, for the silica supported catalyst (run SA-1090) and precipitated TAMU catalyst (run SB-0470) the fraction of smaller particles decreased with time for all particle size ranges (Figures 5c and $5 \mathrm{~d}$ ). It should be noted that in run SB-0470 the catalyst was not exposed to syngas during the entire test. During first 161 hours the catalyst in oxide form was first exposed to $\mathrm{N}_{2}$ gas (Period 1). After reduction in $\mathrm{CO}$ for 8 hours the carbided catalyst was tested in $\mathrm{N}_{2}$ again between 170 and 282 hours (Period 2). Results from PSD measurements during these two periods (0-281 hours) are shown in Figure 4. Finally, between 284 and 405 hours on stream (Period 3), the catalyst was exposed to synthesis gas $\left(\mathrm{H}_{2} / \mathrm{CO}=2 / 3\right)$ at $260^{\circ} \mathrm{C}, 1.48$ $\mathrm{MPa}$ and $2.3 \mathrm{Nl} / \mathrm{g}$-cat/h.

\section{Conclusions}

The attrition behavior of several commercially available oxide supports and precipitated TAMU catalyst $\left(100 \mathrm{Fe} / 3 \mathrm{Cu} / 4 \mathrm{~K} / 16 \mathrm{SiO}_{2}\right)$ was studied by ultrasound fragmentation and testing in STSR. The ultrasonic fragmentation method requires a small sample amount and is much quicker than actual testing in a reactor. Condea HP 14 boehmite alumina, Condea HP 14-150 $\gamma-\mathrm{Al}_{2} \mathrm{O}_{3}$ and Davison 948 silica appear to be prepared by spray drying, since they have nearly spherical particles. Alumina supports showed evidence of significant fracture, and some break-up due to erosion, during the ultrasonic fragmentation tests. Davison 948 silica and precipitated TAMU catalyst were resistant to ultrasonic fragmentation, and showed very little erosion. Several of these supports were tested for long term periods in a stirred tank reactor under conditions simulating F-T synthesis reaction conditions. We found that the STSR testing may be more severe to erosion in terms of its effect on the break-up of the support particles. However, both the alumina and Davison 948 silica supports were found to be sufficiently strong for testing under reaction conditions. In the next step, we synthesized Fe F-T catalysts with $20 \mathrm{wt} \%$ loading on Condea alumina supports (HP 14 and HP 14-150) and Davison 948 silica support. These catalysts were then tested under actual F-T reaction conditions for extended times. With the alumina supported catalysts fine particles in the size range of 1-10 $\mu \mathrm{m}$ were generated (about $15 \mathrm{wt} \%$ ). The silica supported catalyst (Davison 948) appears to be more resistant to erosion than the alumina supports. Attrition resistance behavior of the precipitated TAMU catalyst was comparable to or better than that of Davison 948 silica in both types of tests (ultrasound fragmentation and STSR tests). Its attrition resistance could be further improved by preparing the catalyst in form of micro-spherical particles (e.g. by spray drying). 


\section{Task 4. Catalyst Testing and Data Analysis}

Catalysts synthesized in Task 2 were tested in a stirred tank slurry reactor (STSR) to determine their activity, selectivity and stability during F-T synthesis. A complete list of tests conducted and catalysts employed is given in Table 2.

Table 2. Catalysts tested and reaction conditions

\begin{tabular}{|c|c|c|c|}
\hline Run \# & Catalyst/Support* & Preparation & $\begin{array}{l}\text { Test conditions/ } \\
\text { Hours }\end{array}$ \\
\hline SB-0470 & $100 \mathrm{Fe} / 3 \mathrm{Cu} / 4 \mathrm{~K} / 16 \mathrm{SiO}_{2}$ & Precipitation & Baseline $(0-103 \mathrm{hrs})^{\mathrm{b}}$ \\
\hline SA-1090 & $20 \% \mathrm{Fe} /$ Davison $948 \mathrm{SiO}_{2}$ & Aqueous IWI & 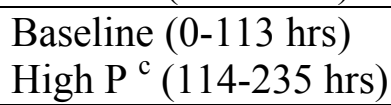 \\
\hline SB-1250 & $20 \% \mathrm{Fe} / \mathrm{HP} 14 \mathrm{Al}_{2} \mathrm{O}_{3}$ & Aqueous IWI & Baseline (0-160 hrs) \\
\hline SA-1380 & $20 \% \mathrm{Fe} / \mathrm{HP} 14-150 \mathrm{Al}_{2} \mathrm{O}_{3}$ & Aqueous IWI & 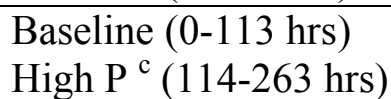 \\
\hline SB-1640 & $\begin{array}{l}20 \% \mathrm{Fe} / \mathrm{HP} 14-150 \mathrm{Al}_{2} \mathrm{O}_{3} \\
\text { (uncalcined support) }\end{array}$ & Aqueous IWI & $\begin{array}{l}\text { Baseline }(0-165 \mathrm{hrs}) \\
\text { High } \mathrm{P}^{\mathrm{c}}(166-236 \mathrm{hrs})\end{array}$ \\
\hline SA-1780 & $20 \% \mathrm{Fe} /$ Davison $948 \mathrm{SiO}_{2}$ & Organic IWI & $\begin{array}{l}\text { High SV }^{\mathrm{d}}(0-53 \mathrm{hrs}) \\
\text { Baseline }(54-195 \mathrm{hrs}) \\
\text { High P }^{\mathrm{c}}(196-318 \mathrm{hrs})\end{array}$ \\
\hline SA-2450 & $\begin{array}{l}20 \% \mathrm{Fe} / \mathrm{Davison} 948 \mathrm{SiO}_{2} \\
\text { (unpromoted) }\end{array}$ & Aqueous IWI & $\begin{array}{l}\text { Baseline }(0-130 \text { hrs }) \\
\text { Low SV }(131-240) \\
\text { High P }^{\text {f }}(242-315 \text { hrs })\end{array}$ \\
\hline SA-3210 & $\begin{array}{l}20 \% \mathrm{Fe} / \text { Davison } 948 \mathrm{SiO}_{2} \\
\text { (unpromoted) }\end{array}$ & Organic IWI & 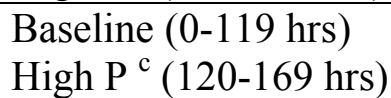 \\
\hline SB-1221 & $\begin{array}{l}20 \% \mathrm{Fe} / \text { Davison } 948 \mathrm{SiO}_{2} \\
(\mathrm{Na} \text { promoted })^{\mathrm{a}}\end{array}$ & Organic IWI & Baseline (0-160 hrs) \\
\hline
\end{tabular}

Footnotes for Table 2:

*All supports were calcined at $500^{\circ} \mathrm{C}$ for 5 hours unless indicated otherwise. All supported catalysts were promoted with both $\mathrm{Cu}$ and $\mathrm{K}(100 \mathrm{Fe} / 8 \mathrm{Cu} / 8 \mathrm{~K}$ in pbw) unless indicated otherwise. Unpromoted catalyst contains only Fe.

${ }^{\mathrm{a}}$ This catalyst contains $\mathrm{Na}$ instead of $\mathrm{K}$ as an alkali promoter $(100 \mathrm{Fe} / 8 \mathrm{Cu} / 8 \mathrm{Na}$ in pbw).

${ }^{\mathrm{b}}$ Baseline conditions: $\quad 260^{\circ} \mathrm{C}, \mathrm{H}_{2} / \mathrm{CO}=2 / 3, \mathrm{P}=1.48 \mathrm{MPa}, \mathrm{SV}=4.0 \mathrm{Nl} / \mathrm{g}-\mathrm{Fe} / \mathrm{h}$.

${ }^{\mathrm{c}}$ High P conditions: $\quad 260^{\circ} \mathrm{C}, \mathrm{H}_{2} / \mathrm{CO}=2 / 3, \mathrm{P}=2.17 \mathrm{MPa}, \mathrm{SV}=5.9 \mathrm{Nl} / \mathrm{g}-\mathrm{Fe} / \mathrm{h}$.

${ }^{\mathrm{d}}$ High SV conditions: $\quad 260^{\circ} \mathrm{C}, \mathrm{H}_{2} / \mathrm{CO}=2 / 3, \mathrm{P}=1.48 \mathrm{MPa}, \mathrm{SV}=6.0 \mathrm{Nl} / \mathrm{g}-\mathrm{Fe} / \mathrm{h}$.

${ }^{\mathrm{e}}$ Low SV conditions: $\quad 260^{\circ} \mathrm{C}, \mathrm{H}_{2} / \mathrm{CO}=2 / 3, \mathrm{P}=1.48 \mathrm{MPa}, \mathrm{SV}=2.1 \mathrm{Nl} / \mathrm{g}-\mathrm{Fe} / \mathrm{h}$.

${ }^{\mathrm{f}}$ High $\mathrm{P}$ conditions: $\quad 260^{\circ} \mathrm{C}, \mathrm{H}_{2} / \mathrm{CO}=2 / 3, \mathrm{P}=2.17 \mathrm{MPa}, \mathrm{SV}=3.1 \mathrm{Nl} / \mathrm{g}-\mathrm{Fe} / \mathrm{h}$.

The following coding system was used to designate experimental tests. Two letter prefix (SA or $\mathrm{SB}$ ) refers to the reactor unit used for the test $(\mathrm{S}=$ slurry reactor; A or B - reactor unit). The first three digits refer to the day of the year corresponding to the start of the run, whereas fourth digit corresponds to the last digit in the year of the start date (e.g. 0 for 2000. 1 for 2001). 


\section{Experimental}

A detailed description of our stirred tank slurry reactor and product analysis systems used in this study was provided elsewhere (Bukur et al., 1990b, 1994; Zimmerman and Bukur, 1990). Briefly, experiments were conducted in a $1 \mathrm{dm}^{3}$ reactor (Autoclave Engineers, Erie, Pennsylvania). A standard six-blade turbine impeller of $3.2 \mathrm{~cm}$ in diameter and a stirrer speed of $1200 \mathrm{rpm}$ were used in all experiments. The feed gas flow rate was adjusted with a mass flow controller and passed through a series of oxygen removal, alumina and activated charcoal traps to remove trace impurities. The feed was preheated before entering the reactor. After leaving the reactor, the exit gas passed through a series of high and low (ambient) pressure traps to condense liquid products.

During mass balance periods liquid products were allowed to accumulate in high and low pressure mass balance traps, and their mass was recorded at the conclusion of the mass balance period. After the startup, and following any change in process conditions, the reactor was allowed to operate undisturbed for 20 - 40 hours in order to achieve steady conditions before the next mass balance was performed. Liquid products, collected in a low pressure ice trap, were analyzed by gas chromatography. The reactants and noncondensible products leaving the ice traps were analyzed on an on-line GC (Carle AGC 400, Tulsa, Oklahoma) equipped with multiple columns and both flame ionization and thermal conductivity detectors.

Typically, the reactor was loaded with 20-25 g of catalyst and 420-460 g of start-up liquid (Durasyn 164). After pressure testing, the temperature was increased to $150^{\circ} \mathrm{C}$ at $120^{\circ} \mathrm{C} / \mathrm{h}$ in flowing $\mathrm{N}_{2}(3 \mathrm{Nl} / \mathrm{g}$-cat $/ \mathrm{h})$ and held at $150^{\circ} \mathrm{C}$ for 2 hours. Then, pressure was increased to $0.78 \mathrm{MPa}(100 \mathrm{psig})$ and temperature to $280^{\circ} \mathrm{C}$ at $65^{\circ} \mathrm{C} / \mathrm{h}$, followed by reduction at these conditions in $\mathrm{CO}(3 \mathrm{Nl} / \mathrm{g}$-cat $/ \mathrm{h})$ for $8 \mathrm{~h}\left(12 \mathrm{~h}\right.$ in run SA-1780). After cooling to $260^{\circ} \mathrm{C}$ in $\mathrm{N}_{2}$, the pressure was increased to $1.48 \mathrm{MPa}(200 \mathrm{psig})$ and the feed switched to syngas with a $\mathrm{H}_{2} / \mathrm{CO}$ ratio of 0.67 at a gas space velocity (SV) of $4 \mathrm{Nl} / \mathrm{g}-\mathrm{Fe} / \mathrm{h}$ (baseline process conditions). After 5-8 days on stream at the baseline conditions, the pressure was increased to $2.17 \mathrm{MPa}$ (300 psig), while the space velocity was adjusted to $5.9 \mathrm{Nl} / \mathrm{g}-\mathrm{Fe} / \mathrm{h}$ to give the same residence time in the reactor. In some tests (SA-1780 and SA-2450) different process conditions were employed as shown in Table 2. However, all catalysts were tested at the baseline process conditions for comparison purposes.

\section{Results and Discussion}

\subsection{Activity and Selectivity Definitions}

Before describing results from stirred tank slurry reactor tests we provide definitions of activity and selectivity used in this report.

$$
\left.\left(\mathrm{H}_{2}+\mathrm{CO}\right) \text { conversion }(\%)=100 \times\left(\left(\text { Moles of } \mathrm{H}_{2}+\mathrm{CO}\right)_{\text {in- }}-\left(\text { Moles of } \mathrm{H}_{2}+\mathrm{CO}\right)_{\text {out }}\right)\right) /\left(\text { Moles of } \mathrm{H}_{2}+\mathrm{CO}\right)_{\text {in }}
$$


Apparent reaction rate constant, $\mathrm{k}\left(\mathrm{mmol}\left(\mathrm{H}_{2}+\mathrm{CO}\right)\right.$ converted $\left./ \mathrm{g}-\mathrm{Fe} / \mathrm{h} / \mathrm{MPa}\right)$, was calculated assuming that the rate of disappearance of $\left(\mathrm{H}_{2}+\mathrm{CO}\right)$ has a first order dependence on hydrogen partial pressure:

$$
k=\frac{1000 \times S V \times X_{\mathrm{H}_{2}+\mathrm{CO}}}{22.4 \times P_{\mathrm{H}_{2}} \times w_{\mathrm{Fe}}}
$$

where: $\mathrm{SV}=$ gas space velocity $(\mathrm{Nl} / \mathrm{g}$-cat $/ \mathrm{h}) ; X_{\mathrm{H}_{2}+\mathrm{CO}}=$ syngas conversion $(-) ; P_{\mathrm{H}_{2}}=$ partial pressure of hydrogen $(\mathrm{MPa}) ; \mathrm{w}_{\mathrm{Fe}}=$ mass fraction of iron in the catalyst $(-)$.

$$
\mathrm{CO}_{2} \text { selectivity }(\%)=100 \times \frac{\left(n_{\mathrm{CO}_{2}}\right)_{\text {out }}}{\left(n_{\mathrm{CO}}\right)_{\text {in }}-\left(n_{\mathrm{CO}}\right)_{\text {out }}}
$$

Hydrocarbon selectivity on carbon atom basis is calculated from:

$$
S_{i j}(\%)=\frac{100 \times\left(\operatorname{in}_{i j}\right)}{\left(n_{C O}\right)_{\text {in }}-\left(n_{C O}\right)_{\text {out }}-\left(n_{\mathrm{CO}_{2}}\right)_{\text {out }}}
$$

where: $S_{i j}$ is the selectivity of hydrocarbon species $\mathrm{j}$ containing i carbon atoms, $n_{i j}$ is molar flow of compound $\mathrm{j}$ in the gas phase, $\left(n_{C O}\right)_{\text {in }}$ and $\left(n_{C O}\right)_{\text {out }}$ are molar flow rates of CO in and out of the reactor, and $\left(n_{\mathrm{CO}_{2}}\right)_{\text {out }}$ is the molar flow rate of carbon dioxide out of the reactor. The above formulas assume that there is no carbon dioxide in the feed.

Olefin selectivities (contents) are calculated as:

$$
\begin{aligned}
& \text { 1-olefin selectivity }(\%)=100 \times(1 \text {-olefin }) /(1 \text {-olefin }+2 \text {-olefin }) \\
& \text { 2-olefin selectivity }(\%)=100 \times(2 \text {-olefin }) /(1 \text {-olefin }+2 \text {-olefin })
\end{aligned}
$$

Total olefin selectivity $(\%)=100 \times$ (linear olefins) $/($ n-paraffin + linear olefins $)$

\subsection{Run SB-0470 with Precipitated Iron Catalyst $100 \mathrm{Fe} / 3 \mathrm{Cu} / 4 \mathrm{~K} / 16 \mathrm{SiO}_{2}$}

Some of precipitated iron F-T catalysts $\left(\mathrm{Fe} / \mathrm{Cu} / \mathrm{K} / \mathrm{SiO}_{2}\right)$ synthesized and tested at TAMU, under DOE sponsorship, have excellent performance characteristics. They are more active than iron catalysts developed by Mobil (Kuo, 1985) and Rheinpreussen (Kölbel et al., 1955) while exhibiting high syngas conversion and selectivity to liquid and wax hydrocarbons. One of the best catalysts developed at TAMU has a nominal composition of $100 \mathrm{Fe} / 3 \mathrm{Cu} / 4$ $\mathrm{K} / 16 \mathrm{SiO}_{2}$. 
Performance characteristics of this catalyst from tests in a STSR are as follows (Bukur et al., 1994, 1998, 1999a; Bukur 1999b):

- Syngas conversion: $80 \%$

- Catalyst productivity: $0.86 \mathrm{~g}-\mathrm{HC} / \mathrm{g}-\mathrm{Fe} \cdot \mathrm{h}$ (at $2.17 \mathrm{MPa}$ and $260^{\circ} \mathrm{C}$ )

- Low methane selectivity: $3 \mathrm{wt} \%$ (2.5\% on carbon atom basis)

- $\alpha=0.92-0.95$ (high alpha catalyst)

- $\mathrm{C}_{5}+$ selectivity: $\sim 85 \%$ (high yield of liquid and hydrocarbon wax)

- No deactivation after $500 \mathrm{~h}$ of testing (runs SA-0946 and SA-2186)

However, even though TAMU's catalyst performance is excellent in terms of activity, selectivity and stability, there is a concern that the catalyst is structurally too weak and that it may disintegrate during F-T synthesis in a slurry bubble column reactor to form fine particles. The presence of fine particles causes problems with wax/catalyst separation by filtration or use of gravity settlers.

In order to test attrition properties of this catalyst, as well as to perform a test of our reactor system and analytical procedures, a run SB-0470 was conducted. The start-up procedure for this test was different than that employed in other tests. The entire test had four distinct periods, whose characteristics and purpose were as follows:

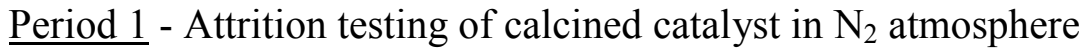

$\left(260^{\circ} \mathrm{C}, 1.48 \mathrm{MPa}, 3 \mathrm{Nl} / \mathrm{g}\right.$-cat/h, TOS $=0$-161 hours $)$

$\underline{\text { Period } 2}$ - Reduction with $\mathrm{CO}$ at $280{ }^{\circ} \mathrm{C}, 0.78 \mathrm{MPa}, 3 \mathrm{Ndm}^{3} /$ g-cat $/ \mathrm{h}$ for 8 hours $(162-170 \mathrm{~h})$

$\underline{\text { Period } 3}$ - Attrition testing of reduced catalyst in $\mathrm{N}_{2}$ atmosphere $\left(260^{\circ} \mathrm{C}, 1.48 \mathrm{MPa}, 3 \mathrm{Nl} / \mathrm{g}\right.$-cat/h, 170-282 hours)

$\underline{\text { Period } 4}$ - Fischer-Tropsch synthesis $\left(260^{\circ} \mathrm{C}, 1.48 \mathrm{MPa}, \mathrm{H}_{2} / \mathrm{CO}=0.67,2.3 \mathrm{Nl} / \mathrm{g}\right.$-cat $/ \mathrm{h}, 284$ 405 hours)

Catalyst samples were withdrawn from the reactor at: $0,24,161,186,281,308$ and $404 \mathrm{~h}$ on stream, and changes in particle size distribution with time were measured using a Sedigraph analyzer. Results from these measurements were described in the previous section of this report (Task 3. Attrition Resistance Tests) and it was found that this catalyst has good attrition properties (no fragmentation and very little erosion).

Figure 6 shows activity (syngas conversion), methane and $\mathrm{C}_{5}+$ hydrocarbon selectivity variation with time in runs SB-0470 and SA-0946. Run SA-0946 was conducted in 1986 (DOE Contract DE-AC-22-94PC93069) in the slurry reactor A using precipitated catalyst from a different preparation batch than that used in run SB-0470. Also, in run SA-0946 the catalyst was reduced with $\mathrm{CO}$ at the beginning of the test, and F-T synthesis was initiated immediately after the reduction, whereas in run SB-0470 the F-T synthesis was initiated after 274 hours of stirring in nitrogen. In spite of differences in operating procedure, reactor used, and preparation batch similar results were obtained in these two tests. Activity (measured by 
syngas conversion) was essentially the same in both tests. After 30 hours on stream methane selectivity was somewhat lower and $\mathrm{C}_{5}+$ selectivity higher in run SB-0470. These two tests confirm reproducibility of catalyst preparation procedure, which was established previously (Bukur et al., 1998; Bukur 1999b) and demonstrate robustness of this catalyst.

\subsection{Tests with Alumina Supported Catalysts}

Two types of alumina from Condea were used as supports: HP 14 (boehmite) and HP 14-150 $(\gamma$-alumina). The latter was used to prepare two different catalysts. In one case as received (uncalcined) support was impregnated with iron and promoter salts and the resulting catalyst was tested in run SB-1640, whereas the second catalyst was prepared by impregnation of the calcined support and tested in run SA-1380. Results from three tests with alumina supports at the baseline conditions $\left(260^{\circ} \mathrm{C}, 1.48 \mathrm{MPa}, 4 \mathrm{Nl} / \mathrm{g}-\mathrm{Fe} / \mathrm{h}, \mathrm{H}_{2} / \mathrm{CO}=2 / 3\right)$ are shown in Figures 7 and 8.

Catalyst prepared by impregnation of calcined $\gamma$-alumina (SA-1380) was the most active (Figures $7 \mathrm{a}$ and $7 \mathrm{~b}$ ), whereas catalyst prepared by impregnation of HP 14 alumina (SB-1250) was the least active. Both of these catalysts deactivated with time, whereas catalyst obtained by impregnation of uncalcined $\gamma$-alumina (SB-1640) was fairly stable during 165 hours of testing at the baseline conditions. Carbon dioxide selectivity is a measure of the extent of water-gas-shift (WGS) reaction, and 50\% selectivity corresponds to complete conversion of water produced in F-T synthesis reaction (primary reaction step) to $\mathrm{CO}_{2}$. The extent of WGS reaction follows the catalyst F-T activity (Figure $7 \mathrm{c}$ ); i.e. the catalyst with the highest F-T activity has the highest extent of the WGS reaction.

Methane selectivity was the least and $\mathrm{C}_{5}+$ selectivity the highest in run SA-1380 (Figure 8). Methane and $\mathrm{C}_{5}+$ selectivities in tests SB-1250 and SB-1640 were similar.

\subsection{Effect of Support Type (Silica vs. $\gamma$-Alumina)}

Results from tests with the calcined $\gamma$-alumina supported catalyst (SB-1380) and the silica supported catalyst (SA-1090) are shown in Figures 9 to 11. Both catalysts were prepared by aqueous impregnation (Table 2).

Figure 9 shows that the alumina supported catalyst was more active during testing at the baseline conditions $(\mathrm{P}=1.48 \mathrm{MPa})$, with syngas conversion decreasing from $70 \%$ initially to $60 \%$ after $100 \mathrm{~h}$ on stream. The silica supported catalyst also deactivated during this time period and syngas conversion decreased from $60 \%$ initially to $50 \%$ at $100 \mathrm{~h}$. After increasing pressure to $2.17 \mathrm{MPa}$ and gas space velocity (see Table 2) the alumina supported catalyst deactivated rapidly initially and then more slowly reaching $40 \%$ conversion at $280 \mathrm{~h}$ on stream, whereas the silica supported catalyst did not show any further deactivation. $\mathrm{CO}_{2}$ selectivity was similar for the two catalysts (Figure 9c) and was in the range $40-45 \%$.

Methane and $\mathrm{C}_{5}+$ selectivities were more favorable on the alumina supported catalyst (Figure 10). Methane selectivity on the silica supported catalyst was fairly stable (7-8\%), while in run SA-1380 it decreased from $6 \%$ initially to $4 \%$ after $200 \mathrm{~h}$ on stream (Figure 10a). As 
expected $\mathrm{C}_{5}+$ selectivity in run SA-1380 exhibited the opposite trend, i.e. it increased from $72 \%$ to almost $80 \%$ (Figure $10 \mathrm{~b}$ ). $\mathrm{C}_{5}+$ selectivity in run SA-1090 was fairly stable, about $70 \%$, decreasing somewhat after the increase in reaction pressure to $2.17 \mathrm{MPa}$.

Olefin selectivities are shown in Figure 11. The observed decrease in 1-olefin selectivity and increase in 2-olefin selectivity with increase in carbon number is due to secondary readsorption of 1-olefins and their subsequent conversion to n-paraffins (secondary hydrogenation) and to 2-olefins (secondary isomerization). Olefin selectivities were similar on both catalysts during testing at $1.48 \mathrm{MPa}$ (baseline process conditions). Upon increasing reaction pressure to $2.17 \mathrm{MPa}$ the 1-olefin selectivity increased and 2-olefin selectivity decreased in run SA-1380, whereas olefin selectivities did not change markedly with pressure in run SA-1090. The observed olefin selectivity trends in run SA-1380 may be explained in part by decrease in conversion, since lower conversion favors the primary reactions.

\subsection{Effect of Preparation Procedure (Aqueous vs. Organic Impregnation)}

\subsubsection{Runs SA-1090 and SA-1780 with Promoted Silica Supported Catalysts}

In an attempt to improve performance of the silica supported catalyst we used methanol as a solvent instead of water for incipient wetness impregnation (IWI). Two catalysts containing $20 \% \mathrm{Fe}$, and $\mathrm{Cu}$ and $\mathrm{K}$ as promoters $(100 \mathrm{Fe} / 8 \mathrm{Cu} / 8 \mathrm{~K}$ in pbw) prepared by these two methods (see Task 2. Catalyst Synthesis and Characterization), were tested in runs SA-1090 (aqueous IWI) and SA-1780 (organic IWI). Reduction time in CO was 8 hours in run SA1090 and 12 hours in run SA-1780. During first 53 hours on stream the catalyst in run SA1780 was tested at a gas space velocity higher than the baseline space velocity (see Table 2) but these results are not shown here.

Initial catalyst activities in both tests were about the same as shown in Figure 12. Initially the syngas conversion was $60-63 \%$ and the apparent reaction rate constant about 330 $\mathrm{mmol} / \mathrm{g}-\mathrm{Fe} / \mathrm{MPa} / \mathrm{h}$. Catalyst prepared from the organic solution did not deactivate during testing at the baseline conditions, whereas catalyst prepared from the aqueous solution deactivated with time and reached $46 \%$ syngas conversion at 150 hours. Catalyst activity was stable in both tests during testing at $2.17 \mathrm{MPa}$ and gas space velocity of $5.9 \mathrm{N1} / \mathrm{g}-\mathrm{Fe} / \mathrm{h}$. However, activity of the catalyst prepared by organic IWI method was higher. $\mathrm{CO}_{2}$ selectivities in both tests were between $40 \%$ and $45 \%$, and did not vary much with time (Figure 12c).

Methane selectivity (Figure 13a) in run SA-1090 was fairly constant (6-8\%). Methane selectivity on the catalyst prepared from the organic solution was about $11 \%$ during testing at the baseline conditions, and then started to decrease during testing at $2.17 \mathrm{MPa}$ reaching $9 \%$ at 300 hours. In run SA-1090 a maximum $\mathrm{C}_{5}+$ selectivity of $73 \%$ was reached after $60 \mathrm{~h}$ on stream, followed by a decrease to $65 \%$ at the end of the run $(235 \mathrm{~h}) . \mathrm{C}_{5}+$ selectivity in run SA-1780 exhibited the opposite trend, i.e. an increase from $63 \%$ during testing at $1.48 \mathrm{MPa}$ to $70 \%$ after increasing pressure to $2.17 \mathrm{MPa}$ (Figure 13b). Total olefin selectivity did not

vary much with time in both runs and average values are shown in Figure 13c. The catalyst 
prepared from the organic solution had markedly lower olefin selectivity, indicative of a high degree of secondary olefin hydrogenation.

\subsubsection{Runs SA-2450 and SA-3210 with Unpromoted Silica Supported Catalysts}

Two unpromoted $\left(20 \% \mathrm{Fe} /\right.$ Davison $\left.948 \mathrm{SiO}_{2}\right)$ catalysts were prepared in two different waysimpregnation from aqueous and from organic solution, and tested to further examine the effect of preparation procedure on the catalyst performance during F-T synthesis in the STSR. Results from tests SA-2450 (aqueous IWI) and SA-3210 (organic IWI) at the baseline reaction conditions are shown in Figures 14 and 15.

Catalyst prepared from methanol solution had higher activity than the catalyst prepared by aqueous impregnation of Davison 948 silica support, as reflected in higher syngas conversion and apparent reaction rate constant (Figures 14a and 14b). The apparent rate constant was about 50\% higher in run SA-3210. Activity was fairly stable during 120-130 hors of testing at the baseline conditions. $\mathrm{CO}_{2}$ selectivity was about $45 \%$ in run SA-3210 and $40 \%$ in run SA-2450 (Figure 14c). This difference is caused in part by differences in conversions between these two tests. Methane, $\mathrm{C}_{5}{ }^{+}$and olefin selectivities were similar in both tests (Figure 15).

\subsection{Promoter Effects (Unpromoted vs. $\mathrm{Cu}$ and K Promoted) on Silica Supported Catalysts}

Copper and potassium have been commonly used as promoters for precipitated iron F-T catalysts. The primary function of $\mathrm{Cu}$ promoter is to decrease the temperature required for reduction of iron oxides. This may result in higher catalyst F-T and WGS activity relative to unpromoted catalyst (Bukur et al., 1990c). Potassium promotion is known to increase: (1) the average molecular weight (chain length) of hydrocarbon products; (2) total olefin and 1olefin selectivities; (3) the extent of WGS reaction; (4) carbon deposition rate and catalyst deactivation rate (Anderson, 1956; Dry, 1981; Arakawa and Bell, 1983; Bukur et al., 1990c). Also, the addition of $\mathrm{K}$ may have effect on rate of F-T synthesis (both an increase and decrease in reaction rate has been reported depending on the level of $\mathrm{K}$ promotion). Dry (1981, 1983, 1990) reported, based on studies conducted at Sasol, that potassium forms chemical compounds with silica and alumina supports, resulting in reduction of alkali promotional effect. Here we report results on the effect of combined $\mathrm{Cu}$ and $\mathrm{K}$ promotion on silica supported catalysts prepared by both aqueous and organic impregnation.

\subsubsection{Promoter Effects on Silica Supported Catalysts Prepared by Aqueous Impregnation}

Results from tests with $\mathrm{Cu}+\mathrm{K}$ promoted (run SA-1090) and unpromoted (run SA-2450) $\mathrm{Fe}$ catalysts, prepared by aqueous impregnation of Davison 948 silica, are shown in Figures 16 to 18 . Initial activity of the promoted catalyst was slightly higher (Figures 16a and 16b) than that of the unpromoted catalyst, but the former deactivated faster with time and the activity trend was reversed after about 100 hours on stream. The unpromoted catalyst did not show signs of deactivation during 130 hours of testing at the baseline conditions. A discontinuity (drop in conversion and $\mathrm{k}$ values) at $90 \mathrm{~h}$ on stream is due to temporary drop in reaction 
temperature. $\mathrm{CO}_{2}$ selectivity of the promoted catalyst was slightly higher (Figure 16c), but in general both the F-T synthesis and WGS activity were similar on both catalysts.

Promoted catalyst has lower methane and higher $\mathrm{C}_{5}+$ selectivity than the unpromoted catalyst (Figure 17) which is consistent with the expected promotional effect of K. However, the promotional effect is rather small. The promoted catalyst has relatively high methane selectivity and low $\mathrm{C}_{5}+$ selectivity in comparison to TAMU's precipitated Fe catalyst (see Figure 6). The unpromoted catalyst had slightly lower 1-olefin selectivity and higher 2olefin selectivity relative to the promoted catalyst (Figure 18), both of which are in qualitative agreement with the expected effect of K promotion on olefin selectivity.

\subsubsection{Promoter Effects on Silica Supported Catalysts Prepared by Methanol Impregnation}

Comparison of activity and selectivity of the unpromoted (SA-3210) and $\mathrm{Cu}+\mathrm{K}$ promoted (SA-1780) catalysts, prepared by organic impregnation of Davison 948 silica, is shown in Figures 19 and 20.

Both F-T catalyst activity (measured by syngas conversion) and WGS activity (measured by $\mathrm{CO}_{2}$ selectivity) were similar on both catalysts (Figure 19). The unpromoted catalysts had lower methane and $\mathrm{C}_{5}+$ selectivity than the promoted catalyst (Figure 20). The expected lower methane selectivity with $\mathrm{K}$ promotion was not observed in this case, indicating that $\mathrm{K}$ promotion was not effective. 1-olefin selectivities were similar on both catalysts, whereas the unpromoted catalyst had higher 2-olefin selectivity (not shown).

\subsection{Effect of Alkali Promoter (Na vs. K as alkali promoter)}

Since potassium promotion of the silica supported catalyst prepared from methanol solution was found to be ineffective in run SA-1780, we decided to investigate the effect of using sodium instead of $\mathrm{K}$ as an alkali promoter. Solubility of sodium nitrate in methanol is much higher than that of potassium salts, and this may result in a better dispersion of $\mathrm{Na}$ and improved contact with $\mathrm{Fe}$. 20\% Fe/Davison $948 \mathrm{SiO}_{2}$ catalyst containing $\mathrm{Cu}$ and $\mathrm{Na}$ as promoters $(100 \mathrm{Fe} / 8 \mathrm{Cu} / 8 \mathrm{Na})$ was prepared as described on page 8 of this report, and tested at the baseline process conditions in run SB-1221. Results from runs SB-1221 and SA-1780 $(100 \mathrm{Fe} / 8 \mathrm{Cu} / 8 \mathrm{~K}$ catalyst) are shown in Figures 21 and 22 . The $\mathrm{K}$ promoted catalyst was initially (0-53 hours) tested at gas space velocity of $6 \mathrm{Nl} / \mathrm{g}-\mathrm{Fe} / \mathrm{h}$, but these results are not shown.

Activity of the Na promoted catalyst was lower than that of the $\mathrm{K}$ promoted catalyst (Figure 21). Syngas conversion on the K promoted catalyst was stable (61-63\%), whereas the Na promoted catalyst deactivated with time, and conversion decreased from $53 \%$ initially to $46 \%$ at $150 \mathrm{~h}$ on stream. Similar initial $\mathrm{CO}_{2}$ selectivities were obtained, but $\mathrm{CO}_{2}$ selectivity on the $\mathrm{Na}$ decreased with time following the same trend as F-T activity.

Methane selectivity was similar on both catalysts (Figure 22a), but the K promoted catalyst had slightly higher $\mathrm{C}_{5}+$ selectivity $(\sim 64 \%$ vs. $60 \%)$ as shown in Figure $22 \mathrm{~b}$. Total olefin 
selectivity was slightly lower on the Na promoted catalyst relative to the K promoted catalyst (Figure 22c).

\section{Conclusions}

Results from tests with $\mathrm{Cu}$ and $\mathrm{K}$ promoted $\mathrm{Fe}$ catalysts prepared by aqueous IWI of supports, showed that calcined $\gamma$-alumina (HP 14-150) is a more promising support than boehmite alumina (HP 14) for F-T synthesis. Calcination of $\gamma$-alumina is an important step, and the catalyst prepared by IWI of calcined support (at $500^{\circ} \mathrm{C}$ for 5 hours) was superior to the one prepared by IWI of uncalcined (as received) $\gamma$-alumina support. Silica supported catalyst had lower initial activity and selectivity to $\mathrm{C}_{5}+$ hydrocarbons, and higher methane selectivity than the calcined $\gamma$-alumina supported catalyst, but it deactivated less severely. Improvements in stability are needed for both silica and alumina supported catalysts.

With $\mathrm{Cu}$ and $\mathrm{K}$ promoted $20 \% \mathrm{Fe} / \mathrm{SiO}_{2}$ catalysts, the catalyst prepared from methanol solution had better activity maintenance than the catalyst prepared from aqueous solution. However, the initial catalyst activity was the same for both catalysts. Hydrocarbon selectivity of the catalyst prepared by organic IWI was inferior (more methane and less $\mathrm{C}_{5}+$ products) compared to the catalyst prepared by aqueous IWI during testing at the baseline process conditions $(\mathrm{P}=1.48 \mathrm{MPa})$, but its selectivity improved during testing at higher reaction pressure $(\mathrm{P}=2.17 \mathrm{MPa})$.

With unpromoted $20 \% \mathrm{Fe} / \mathrm{SiO}_{2}$ catalysts, the catalyst prepared from methanol solution had higher activity than the catalyst prepared from aqueous solution. This is consistent with higher reducibility of the catalyst prepared by organic impregnation (Figure 2). Hydrocarbon selectivity on unpromoted catalysts was not affected by differences in preparation procedure.

The expected promotional effects of $\mathrm{K}$ (increase in molecular weight of hydrocarbon products, increased olefinicity, increase in WGS activity) were observed to a relatively small extent on the catalyst prepared by aqueous impregnation, but were less evident on the catalyst prepared by organic impregnation of Davison 948 silica support. F-T activity was not significantly affected by addition of $\mathrm{Cu}$ and $\mathrm{K}$ promoters, but the deactivation rate was higher on the promoted catalyst prepared by aqueous impregnation. Catalysts prepared by organic impregnation (both promoted and unpromoted) were more stable (low deactivation rate). The amount of $\mathrm{K}$ promoter used is rather high ( 8 parts per 100 parts of Fe on weight basis) compared to Fe precipitated catalysts, but its promotional effect was small. This is indicative of promoter-support interactions and/or decreased Fe-K contact. Substitution of K with $\mathrm{Na}$ (silica supported catalyst prepared by IWI from methanol solution) was found to result in inferior performance in terms of activity, selectivity and stability with time.

Silica and alumina supported catalysts produced significantly more methane (4-8 \% on carbon atom basis) than the precipitated TAMU catalyst $(\sim 2.5 \%)$. Also, both their activity and stability were inferior in comparison to that of the precipitated catalysts. Further work is needed to develop basic understanding of underlying causes for differences in the reaction behaviors and to synthesize improved supported Fe catalysts for slurry phase F-T synthesis. 


\section{Acknowledgments}

Ms. Patricia O'Dowd (graduate student) synthesized most of the catalysts used in this study. Mr. Alec Klinghoffer (graduate student) performed some of the attrition tests of supports under non-reactive conditions. Drs. Ketil Hanssen and Lech Nowicki evaluated catalyst performance in a stirred tank slurry reactor, performed attrition tests in a STSR, and synthesized some of the catalysts. Ms. Yanjun Wang helped with preparation of figures for this report. We had many valuable discussions with our collaborators at the UNM (Professor Datye and Dr. Hien Pham) and BYU (Professor Bartholomew and Mr. Jian Xu, graduate student).

\section{References}

Anderson, R. B., "Catalysts for the Fischer-Tropsch Synthesis". In Catalysis (Vol. IV); Emmett, P. H. Ed.; p. 29. Van Nostrand-Reinhold: New York, 1956.

Bukur, D. B., Lang, X., Rossin, J. A., Zimmerman, W. H., Rosynek, M. P., Yeh, E. B and Li, C., "Activation Studies with a Promoted Precipitated Iron Fischer-Tropsch Catalyst", Ind. Eng. Chem. Res., 1989, 28, 1130.

Bukur, D. B., Lang, X., Mukesh, D., Zimmerman, W. H., Rosynek, M. P. and Li, C., "Binder/support Effects on the Activity and Selectivity of Iron Catalyst in the Fischer-Tropsch Synthesis", Ind. Eng. Chem. Res., 1990a, 29, 1588.

Bukur, D. B.; Patel, S. A.; Lang, X., "Fixed Bed and Slurry Reactor Studies of FischerTropsch Synthesis on Precipitated Iron Catalyst", Appl. Catal., 1990b, 61, 329.

Bukur, D. B.; Mukesh, D.; Patel, S. A.," Promoter Effects on Precipitated Iron Catalysts for Fischer-Tropsch Synthesis", Ind. Eng. Chem. Res., 1990c, 29, 194.

Bukur, D. B.; Nowicki, L.; Lang, X., "Fischer-Tropsch Synthesis in a Stirred Tank Slurry Reactor", Chem. Eng. Sci., 1994, 49, 4615.

Bukur, D. B.; Lang, X., "A Precipitated Iron Fischer-Tropsch Catalyst for Synthesis Gas Conversion to Liquid Fuels", Stud. Surf. Sci. Catal., 1998, 119, 113.

Bukur, D. B. and Lang, X. S., "Highly Active and Stable Iron Fischer-Tropsch Catalyst for Synthesis Gas Conversion to Liquid Fuels", Ind. Eng. Chem. Res., 1999a, 38, 3270.

Bukur, D. B., "Development of Precipitated Iron Fischer-Tropsch Catalysts", Final Report, U. S. DOE Contract No. DE-AC22-94PC93069, Texas Engineering Experiment Station, College Station, TX, 1999b.

Dry, M. E., "The Fischer-Tropsch Synthesis", in Catalysis-Science and Technology (Vol. 1); Anderson, J. R., Boudart, M., Eds.; p. 160. Springer-Verlag: New York, 1981.

Dry, M. E., "The Sasol Fischer-Tropsch Processes", in "Applied Industrial Catalysis" (B. E. Leach, Ed), Vol. 2, p.167. Academic Press, New York, 1983.

Dry, M. E., "Fischer-Tropsch Synthesis over Iron Catalysts",Catal. Lett., 1990, 7, 241.

Kalakkad, D. S., Shroff, M. D., Köhler, S., Jackson, N., Datye, A. K., "Attrition of Precipitated Iron Fischer-Tropsch Catalysts", Appl. Catal., 1995, 133, 335.

Kuo, J. C. W., "Two Stage Process for Conversion of Synthesis Gas to High Quality Transportation Fuels", Final Report, DOE Contract No. DE-AC22-83PC600019; Mobil Research and Development Corp.: Paulsboro, NJ, 1985. 
Kölbel, H.; Ackerman, P.; Engelhardt, F., "New Developments in Hydrocarbon Synthesis", in Proc. Fourth World Petroleum Congress, Section IV/C, Carlo Colombo Publishers: Rome, 1955.

Pham, H. N., Reardon, J. and Datye, A. K., "Measuring the Strength of Slurry Phase Heterogeneous Catalysts," Powder Technol., 1999,103, 95.

Pham, H. N. and Datye, A. K., "The Synthesis of Attrition Resistant Slurry Phase Iron Fischer-Tropsch Catalysts," Catal. Today, 2000, 58, 233.

Zimmerman, W. H.; Bukur, D. B., "Reaction Kinetics over Iron Catalyst used for FischerTropsch Synthesis", Can. J. Chem. Engng., 1990, 68, 292. 


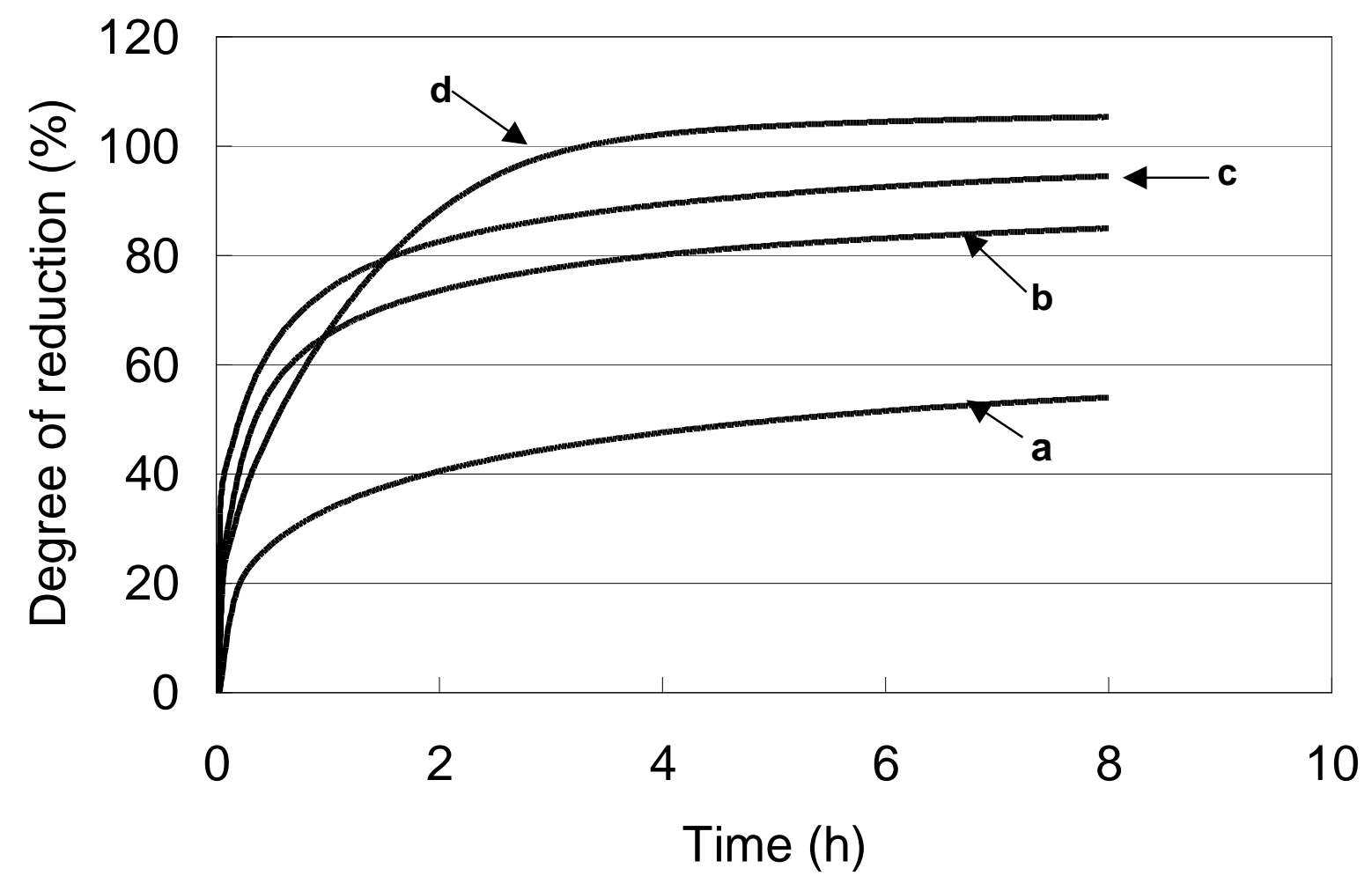

Figure 1 Isothermal reduction studies in pure $\mathrm{H}_{2}$ with alumina and silica supported Fe catalysts: (a) HP 14 alumina; (b) HP 14-150 calcined $\gamma$-alumina; (c) HP 14-150 uncalcined $\gamma$-alumina; (d) Davison 948 silica. 


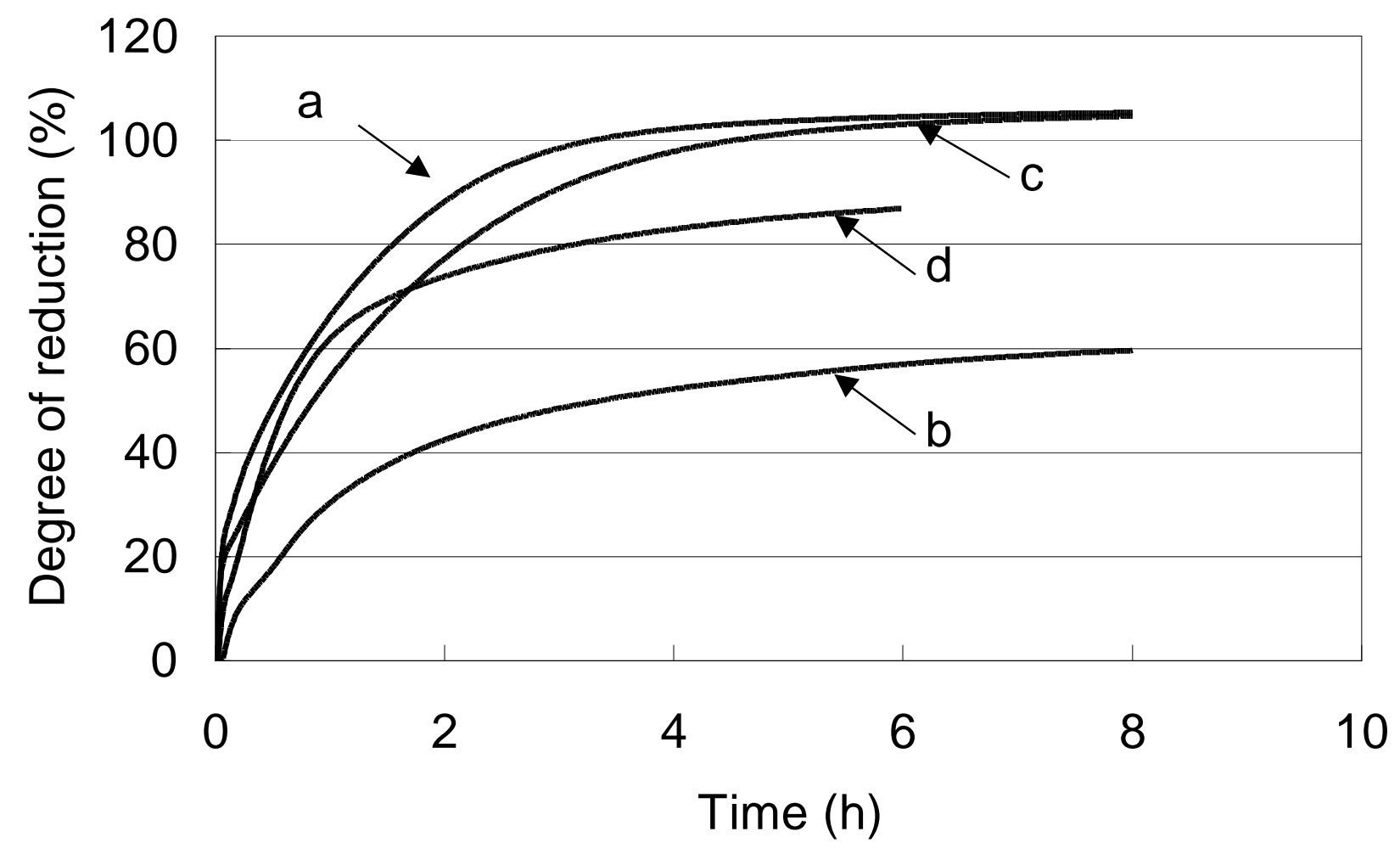

Figure 2 Effect of preparation procedure and promoters on reduction behavior of $20 \% \mathrm{Fe} /$ Davison 948 silica catalysts: (a) $\mathrm{K}$ and $\mathrm{Cu}$ promoted (aq. impreg.); (b) Unpromoted (aq. impreg.); (c) $\mathrm{K}$ and $\mathrm{Cu}$ promoted (org. impreg.); (d) Unpromoted (org. impreg.). 
CONDEA VISTA HP 14-150

(calcined)

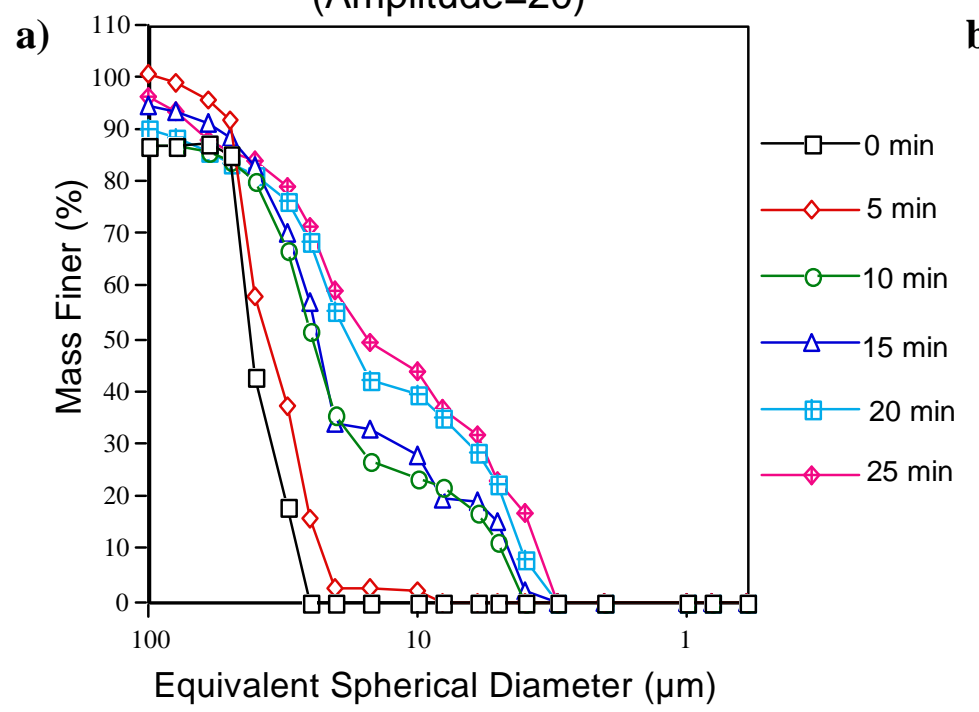

GRACE DAVISON 948

(calcined)

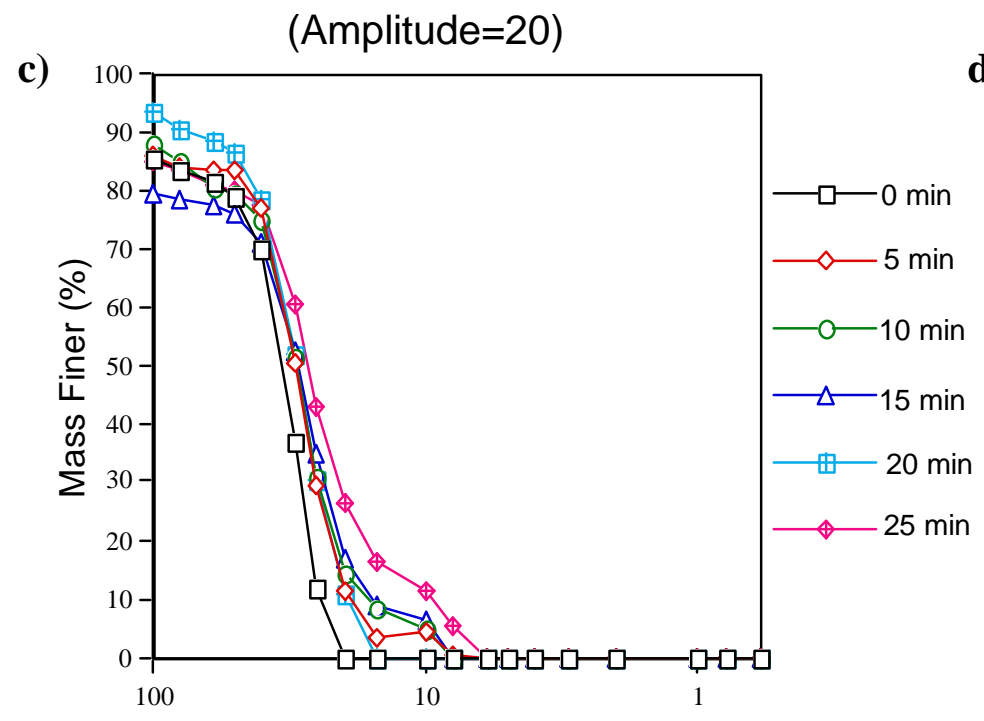

Equivalent Spherical Diameter $(\mu \mathrm{m})$
CONDEA VISTA HP 14

(calcined)

(Amplitude=20)

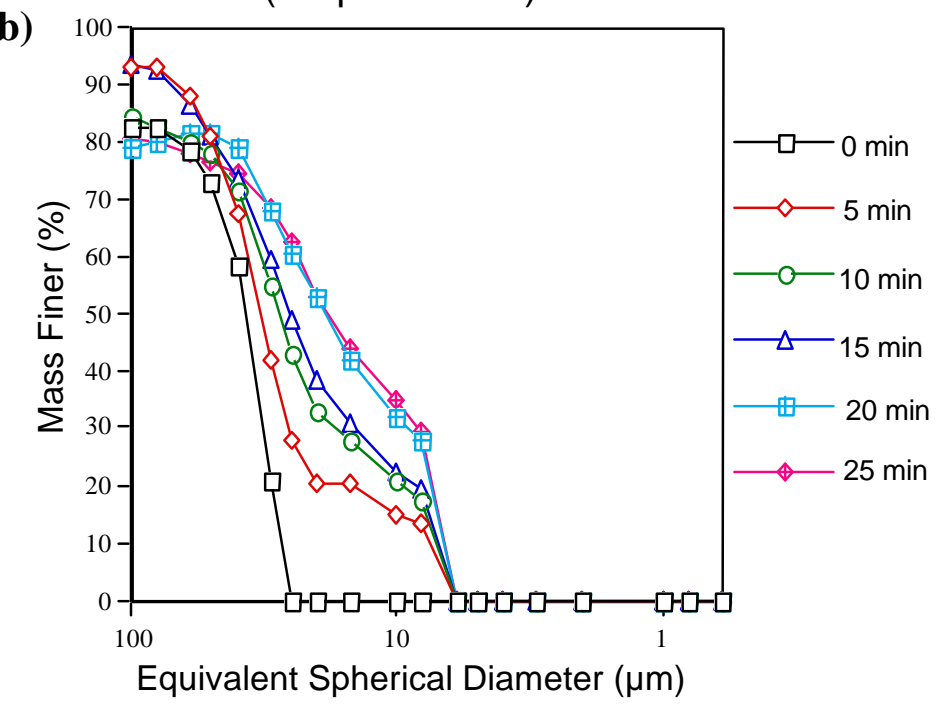

100Fe/3Cu/4K/16SiO2

(uncalcined)

Amplitude $=20$

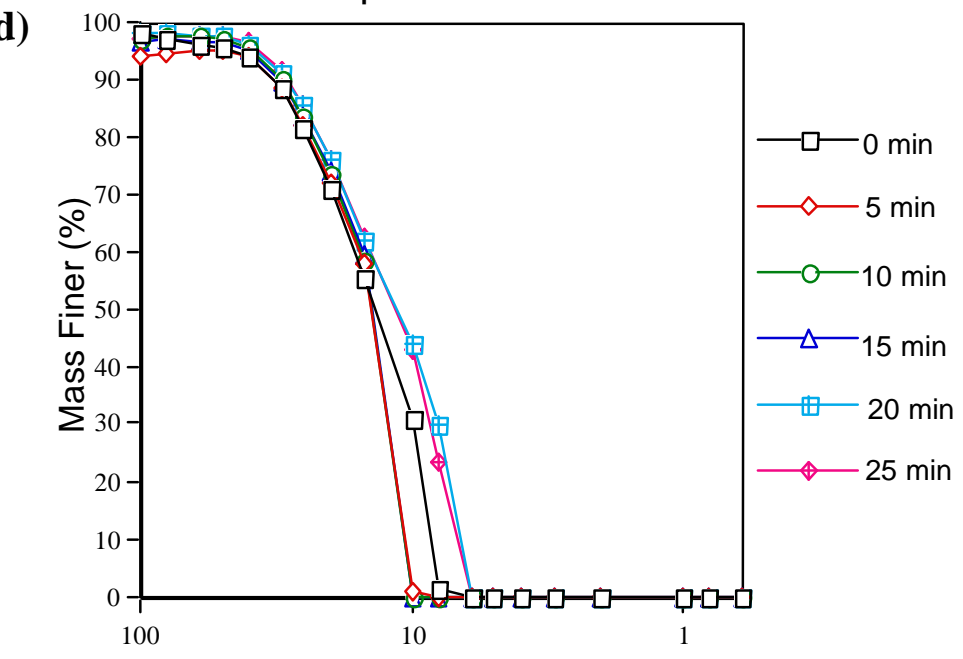

Equivalent Spherical Diameter

Figure 3. Sedigraph particle size distribution plots of these materials, performed under ultrasonic fragmentation tests. More fine particles are seen with Condea HP 14-150 (a) than with Condea HP 14 (b), during ultrasonic irradiation. For Davison 948 silica (c), very little attrition of particles due to fracture and erosion is seen after $25 \mathrm{~min}$ of ultrasonic irradiation. Similar results are found for the uncalcined precipitated iron catalyst (d). 


\section{Alumina HP 14}

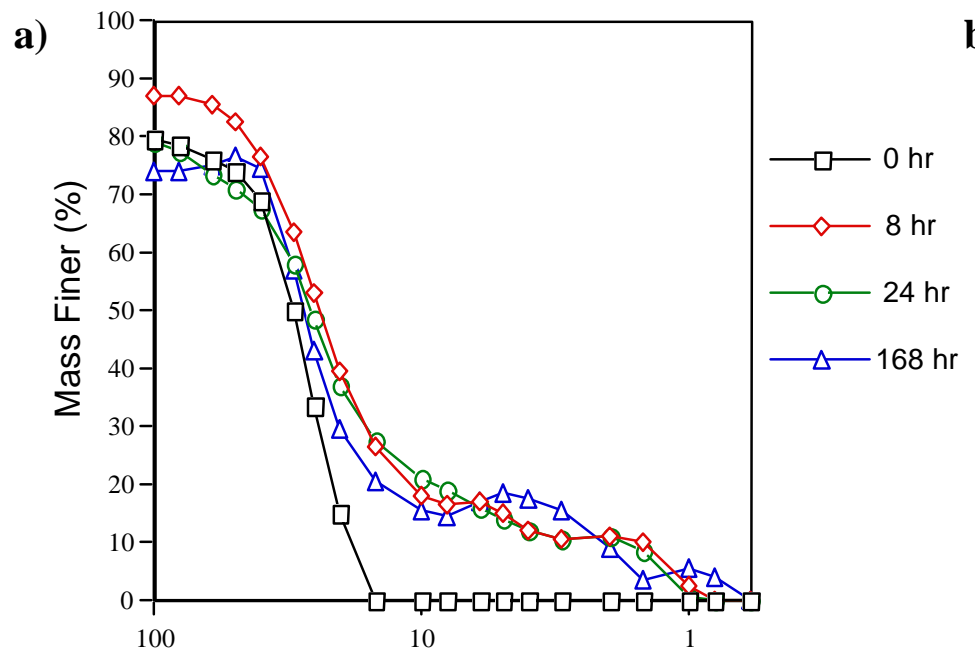

Equivalent Spherical Diameter $(\mu \mathrm{m})$

SB-1890

Davison 948

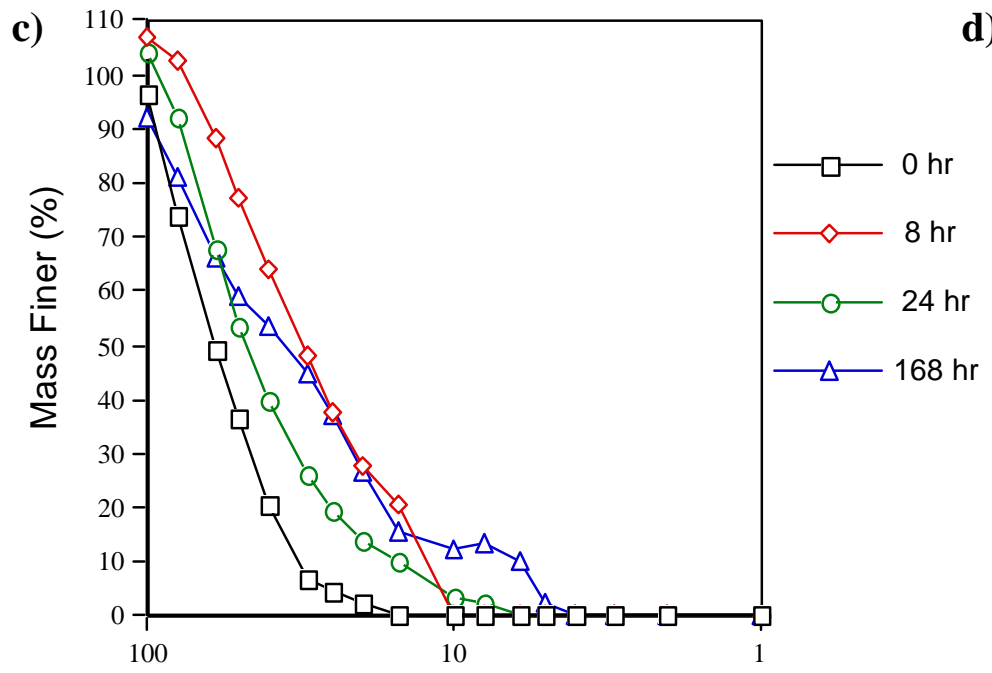

Equivalent Spherical Diameter $(\mu \mathrm{m})$

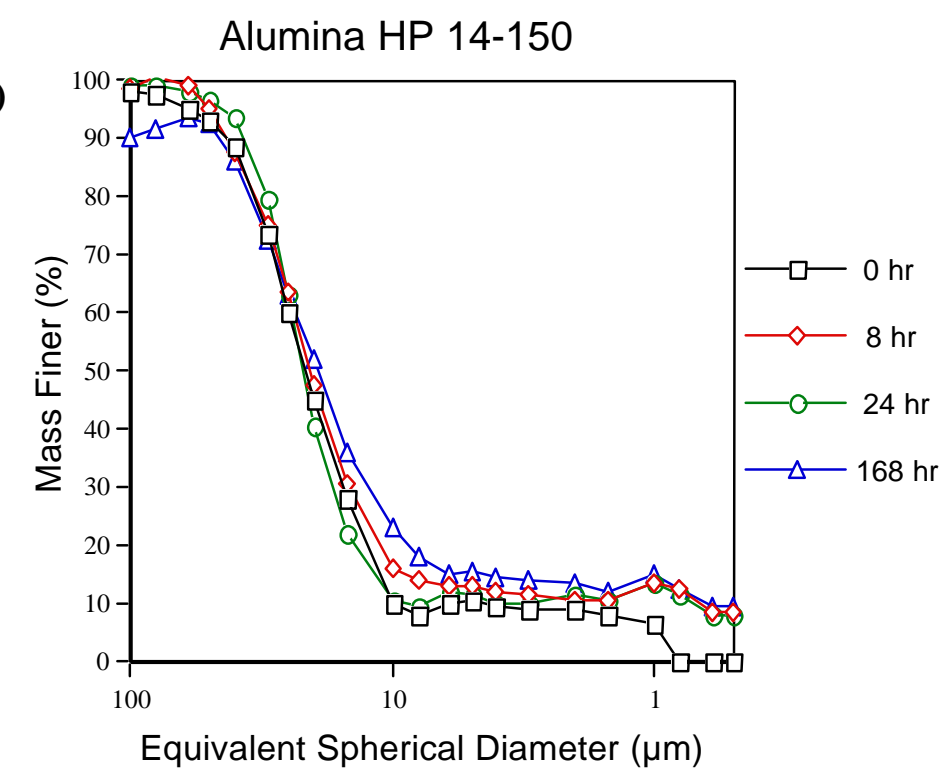

b)

$$
\text { Equivalent Spherical Diameter }(\mu \mathrm{m})
$$

SB-0470

$100 \mathrm{Fe} / 3 \mathrm{Cu} / 4 \mathrm{~K} / 16 \mathrm{SiO} 2$

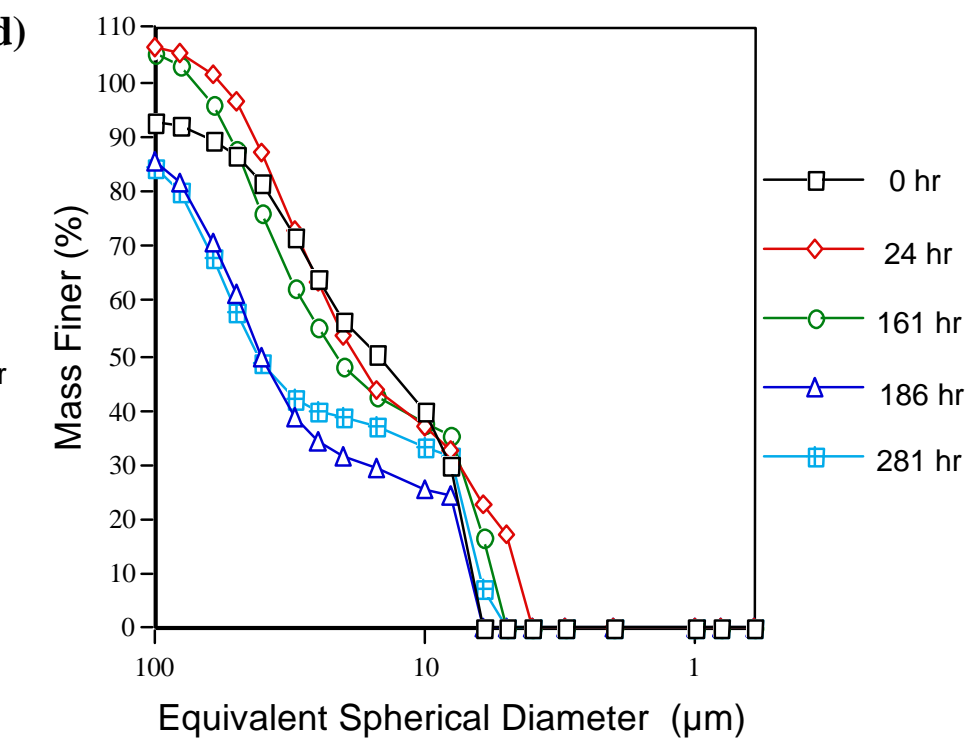

Figure 4. Sedigraph particle size distribution plots of these materials, performed in a STSR under non-reactive F-T conditions. Condea HP 14 (a) and HP 14-150 (b) do not show significant fracture, but there is generation of fine particles. For Davison 948 (c), there is some fragmentation after $8 \mathrm{~h}$ in the STSR. The precipitated catalyst (d) shows a change in particle size distribution when the reaction conditions were changed from inert atmosphere to $\mathrm{CO}$ reduction, after $161 \mathrm{~h}$ of testing. 
SB-1640

20\% Fe, Condea HP14 Alumina

a)
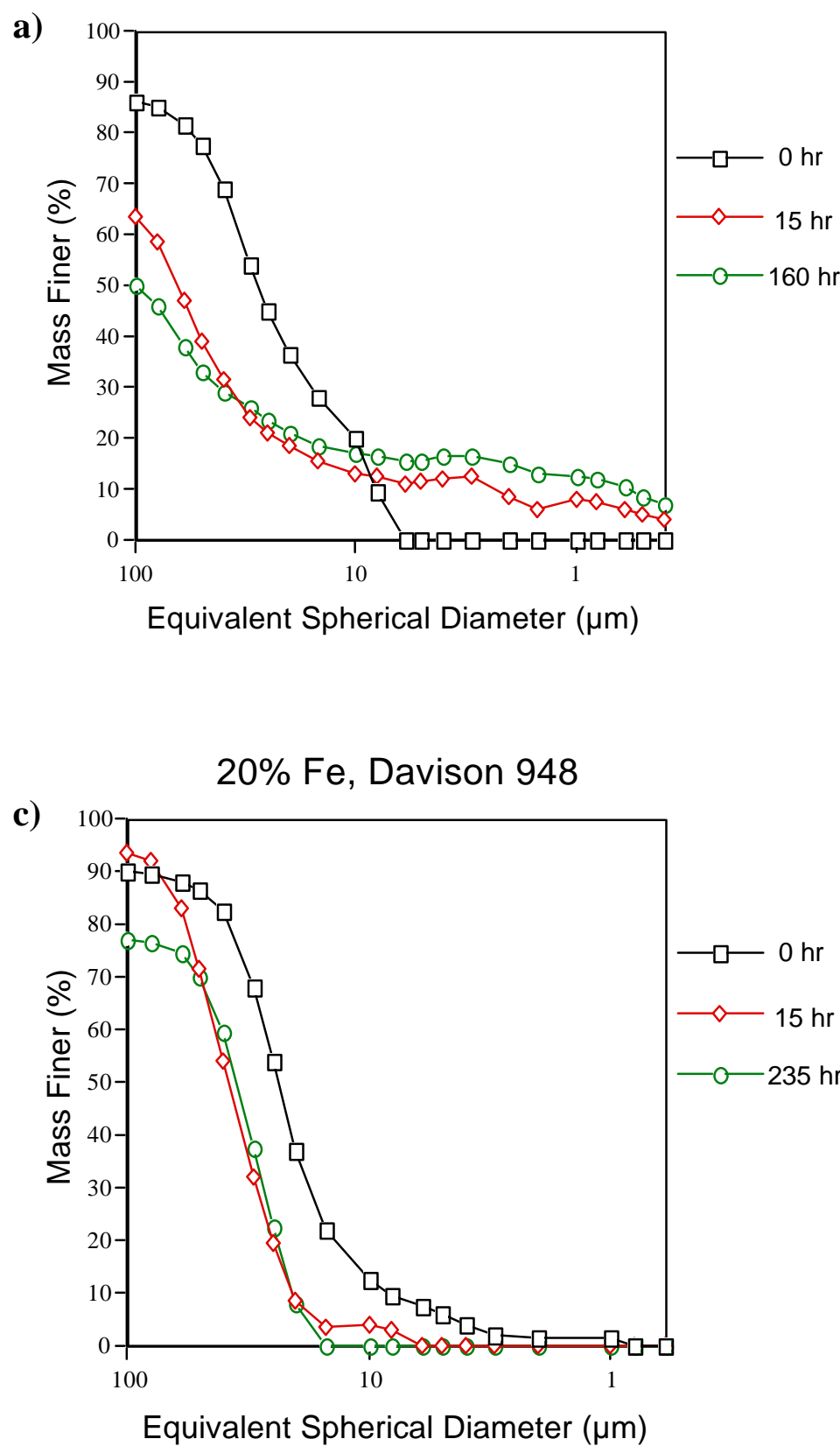

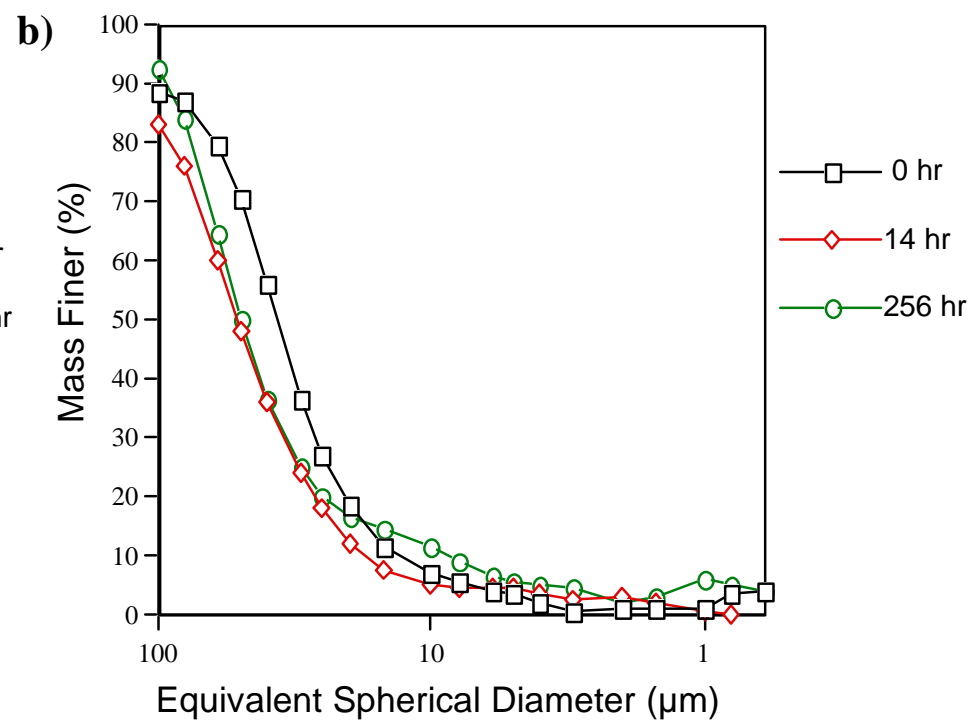

Equivalent Spherical Diameter ( $\mu \mathrm{m})$

SB-0470
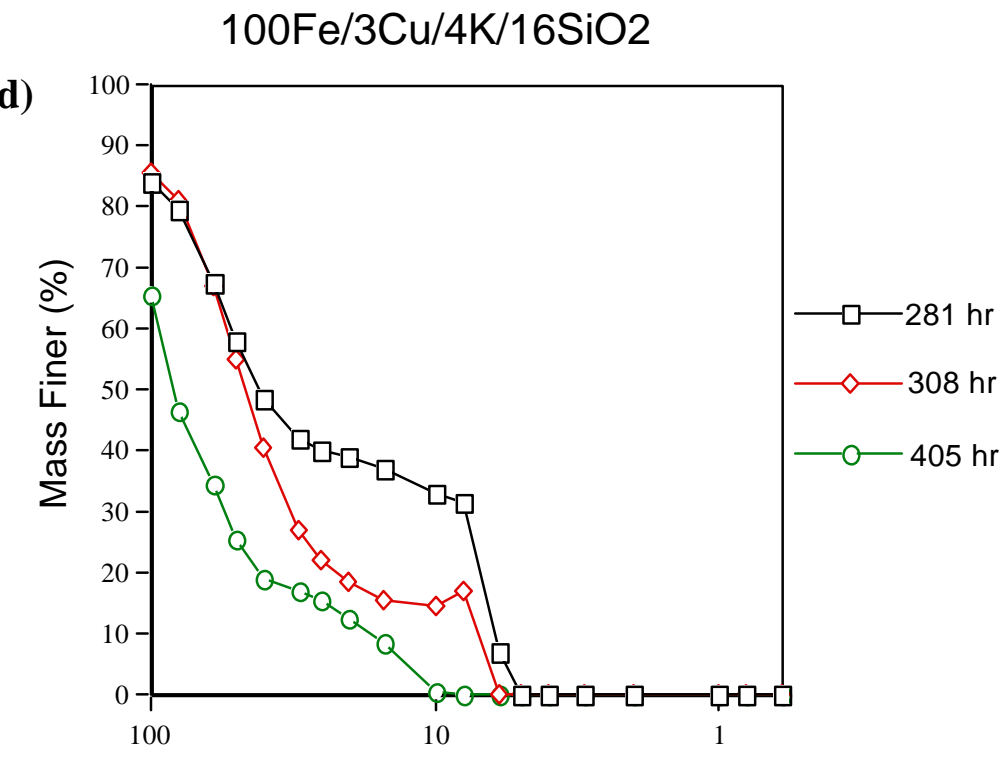

Equivalent Spherical Diameter $(\mu \mathrm{m})$

Figure 5. Sedigraph particle size distribution plots of these materials, performed in a STSR under F-T conditions. Particle size distribution shifted to the left with time in all cases (a-d), which is indicative of particle agglomeration. Note that for the precipitated catalyst (d), F-T reaction starts at $281 \mathrm{~h}$, after non-reactive and CO reduction tests in the STSR. 

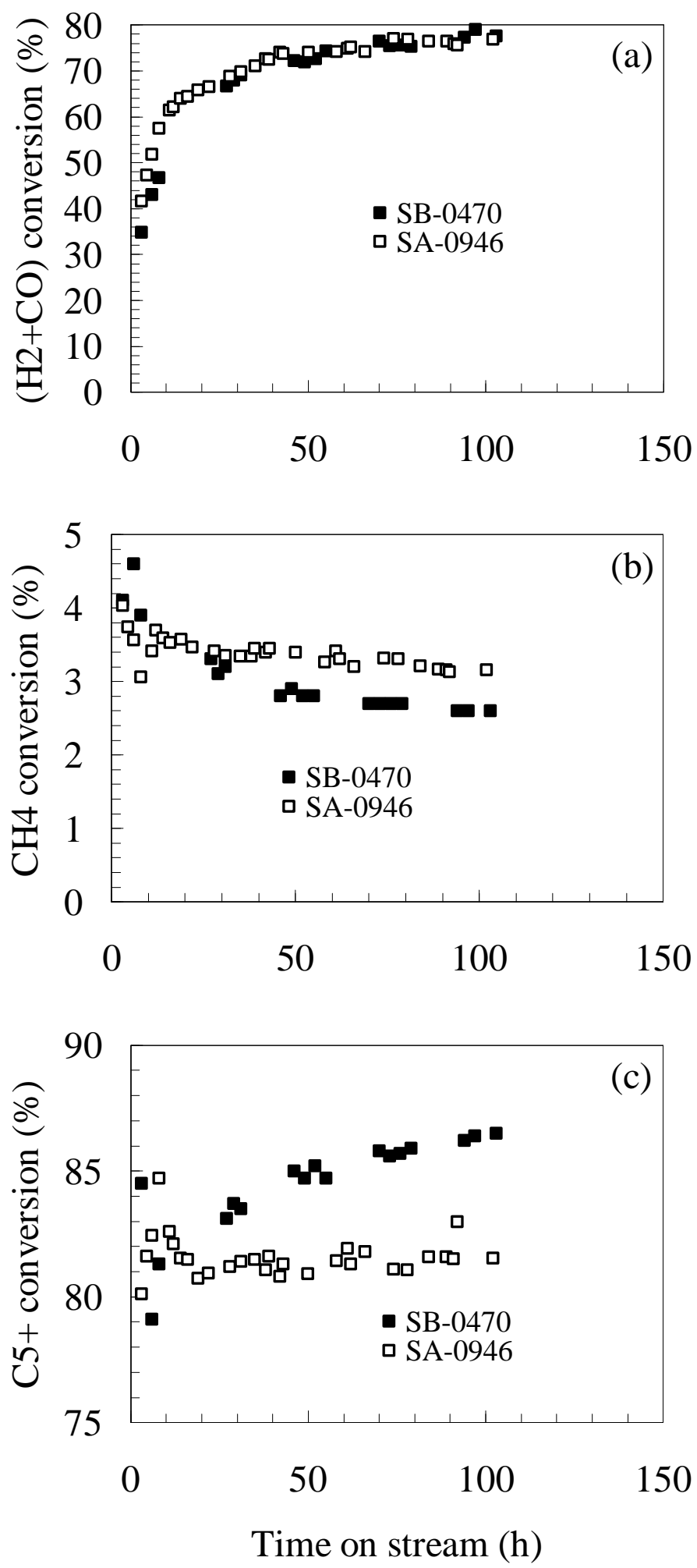

Figure 6 Activity and selectivity of precipitated $100 \mathrm{Fe} / 3 \mathrm{Cu} / 4 \mathrm{~K} / 16 \mathrm{SiO}_{2}$ catalyst in stirred tank slurry reactor tests SA-0946 and SB-0470. 

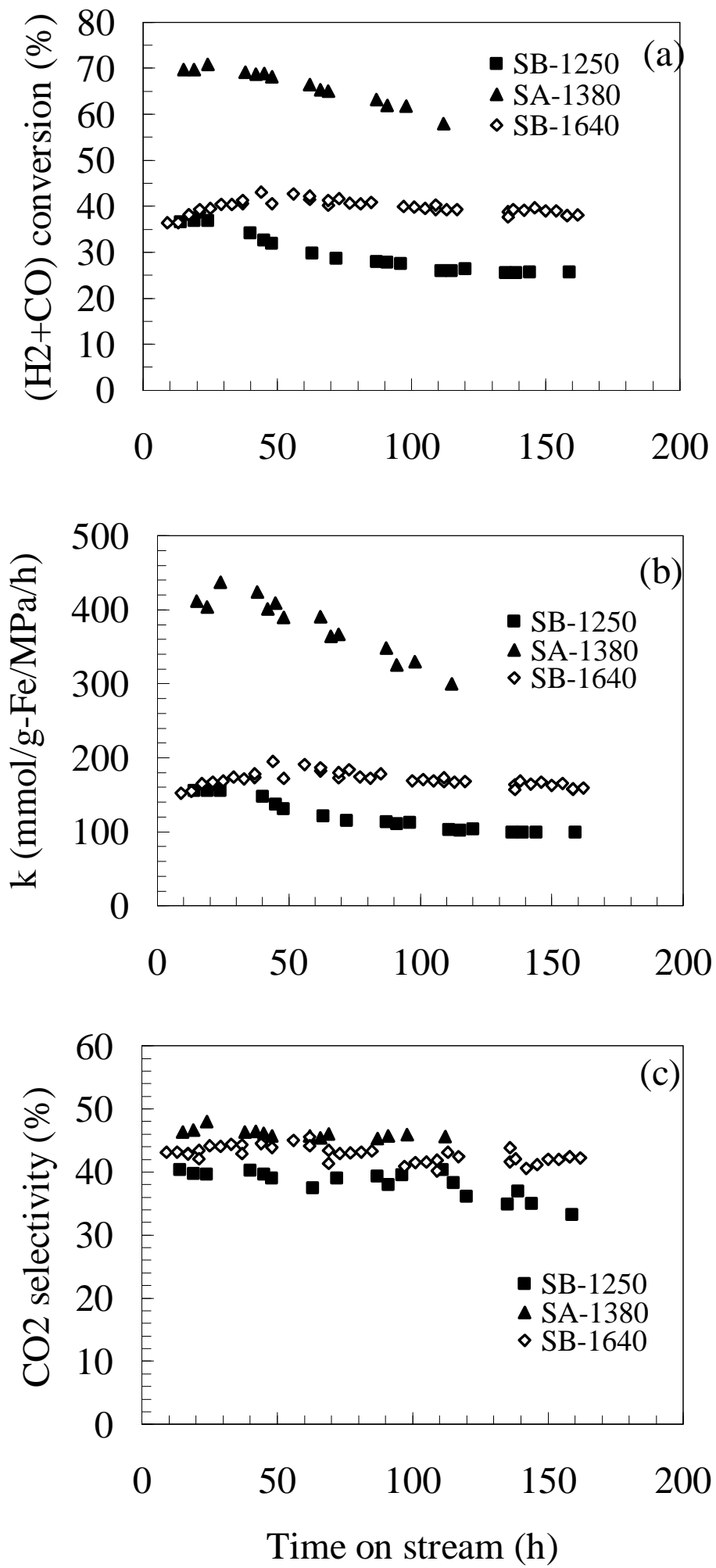

Figure 7 Slurry reactor tests of alumina supported catalysts - F-T and WGS activity (SB-1250 HP 14; SA-1380 HP 14-150 calcined; SB-1640 HP 14-150 uncalc.) Reaction conditions: $260^{\circ} \mathrm{C}, 1.48 \mathrm{MPa}, 4.0 \mathrm{Nl} / \mathrm{g}-\mathrm{Fe} / \mathrm{h}, \mathrm{H}_{2} / \mathrm{CO}=2 / 3$ 

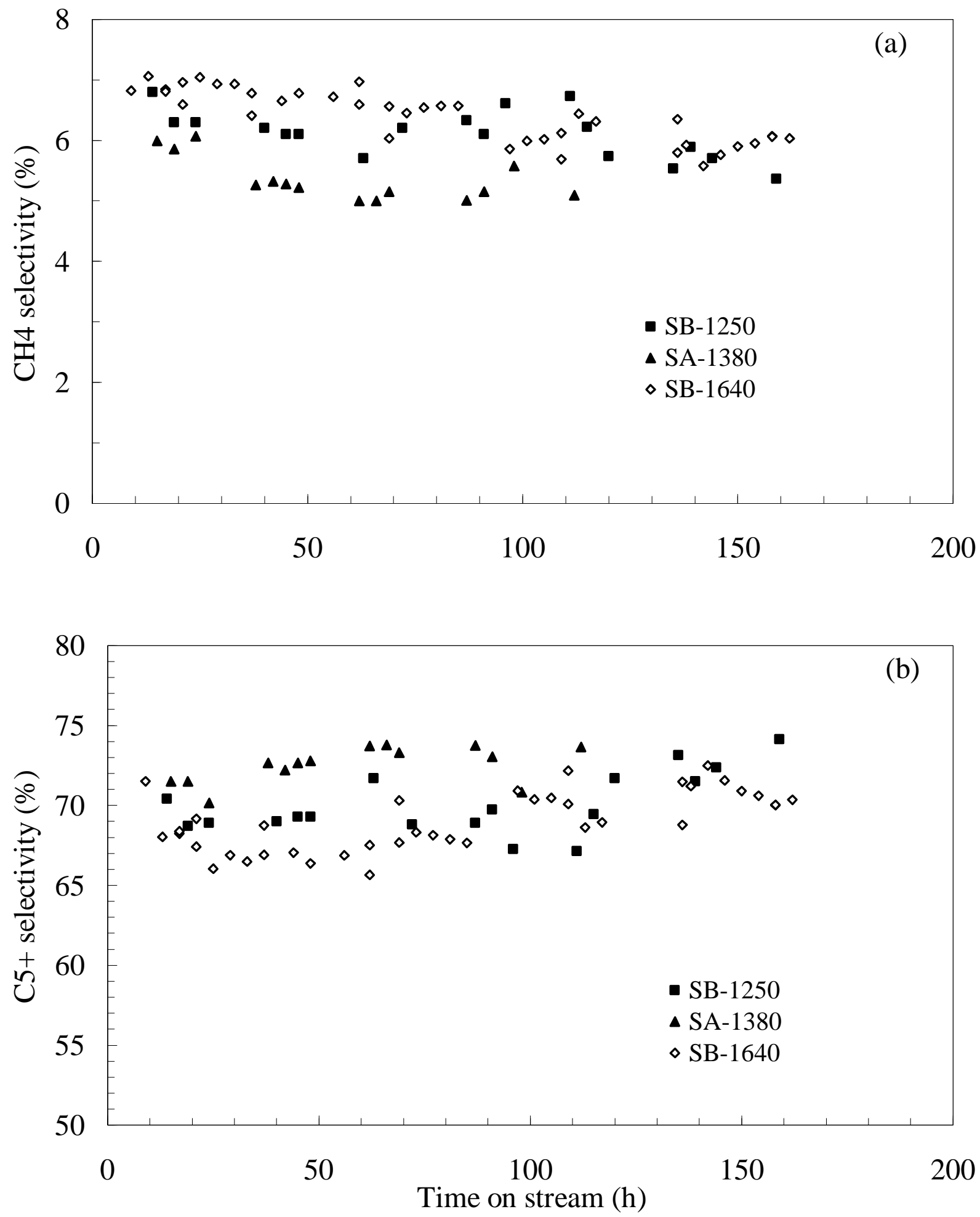

Figure 8 Slurry reactor tests of alumina supported catalysts - Product Selectivity (SB-1250 HP 14; SA-1380 HP 14-150 calcined; SB-1640 HP 14-150 uncalc.) Reaction conditions: $260^{\circ} \mathrm{C}, 1.48 \mathrm{MPa}, 4.0 \mathrm{Nl} / \mathrm{g}-\mathrm{Fe} / \mathrm{h}, \mathrm{H}_{2} / \mathrm{CO}=2 / 3$ 

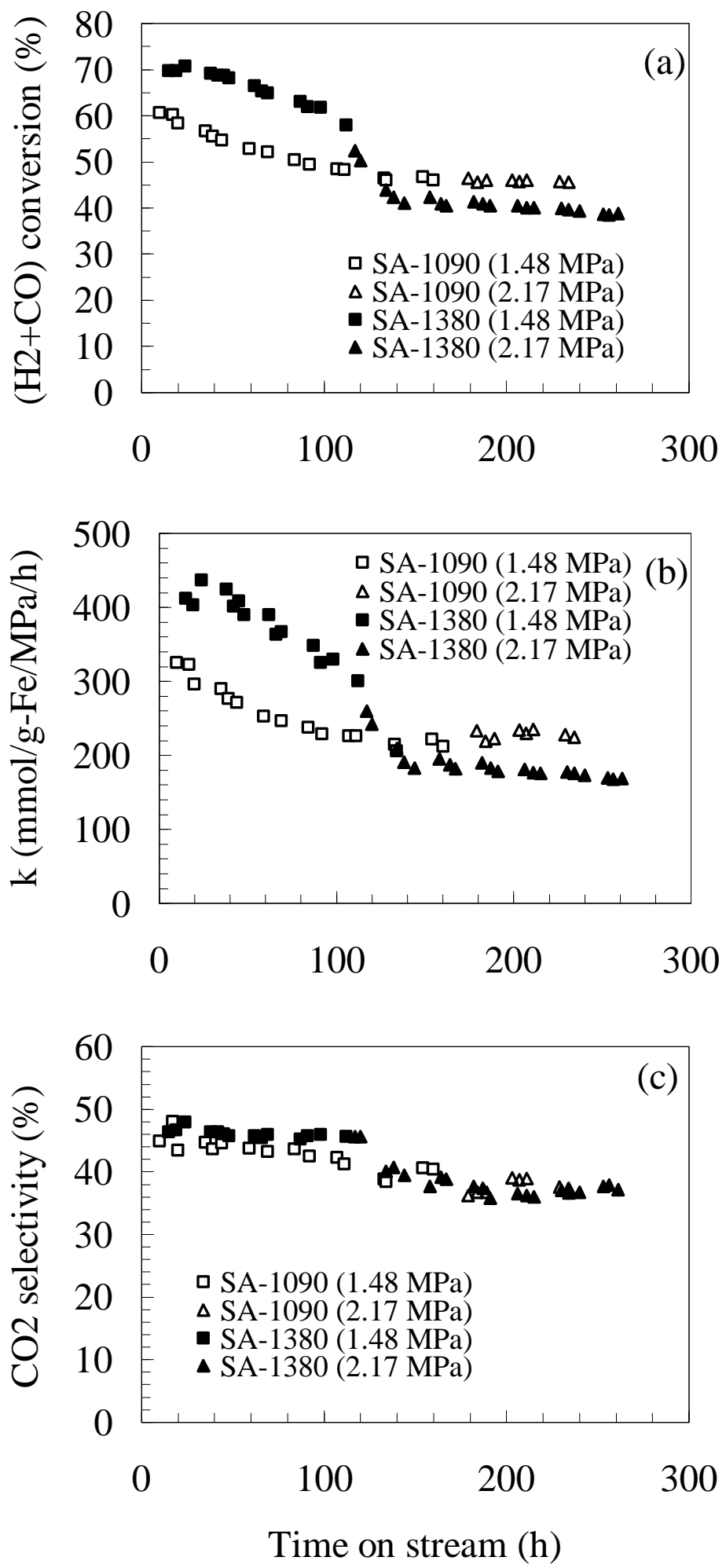

Figure 9 Effect of support type on F-T and WGS activity

(SA-1380 HP 14-150 $\mathrm{Al}_{2} \mathrm{O}_{3}$ (calcined); SA-1090 Davison $948 \mathrm{SiO}_{2}$ )

Process conditions: $1.48 \mathrm{MPa} \& 4.0 \mathrm{Nl} / \mathrm{g}-\mathrm{Fe} / \mathrm{h}$; or $2.17 \mathrm{MPa} \& 5.9 \mathrm{Nl} / \mathrm{g}-\mathrm{Fe} / \mathrm{h}$ 

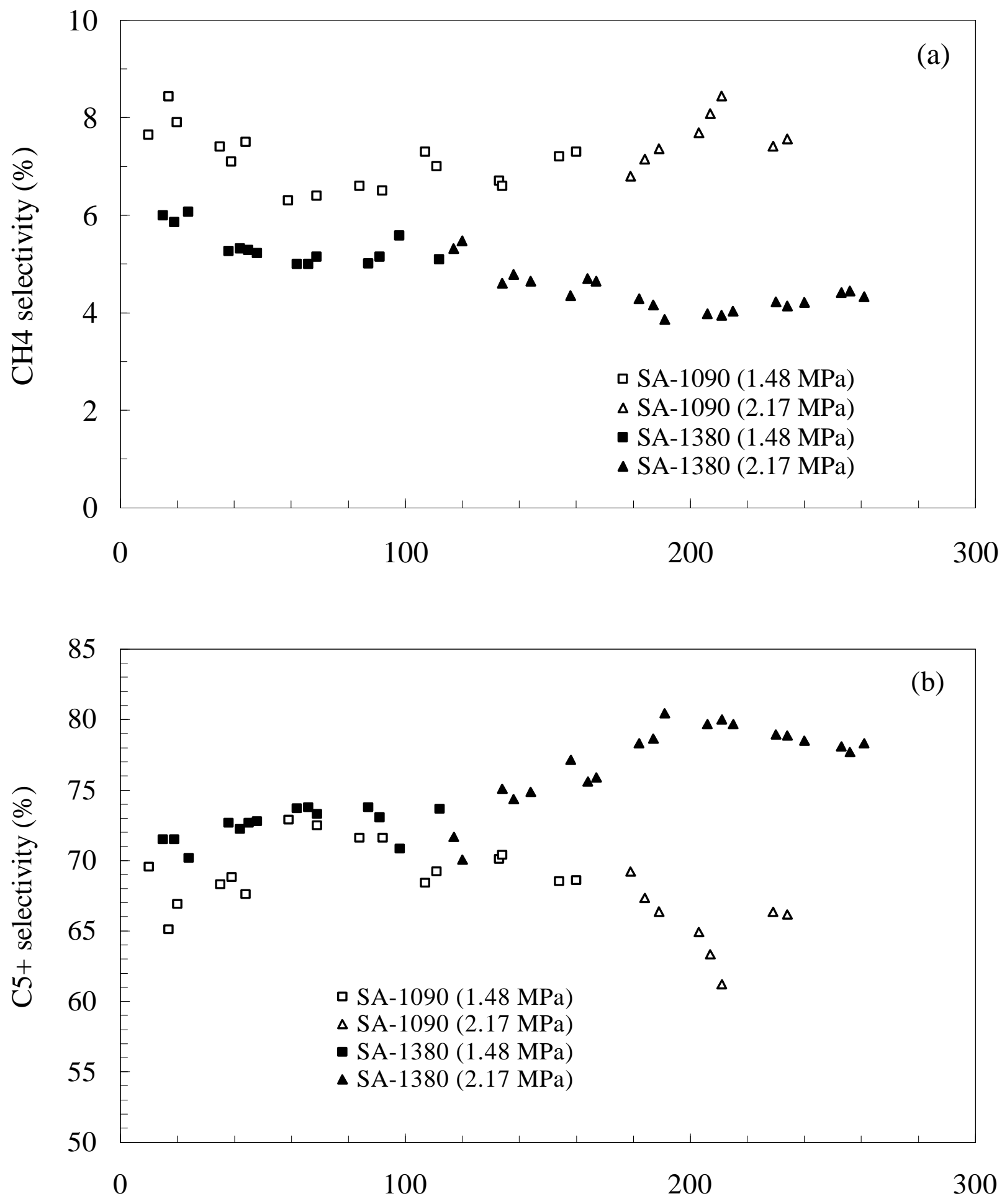

Time on stream $(\mathrm{h})$

Figure 10 Effect of support type on hydrocarbon selectivity (SA-1380 HP 14-150 $\mathrm{Al}_{2} \mathrm{O}_{3}$ (calcined); $\mathrm{SA}-1090$ Davison $948 \mathrm{SiO}_{2}$ ) Process conditions: $1.48 \mathrm{MPa} \& 4.0 \mathrm{Nl} / \mathrm{g}-\mathrm{Fe} / \mathrm{h}$; or $2.17 \mathrm{MPa} \& 5.9 \mathrm{Nl} / \mathrm{g}-\mathrm{Fe} / \mathrm{h}$ 

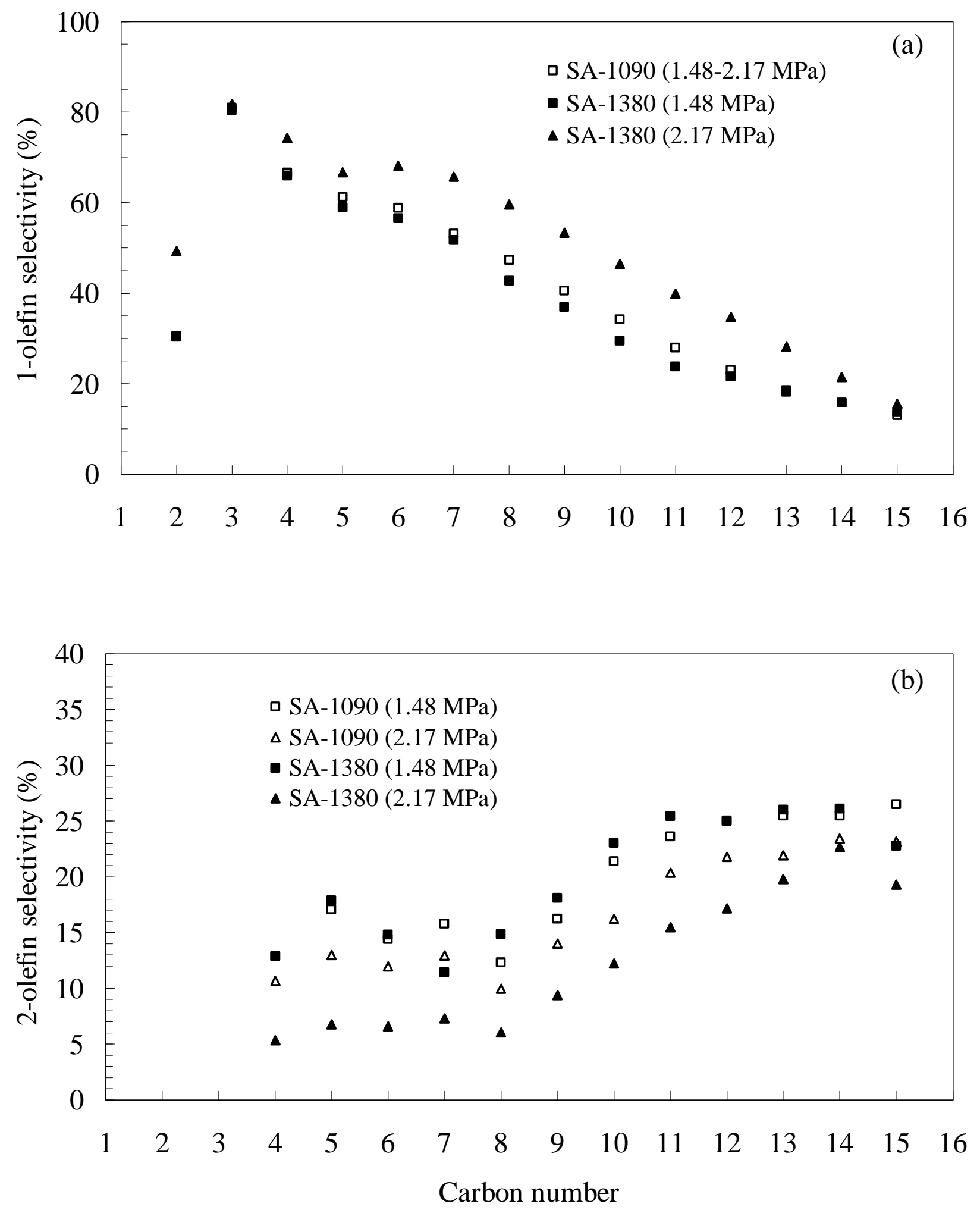

Figure 11 Effect of support type on olefin selectivity (SA-1380 HP 14-150 $\mathrm{Al}_{2} \mathrm{O}_{3}$ (calcined); $\mathrm{SA}-1090$ Davison $948 \mathrm{SiO}_{2}$ ) Process conditions: $1.48 \mathrm{MPa} \& 4.0 \mathrm{Nl} / \mathrm{g}-\mathrm{Fe} / \mathrm{h}$; or $2.17 \mathrm{MPa} \& 5.9 \mathrm{Nl} / \mathrm{g}-\mathrm{Fe} / \mathrm{h}$ 

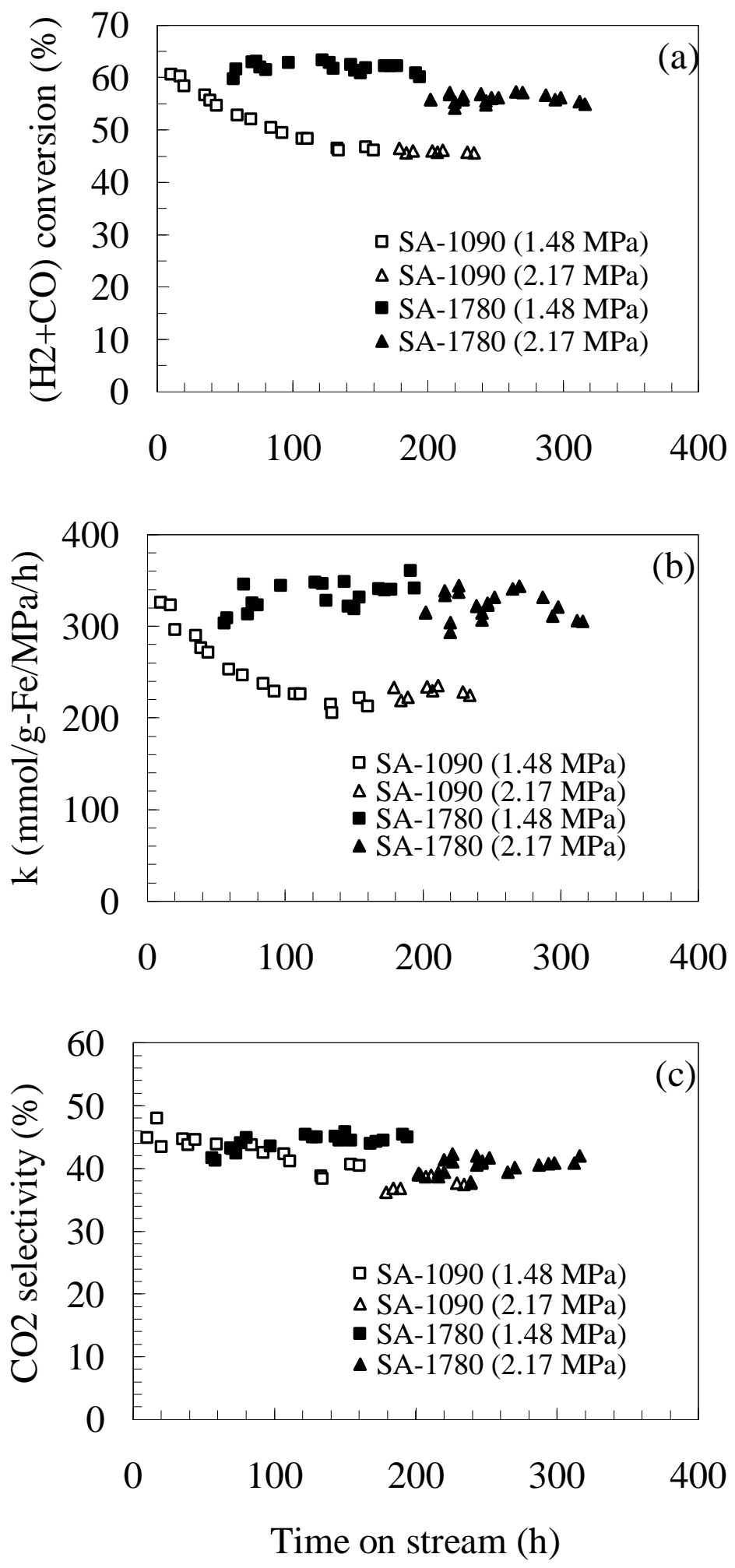

Figure 12 Effect of preparation procedure on F-T and WGS activity (SA-1090 aqueous solution; SA-1780 methanol solution)

Process conditions: $1.48 \mathrm{MPa} \& 4.0 \mathrm{Nl} / \mathrm{g}-\mathrm{Fe} / \mathrm{h}$; or $2.17 \mathrm{MPa} \& 5.9 \mathrm{Nl} / \mathrm{g}-\mathrm{Fe} / \mathrm{h}$ 

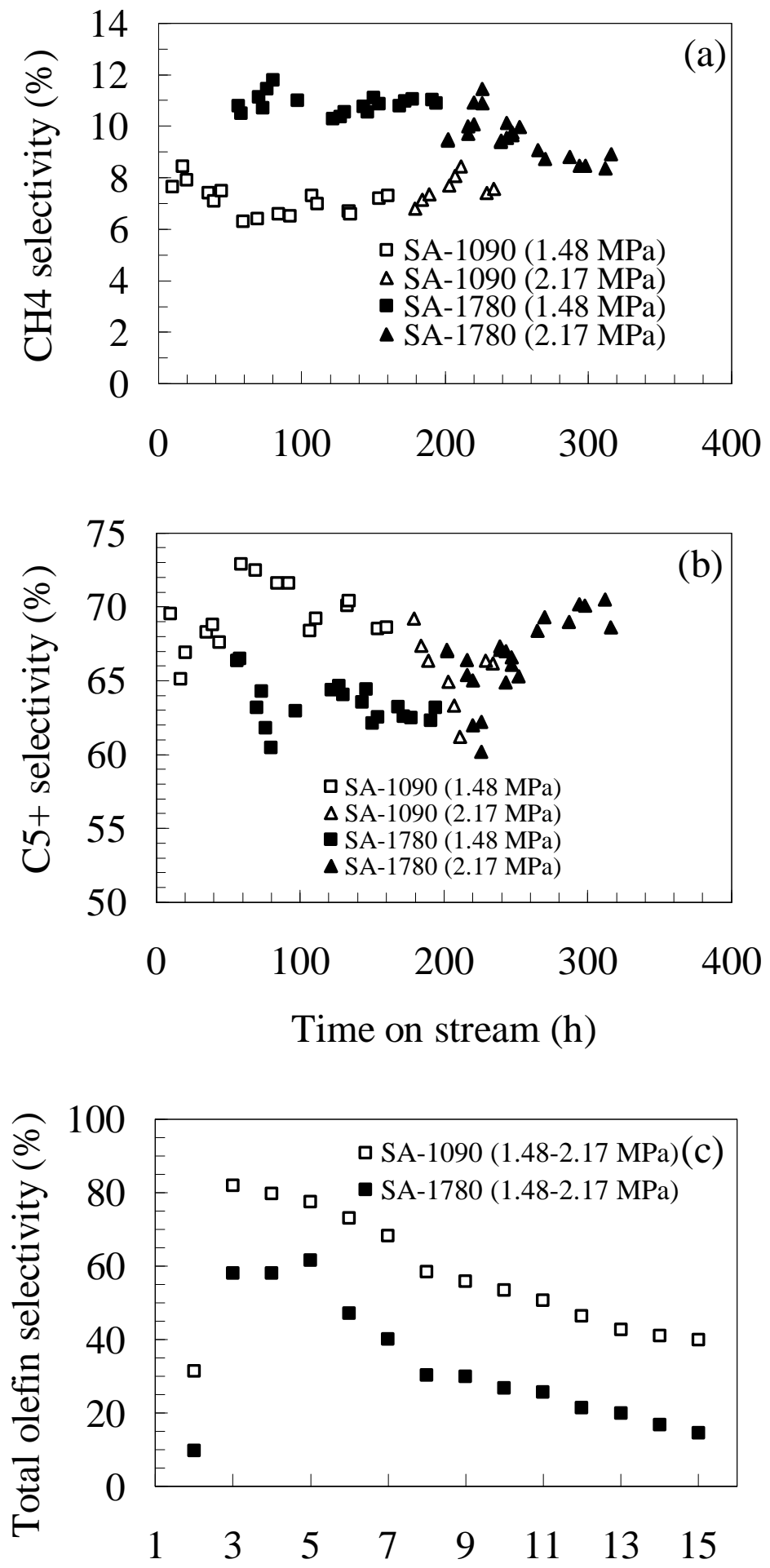

Carbon number

Figure 13 Effect of preparation procedure on product selectivity (SA-1090 aqueous solution; SA-1780 methanol solution)

Process conditions: $1.48 \mathrm{MPa} \& 4.0 \mathrm{Nl} / \mathrm{g}-\mathrm{Fe} / \mathrm{h}$; or $2.17 \mathrm{MPa} \& 5.9 \mathrm{Nl} / \mathrm{g}-\mathrm{Fe} / \mathrm{h}$ 

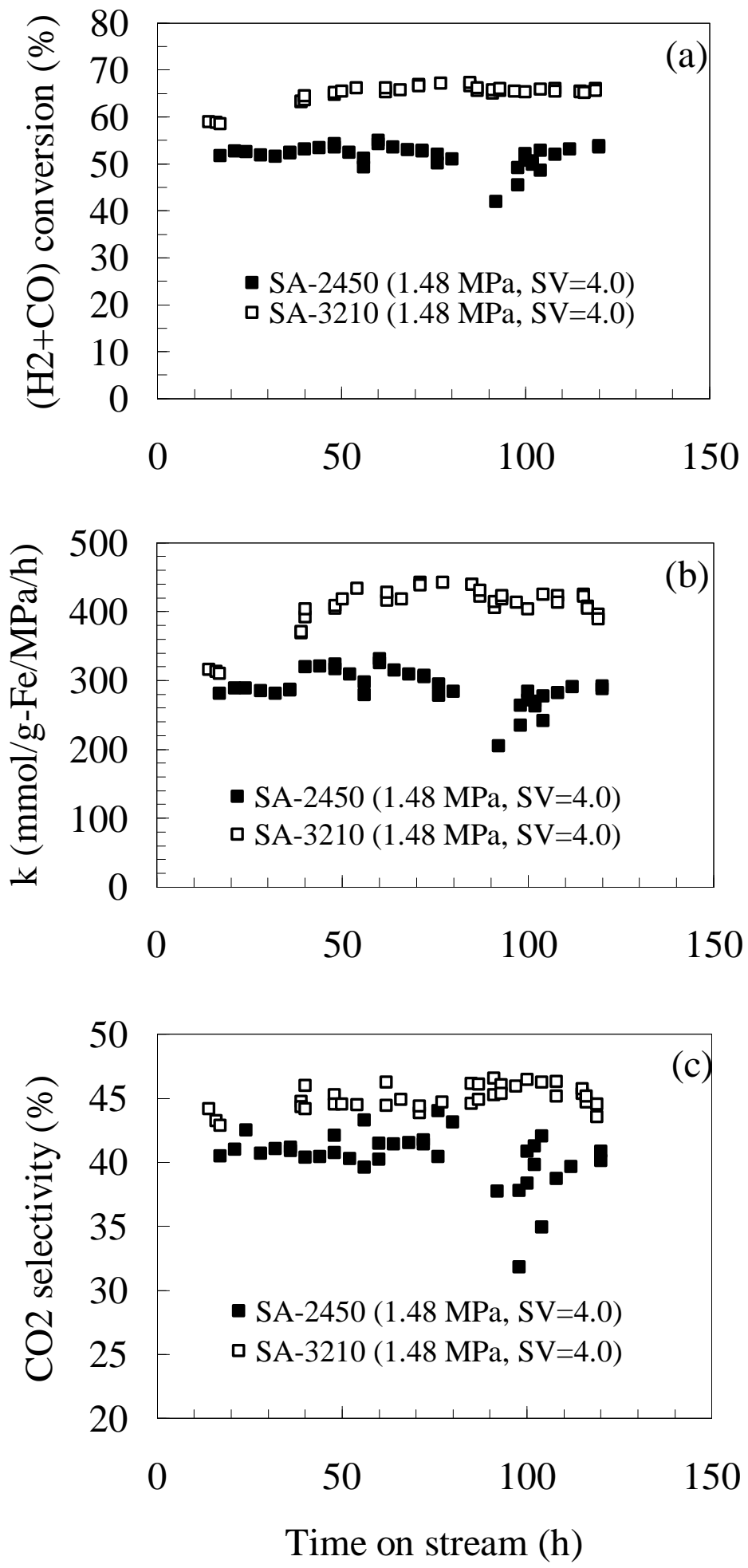

Figure 14 Effect of preparation procedure on F-T and WGS activity - Unpromoted catalyst (SA-2450 aqueous solution; SA-3210 methanol solution) Process conditions: $260^{\circ} \mathrm{C}, 1.48 \mathrm{MPa}, 4.0 \mathrm{Nl} / \mathrm{g}-\mathrm{Fe} / \mathrm{h}, \mathrm{H}_{2} / \mathrm{CO}=2 / 3$ 

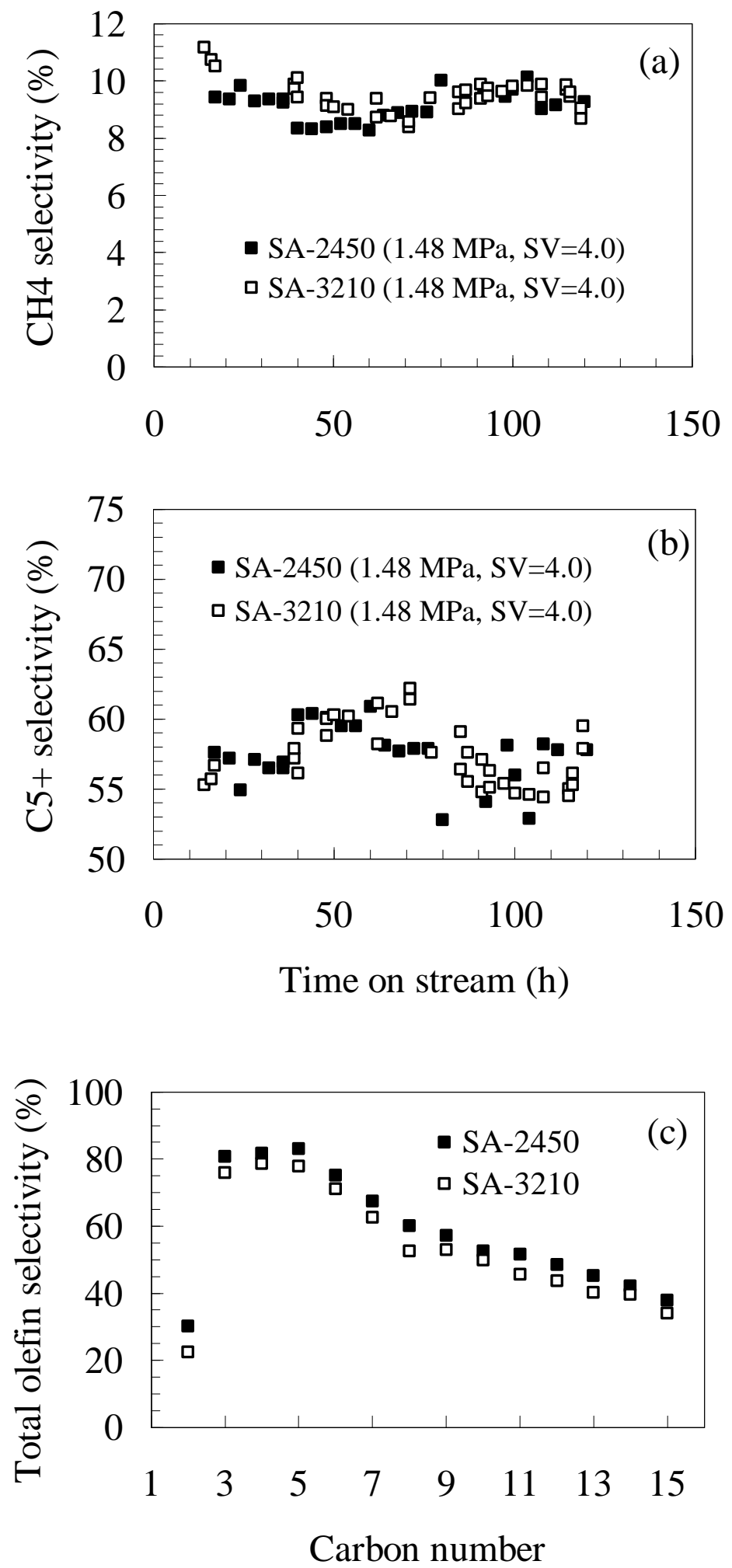

Figure 15 Effect of preparation procedure on product selectivity - Unpromoted catalyst (SA-2450 aqueous solution; SA-3210 methanol solution) Process conditions: $260^{\circ} \mathrm{C}, 1.48 \mathrm{MPa}, 4.0 \mathrm{Nl} / \mathrm{g}-\mathrm{Fe} / \mathrm{h}, \mathrm{H}_{2} / \mathrm{CO}=2 / 3$ 

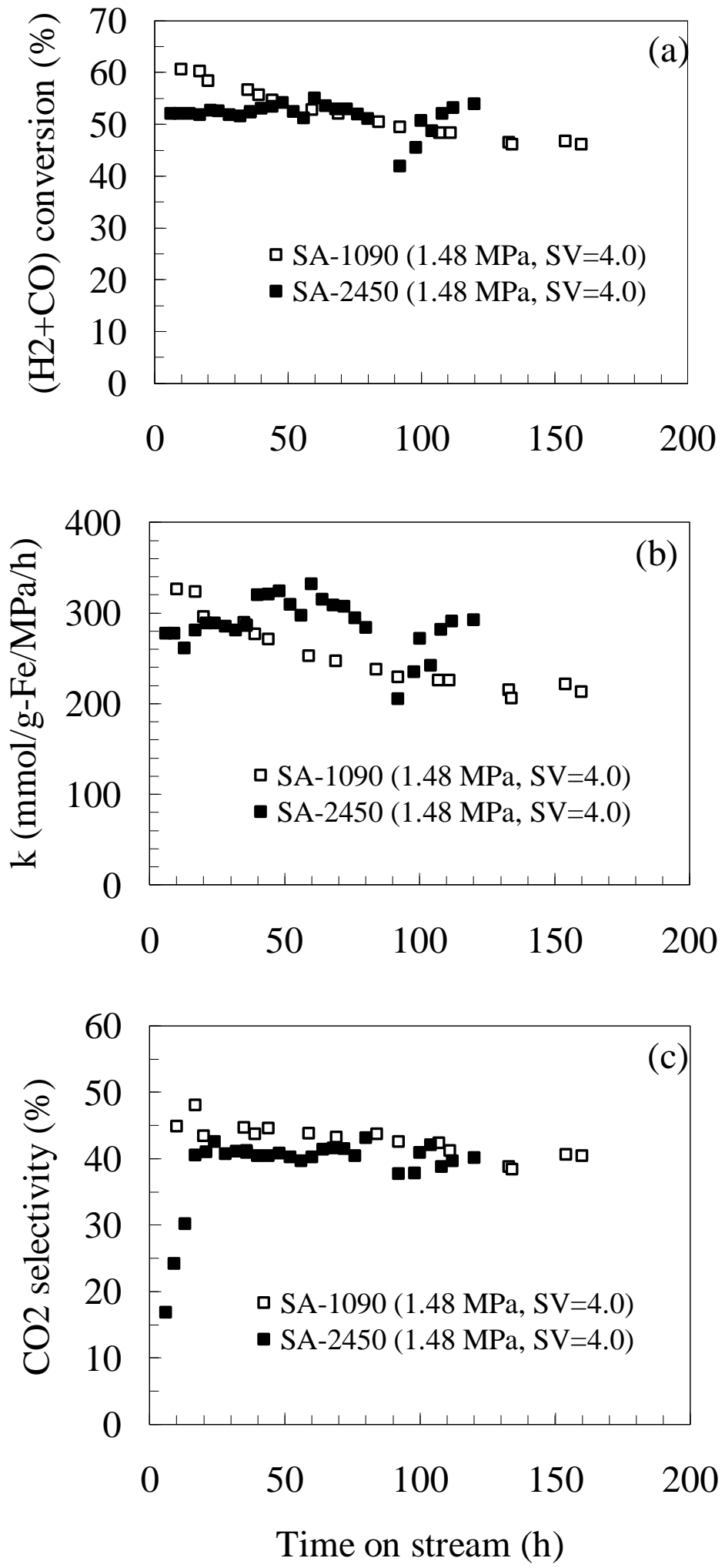

Figure 16 Promoter effects on the silica supported catalyst (aqueous impregnation) - F-T and WGS activity (SA-1090 promoted catalyst; SA-2450 unpromoted)

Process conditions: $260^{\circ} \mathrm{C}, 1.48 \mathrm{MPa}, 4.0 \mathrm{Nl} / \mathrm{g}-\mathrm{Fe} / \mathrm{h}, \mathrm{H}_{2} / \mathrm{CO}=2 / 3$ 

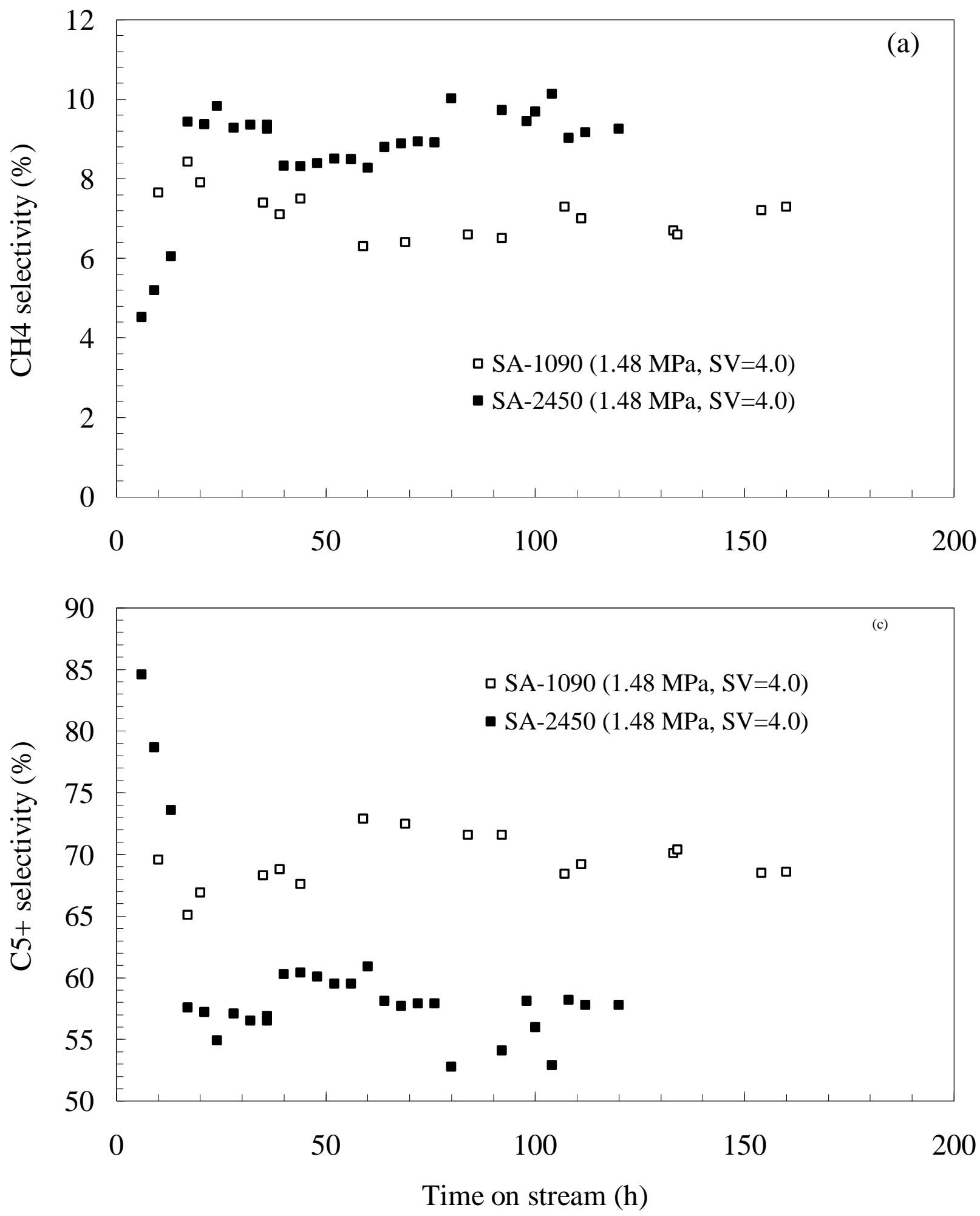

Figure 17 Promoter effects on the silica supported catalyst (aqueous impregnation) Product selectivity (SA-1090 promoted catalyst; SA-2450 unpromoted) Process conditions: $260^{\circ} \mathrm{C}, 1.48 \mathrm{MPa}, 4.0 \mathrm{Nl} / \mathrm{g}-\mathrm{Fe} / \mathrm{h}, \mathrm{H}_{2} / \mathrm{CO}=2 / 3$ 

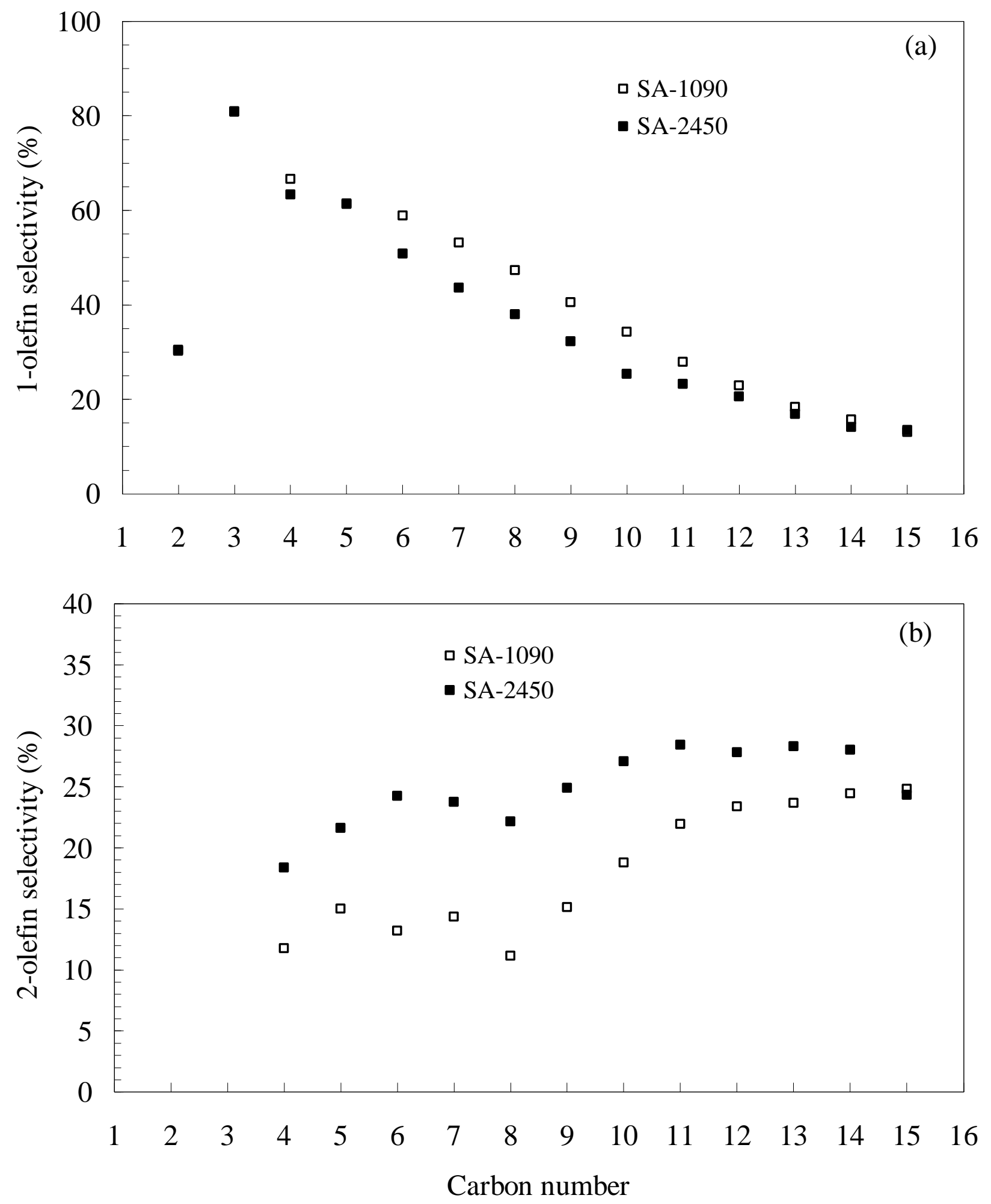

Figure 18 Promoter effects on the silica supported catalyst (aqueous impregnation) Olefin selectivity (SA-1090 promoted catalyst; SA-2450 unpromoted) Process conditions: $260^{\circ} \mathrm{C}, 1.48 \mathrm{MPa}, 4.0 \mathrm{Nl} / \mathrm{g}-\mathrm{Fe} / \mathrm{h}, \mathrm{H}_{2} / \mathrm{CO}=2 / 3$ 

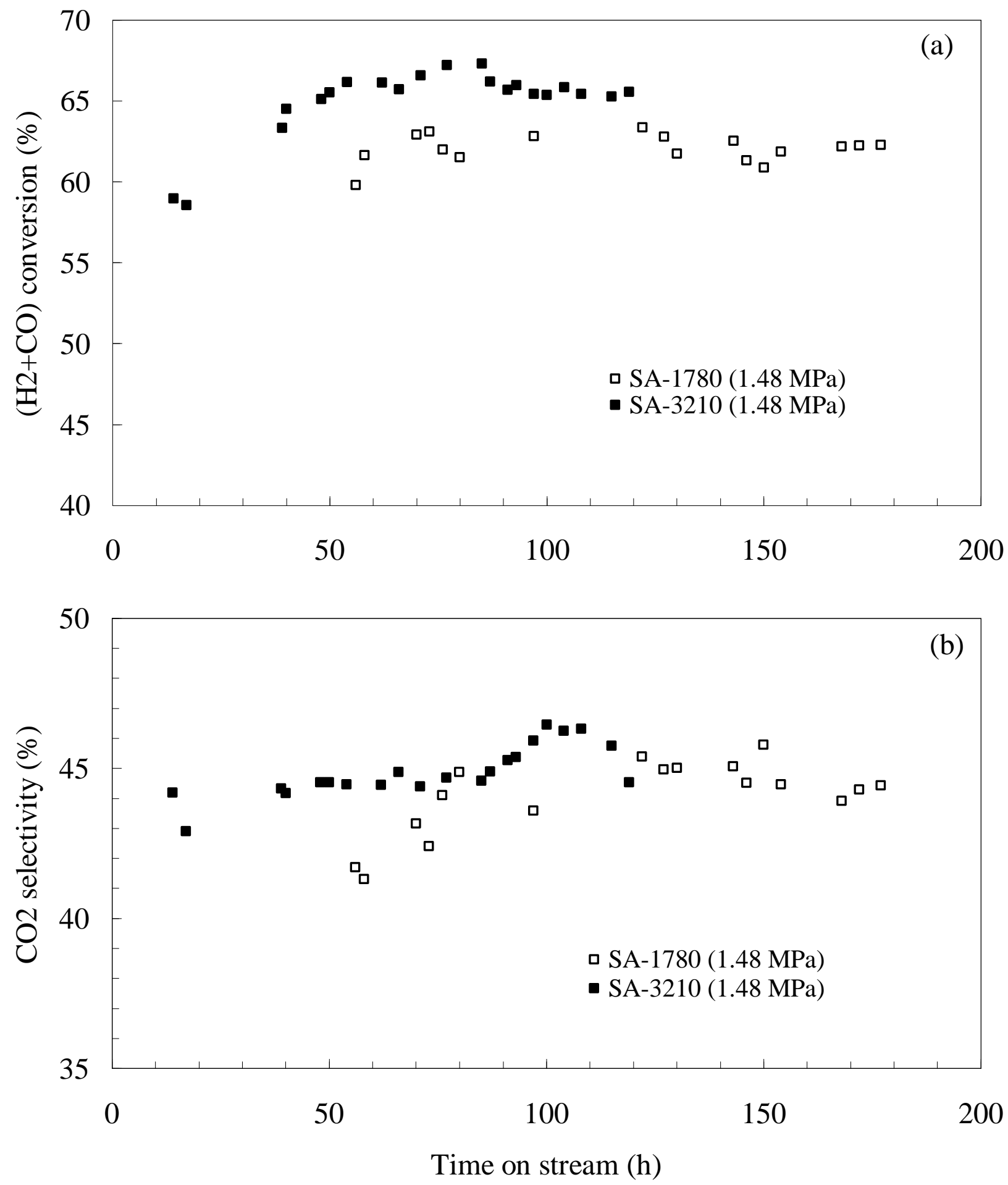

Figure 19 Promoter effects on the silica supported catalyst (organic impregnation) - F-T and WGS activity (SA-1780 promoted catalyst; SA-3210 unpromoted)

Process conditions: $260^{\circ} \mathrm{C}, 1.48 \mathrm{MPa}, 4.0 \mathrm{Nl} / \mathrm{g}-\mathrm{Fe} / \mathrm{h}, \mathrm{H}_{2} / \mathrm{CO}=2 / 3$ 

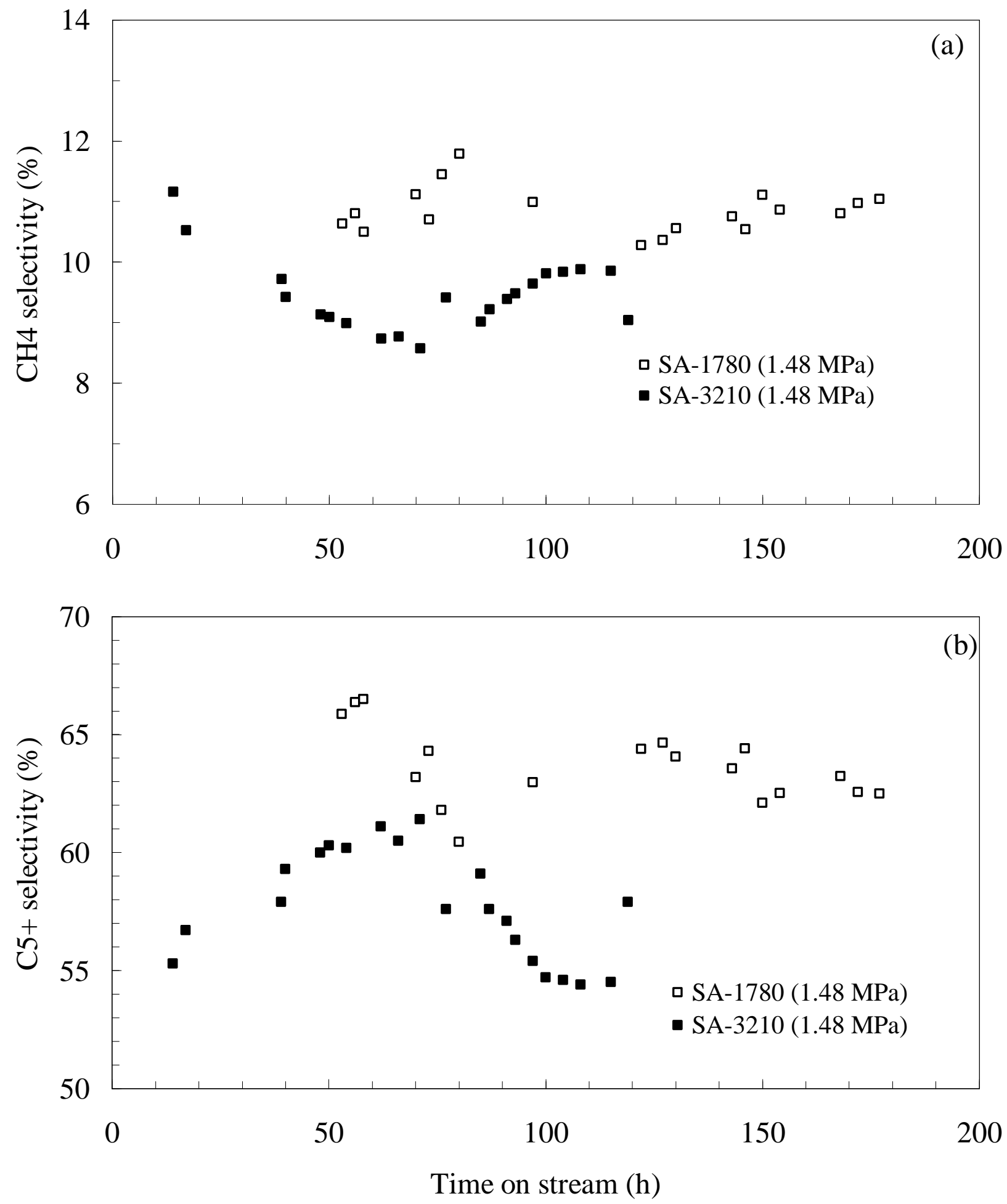

Figure 20 Promoter effects on the silica supported catalyst (organic impregnation) Product selectivity (SA-1780 promoted catalyst; SA-3210 unpromoted) Process conditions: $260^{\circ} \mathrm{C}, 1.48 \mathrm{MPa}, 4.0 \mathrm{Nl} / \mathrm{g}-\mathrm{Fe} / \mathrm{h}, \mathrm{H}_{2} / \mathrm{CO}=2 / 3$ 

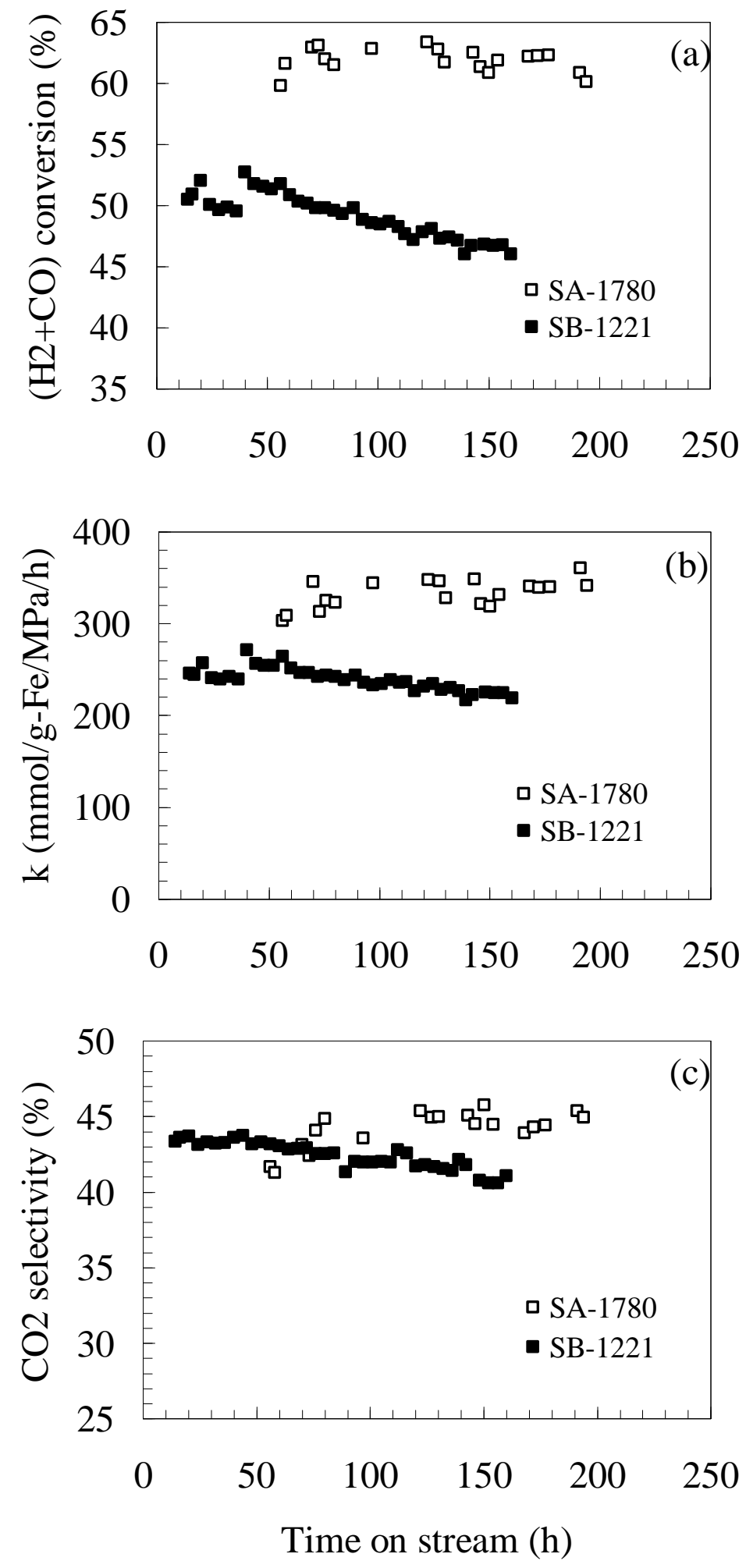

Figure 21 Effect of alkali promoter (silica supported catalyst - methanol solution) on F-T and WGS activity (SA-1780 K promoted; SA-1221 Na promoted) Process conditions: $260^{\circ} \mathrm{C}, 1.48 \mathrm{MPa}, 4.0 \mathrm{Nl} / \mathrm{g}-\mathrm{Fe} / \mathrm{h}, \mathrm{H}_{2} / \mathrm{CO}=2 / 3$ 

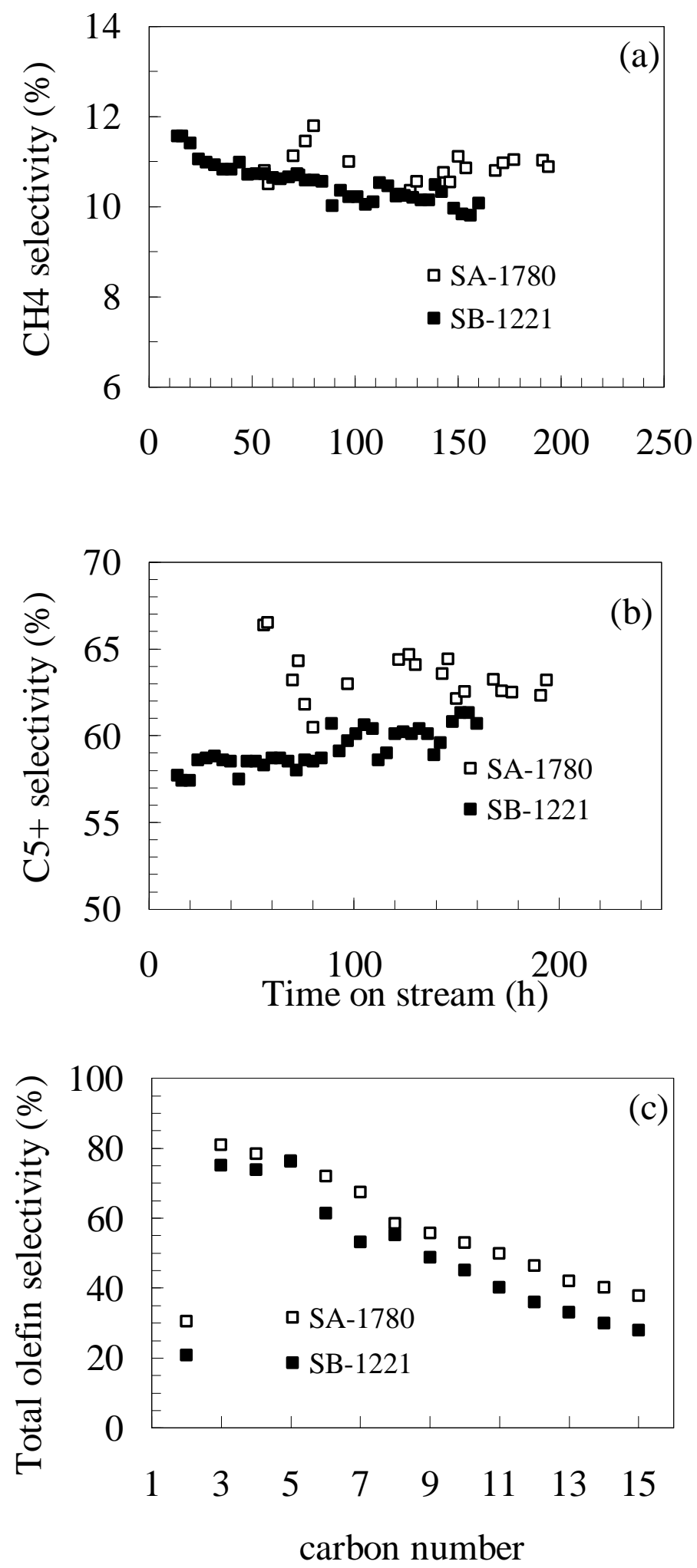

Figure 22 Effect of alkali promoter (silica supported catalyst - methanol solution) on product selectivity (SA-1780 K promoted; SA-1221 Na promoted) Process conditions: $260^{\circ} \mathrm{C}, 1.48 \mathrm{MPa}, 4.0 \mathrm{Nl} / \mathrm{g}-\mathrm{Fe} / \mathrm{h}, \mathrm{H}_{2} / \mathrm{CO}=2 / 3$ 


\title{
Attrition \\ Resistance of Supports for Iron Fischer-Tropsch Catalysts
}

Hien N. Pham ${ }^{\dagger}$, Alec Klinghoffer ${ }^{\ddagger}$, Lech Nowicki ${ }^{\ddagger}$, Jian Xu* Abhaya K. Datye ${ }^{\dagger}$, Dragomir Bukur ${ }^{\ddagger}$, Calvin Bartholomew*

${ }^{\dagger}$ Center for Microengineered Materials and Department of Chemical \& Nuclear Engineering, University of New Mexico, Albuquerque, NM 87131

${ }^{\ddagger}$ Department of Chemical Engineering, Texas A\&M University, College Station, TX 77843

* Department of Chemical Engineering, Brigham Young University, Provo, UT 84602

\begin{abstract}
Seven commercially available aluminas and silicas were screened for their use as supports for preparing attrition resistant iron Fischer-Tropsch (F-T) catalysts. We used ultrasonic fragmentation to determine the attrition resistance of these supports. Among the supports tested, one alumina support and two silica supports were found to possess adequate attrition resistance. These supports were then tested in a stirred tank slurry reactor (STSR) under non-reactive conditions, using either $\mathrm{N}_{2}$ gas or syngas as the feed. Particle size distributions of these supports provided a measure of attrition as these supports were used for the simulated F-T synthesis runs. Particle size distributions allow us to infer the extent of fracture and erosion during attrition tests. Our work showed that ultrasonic fragmentation was less severe than stirring of the supports in the STSR for causing erosion of particles from these supports.
\end{abstract}




\section{Introduction}

The Fischer Tropsch synthesis reaction is attracting increasing attention as a possible route for conversion of natural gas and coal into liquid fuels. Fe is an active catalyst for this reaction, however, attrition of Fe Fischer Tropsch catalysts has been identified as a major problem in commercial implementation of slurry bubble column reactors [1]. It is also recognized that precipitated Fe catalysts, while possessing high activity for F-T synthesis may not possess the optimal morphology for slurry bubble column reactors. Our work is directed at supported Fe catalysts, and as a first step, we have studied commercially available silica and alumina materials for their suitability for preparing attrition resistant iron Fischer-Tropsch $(\mathrm{F}-\mathrm{T})$ catalysts. The attrition resistance of these supports was studied via ultrasonic fragmentation, a method we have shown to be useful for rapid screening of attrition behavior [2,3]. The more promising supports from this initial screening were then tested in a stirred tank slurry reactor (STSR), where either nitrogen gas or syngas $\left(\mathrm{CO}+\mathrm{H}_{2}\right)$ was bubbled during stirring to simulate the mechanical forces that would be encountered during slurry reactor operation. In subsequent work, catalyst supports of adequate stability will be used to prepare supported Fe F-T catalysts.

\section{Previous Work}

In a previous study, Pham et al. [4] reported on the synthesis of attrition resistant Fe catalysts for F-T synthesis, a reaction that allows conversion of coal or natural gas into liquid fuels. These catalysts were prepared using a spray dryer, and the processing steps were examined to correlate the microstructure with the attrition resistance of the catalysts [5]. Other researchers have also used spray drying to prepare Fe F-T catalysts [6,7]. 
Recently, Zhao et al. [8] investigated in greater detail the catalyst properties affecting the attrition resistance of spray-dried Fe catalysts. They found that particle density, among all of the particle properties, was most significant in determining the catalyst attrition resistance. A higher particle density resulted in a more compact catalyst structure that provided better mechanical strength. In addition, the silica type and concentration were critical in the improvement of the attrition resistance of the spray-dried Fe catalysts.

It is important to improve the attrition resistance of the Fe F-T catalysts without sacrificing both the activity and selectivity of the catalysts. Previously, precipitated $\mathrm{Fe}$ catalysts were found to have higher activities [9-12] compared to supported Fe catalysts, which were attrition resistant but had lower catalytic activities [13,14]. Recently, O’ Brien et al. [15] characterized the activity, selectivity and attrition of several supported Fe catalysts. They found that the Fe catalysts supported on alumina (commercial) or magnesium aluminate (prepared) had higher activity after running the catalysts in a CSTR than the Fe catalysts supported with silica or magnesium silicate (both commercial). On the other hand, the silica and magnesium silicate based catalysts were more attrition resistant than the alumina and magnesium aluminate based catalysts during the CSTR runs.

O' Brien et al. [15] reported the range of particle sizes for the alumina- and aluminate-containing catalysts before and after attrition, presumably derived from scanning electron microscope (SEM) images. The SEM images of the silica- and silicatecontaining catalysts before and after the CSTR runs suggest that there was little sign of attrition during use. However, it is difficult to derive accurate particle size distributions from SEM images because weakly agglomerated particles will not clearly show up in 
these images. In order to provide better insight into the relative extent of fracture and erosion, we have used a sedigraph particle size analyzer that directly measures particle size distribution. By following particle size distributions as function of time on stream in a slurry reactor we gain insight into the extent of attrition during STSR runs. In this work, we present an evaluation of commercially available silica and alumina supports for their suitability in preparing attrition resistant Fe F-T catalysts. We used ultrasonic fragmentation because it can evaluate, in a very short time, the attrition behavior of these catalysts. However, ultrasonic fragmentation is performed in an aqueous suspension while F-T synthesis is carried out in an organic wax medium. There is some concern about the suitability of the ultrasonic fragmentation approach for predicted performance in a slurry reactor. We therefore present a comparison of the ultrasonic tests with the behavior of supports subjected to long-term tests in a stirred tank slurry reactor.

\section{Experimental}

Four silica supports and three alumina supports were used for the attrition tests: Grace Davison 644, 654, 948, 952 silicas and Condea Vista B, HP 14, HP 14-150 aluminas. Tables 1 and 2 show the properties of the alumina and silica supports, respectively. For the ultrasonic fragmentation tests, $1 \mathrm{~g}$ of support was added to $50 \mathrm{ml}$ of a 0.05 wt.\% sodium hexametaphosphate solution, which was used as a dispersant. A Micromeritics Sedigraph 5100 analyzer was used to measure the particle size distribution at time 0 min. The suspension was then subjected to ultrasonic energy at an amplitude setting of $20(100 \mathrm{~W})$ at 5 min intervals using a Tekmar 501 ultrasonic disrupter $(20 \mathrm{kHz}$ $\pm 50 \mathrm{~Hz}$ ) equipped with a V1A horn and a $1 / 2 "$ probe tip. After different extents of 
ultrasonic irradiation, the particle size distribution was analyzed to detect the mode of particle fragmentation.

After screening, the more promising supports were tested in a STSR. Under nonreacting conditions, $\mathrm{N}_{2}$ gas was used as the feed gas, while under reacting F-T conditions, syngas was used as the feed gas. A hydrogenated 1-decene homopolymer (Durasyn-164 oil) was used as the slurry liquid medium. The samples were collected at various times on stream, after which particle size distributions were measured after the hydrocarbons were removed from the support by repeated washing in a solvent.

\section{Results}

\section{Ultrasonic Fragmentation Runs}

Fig. 1 shows cumulative mass distribution plots of Vista HP 14 and Vista HP 14150 aluminas, respectively. These plots show the mass $\%$ of the sample that is finer than a given size as a function of ultrasonic irradiation. The shift in the median particle size to smaller particles is indicative of the fracture of larger particles into smaller fragments. Smaller fragments are seen with Vista HP 14-150 than with Vista HP 14, after ultrasonic irradiation. However, neither alumina leads to generation of fine particles below $6 \mu \mathrm{m}$ suggesting very little erosion of the primary agglomerates during ultrasonic irradiation. SEM images (Fig. 2) show that these alumina particles are roughly spherical in shape, a shape that would be more suitable for a slurry reactor.

Fig. 3 shows a cumulative particle size distribution plot for Vista B alumina. In our previous work [16], this alumina was used as a test sample for comparing the strength of other slurry phase heterogeneous catalysts. In this figure, we see that the extent of 
particle fracture is much less pronounced than in Fig. 2. However, unlike Vista HP 14 and HP 14-150, fine particles smaller than $3 \mu \mathrm{m}$ are generated throughout the ultrasonic fragmentation process for the Vista B alumina. These results suggest that this support is not as resistant to erosion as the Vista HP 14 and HP 14-150 supports. The SEM image (Fig. 4) shows that the Vista B particles are irregularly-shaped, suggesting that this alumina may not be as suitable as the HP-14 for a slurry phase reactor.

Fig. 5 shows cumulative particle size distribution plots of Davison 644 and Davison 654 silicas, respectively. The median particle size for Davison 644 and 654 are $38 \mu \mathrm{m}$ and $42 \mu \mathrm{m}$, respectively. For Davison 644, there is fracture of particles after 5 min of ultrasonic irradiation, but little fracture occurs thereafter. There also appears to be very little generation of fine particles below $8 \mu \mathrm{m}$, suggesting that Davison 644 is attrition resistant to erosion. On the other hand, Davison 654 is not attrition resistant either to fracture and erosion after $25 \mathrm{~min}$ of ultrasonic irradiation. SEM images (Fig. 6) show that Davison 644 particles are irregular-shaped, similar to those seen for Vista B alumina by SEM.

Fig. 7 shows cumulative particle size distribution plots of Davison 948 and 952 silicas, respectively. For Davison 948, very little attrition of particles due to fracture is seen after 25 min of ultrasonic irradiation. Also, little generation of fine particles due to erosion is seen below $6 \mu \mathrm{m}$. Fracture of particles is also seen for Davison 952 . Generation of fine particles suggests that it is not attrition resistant to erosion. The median particle sizes for Davison 948 and 952 are $33 \mu \mathrm{m}$ and $44 \mu \mathrm{m}$, respectively. SEM images (Fig. 8) show that Davison 948 particles are roughly spherical, whereas Davison 952 particles are irregularly-shaped. 
Of the alumina supports we have studied, Vista B alumina is more resistant to fracture than Vista HP 14 or HP 14-150. However, Vista B alumina is not resistant to erosion. The generation of particles smaller than $5 \mu \mathrm{m}$ occurs for Vista HP 14-150, whereas no particles smaller than $5 \mu \mathrm{m}$ are observed with Vista HP 14, both after 25 min of ultrasonic irradiation. The generation of fine particles due to erosion below $5 \mu \mathrm{m}$ may not be acceptable for slurry F-T reactors based on the work reported in U.S. Pat. No. $5,348,928$. This patent discloses a process for optimally operating a three-phase slurry bubble column where the inventors find that although smaller catalyst particles improve fluidization, these particles also increase the difficulty in separating them from the liquid product stream. Thus, particle diameters less than $5 \mu \mathrm{m}$ should be avoided. Since no generation of particles below $5 \mu \mathrm{m}$ has been observed for Vista HP 14, this alumina may be more suitable as a support for preparing the attrition-resistant Fe F-T catalysts.

Of the silica supports we have studied, Davison 654 is the least attrition resistant to fracture, while Davison 952 is the least attrition resistant to erosion, during the ultrasonic fragmentation runs. Very little generation of fine particles below $5 \mu \mathrm{m}$ due to erosion was observed for Davison 644 and 948. Furthermore, these silicas are attrition resistant to fracture throughout the ultrasonic fragmentation process, even though fracture of particles for Davison 644 is initially observed after $5 \mathrm{~min}$ of ultrasonic irradiation. Thus, Davison 644 and 948 may also be suitable for preparing attrition resistant $\mathrm{Fe}$ catalysts.

\section{Simulated F-T synthesis runs}


Two of the alumina and two silica supports were processed in a STSR under nonreacting $\left(\mathrm{N}_{2}\right)$ conditions, using Durasyn-164 oil as the slurry liquid medium. The particle size distributions were measured with the same sedigraph analyzer as used for the ultrasonic fragmentation runs with all other experimental conditions being maintained the same. The setup for the STSR runs has been described elsewhere [9]. Fig. 9 shows cumulative particle size distribution plots of Vista HP 14 alumina and Davison 948 silica. In this case, Vista HP 14 shows no significant fracture, but there is generation of fine particles in the $1-10 \mu \mathrm{m}$ range after use in the STSR for $168 \mathrm{~h}$. In contrast, the generation of fine particles is less pronounced in Davison 948. Fig. 10 shows cumulative particle size distribution plots for Vista B alumina and Davison 952 silica after being processed in the STSR under non-reacting conditions. The Vista B alumina appears to be resistant to fracture, since the median particle size does not increase with time on stream, but there is evidence for erosion since small particles start to appear after stirring in oil. Davison 952 is clearly not very attrition resistant since the particles seem to fracture with stirring time in the STSR. This behavior confirms the trend seen in ultrasonic fragmentation tests.

\section{Discussion}

Table 3 provides a summary of the attrition resistance as determined by ultrasonic fragmentation and the simulated F-T synthesis runs. These two methods rely on different mechanisms to cause attrition of the support agglomerates. Ultrasonic fragmentation relies on cavitation caused by collapse of bubbles in solution, while it is the shear forces that cause fragmentation during mixing in a STSR. The behavior of the supports with respect to their attrition resistance was similar despite the different approaches to fragmentation. For example, the Vista B alumina and Davison 952 show similar extents 
of particle break up during ultrasonic fragmentation or during stirring in a CSTR. In the case of Vista HP 14 and Davison 948 more erosion is seen after the STSR runs than during ultrasonic fragmentation. We would expect to see more erosion with irregular shaped, non-spherical particles. Since Vista B alumina and Davison 952 particles are irregularly-shaped compared to Vista HP 14 and Davison 948, more erosion is observed for Vista B alumina and Davison 952 via ultrasonic fragmentation and STSR runs. However, significant erosion is also observed for Vista HP 14 and Davison 948 after the STSR runs, while both supports have roughly spherical particles, with more erosion seen for Vista HP 14 than for Davison 948. This means that having nearly spherical, smooth shapes is not sufficient to prevent erosion during F-T synthesis runs. In fact, the supports with irregular particles seemed to be more resistant to fracture than those with nearly spherical shapes.

One variable that needs to be considered is the extent of residual oil present on the support particles. Residual oil may cause the fine particles generated during CSTR runs to stick to the larger particles so that the Sedigraph analyzer may not be able to detect them. Residual oil could therefore interfere with the accuracy of the particle size analysis, which is performed in an aqueous solution. To avoid this artifact, we used a consistent washing procedure to remove the hydrocarbon oils, and do not expect to see major differences among the supports. Since some of the supports clearly show the generation of fine particles after long term tests in the CSTR, we feel confident that the results are indicative of the extent of attrition resistance of these particles.

\section{Summary}


We have investigated several commercially available aluminas and silicas for use as a suitable support in preparing attrition resistant Fe F-T catalysts. After initially screening these supports by the ultrasonic fragmentation method, it was found that alumina supports were generally less attrition resistant than the silica. Among the alumina supports we tested, Vista HP 14 alumina, showed evidence for fracture and erosion. In contrast, there was no fracture of the particles in Vista B alumina, but erosion was observed both during ultrasonic fragmentation as well as during STSR runs. Among the silica supports, Davison 644 and 948 silicas were more attrition resistant than either of the aluminas we tested: Vista B and HP 14-150 alumina. Davison 654 and 952 silica showed considerable fracture and particle erosion. Results also showed that the STSR runs were more severe on the particles and led to increased erosion compared to the ultrasonic irradiation approach.

In future work, the attrition resistant supports will be used to load iron onto them. The prepared catalysts will then be tested in the STSR under actual F-T conditions, after which the reactivities of these catalysts will be evaluated to see which of the supports will provide optimal catalytic performance. These tests will be long term, hence slurry supports will be periodically withdrawn from the STSR in an inert atmosphere for particle size distribution measurements and catalyst characterization. Also, experimental data will be analyzed to calculate catalyst activity and selectivity as a function of process and/or pretreatment conditions and time on stream.

\section{References}

[1] Saxena, S.C., Catal. Rev. Sci. Engr. 37 (1995) 227. 
[2] Thoma, S.G., Ciftcioglu, M., Smith, D.M., Powder Technol. 68 (1991) 53.

[3] Thoma, S.G., Ciftcioglu, M., Smith, D.M., Powder Technol. 68 (1991) 71.

[4] Pham, H.N., Viergutz, A., Gormley, R.J., Datye, A.K., Powder Technol. 110 (2000) 196.

[5] Pham, H.N., Datye, A.K., Catal. Today 58 (2000) 233.

[6] Srinivasan, R., Xu, L., Spicer, R.L., Tungate, F.L., Davis, B.H., Fuel Sci. Technol. Int. 14 (1996) 1337.

[7] Jothimurugesan, K., Goodwin Jr., J.G., Gangwal, S.K., Spivey, J.J., Catal. Today $58(2000) 335$.

[8] Zhao, R., Goodwin Jr., J.G., Jothimurugesan, K., Gangwal, S.K., Spivey, J.J., Ind. Eng. Chem. Res. 40 (2001) 1065.

[9] Bukur, D.B., Lang, X., Rossin, J.A., Zimmerman, W.H., Rosynek, M.P., Yeh, E.B., Li, C., Ind. Eng. Chem. Res. 28 (1989) 1130.

[10] Bukur, D.B., Okabe, K., Rosynek, M.P., Li, C., Wang, D., Rao, K.R.P.M., Huffman, G.P., J. Catal. 155 (1995) 353.

[11] Bukur, D.B., Nowicki, L., Patel, S.A., Canadian J. Chem. Eng. 74 (1996) 399.

[12] Bukur, D.B., Nowicki, L., Lang, X., Chem. Eng. Sci. 49 (1994) 4615.

[13] Bukur, D.B., Mukesh, D., Patel, S.A., Ind. Eng. Chem. Res. 29 (1990) 194.

[14] Bukur, D.B., Lang, X., Mukesh, D., Zimmerman, W.H., Rosynek, M.P., Li, C., J. Catal. 29 (1990) 1588.

[15] O’ Brien, R.J., Xu, L., Bao, S., Raje, A., Davis, B.H., Appl. Catal. A 196 (2000) 173.

[16] Pham, H.N., Reardon, J., Datye, A.K., Powder Technol. 103 (1999) 95. 
Table 1. Properties of commercially available alumina supports.

\begin{tabular}{|c|c|c|c|c|c|}
\hline Name & \multicolumn{2}{|c|}{$\begin{array}{c}\text { Condea } \\
\text { Vista HP14 }\end{array}$} & \multicolumn{2}{c|}{$\begin{array}{c}\text { Condea } \\
\text { Vista B }\end{array}$} & \multicolumn{2}{c|}{$\begin{array}{c}\text { Condea } \\
\text { Vista HP14-150 }\end{array}$} \\
\hline Type & \multicolumn{2}{|c|}{ Boehmite } & \multicolumn{2}{c|}{$\gamma$-Alumina } \\
\hline $\begin{array}{c}\text { Uncalc. } \\
\text { Density } \\
\left(\mathrm{g} / \mathrm{cm}^{3}\right)\end{array}$ & 2.71 & 2.68 & ----------- & 3.07 & 3.07 \\
\hline $\begin{array}{c}\text { Pore Volume } \\
\left(\mathrm{cm}^{3} / \mathrm{g}\right)\end{array}$ & 0.94 & ------ & 0.47 & 0.97 & ------ \\
\hline $\begin{array}{c}\text { Surface Area } \\
\left(\mathrm{m}^{2} / \mathrm{g}\right)\end{array}$ & 150 & 156 & 243 & 153 & 157 \\
\hline
\end{tabular}

${ }^{\mathrm{a}} 500^{\circ} \mathrm{C}$ for 5 hours

Vista HP14 and HP14-150 microspherical particles (spray drying) 
Table 2. Properties of commercially available silica supports.

\begin{tabular}{|c|c|c|c|c|c|}
\hline Name & $\begin{array}{c}\text { Grace } \\
\text { Davison 644 }\end{array}$ & $\begin{array}{c}\text { Grace } \\
\text { Davison 654 }\end{array}$ & \multicolumn{2}{|c|}{$\begin{array}{c}\text { Grace } \\
\text { Davison 948 }\end{array}$} & $\begin{array}{c}\text { Grace } \\
\text { Davison 952 }\end{array}$ \\
\hline Type & Uncalc. & Uncalc. & Uncalc. & Calc. ${ }^{\text {a }}$ & Uncalc. \\
\hline $\begin{array}{c}\text { Density } \\
\left(\mathrm{g} / \mathrm{cm}^{3}\right)\end{array}$ & 2.29 & 2.23 & 2.09 & 2.08 & 2.32 \\
\hline $\begin{array}{c}\text { Pore Volume } \\
\left(\mathrm{cm}^{3} / \mathrm{g}\right)\end{array}$ & 1.10 & 1.70 & 1.62 & ------ & 1.61 \\
\hline $\begin{array}{c}\text { Surface Area } \\
\left(\mathrm{m}^{2} / \mathrm{g}\right)\end{array}$ & 268 & 272 & 279 & 304 & 309 \\
\hline
\end{tabular}

${ }^{\mathrm{a}} 500^{\circ} \mathrm{C}$ for 5 hours 
Table 3 Extent of Attrition Via After Ultrasonic Fragmentation and Simulated STSR runs

\begin{tabular}{|l|l|l|l|l|l|}
\hline Support & Morphology & \multicolumn{2}{l|}{$\begin{array}{l}\text { Ultrasonic } \\
\text { Fragmentation }\end{array}$} & \multicolumn{2}{l|}{ STSR tests } \\
\hline \multicolumn{7}{|c|}{ Fracture } & Erosion & Fracture & Erosion \\
\hline \multicolumn{7}{|c|}{ Alumina } \\
\hline $\begin{array}{l}\text { Vista HP- } \\
14\end{array}$ & $\begin{array}{l}\text { Smooth, } \\
\text { rounded }\end{array}$ & Pronounced & None & Modest & Pronounced \\
\hline $\begin{array}{l}\text { Vista HP- } \\
14-150\end{array}$ & $\begin{array}{l}\text { Smooth, } \\
\text { rounded }\end{array}$ & Pronounced & Some & --- & --- \\
\hline $\begin{array}{l}\text { Vista B- } \\
965\end{array}$ & $\begin{array}{l}\text { Irregular, } \\
\text { fines visible }\end{array}$ & None & Significant & None & Some \\
\hline \multicolumn{7}{|c|}{ Silica } & -- & -- \\
\hline $\begin{array}{l}\text { Davison } \\
644\end{array}$ & $\begin{array}{l}\text { Irregular, } \\
\text { fines visible }\end{array}$ & Significant & None & --- & --- \\
\hline $\begin{array}{l}\text { Davison } \\
654\end{array}$ & Pronounced & Pronounced & --- & None \\
\hline $\begin{array}{l}\text { Davison } \\
948\end{array}$ & $\begin{array}{l}\text { Smooth, } \\
\text { rounded }\end{array}$ & Very small & None & Some & Pronounced \\
\hline $\begin{array}{l}\text { Davison } \\
\text { 952 }\end{array}$ & $\begin{array}{l}\text { Irregular, } \\
\text { fines visible }\end{array}$ & Pronounced & Pronounced & Pronounced & \\
\hline
\end{tabular}



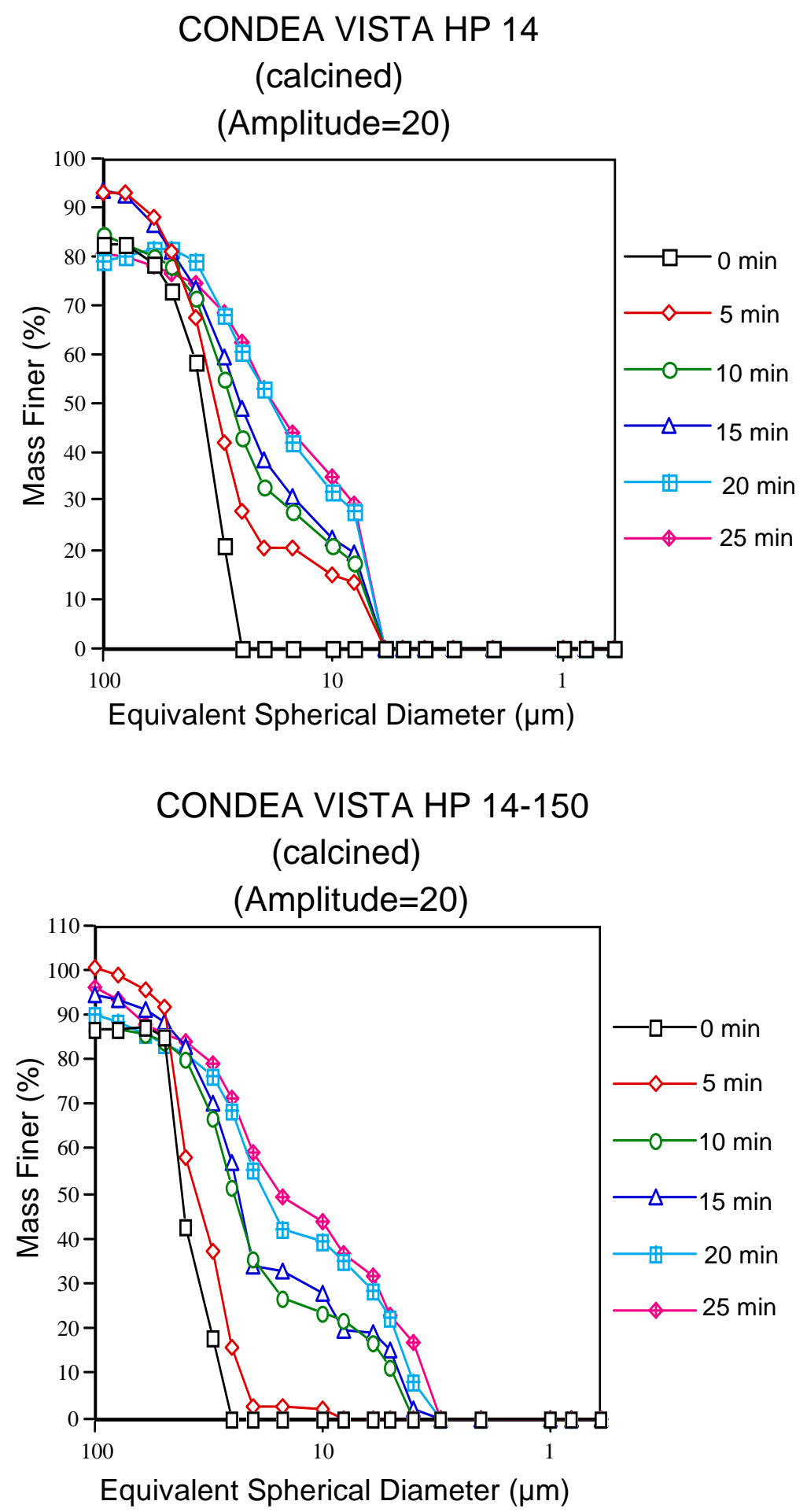

Fig. 1. Sedigraph particle size distributions of Vista HP 14 and HP 14-150 alumina supports. The shift in the median particle size to smaller particles indicates fracture of the primary agglomerates, which occurs more readily with Vista HP 14-150 than with Vista HP 14. 

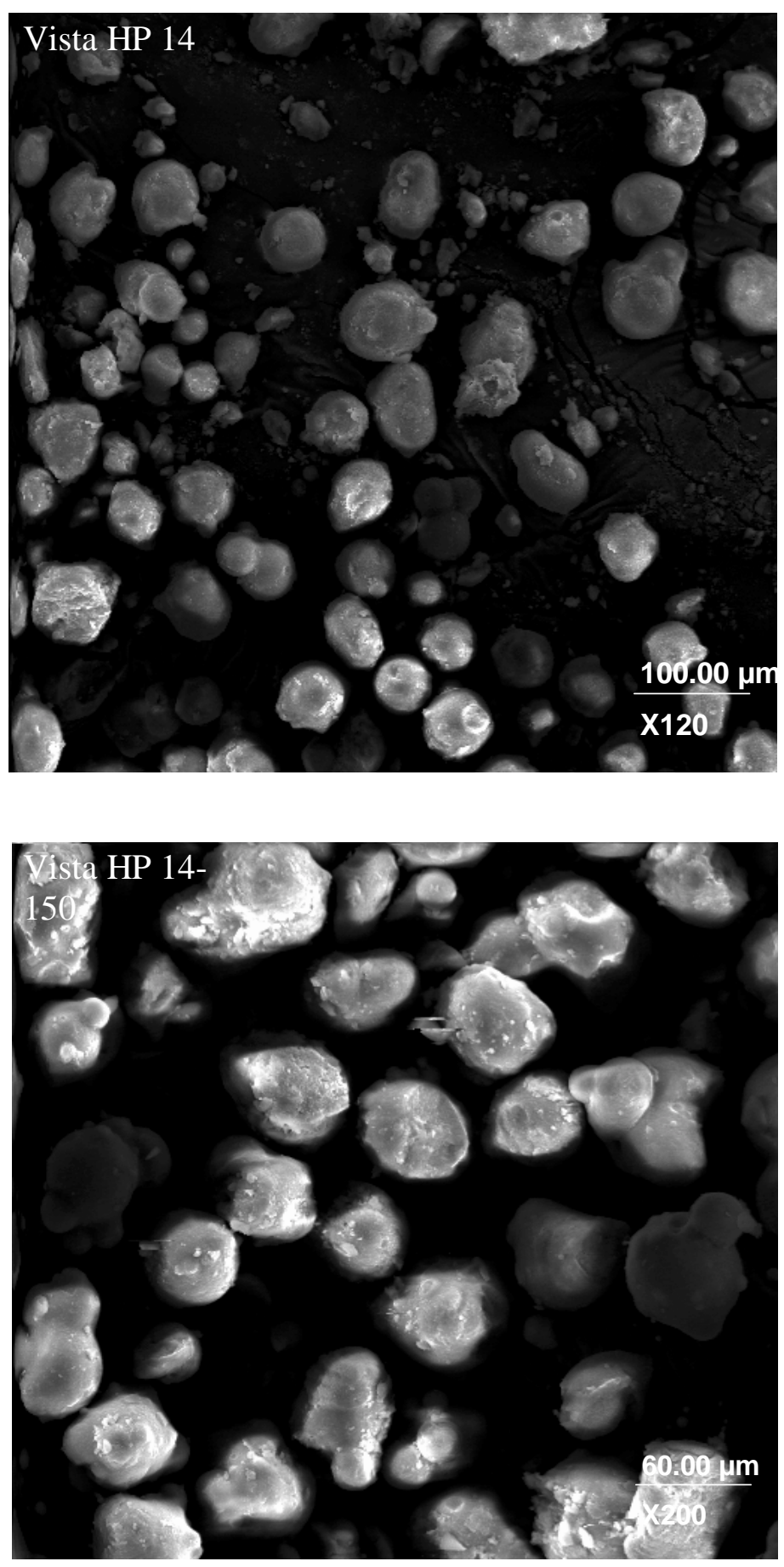

Fig. 2. SEM images of Vista HP 14 and HP 14-150 alumina supports. These particles are roughly spherical, as expected from a spray drying process. 


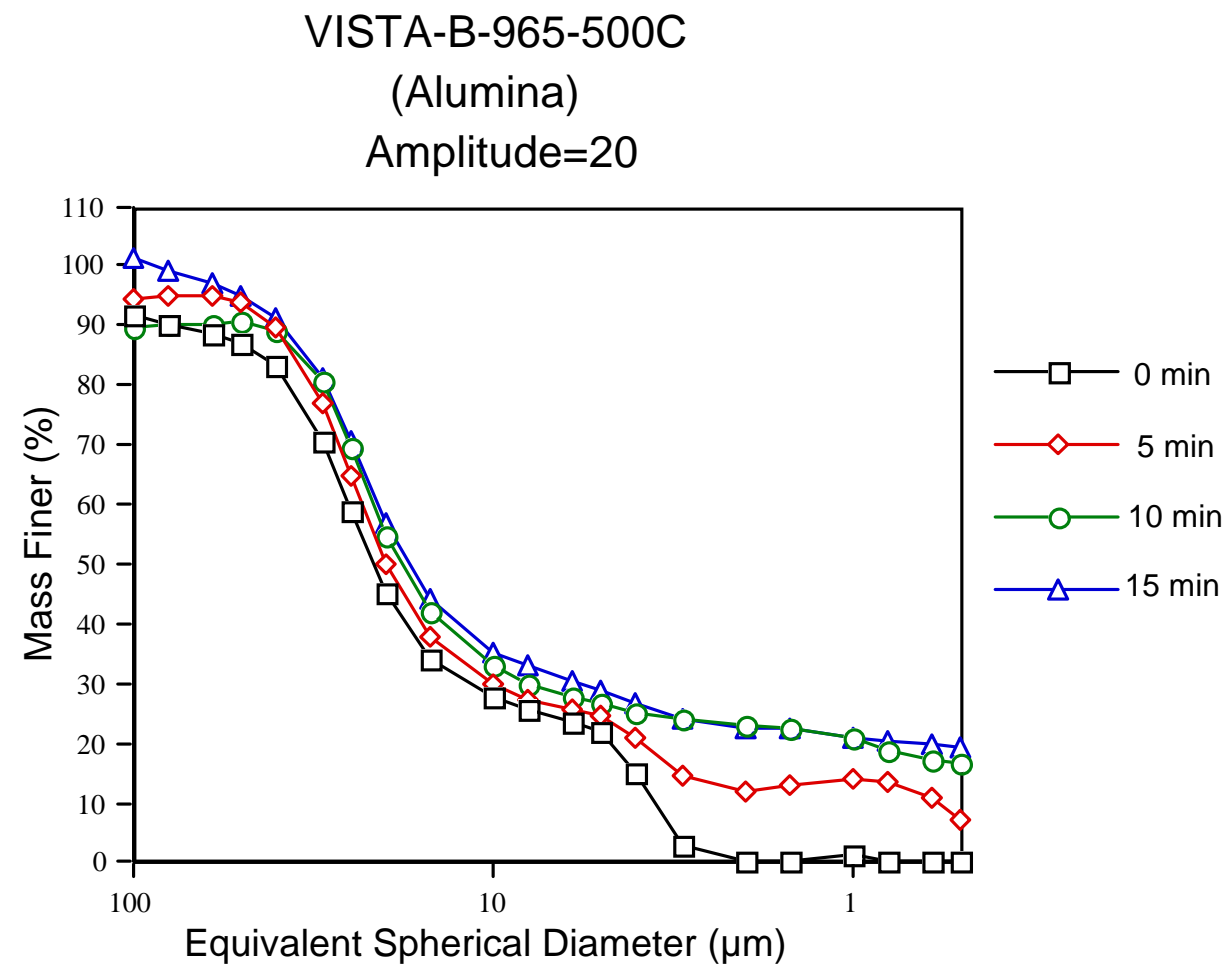

Fig. 3. Sedigraph particle size distribution for Vista B alumina as a function of ultrasonic irradiation time. The starting alumina from VISTA was sieved and calcined in air at $500^{\circ} \mathrm{C}$ before use in this test. 


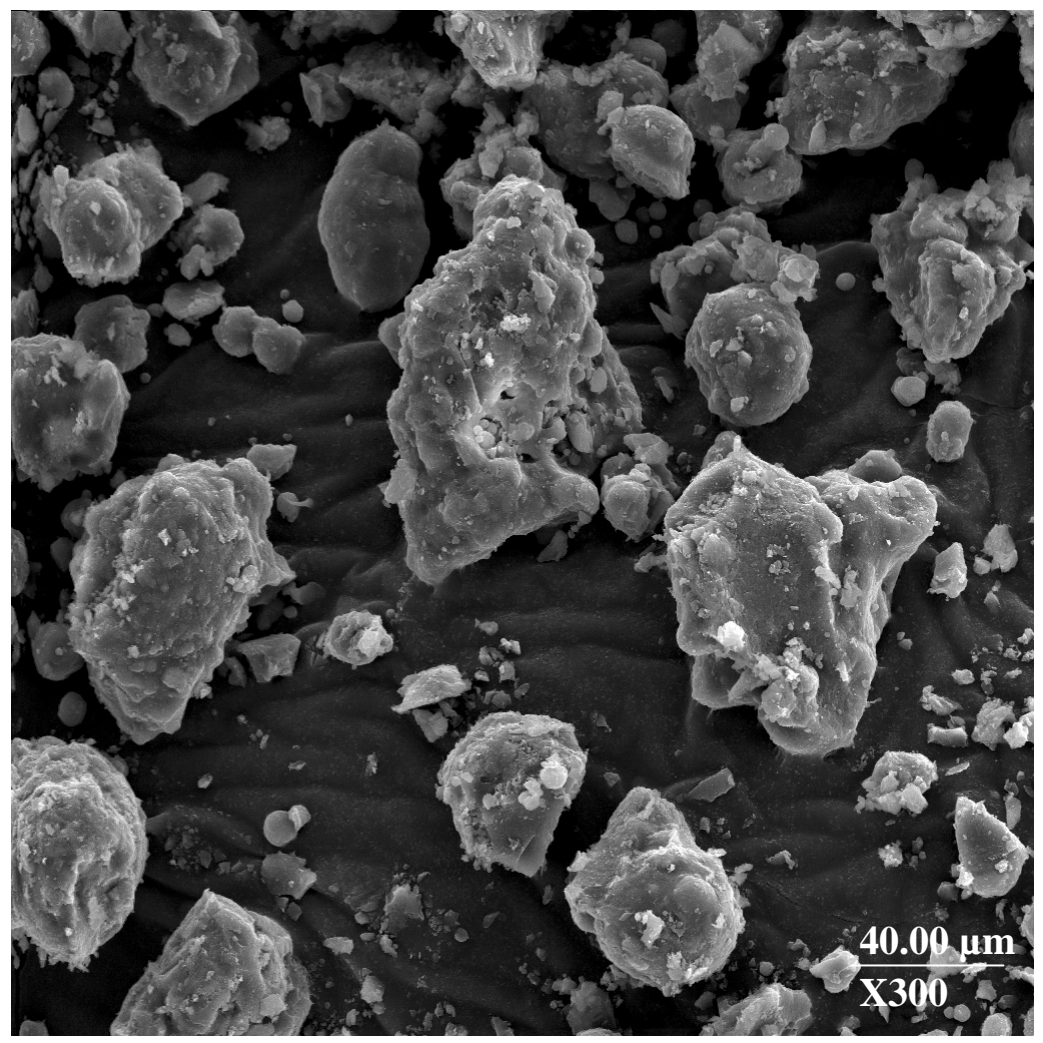

Fig. 4. SEM picture of Vista B alumina. This alumina shows particles that are considerable more irregular when compared to Vista HP 14 and Vista HP 14-150. 


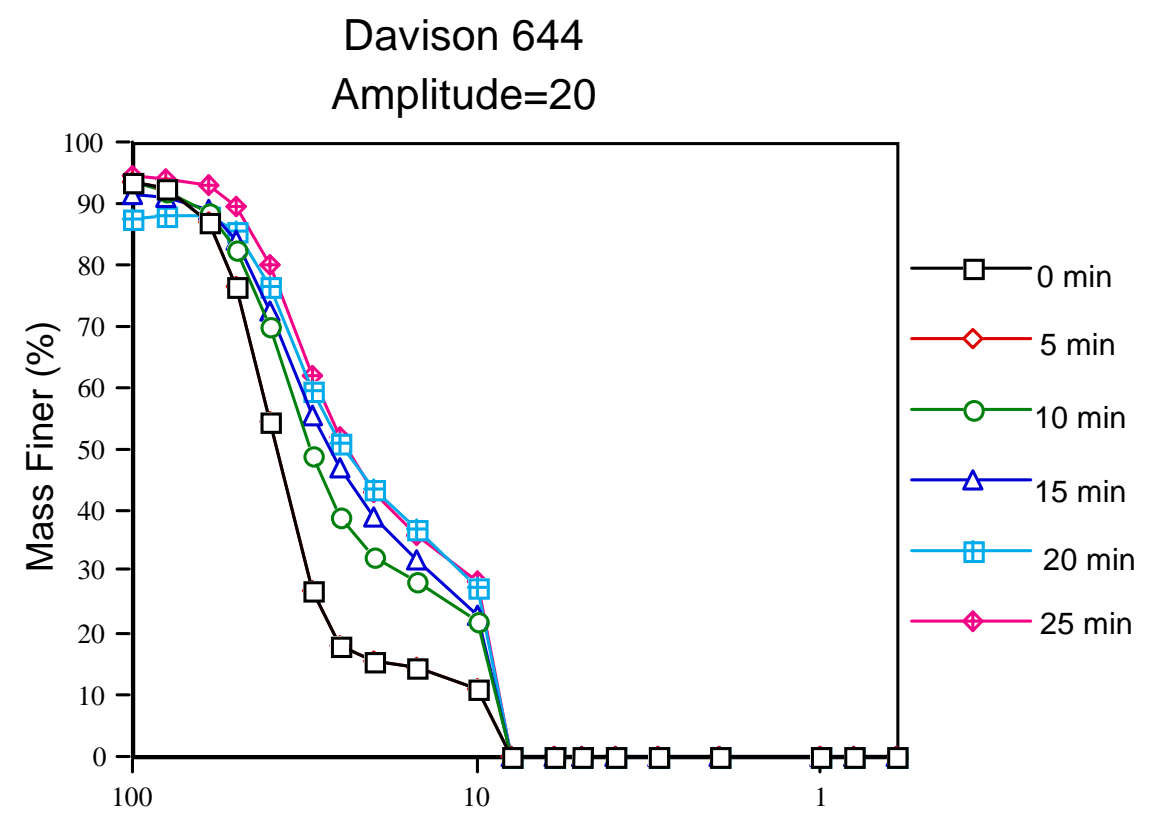

Equivalent Spherical Diameter $(\mu \mathrm{m})$

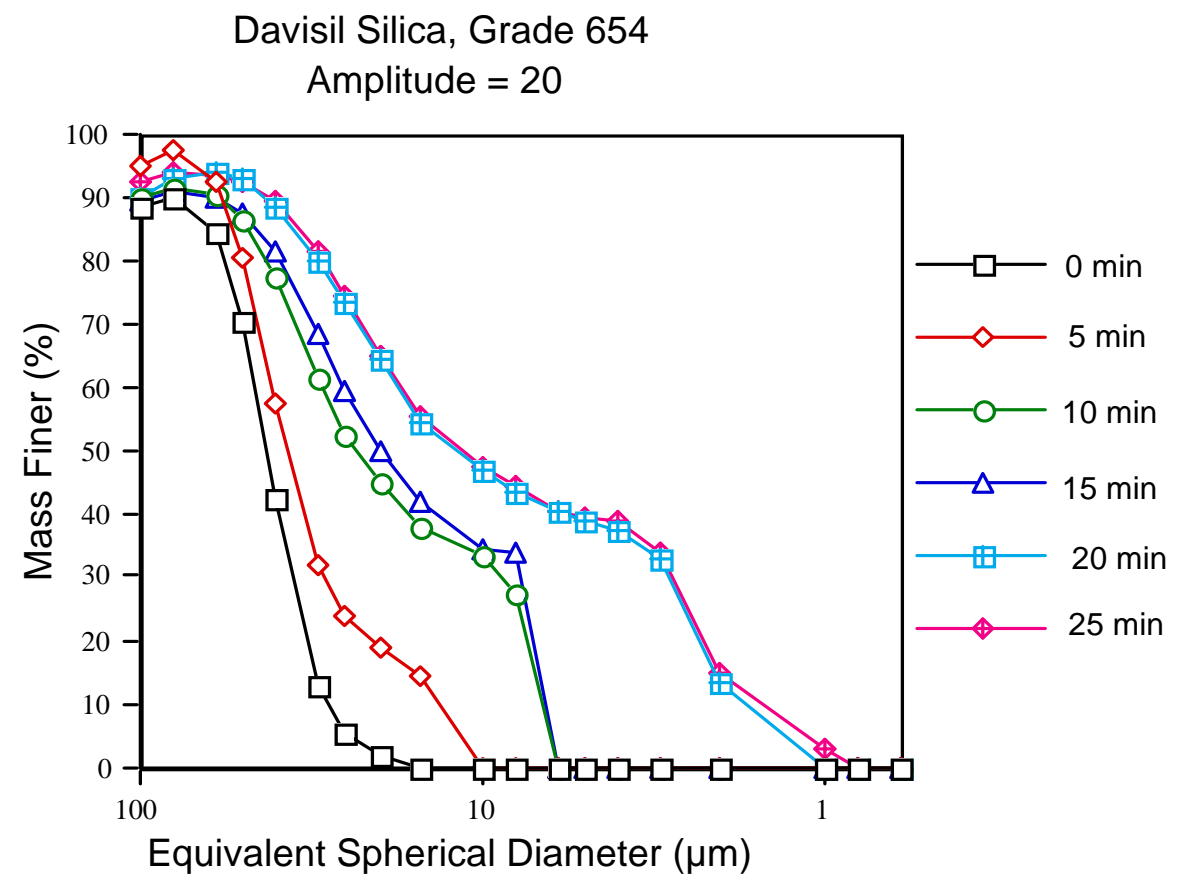

Fig. 5. Sedigraph particle size distributions of Davison 644 and 654 silica supports. Davison 644 appears to be more attrition resistant to fracture and erosion than Davison 654. 


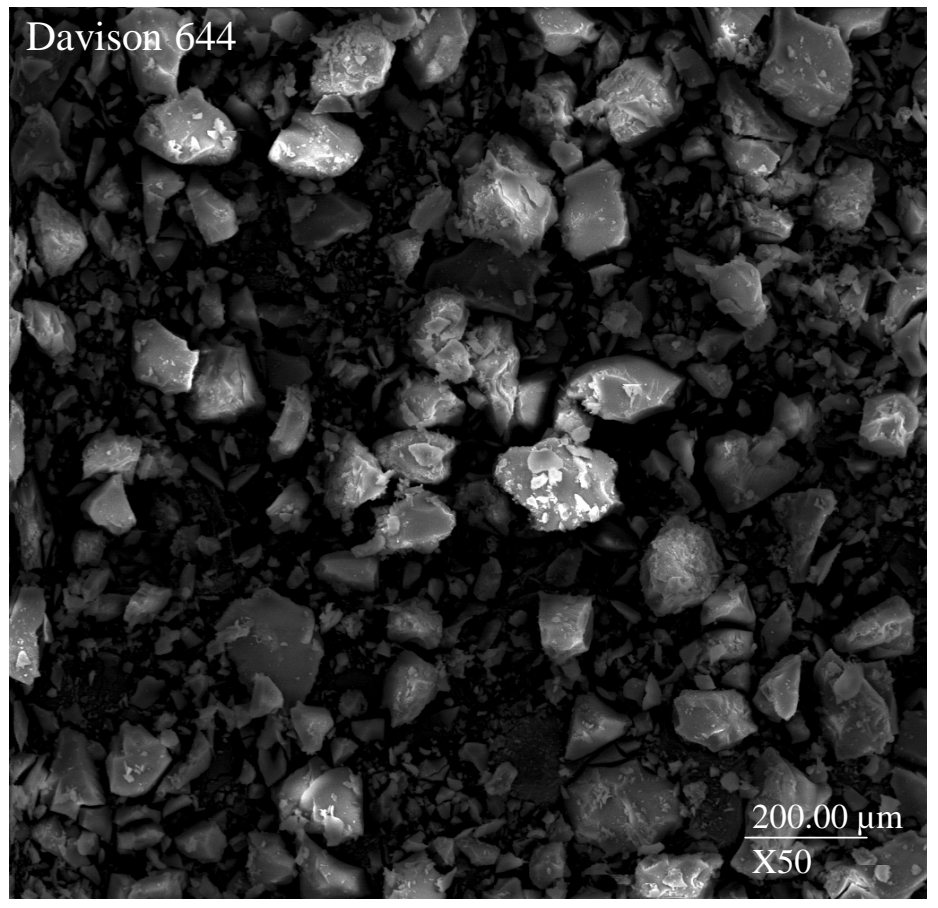

Fig. 6. SEM image of Davison 644. These particles are irregularly shaped, similar to those seen for Vista B alumina. 


\section{GRACE DAVISON 948}

(calcined)

(Amplitude=20)

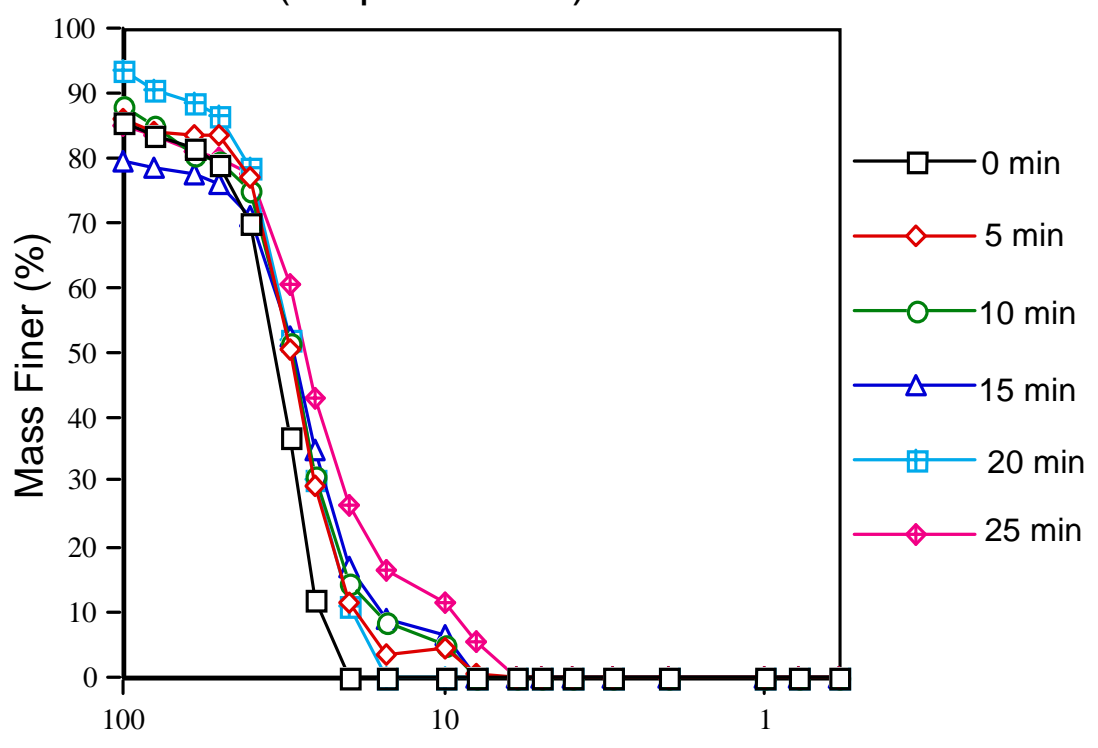

Equivalent Spherical Diameter $(\mu \mathrm{m})$

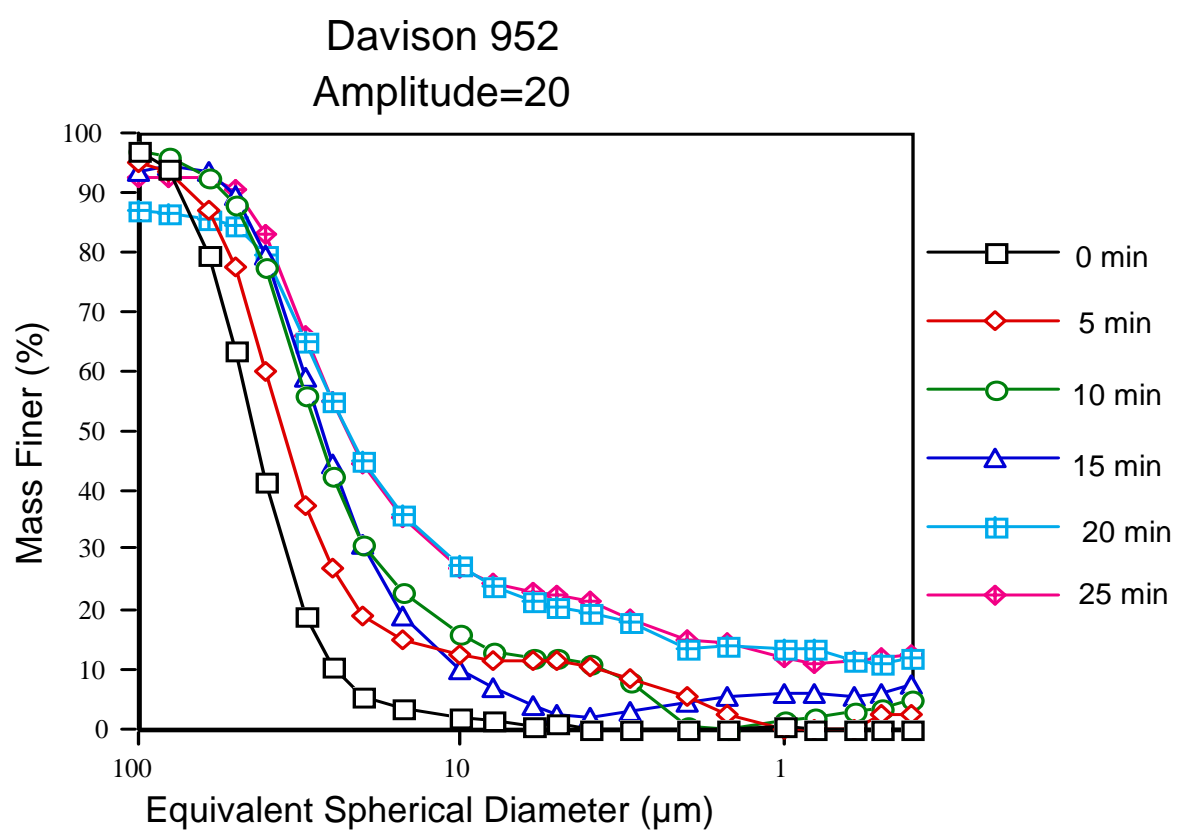

Fig. 7. Sedigraph particle size distributions of Davison 948 and 952 silica supports. Davison 948 appears to be more attrition resistant to fracture and erosion than Davison 952. 

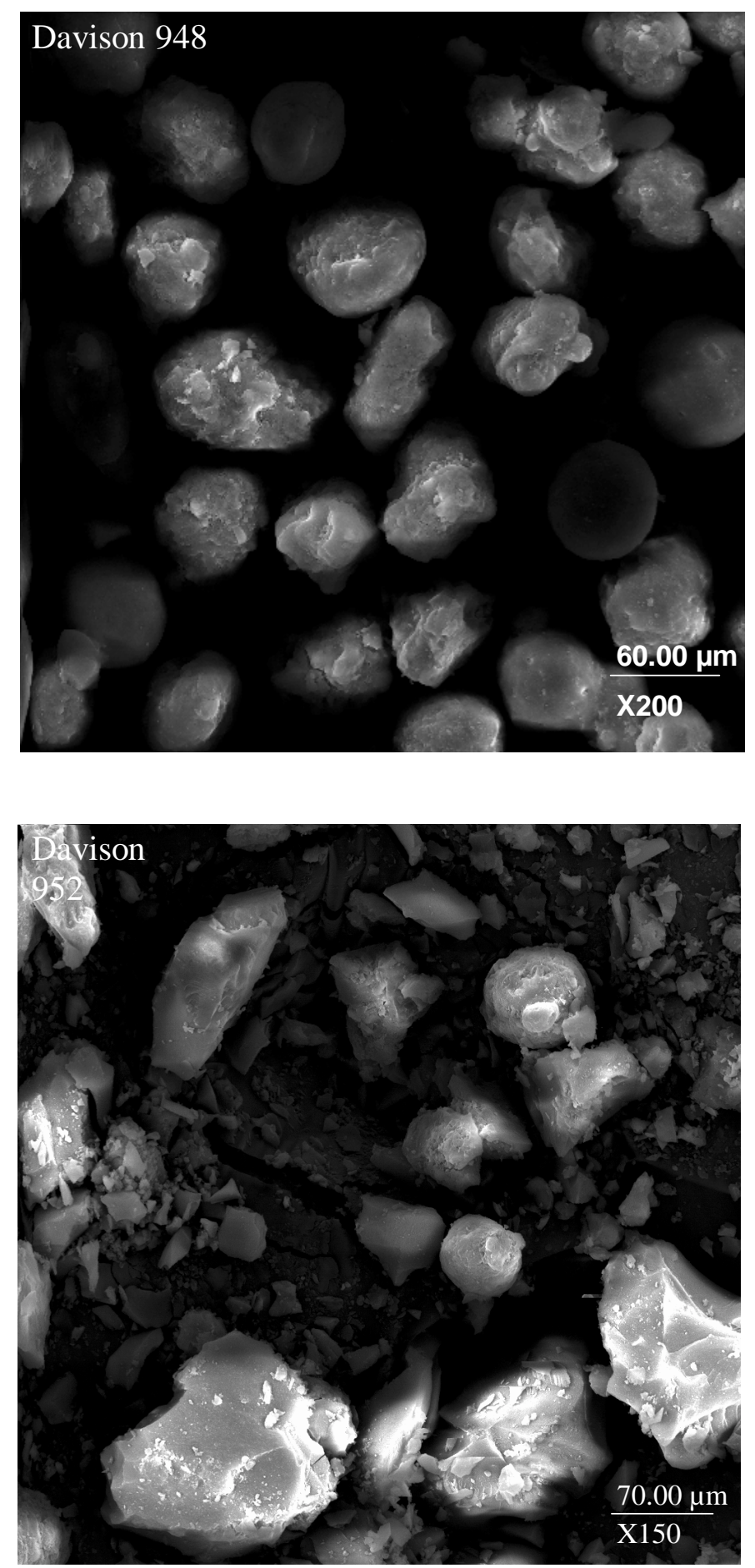

Fig. 8. SEM images of Davison 948 and Davison 952 silica supports. Davison 948 is roughly spherical in shape, while Davison 952 is irregularly shaped. 


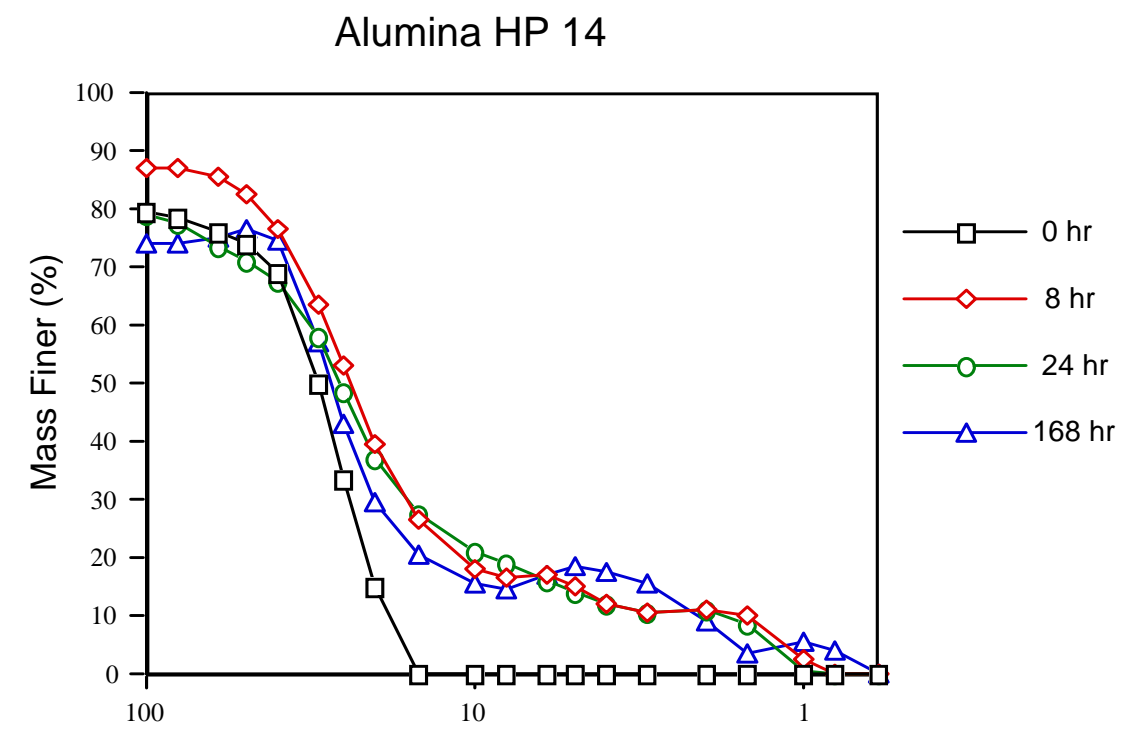

Equivalent Spherical Diameter $(\mu \mathrm{m})$

Davison 948

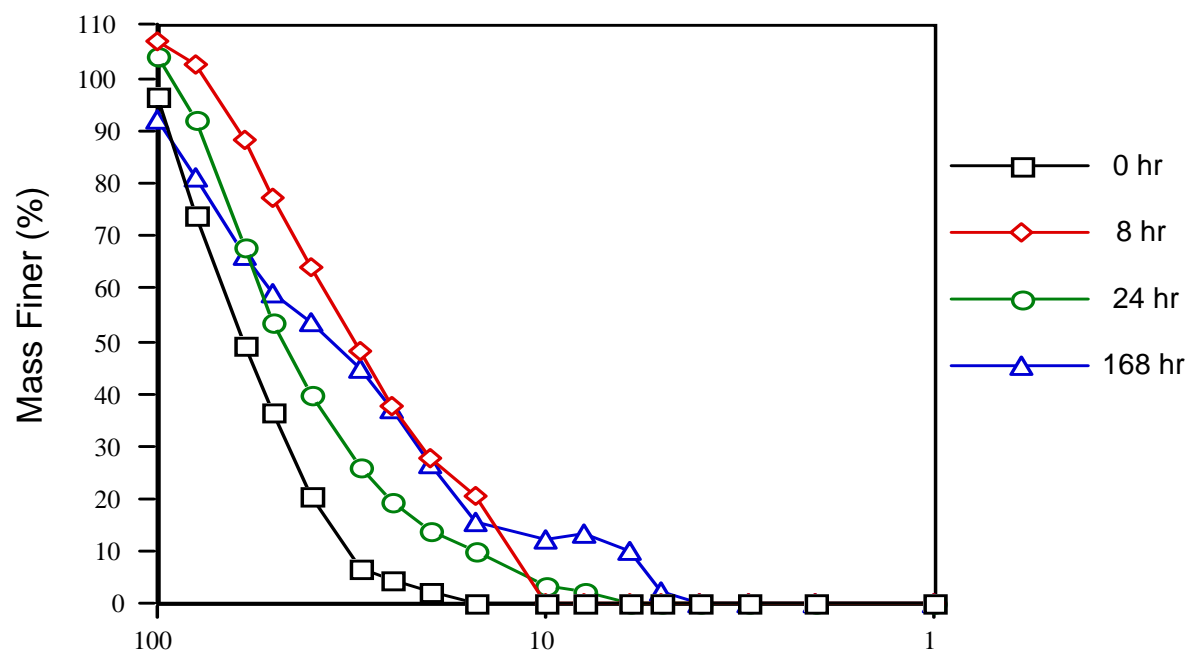

Equivalent Spherical Diameter $(\mu \mathrm{m})$

Fig. 9. Sedigraph particle size distributions of Vista HP 14 and Davison 948, performed in a STSR under non-reactive F-T conditions. The production of fines is not as pronounced in the silica support. In both cases, this seems to be a result of erosion of these particles as they are subjected to agitation in the STSR. 

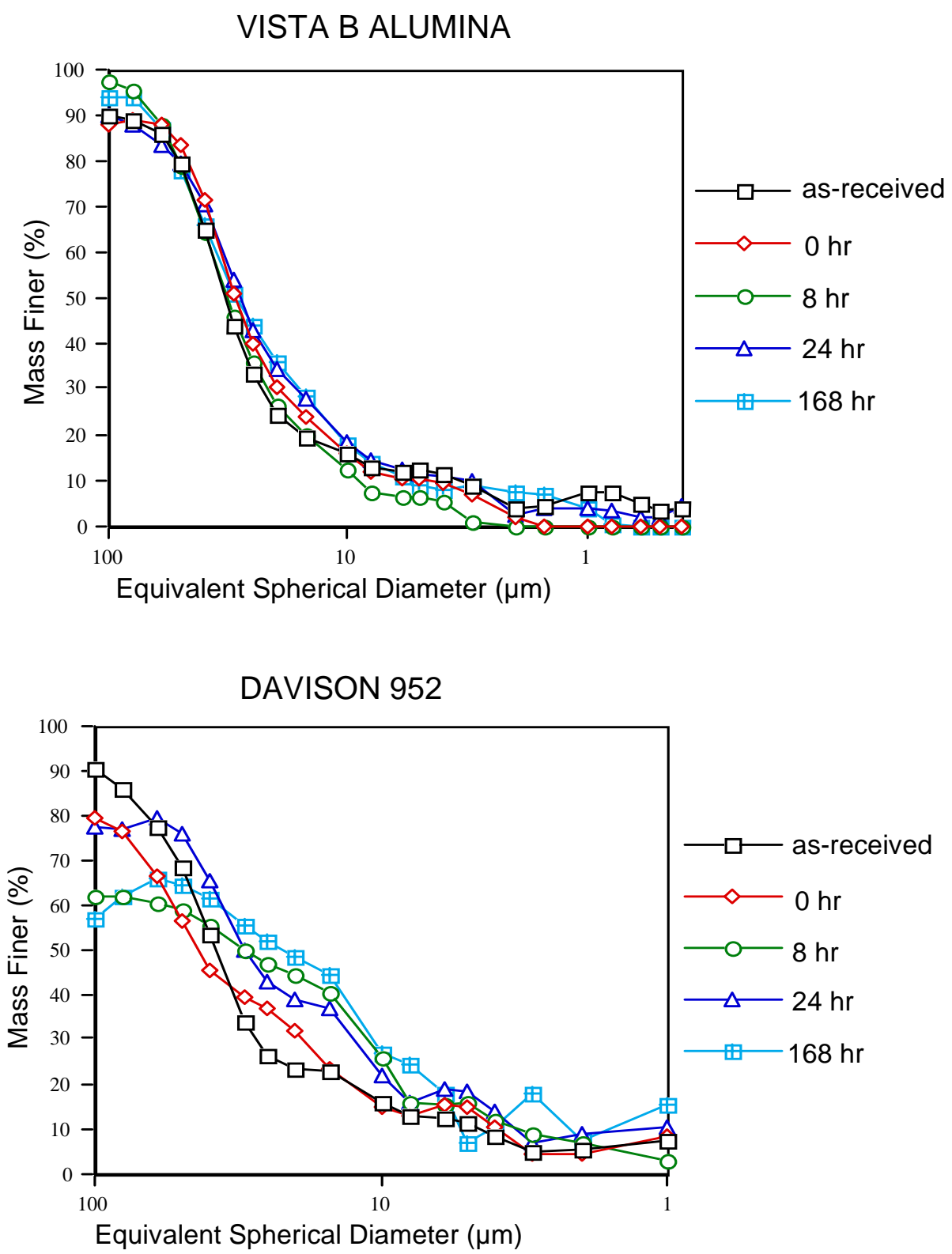

Fig. 10. Sedigraph particle size distributions of Vista B alumina and Davison 952 silica, performed in a STSR under non-reacting conditions. These supports appear to be more attrition resistant after the STSR runs than after the ultrasonic fragmentation runs. 


\title{
Synthesis of Attrition Resistant Fe Catalysts Using Templated Mesoporous Silica
}

\author{
Hien N. Pham, Magnus Bergroth and Abhaya K. Datye
}

Center for Microengineered Materials and Department of Chemical \& Nuclear Engineering, University of New Mexico, Albuquerque, NM 87131

\begin{abstract}
A novel approach has been developed to synthesize attrition resistant heterogeneous catalysts using templated mesoporous silica. This technique makes use of a liquid-crystal template mechanism to create a silica structure where high loadings of iron oxide nanoparticles are trapped inside. The structure provides controlled porosity for transport of reactants and products to the catalytically active phase. By encapsulating the catalytically active phase, we prevent attrition of the catalyst particles as iron oxide undergoes phase changes in a reactor. Spray pyrolysis provides a rapid, inexpensive process for the synthesis of encapsulated catalysts ranging from sub-micron to tens of micron in diameter. These catalysts are suited to the Fischer-Tropsch (F-T) synthesis where the attrition of the catalytically active phase hinders performance. This method may be applicable to other mesoporous materials and active phase combinations.
\end{abstract}

\section{Introduction}

This work is directed towards developing a novel approach to the synthesis of heterogeneous catalyst particles encapsulated in a templated mesoporous silica. We make use of a liquid-crystal template mechanism to create a silica shell whereby nanosized particles are trapped inside the shell. The silica shell acts as a filter to allow 
gas to diffuse inside the shell for reaction to proceed, while keeping the catalyst nanoparticles inside the shell.

Our proposed technique of catalyst synthesis is novel in that it makes use of liquid-crystal templates to produce controlled porosity. The porous matrix is synthesized using silica, but the approach can be extended to other catalytic supports such as titania, zirconia or alumina. The proposed catalyst synthesis may be particularly attractive for FT synthesis, a process used to convert energy reserves of coal and natural gas into liquid transportation fuels, using a slurry phase bubble column reactor (SBCR). The SBCR involves the suspension of the catalyst particles in a hydrocarbon oil slurry, while the gas phase reactants are bubbled through the slurry. If the catalyst undergoes attrition and generates fine particles, separation of the hydrocarbon wax products becomes difficult, particularly when nanosized particles are formed from the catalyst. The filter system can become plugged by the submicron and smaller sized particles. In the proposed technique, attrition is minimized by keeping the catalyst particles inside an attrition resistant shell.

In a previous study [1], we have explored the role of binder morphologies to provide improved attrition resistance for $\mathrm{Fe}$ F-T catalysts. Using the ultrasonic fragmentation approach $[2,3]$, we found that a precipitated $\mathrm{Fe}-\mathrm{Cu}$ catalyst, as-prepared, was weak compared to the same catalyst, which was spray-dried. Spray-drying improved the attrition resistance of the catalyst. The role of silica binder addition and calcination was then explored to increase the attrition resistance, and the synthesized catalysts were compared to a VISTA alumina. Results showed that the spray-dried catalyst containing silica was the best amongst the synthesized Fe F-T catalysts. Also, we investigated factors that determined the strength of our catalysts. We concluded that particle 
morphology was an important parameter dependent on strength. The precipitated silica was found to provide a morphology that was suitable for holding together the primary catalyst particles.

Even though the spray-dried catalyst containing precipitated silica is attrition resistant, the pores are randomly distributed. With our novel approach, we can obtain a more narrow distribution of pore size and control the porosity of silica. Obtaining a narrow distribution of pore size may be beneficial to certain catalytic applications where the size may limit the range of products that can be formed due to diffusion limitations.

The synthesis of mesoporous materials has attracted great interest in the field of catalysis, biomaterials, membrane and separation technology, and molecular engineering. However, some mesoporous materials, such as silica, are invariably amorphous, with pores that are irregularly spaced and broadly distributed in size [4,5]. Recently, mesoporous silica has been synthesized by means of a liquid-crystal template mechanism, in which the silicate material forms inorganic walls between ordered surfactant micelles. Kresge et al. [6] first described the synthesis of mesoporous silica by means of a liquidcrystal template mechanism, in which the silicate material forms inorganic walls between ordered surfactant micelles. Ordered arrays of cylindrical micelles are formed, with the silicate species occupying the space between the micelles. Once an ordered array of uniform channels is established, the original organic material can be burnt off to produce a stable mesoporous molecular sieve.

Göltner et al. [7] used the liquid crystal phase to form ordered mesoporous silica, where the sol-gel synthesis of the inorganic nanostructure took place in the ordered environment of a bulk surfactant mesophase. Beck et al. [8] described a new family of 
mesoporous molecular sieves prepared with liquid crystal templates. One member of this family, MCM-41, was characterized as hexagonal, with uniform and controllable pore size from $\sim 15 \AA$ to $>100 \AA$, high surface area, and high hydrocarbon sorption capacity. Other members, such as those exhibiting cubic symmetry, have been synthesized. Schulz-Ekloff et al. [9] developed a new procedure based on the precipitation of MCM41 particles due to a gradual decrease in $\mathrm{pH}$, enabling control of the morphology of mesoporous molecular sieves. Both ordering and worm-like morphologies of the mesoporous silica were formed. The consistency of the structure parameters determined by physically differing methods was checked using a geometrical model of the honeycomb structure.

Behrens et al. [10] and Monnier et al. [11] reported that mixtures of CTAB/silica precursor/water at low $\mathrm{pH}$ and low surfactant concentration $(\sim 1$ wt. $\%)$ produced mesoporous solid precipitates. Attard et al. [12] showed that hexagonal mesophases were obtained at higher $\mathrm{CTAB} /$ water ratios $(\sim 50 \mathrm{wt} . \%)$. Also, in the case of low $\mathrm{pH}$ and low surfactant concentration, three factors were proposed for successful templating: multidentate binding of positively charged silicate oligomers to surfactant molecules via an anion, polymerization of inorganic species at the interface, and charge-density matching at the interface [11]. However, these factors were independent in the formation of mesostructures at high surfactant concentrations. Instead of using a cationic surfactant such as CTAB, Bagshaw et al. [13] used a nonionic polyethylene oxide surfactant as a template to form mesoporous molecular sieves. Disordered channel structures were obtained by varying the size and structure of the surfactant molecules. 
Bergna [14] showed that attrition resistance could be conferred to catalyst particles if they were embedded in a continuous framework or skeleton of a hard and relatively inert material. This approach required the fraction of the hard phase volume to be nearly $50 \%$ to form an attrition resistant continuous framework within the grain pores. By using sub-colloidal or very small colloidal particles capable of coalescing or sintering to form a hard egg-shell, attrition resistance could also be conferred with smaller amounts (10\%) of the hard phase (silica). In this case, the silica needed to be distributed on the periphery of the particles, which could be achieved by ensuring that the silica was not agglomerated during spray-drying, and that the silica particles migrated easily to the surface.

The synthesis proposed by Kresge et al. [6] involved placing a mixture of reagents in an autoclave for 48 hours. From an application standpoint, the synthesis approach would not be suitable for large-scale production. An alternative approach was described by $\mathrm{Lu}$ et al. [15] where they used an aerosol process for the synthesis of mesostructured spherical nanoparticles. Their methodology involves evaporation-induced surfactant selfassembly to synthesize silica thin films, membranes, particles, and nano-composite materials with highly ordered mesophase structures via dip coating or aerosol processes. A similar evaporation approach was also reported by Bruinsma et al. [16] to yield mesoporous silica. In this latter work, the authors spray-dried powders, using a precursor solution comprised of cetyltrimethylammonium chloride, hydrochloric acid, tetraethoxysilane, and water. These spray-dried mesoporous powders had structures ranging from hollow spheres to collapsed particles. Particle morphology was dependent on the precursor solution composition and drying conditions. 
In this study, we examine the attrition resistance, morphology and extent of reducibility of the product material. Techniques such as ultrasonic fragmentation, pore size distribution, X-ray diffraction (XRD), transmission electron microscopy (TEM), and scanning electron microscopy (SEM) were used for the analysis. Some of the catalyst samples were studied using cross-section TEM, which was recently applied to the study of Fe F-T catalysts [17].

\section{Experimental}

A precipitated $\mathrm{Fe}-\mathrm{Cu}$ catalyst $(64.80 \% \mathrm{Fe}, 6.24 \% \mathrm{Cu}$ by ICP based on dried weight) in its wet form (labeled PRFECU-ED20-124) was used for the experiments. The starting materials were the nitrates of $\mathrm{Fe}$ and $\mathrm{Cu}$, and $\mathrm{NH}_{4} \mathrm{OH}$. Solutions of $\mathrm{Fe}-\mathrm{Cu}$ nitrate and $\mathrm{NH}_{4} \mathrm{OH}$ were mixed at $80^{\circ} \mathrm{C}$ in a continuous flow through mixer, causing the iron oxide to precipitate out. The product catalyst was discarded until the $\mathrm{pH}$ was between 6.8 and 7.2. The catalyst was then collected in a filter funnel, and the filter cake was pumped down to being wet but not cracked. Samples of the filtrate were obtained; a $\mathrm{pH}$ and brown ring test were performed for each sample to ensure that the $\mathrm{pH}$ remained near 7.0 and that traces of nitrate ions were removed from the catalyst, respectively. The cake was removed and then re-suspended in hot water. After filtering the slurry, samples of the filtrate were obtained for $\mathrm{pH}$ and brown ring testings. After the brown ring test was negative, the filter cake was pumped moist. Finally, once the precipitated $\mathrm{Fe}-\mathrm{Cu}$ catalyst was dry enough to remove it off the filter, the catalyst was suspended in deionized water.

In a typical run, $100 \mathrm{ml}$ of the precipitated $\mathrm{Fe}-\mathrm{Cu}$ catalyst was ultrasonicated at an amplitude of 20 for 2 min to break up any loose agglomerates. The sample was then 
mixed with a templated silica precursor consisting of $5 \mathrm{~g}$ cetyltrimethylammonium bromide (CTAB; Aldrich), $2 \mathrm{ml} \mathrm{HCl}$ (1N; J.T. Baker), $20 \mathrm{ml}$ tetraethyl orthosilicate (TEOS; Aldrich), and $100 \mathrm{ml}$ deionized water. More deionized water was added to prepare $250 \mathrm{ml}$ of slurry, and the mixture was spray-dried using a Buchi 190 Mini Spray Dryer. The inlet temperature of the spray dryer was over $200^{\circ} \mathrm{C}$ with the outlet being maintained over $100^{\circ} \mathrm{C}$. The product was calcined in air at $400^{\circ} \mathrm{C}$ for $4 \mathrm{hr}$ to remove the CTAB template, thereby creating a porous structure. The catalyst was then subjected to ultrasonic energy at an amplitude setting of $20(100 \mathrm{~W})$ at 5 min intervals using a Tekmar 501 ultrasonic disrupter $(20 \mathrm{kHz} \pm 50 \mathrm{~Hz})$ equipped with a V1A horn and a $1 / 2$ ” probe tip. After different extents of ultrasonic irradiation, the particle size distribution was analyzed to detect the mode of particle fragmentation.

\section{Physisorption Method}

A Micromeritics ASAP 2010 unit was used to analyze the pore size distribution of the encapsulated material. In a typical run, $0.1 \mathrm{~g}$ of the catalyst sample was degassed in $\mathrm{N}_{2}$ at $120^{\circ} \mathrm{C}$ for $18 \mathrm{hr}$ to remove any contaminants and moisture which may have adsorbed onto the surface of the sample. The sample was re-weighed to determine the weight loss after degassing. Nitrogen adsorption/desorption isotherm analysis was then performed at $77 \mathrm{~K}$ for several hours.

\section{Reduction Studies}

For reduction studies, $\mathrm{H}_{2}$ was obtained from Trigas, and $\mathrm{O}_{2}$ and $\mathrm{He}$ were obtained from Argyle. The $\mathrm{H}_{2}$ and $\mathrm{He}$ gases were further purified by passing it through an 
AllTech Oxy-Trap. The reactor was a differential fixed bed reactor consisting of a stainless steel U-tube in which a known weight of catalyst was placed over a quartz wool plug. The reactor was enclosed by an electrically heated Glass-Col heating mantle, and the catalyst temperature was monitored and controlled by a thermocouple connected to an Omega PID controller. The gas flow rates were set and controlled by Tylan FC-260 mass flow controllers.

In a typical reaction run, approximately $50 \mathrm{mg}$ of the sample was loaded into the reactor. The sample was initially degassed in $\mathrm{He}$ at $200^{\circ} \mathrm{C}$ for $1 \mathrm{hr}$ to remove moisture or contaminants adsorbed on the surface of the sample, and then cooled back to room temperature. The sample was heated in $\mathrm{H}_{2}$ from $25^{\circ} \mathrm{C}$ to $300^{\circ} \mathrm{C}$ at a rate of $10^{\circ} \mathrm{C} / \mathrm{min}$, and was reduced at $300^{\circ} \mathrm{C}$ overnight.

In order to passivate the sample, it was initially purged in $\mathrm{He}$ at $300^{\circ} \mathrm{C}$ for $30 \mathrm{~min}$ and cooled to room temperature. A very small amount of $\mathrm{O}_{2}$ was introduced in the flowing $\mathrm{He}\left(<1 \% \mathrm{O}_{2}\right.$ in $\left.\mathrm{He}\right)$. The oxygen was then gradually increased to a final concentration of $20 \% \mathrm{O}_{2}$ in $\mathrm{He}$ in order to simulate atmospheric conditions. Passivation was achieved when there was no further rise in temperature with an increase in $\mathrm{O}_{2}$ intake. The sample was then removed for further characterization tests.

\section{Results}

Fig. 1 shows a cumulative mass distribution plot for a precipitated $\mathrm{Fe}-\mathrm{Cu}$ catalyst encapsulated in a spray-dried silica. There is attrition of particles after 5 min of ultrasonic irradiation due to fracture, as indicated by the shift in curves to the right, i.e., towards smaller size particles. However, little fracture occurs thereafter. Furthermore, 
very little generation of fine particles below $6 \mathrm{~mm}$ occurs after $25 \mathrm{~min}$ of ultrasonic irradiation due to erosion, as indicated by an increase in the percentage of fines for a particular particle size. SEM image (Fig. 2) shows that some of the particles are spherical, while others contain several dimples on their surfaces due to rupturing of the particles during the spray-drying process. A few of the particles are hollow and broken as seen in the SEM image. This is due to the formation of a rigid crust by premature solidification of silica. Furthermore, because the wall of the crust is thin, the particles break down easily due to particle-particle collision, particle-wall collision or handling of the dry powder. The majority of the particles are dense, as seen in the TEM images below.

TEM image (Fig. 3) shows the precipitated $\mathrm{Fe}-\mathrm{Cu}$ catalyst particles, with an average size of $80 \mathrm{~nm}$, are uniformly distributed within the silica. Furthermore, the nanoparticles appear to be almost completely encapsulated inside the spray-dried mesoporous silica. This is clarified by X-ray Photoelectron Spectroscopy, where the surface compositions of the $\mathrm{Fe}$ and $\mathrm{Si}$ elements are 3.45 wt.\% and 55.25 wt.\%, respectively. The surface composition is much less than the bulk composition, indicating that the iron phase is distributed preferentially in the interior of the particles. Fig. 4 shows a higher magnification view. From this image, it is difficult to interpret the actual internal microstructure of the encapsulated material. Hence, cross-sectioning was performed to investigate the internal microstructure.

Fig. 5 shows a XTEM image of an encapsulated particle. The image shows that we can disperse a high loading of precipitated $\mathrm{Fe}-\mathrm{Cu}$ catalyst, within the mesoporous silica. Fig. 6 shows a XTEM image of this particle at a higher magnification. In this 
image, the ordered pore structure in the silica phase can be clearly seen to be preserved all around the iron nanoparticles. Fig. 7 shows another XTEM image where the crystalline particles are surrounded by mesoporous silica. The internal microstructure does not involve a silica shell that encapsulates the catalyst particles. Rather, the iron particles seem to be uniformly distributed throughout the spray-dried particle. Fig. 8 shows a XTEM image of a larger particle. The area near the surface of the encapsulated particle is similar to a spray-dried silica shell (not shown), whereby there are ordered pore structures. Internally, there appears to be a mixture of both ordered and less ordered silica structures, yet does not involve the silica shell, as seen by the image in Fig. 7.

Fig. 9 is a $\mathrm{N}_{2}$ adsorption/desorption isotherm curves for the encapsulated material. The curves show hysteresis, indicating that a multi-dispersed phase is present. BJH pore size distribution plot (Fig. 10) shows three peaks. The peak at $\sim 23 \AA$ corresponds to the ordered mesoporous silica shell. The other two peaks at $\sim 50 \AA$ and $\sim 150 \AA$ correspond to the less ordered structures inside the silica shell.

Fig. 11 shows XRD plots for the encapsulated material, before and after reduction. Before reduction, the precipitated $\mathrm{Fe}-\mathrm{Cu}$ catalyst is determined to be hematite $\left(\alpha-\mathrm{Fe}_{2} \mathrm{O}_{3}\right)$ with copper as a promoter. After reduction, there are no peaks corresponding to hematite. Instead, hematite has been reduced to $\alpha$-Fe. Silica does not appear to affect the reducibility of the catalyst. The pores of the silica are large enough to allow catalyst accessibility to the gas phase, while the nanoparticles are maintained inside the silica structure. This experiment shows that the iron phase is completely reducible in $\mathrm{H}_{2}$, as determined by XRD. Reduction of the iron oxide is a necessary step in making it active as a F-T catalyst. 


\section{Discussion}

In a previous study [1], we have shown that a precipitated silica improved the attrition resistance of Fe F-T catalysts. Further analyses of pore size distribution-not shown in our previous paper-showed that the catalysts containing precipitated silica has a broad distribution of pore sizes. This type of pore size distribution may limit the selectivity of hydrocarbon products due to diffusion limitations. By obtaining a much narrower pore size distribution, the encapsulated material allows for far greater selectivity of hydrocarbon products, which results in a more tightly controlled reaction with fewer by products. The ordered pore structure also allows facile transport of reactants and products to the catalytically active sites.

Bergna' s method for preparing attrition resistant catalysts [13] may not be entirely suitable for catalysts which undergo phase transformations during their use. For example, as shown by Shroff et al. [18], iron catalysts start out in the form of an oxide and get converted to an iron carbide after activation in a F-T reaction environment. The changes in density between the oxide and carbide phase leads to a break-up of the iron oxide to form nanoparticles of iron carbide. Hence, even if the catalyst could be prepared in attrition resistant form, the phase changes may tend to weaken the catalyst during use. In our method, the iron particles could be retained from this phase transformation within the silica structure.

The method by Bruinsma et al. [15] yielded hollow silica shells when liquid droplets were spray-dried. The hollow shells could be easily crushed and would not provide any attrition resistance, especially if the shell wall was too thin to maintain its 
strength. We have shown that the encapsulated material consisted of a silica shell filled iron nanoparticles. By producing a more solid structure, this material possesses the desired attrition resistance properties, as shown by the cumulative mass distribution plot in Fig. 1. Attrition of the catalyst particles is minimized since the active phase crystallites are encapsulated inside an attrition resistant mesoporous silica shell.

In many applications where high loadings of the dispersed phase are required, impregnating a mesoporous support with a catalytically active metal will result in nonspherical particles. With our method, we can produce more spherically shaped particles with high loadings of the dispersed phase. The spherical shape of the particles may be important for proper slurry hydrodynamics, such as in a bubble column reactor. For example, during operation of stirred tank reactor, more attrition would be expected with non-spherical particles than with smooth spherical particles.

In addition to attrition testing and characterization, we have shown that by reducing in hydrogen at $300^{\circ} \mathrm{C}$, the iron oxide, hematite, could be completely reduced to metallic iron. Usually, silica tends to decrease the catalytic activity of Fe F-T catalysts. In this case, silica does not affect reducibility of the catalyst. The supporting structure of the encapsulated material appears to retain the nanoparticles, yet at the same time it provides access to the catalytic sites to the reactants and easy egress of the products of reaction. In future work, we plan to study the reduction of the encapsulated material in syngas $\left(\mathrm{H}_{2} / \mathrm{CO}=0.7\right)$ and to determine the reactivity under F-T synthesis conditions. 


\section{Summary}

We have developed a novel approach to the synthesis of attrition resistant heterogeneous catalysts using a templated mesoporous silica. This technique makes use of a liquid-crystal template mechanism to create a silica structure where nanoparticles are trapped inside. Ultrasonic fragmentation followed by particle size distribution measurements was used to characterize the strength of this material. It was found that there was attrition due to fracture (as the hollow shells break up) after 5 min of ultrasonic irradiation, but little fracture occurred thereafter. Also, very little generation of fine particles below $6 \mu \mathrm{m}$ occurred after 25 min of ultrasonic irradiation. A few of the particles were hollow due to premature solidification of silica and therefore broke up easily, but the majority of the particles were dense.

From TEM, the catalyst particles were uniformly distributed within the silica and were almost completely encapsulated inside the silica shell. Using cross-sectioning, we could confirm that a high loading of catalyst was present within the mesoporous silica structure. From pore size distribution, three peaks were present: one peak at a small pore size corresponded to the ordered mesoporous silica shell and the two peaks at higher pore sizes corresponded to the less ordered structures inside the shell.

Finally, XRD showed that the Fe catalyst, determined to be hematite, was reduced to metallic iron in hydrogen. Silica did not appear to affect the reducibility of the catalyst. Furthermore, the pores of the silica were large enough to allow catalyst accessibility to the gas phase. Reduction of the encapsulated material in syngas will be the subject of future work. 


\section{References}

[1] H.N. Pham, A. Viergutz, R.J. Gormley, A.K. Datye, "Measuring the Attrition Resistance of Slurry Phase Heterogeneous Catalysts", Powder Technology, in press.

[2] S.G. Thoma, M. Ciftcioglu, D.M. Smith, Powder Technol. 68 (1991) 53.

[3] S.G. Thoma, M. Ciftcioglu, D.M. Smith, Powder Technol. 68 (1991) 71.

[4] T.J. Pinnavaia, Science 220 (1983) 365.

[5] R.M. Tindwa, D.K. Ellis, G.Z. Peng, A. Clearfield, J. Chem. Soc. Faraday Trans 1. $81(1985) 545$.

[6] C.T. Kresge, M.E. Leonowicz, W.J. Roth, J.C. Vartuli, J.S. Beck, Nature 359 (1992) 710.

[7] C.G. Göltner, S. Henke, M.C. Weissenberger, M. Antonietti, Angew. Chem. Int. Ed. Engl. 37 (1998) 613.

[8] J.S. Beck, J.C. Vartuli, W.J. Roth, M.E. Leonowicz, C.T. Kresge, K.D. Schmitt, C. T-W Chu, D.H. Olson, E.W. Sheppard, S.B. McCullen, J.B. Higgins, J.L. Schlenker, J. Am. Chem. Soc. 114 (1992) 10834.

[9] G. Schulz-Ekloff, J. Rathouský, A. Zukal, Micr. Meso. Mater. 27 (1999) 273.

[10] P. Behrens, G.D. Stucky, Angew. Chem. Int. Ed. Engl. 32 (1993) 696.

[11] A. Monnier, F. Schüth, Q. Huo, D. Kumar, D. Margolese, R.S. Maxwell, G.D. Stucky, M. Krishnamurty, P. Petroff, A. Firouzi, M. Janicke, Science 261 (1993) 1299.

[12] G.S. Attard, J.C. Glyde, C.G. Göltner, Nature 378 (1995) 366.

[13] S.A. Bagshaw, E. Prouzet, T.J. Pinnavaia, Science 269 (1995) 1242. 
[14] H.E. Bergna, Characterization and Catalyst Development: An Interactive Approach, American Chemical Society, 1989, pp. 55-64.

[15] Y. Lu, H. Fan, A. Stump, T.L. Ward, T. Rieker, C.J. Brinker, Nature 398 (1999) 223.

[16] P.J. Bruinsma, A.Y. Kim, J. Liu, S. Baskaran, S., Chem. Mater. 9 (1997) 2507.

[17] Y. Jin, Phase Transformations of Iron-Based Catalysts for Fischer-Tropsch Synthesis, Dissertation, University of New Mexico, Spring, 1999.

[18] M.D. Shroff, D.S. Kalakkad, K.E. Coulter, S.D. Köhler, M.S. Harrington, N.B. Jackson, A.G. Sault, A.K. Datye, J. Catal. 156 (1995) 185. 


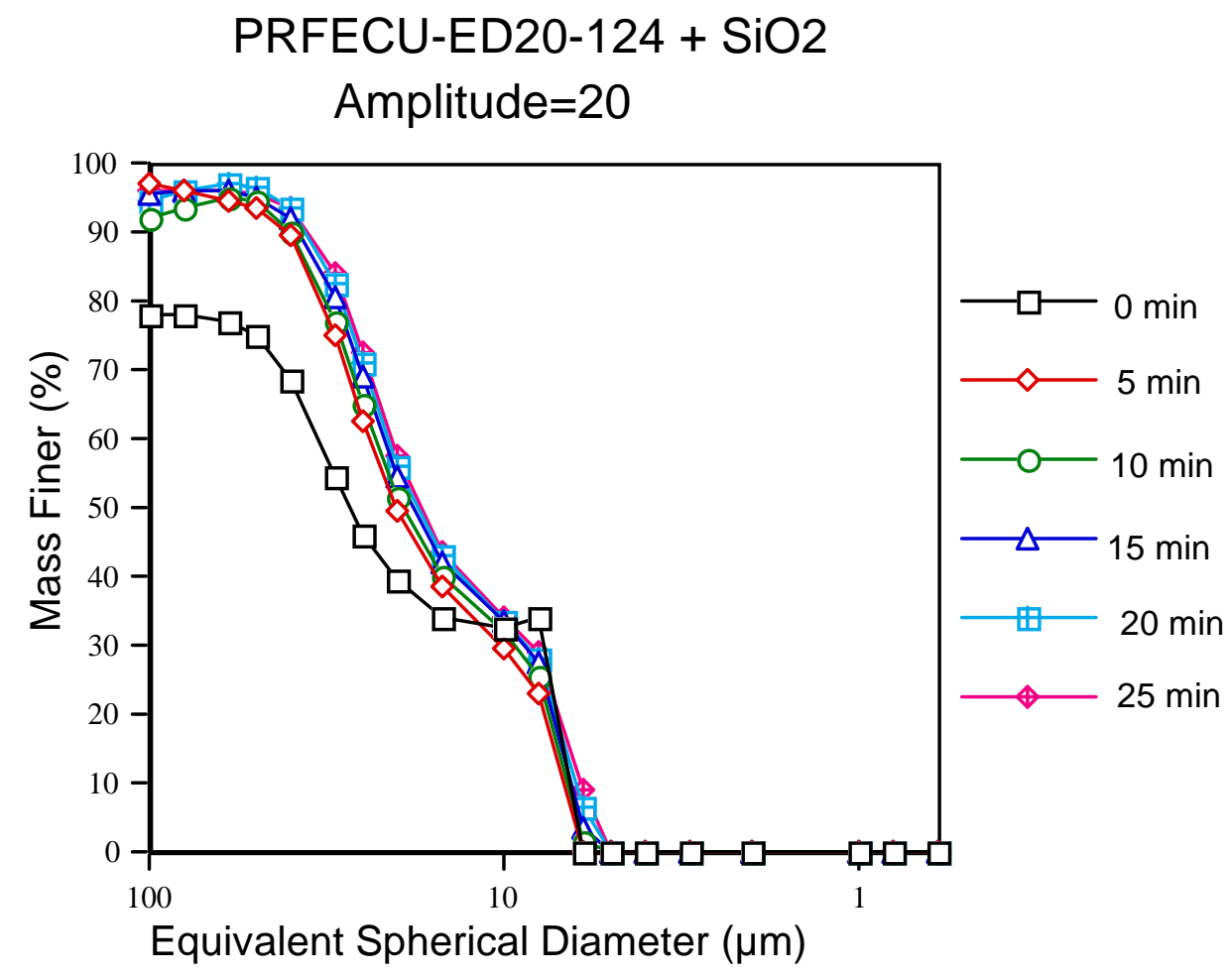

Fig. 1. Sedigraph particle size distribution of precipitated $\mathrm{Fe}-\mathrm{Cu}$ catalyst particles encapsulated in spray-dried silica as function of ultrasonic irradiation. The median size is $28 \mu \mathrm{m}$. The shift in the median size after 5 minutes is caused by the break up of hollow shells. No fracture or erosion is seen after this initial break up. 


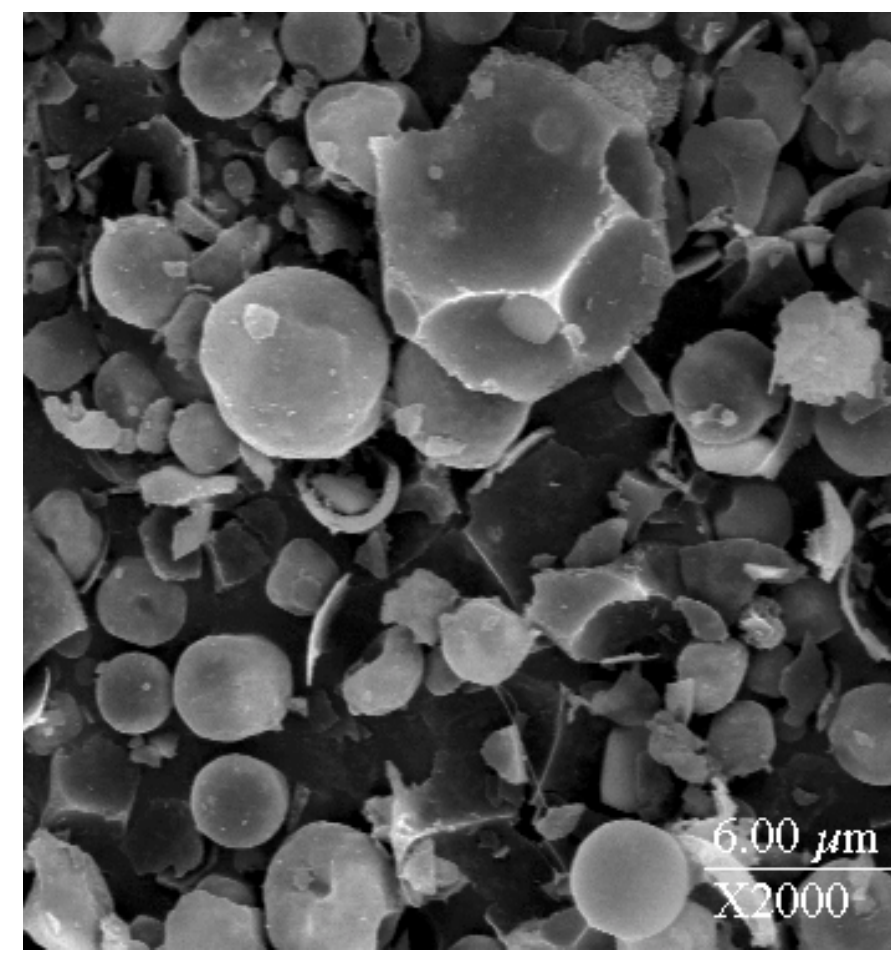

Fig. 2. SEM image of precipitated $\mathrm{Fe}-\mathrm{Cu}$ catalyst particles encapsulated in spray-dried silica. A few of the particles are hollow and broken, but the majority of the particles are dense. 


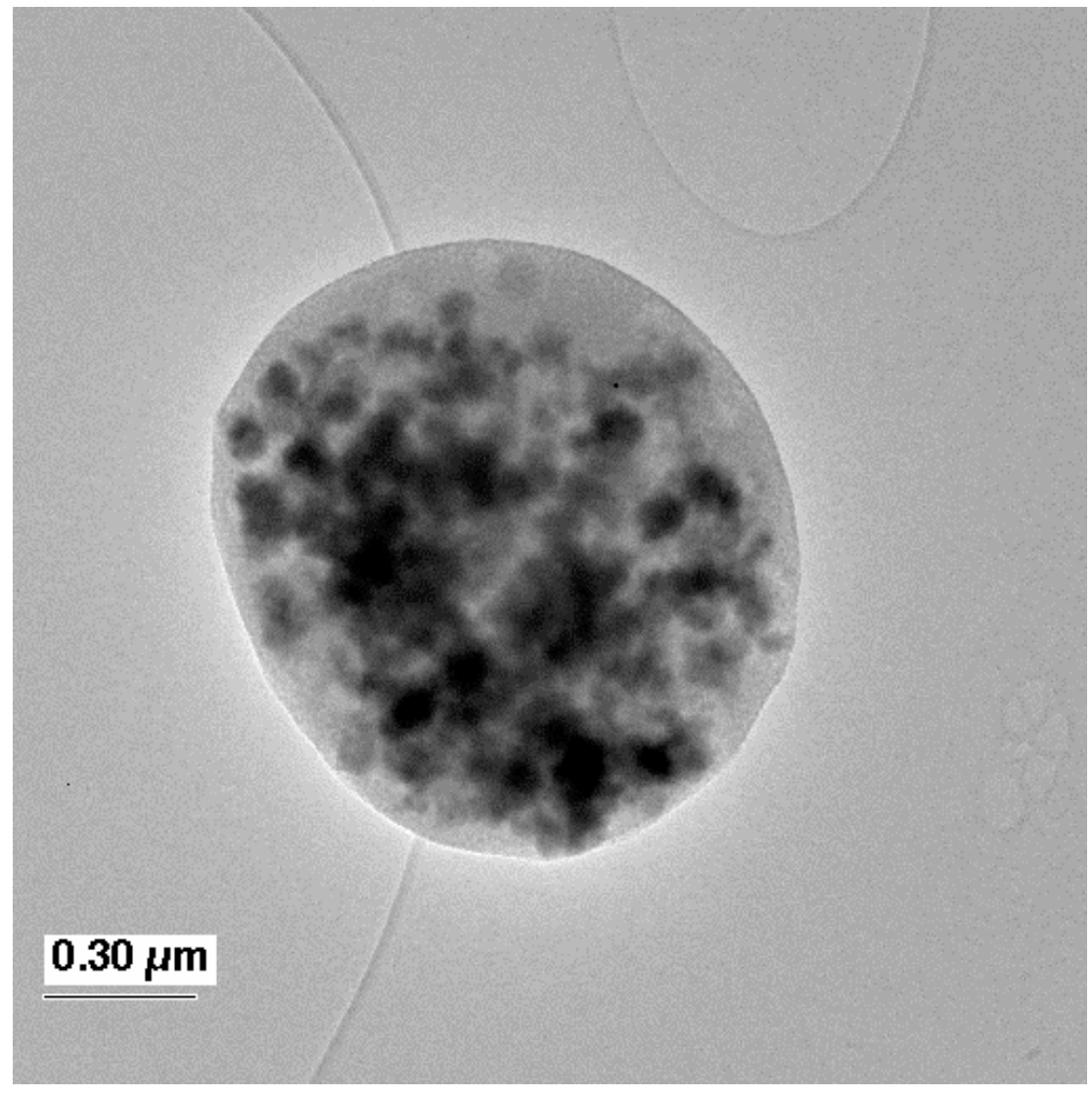

Fig. 3. TEM image of precipitated $\mathrm{Fe}-\mathrm{Cu}$ catalyst particles uniformly distributed within the silica. 


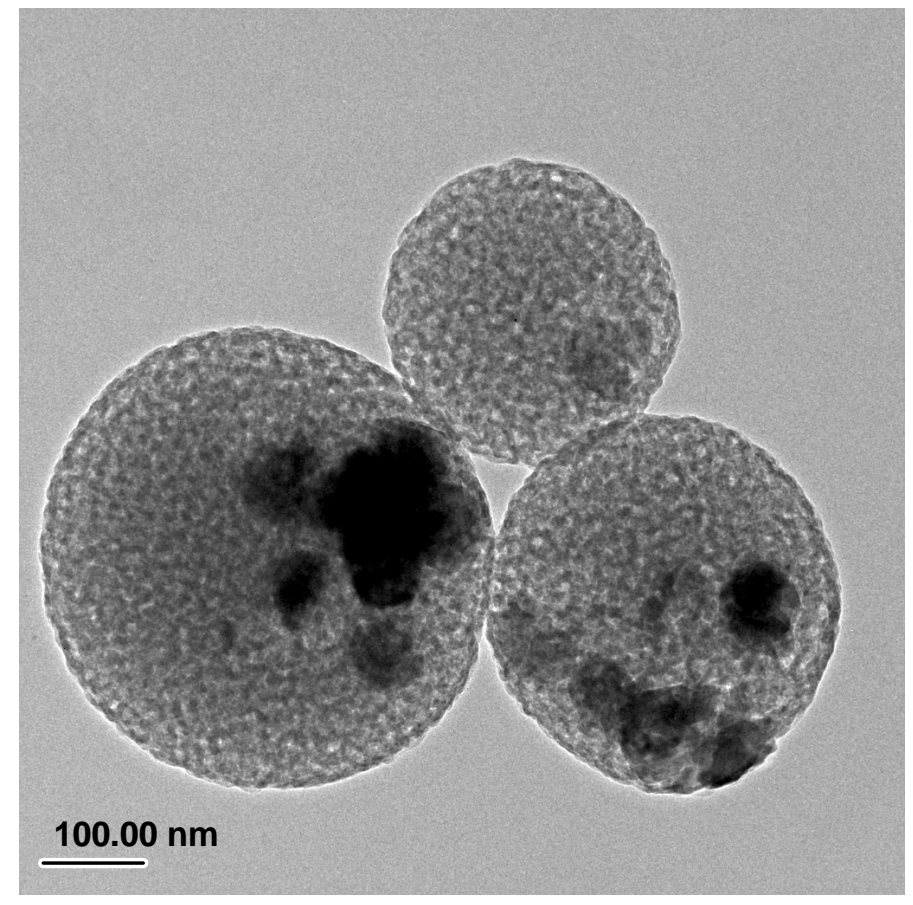

Fig. 4. Cross section TEM image of particles at a higher magnification view. 


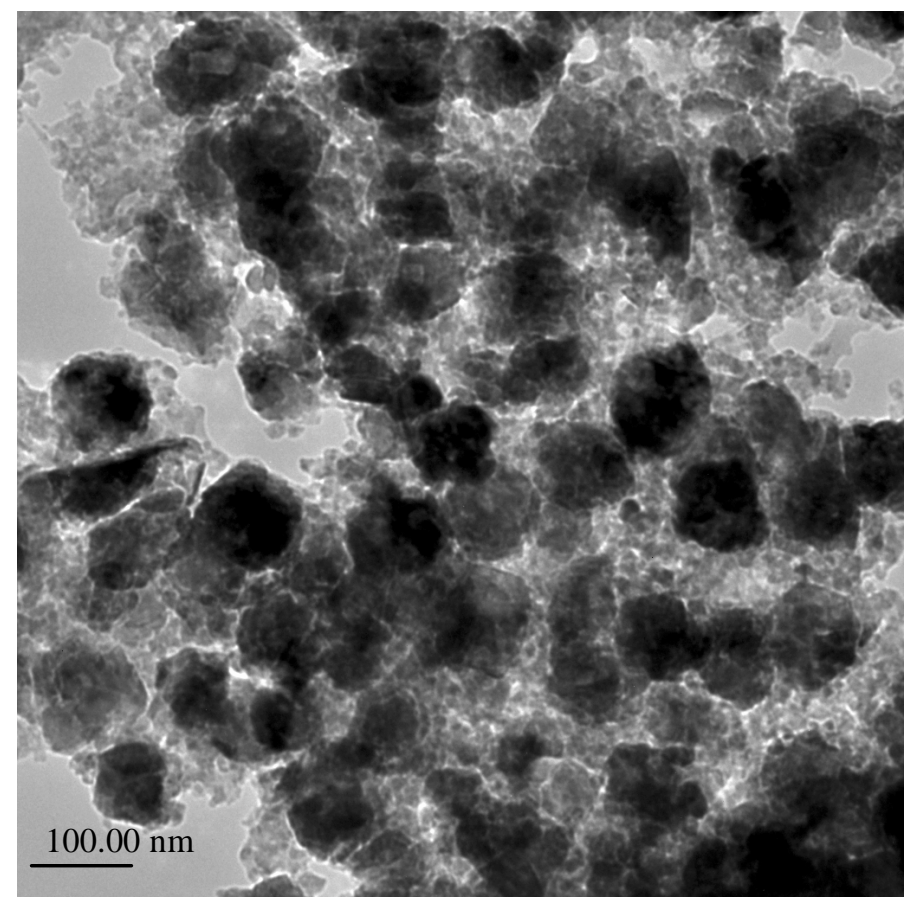

Fig. 5. Cross section TEM image shows a high loading of precipitated Fe$\mathrm{Cu}$ catalyst particles dispersed within the mesoporous silica. 


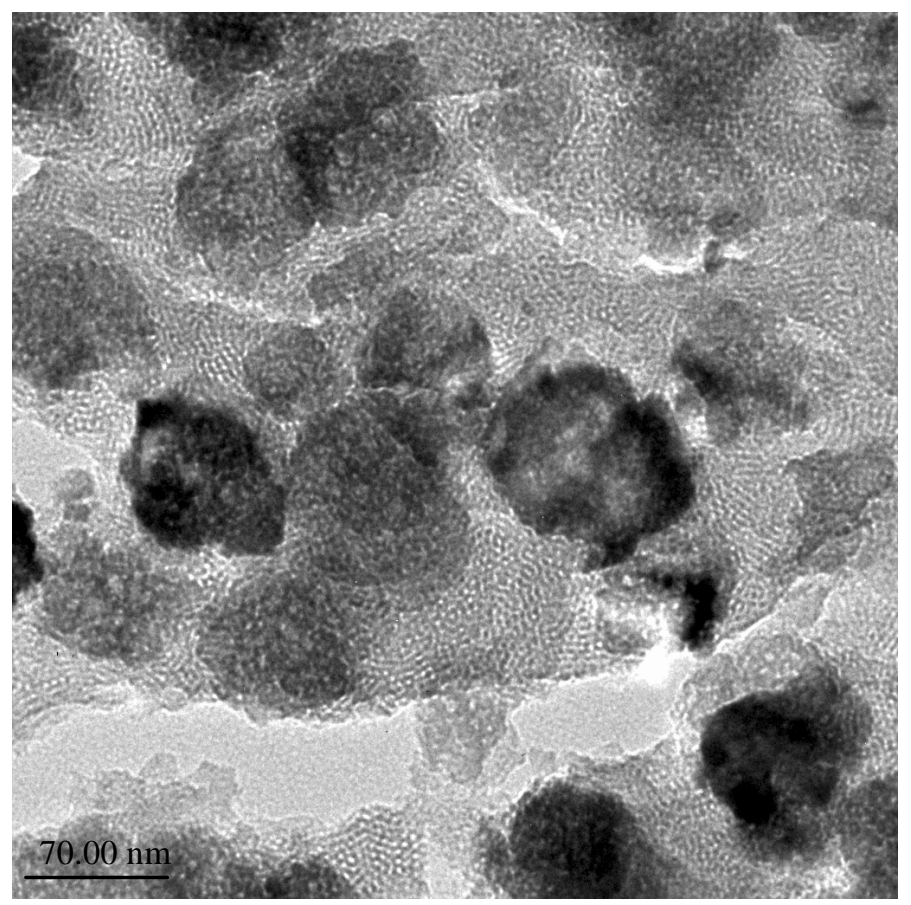

Fig. 6. Cross section TEM image of Fig. 5 at a higher magnification. The ordered pore structure in the silica phase is preserved all around the iron nanoparticles. 


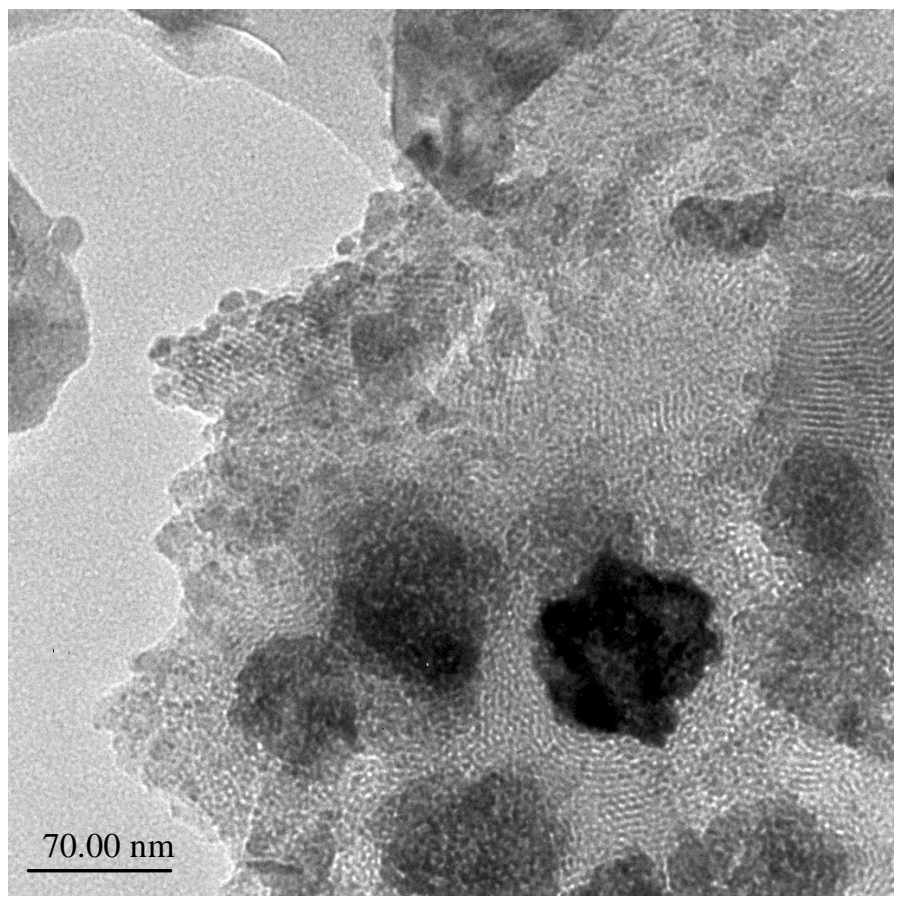

Fig. 7. Another cross section TEM image where the crystalline particles are surrounded by mesoporous silica. 


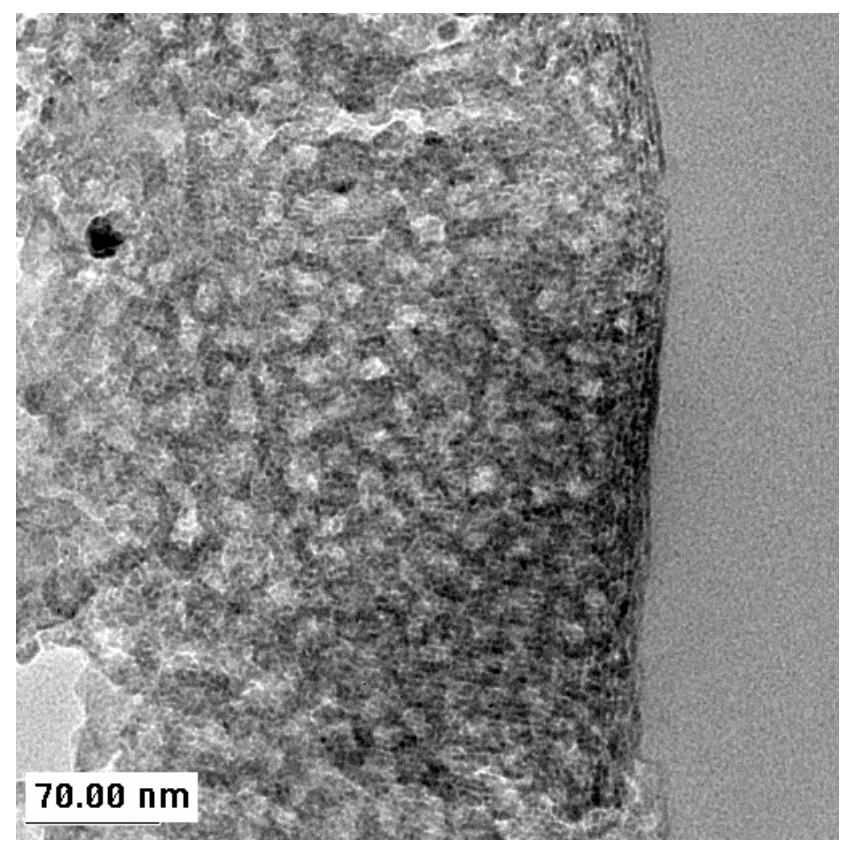

Fig. 8. Cross section TEM image shows that the area near the surface may constitutes the silica shell, with very few $\mathrm{Fe}-\mathrm{Cu}$ particles. Most of the iron oxide is located in the interior of the silica spray dried particles. 


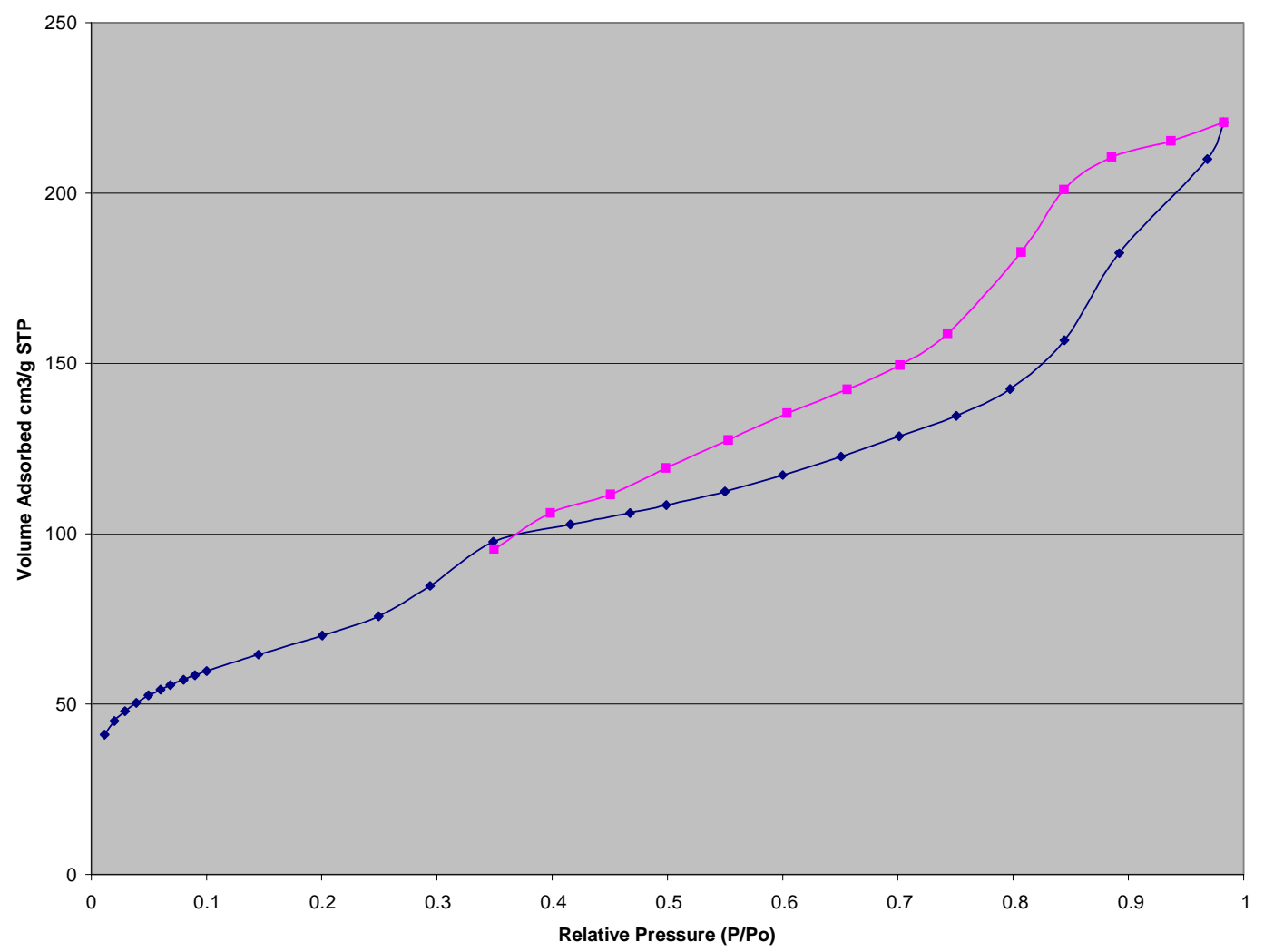

Fig. 9. Nitrogen adsorption/desorption isotherm curves for the encapsulated iron oxide in silica catalyst. The hysteresis in this curve indicates a range of pore sizes are present, as shown in the next figure. 


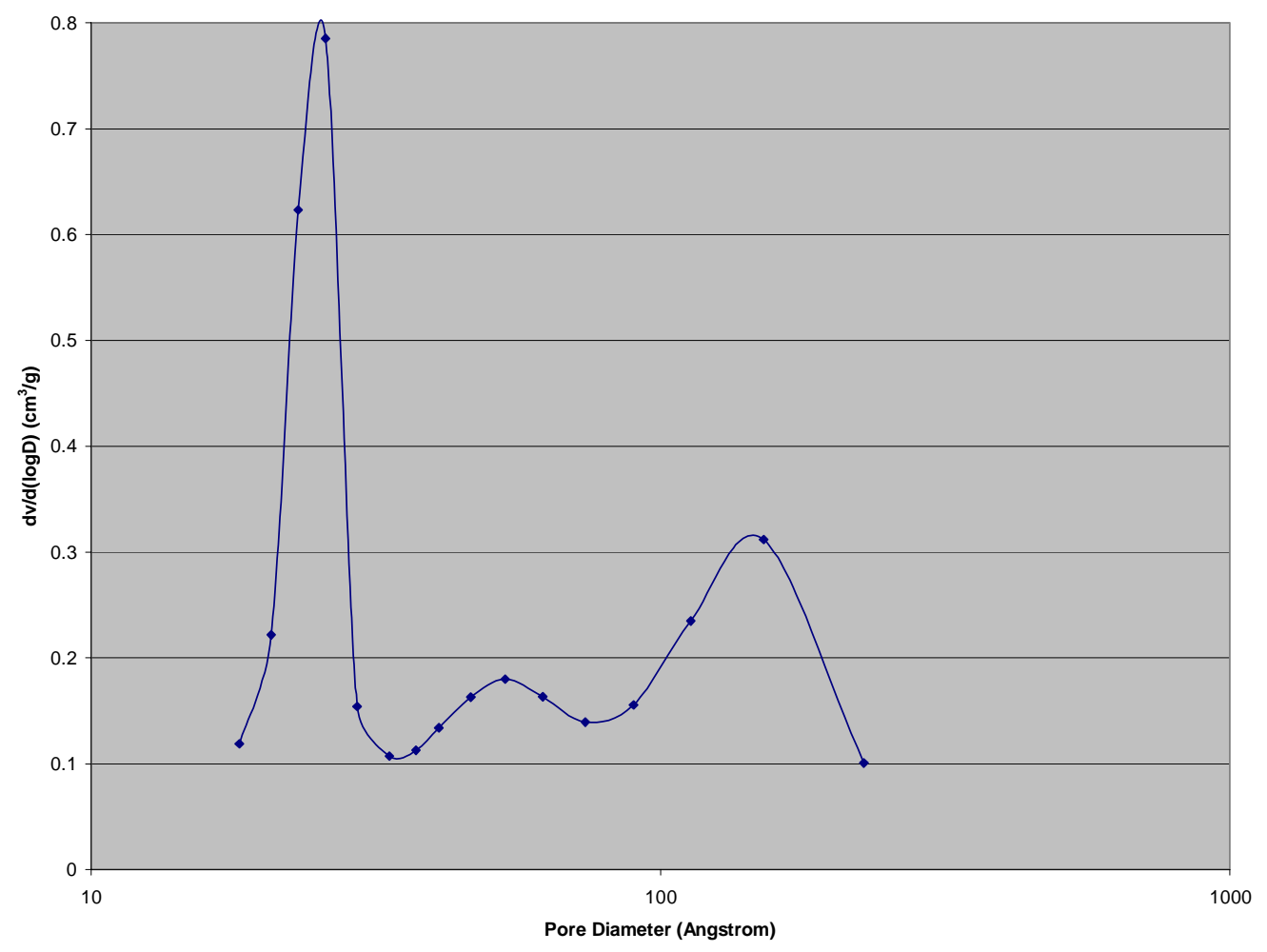

Fig. 10. BJH pore-size distribution plot from the adsorption data in Fig. 9 shows three peaks: the first peak corresponding to the ordered mesoporous silica, and the other two peaks corresponding to the internal microstructure where iron oxide particles are encapsulated in the silica shells. 

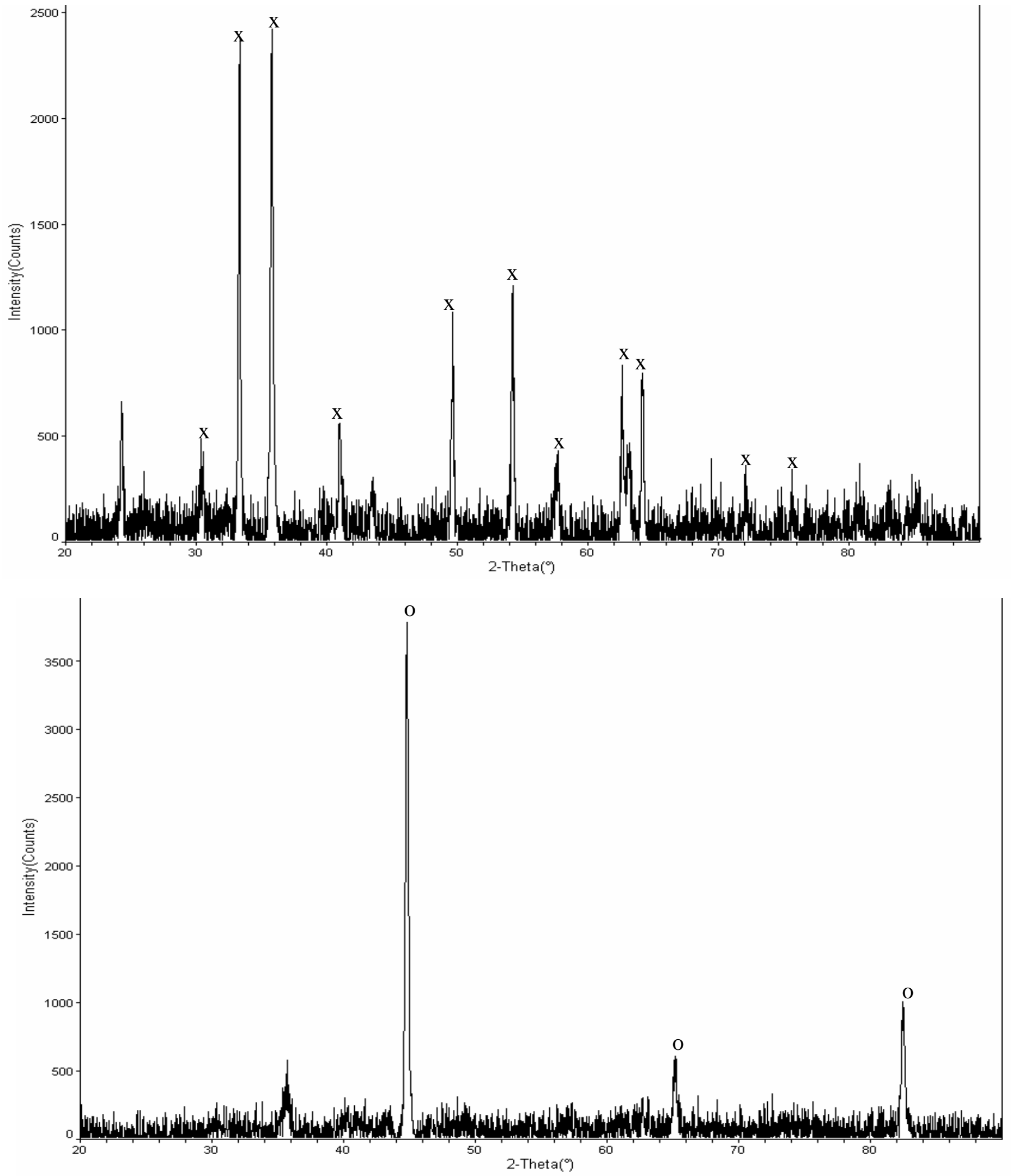

Fig. 11. XRD patterns show that the catalyst is completely reducible in hydrogen at $300{ }^{\circ} \mathrm{C}$. Silica does not appear to affect the reducibility of the catalyst. $x=$ hematite $\left(\alpha-\mathrm{Fe}_{2} \mathrm{O}_{3}\right), o=$ metallic iron $(\alpha-\mathrm{Fe})$ 
Progress Report on

\title{
Rational Design of FePtK/SiO 2 Fischer-Tropsch Catalysts and Study on Their Activity-Nanophase Relationships
}

By

\author{
Jian Xu, and Calvin H. Bartholomew, Professor \\ BYU Catalysis Lab, Dept. of Chemical Engineering, 350CB \\ Brigham Young University
}

Provo, Utah 84602

December 5, 2001 


\section{TABLE OF CONTENTS}

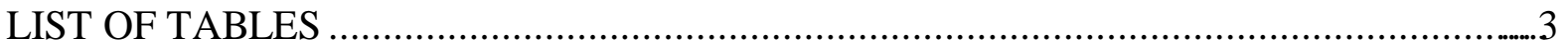

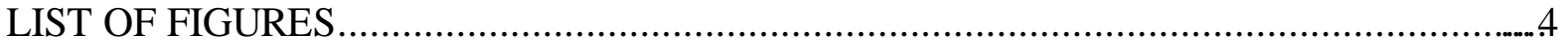

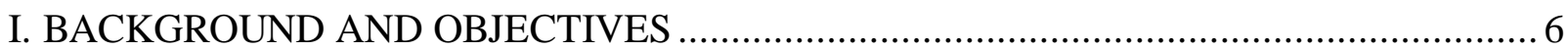

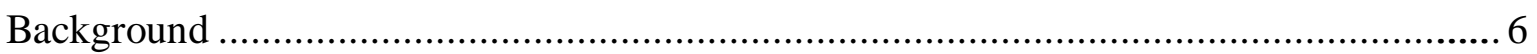

Objectives of Research Program ...................................................................... 7

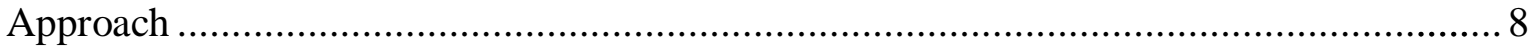

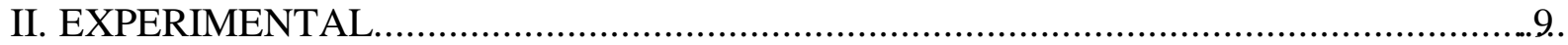

Catalyst Preparation and Compositions .............................................................. 9

BET Surface Area and Hydrothermal Stability Tests .......................................... 11

TGA Studies .........................................................................................

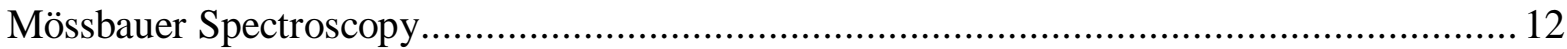

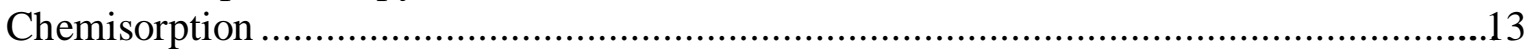

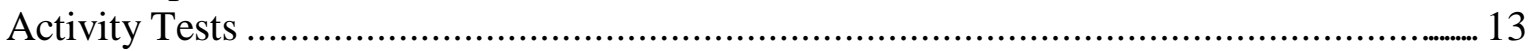

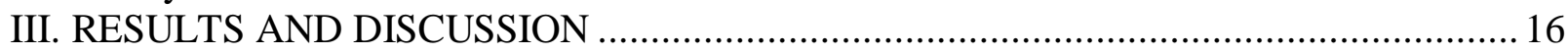

Chemical Analysis of Catalysts .............................................................................. 16

BET Surface Area Measurements and Hydrothermal Stability Tests ............................ 16

Thermal Gravimetric Analysis (TGA) ............................................................ 18

Chemisorption Tests.......................................................................................

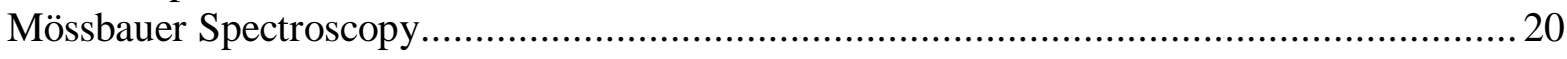

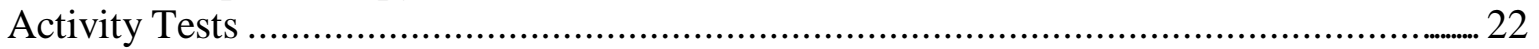

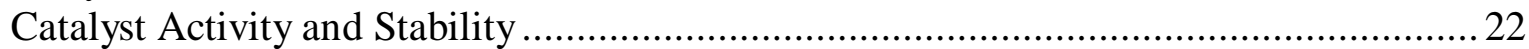

$\mathrm{CH}_{4}$ and $\mathrm{CO}_{2}$ Selectivities........................................................................ 23

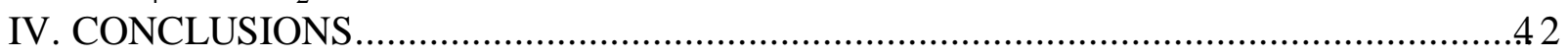

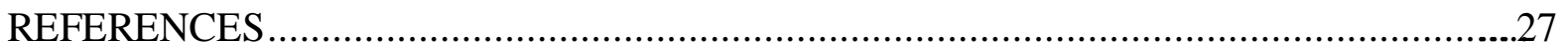




\section{LIST OF TABLES}

Table 1. Design Factors in Statistically Designed Experiments ........................................... 14

Table 2. Dependent Variables in Statistically Designed Experiments................................... 14

Table 3. Catalyst codes and compositions determined by atomic absorption........................22

Table 4. BET surface area of catalysts Davisil supported on $635^{\mathrm{a}}$ and Davisil $644^{\mathrm{b}}$............2 29

Table 5. $\mathrm{H}_{2}$ Chemisorption and Dispersion Measurements ................................................. 34

Table 6. Mössbauer spectroscopy parameters of Fe-S-206 after $55 \mathrm{~h}$ fixed bed run at $270^{\circ} \mathrm{C}, 10 \mathrm{~atm}, \mathrm{H} / \mathrm{CO}=1$.

Table 7. Room Temperature and Liquid $\mathrm{N}_{2}$ Temperature Mössbauer spectroscopy parameters of FePt-S-203 catalyst after fixed bed run at $270^{\circ} \mathrm{C}, 10 \mathrm{~atm}, \mathrm{H}_{2} / \mathrm{CO}=1$

Table 8. Iron phases of unpromoted (Fe-S-206) and promoted (FePt-S-203, FePtK-S-218) catalysts (room temperature and liquid Nㅡ Mössbauer Spectra)

Table 9. Mössbauer spectroscopy parameters of Fe-S-207 after $16 \mathrm{~h}$ in-situ pretreatment at $280^{\circ} \mathrm{C}$ (spectra collected at $298 \mathrm{~K}$ for $24 \mathrm{~h}$ )

Table 10. Mössbauer spectroscopy parameters of $10.7 \mathrm{wt} \% \mathrm{Fe} / \mathrm{SiO}_{2}$ catalyst after statistically

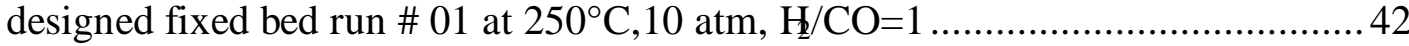

Table 11. Mössbauer spectroscopy parameters of $10.7 \mathrm{wt} \% \mathrm{Fe} / \mathrm{SiO}_{2}$ catalyst after statistically designed fixed bed run $\# 02$ at $265^{\circ} \mathrm{C}, 10 \mathrm{~atm}, \mathrm{H} / \mathrm{CO}=1$

Table 12. Mössbauer spectroscopy parameters of $10.7 \mathrm{wt} \% \mathrm{Fe} / \mathrm{SiO}_{2}$ catalyst after statistically designed fixed bed run $\# 03$ at $250^{\circ} \mathrm{C}, 10 \mathrm{~atm}, \mathrm{H} / \mathrm{CO}=1$.

Table 13. Mössbauer spectroscopy parameters of FePt-S-220 catalyst after statistically designed fixed bed run \# 04 at $250^{\circ} \mathrm{C}, 10 \mathrm{~atm}, \mathrm{H} / \mathrm{CO}=1$; Catalyst pretreated in $\mathrm{H} 2 / \mathrm{CO}=0.1,280^{\circ} \mathrm{C}$ for $16 \mathrm{~h}$

Table 14. Mössbauer spectroscopy parameters of FePtK-S-218 catalyst after statistically

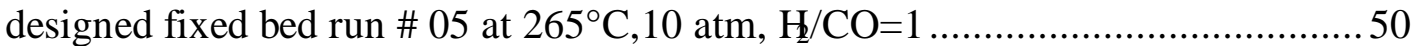

Table 15. Mössbauer spectroscopy parameters of Fe-S-201 catalyst after statistically designed fixed bed run $\# 06$ at $265^{\circ} \mathrm{C}, 10$ atm, $\mathrm{H} / \mathrm{CO}=1$

Table 16. Mössbauer spectroscopy parameters of FePtK-S-218 catalyst after statistically designed fixed bed run \# 07 at $265^{\circ} \mathrm{C}, 10 \mathrm{~atm}, \mathrm{H} / \mathrm{CO}=1$

Table 17. Mössbauer spectroscopy parameters of Fe-S-201 catalyst after statistically designed fixed bed run $\# 08$ at $265^{\circ} \mathrm{C}, 10 \mathrm{~atm}, \mathrm{H} / \mathrm{CO}=1$

Table 18. Mössbauer spectroscopy parameters of FePt-S-220 catalyst after statistically designed fixed bed run \# 09 at $265^{\circ} \mathrm{C}, 10$ atm, $\mathrm{H} / \mathrm{CO}=1$; Catalyst pretreated in $\mathrm{H} / \mathrm{CO}=0.5,320^{\circ} \mathrm{C}$ for $16 \mathrm{~h}$

Table 19. Iron phases of unpromoted (Fe-S-201) and promoted (FePt-S-220, FePtK-S-218) catalysts after statistically designed fixed bed runs (room temperature Mössbauer)..

Table 20. Steady-state activity and selectivity for unpromoted (Fe-S-203, Fe-S-206) and promoted (FePt-S-203, FePt-S-206) catalysts ${ }^{\mathrm{a}}$.

Table 21. Steady-state activity and selectivity for unpromoted (Fe-S-201) and promoted (FePt-S-220, FePtK-S-218) catalysts in statistically designed fixed bed runs 


\section{LIST OF FIGURES}

Fig 1. Thermal stability of Davisil 644 support after heating in air for $24 \mathrm{~h}$ at different

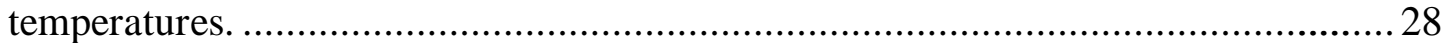

Fig 2. Calculated Water Partial Pressures at Fixed Bed Run Conditions ........................... 30

Fig 3. Hydrothermal Stability of Davisil 644 Silica support and $\mathrm{FeAl}_{2} \mathrm{O}_{4}$ Modified Davisil 644 Support $\left(72 \mathrm{~h}\right.$ steam treatment at $\mathrm{P}_{\text {total }}=10 \mathrm{~atm}, \mathrm{~T}=265^{\circ} \mathrm{C}$, repeat every run $)$ BET

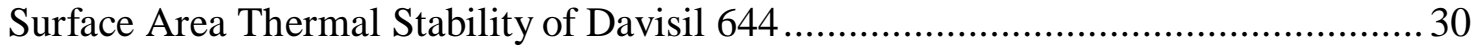

Fig 4. K Promoter Effects on BET Thermal Stability of Davisil 644 _............................ 31

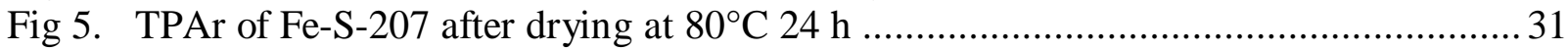

Fig 6. TPR of Fe-S-207 fresh catalyst after drying at $80^{\circ} \mathrm{C}$ for $24 \mathrm{~h} \mathrm{................................} 32$

Fig 7. TPR of calcined Fe-S-207 and FePt-S-207.............................................. 32

Fig 8. TPR of Unpromoted and Promoted Fe Catalysts after $150^{\circ} \mathrm{C} 3 \mathrm{~h}$ calcinations .......... 33

Fig 9. Fe-S-206 After 55hrs fixed bed test run ........................................................ 35

Fig 10. FePt-S-203 after fixed bed run (spectra collected at $298 \mathrm{~K}$ ) ................................. 36

Fig 11. FePt-S-203 after fixed bed run (spectra collected at 77K) ................................ 36

Fig 12. In-situ Mössbauer spectrum of Fe-S-207 after pretreated at $280^{\circ} \mathrm{C}, 1 \mathrm{~atm}$ and $\mathrm{H}_{2} / \mathrm{CO}=1$

Fig 13. Mossbauer Spectrum of Fe-S-201 (10.7\% Fe/SiO 2$)$ after statistically designed experiments run \#01

Fig 14. Mossbauer Spectrum of Fe-S-201 (10.7 \% Fe/SiO 2$)$ after statistically designed experiments run \#02.

Fig 15. Mossbauer Spectrum of Fe-S-201 (10.7\% Fe/SiO 2$)$ after statistically designed experiments run $\# 03$.

Fig 16. Mossbauer Spectrum of FePt-S-220 after statistically designed experiments run \#04

Fig 17. Mossbauer Spectrum of FePtK-S-218 after statistically designed experiments run \#05

Fig 18. Mossbauer Spectrum of Fe-S-201 after statistically designed experiments run \#06.. 51

Fig 19. Mossbauer Spectrum of FePtK-S-218 after statistically designed experiments run \#07

Fig 20. Mossbauer Spectrum of Fe-S-201 after statistically designed experiments run \#08.. 55

Fig 21. Mossbauer Spectrum of FePt-S-220 after statistically designed experiments run \#09

Fig 22. Syngas Conversion and Iron Carbide Content Correlation of Fe-S-201 ................. 59

Fig 23. CO conversion of FePtK-S-215 compared with Fe-S-201 at $265^{\circ} \mathrm{C}, 10 \mathrm{~atm}, \mathrm{H}_{2} / \mathrm{CO}=1$ 60

Fig 24. Repeatability of FePtK-S-215 and FePtK-S-216 fixed bed runs $\mathrm{T}=265^{\circ} \mathrm{C}, \mathrm{P}=10 \mathrm{~atm}$, Total Flow=64 sccm, $\mathrm{H}_{2} / \mathrm{CO}=1$.

Fig 25. Pretreatment effects on FePtK-S-216 and FePtK-S-217 ..................................... 61

Fig 26. Fixed Bed Activity Comparision of FePtK-S-209 and FePtK-S-215 ...................... 61

Fig 27. Statistically Designed Fixed Run 1 of Fe-S-201 Fixed Bed Run; Pretreated in $\mathrm{H}_{2} / \mathrm{CO}=1,250^{\circ} \mathrm{C}, 16 \mathrm{~h}$ Reaction conditions: $\mathrm{T}=250^{\circ} \mathrm{C}, \mathrm{P}=10 \mathrm{~atm}$, Total Flow $=64$ SCCM.

Fig 28. Statistically Designed Fixed Run 4 of FePt-S-220 Fixed Bed Run; Pretreated in $\mathrm{H}_{2} / \mathrm{CO}=0.1,280^{\circ} \mathrm{C}, 16 \mathrm{~h}$ Reaction conditions: $\mathrm{T}=250^{\circ} \mathrm{C}, \mathrm{P}=10$ atm, Total Flow $=64$ 
SCCM

Fig 29. Statistically Designed Fixed Run 7 of FePtK-S-218 Fixed Bed Run; Pretreated in $\mathrm{H}_{2} / \mathrm{CO}=1,320^{\circ} \mathrm{C}, 16 \mathrm{~h}$ Reaction conditions: $\mathrm{T}=265^{\circ} \mathrm{C}, \mathrm{P}=10 \mathrm{~atm}$, Total Flow $=64$

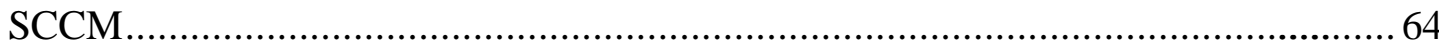




\section{BACKGROUND AND OBJECTIVES}

\section{Background}

The synthesis of hydrocarbons from coal and natural gas (Fischer-Tropsch synthesis) has been known since the late 1920s. In light of decreasing crude oil resources, coal and natural gas are promising feedstock alternatives for the chemical and fuel industries. As oil prices continue to increase, the conversion of natural gas to liquid hydrocarbons via the FischerTropsch synthesis (FTS) becomes economically promising. In addition to SASOL and Shell, who are running commercial FTS plants, other companies including Exxon-Mobil, BPAmoco, and Chevron-Texaco are actively seeking to develop their own FTS processes, license FTS technologies, and build plants to process natural gas.

Many studies have been and are being carried out to develop or improve commercial technologies for FTS. Among these efforts, catalyst technology development plays a key role. Current FTS catalysts include cobalt, ruthenium and iron promoted with copper, potassium, and other oxides. Iron catalysts are used for FTS because of their remarkable water-gas shift (WGS) activity and low cost. Depending on the desired product and operating pressure and reaction conditions, iron catalysts can be used in a multi-tube fixed bed reactor or slurry bubble-column reactor (SBCR). In the slurry process iron catalysts are suspended in the liquid product to improve mixing and heat removal. Slurry reactor technology provides substantial economic benefits for mainstream FTS.

Unfortunately iron catalysts used in the slurry phase process encounter serious problems. First, iron catalysts undergo serious attrition during reaction, producing micron-sized catalyst particles that increase the viscosity of the slurry phase. These catalyst fine particles can cause fouling of downstream equipment and make the separation of the catalyst from the wax 
product extremely difficult. The deactivation and attrition of Fe catalysts in SBCR are due to not only physical processes (e.g., vigorous movement and collision of catalyst particles leading to erosion and attrition) but also to chemical factors e.g. phase changes during pretreatment and reaction. Second, iron catalysts deactivate within 2,000-5000 hours of use and are generally not regenerable, this also increases the operating cost.

Although an SBCR offers more advantages than a fixed bed or fluidized bed reactor, it requires an iron catalyst of high attrition-resistance. At present, the most active, selective iron catalysts are unsupported $\mathrm{Fe} / \mathrm{Cu} / \mathrm{K}$ catalysts prepared by precipitation. Precipitated iron catalysts $\left(\mathrm{Fe} / \mathrm{Cu} / \mathrm{K} / \mathrm{SiO}_{2}\right)$ prepared at Texas $\mathrm{A} \& \mathrm{M}$ University (TAMU) are reported to be more active than precipitated iron catalysts prepared by Mobil and Rheinpreussen [Bukur et al., 1998 and 1999]. Moreover, based on preliminary tests [Pham, 1999], TMAU' s catalyst also has fairly high attrition resistance, although more work is needed to quantify this behavior. Nevertheless, it is conceivable that even the strongest precipitated iron catalysts may not have adequate attrition resistance. Accordingly, there is interest in developing alternative catalysts of high attrition resistance; for example, silica- or alumina-supported iron catalysts. Moreover, addition of noble metal promoters such as Pt to the iron catalyst may improve its reducibility to iron metal and carbides and its regenerability, while enhancing activity maintenance as in cobalt bimetallic FTS catalysts.

\section{Objectives of Research Program}

The principal objectives of this program are to:

1. Prepare active, selective and attrition-resistant silica-supported Fe and Fe-Pt FTS catalysts of high iron reducibility and dispersion. 
2. Understand the effects of catalyst preparation, pretreatment, reaction and promoter ( $\mathrm{Pt}$ ) on iron phase transformations.

3. Obtain an understanding of important preparation-activity-structure relationships such as the effects of reduction temperature on activity, dispersion and state of reduction.

\section{Approach}

To accomplish these objectives, an experimental plan has been designed which incorporates (1) a novel preparation involving non-aqueous (acetone) evaporation deposition of metal salts on a dehydroxylated support to facilitate uniform penetration of support pores, high iron reducibility and high metal dispersion; (2) the application of in-situ Mössbauer and HRTEM to the understanding of Fe chemical speciation and crystallite morphology; (3) temperature programmed reduction (TPR), $\mathrm{H}_{2}$ chemisorption, HRTEM and BET surface area measurements coupled with activity and stability tests of the unpromoted and promoted catalyst in a fixed bed reactor under industrially-relevant process conditions; and (4) a detailed statistical fixed bed experiment design using the L18 orthogonal array in the study of iron FTS catalysts that was formulated with help from the BYU Statistic Consultation Laboratory. Prior to this experimental design, a preliminary study of silica-supported Fe and Fe-Pt bimetallic catalyst was carried out. Both unpromoted and promoted catalysts were tested in a fixed bed reactor at various conditions useful in scoping parameters for the statistical experiment design. Factors in these experiments included catalyst composition, pretreatment gas composition, pretreatment temperature and fixed reaction temperature. The statistically designed experiments should provide a scientific basis for development of an iron FTS catalyst, which is attrition-resistant, highly active and highly stable. 
This report summarizes the results of the scoping experiments and data obtained in several statistically designed experiments.

\section{EXPERIMENTAL}

\section{Catalyst Preparation and Compositions}

A non-aqueous (acetone) evaporative deposition method was used in the preparation of three catalysts: $10 \mathrm{wt} \% \mathrm{Fe} / \mathrm{SiO}_{2}, 10 \mathrm{wt} \% \mathrm{Fe} / 1.0 \mathrm{wt} \% \mathrm{Pt} / \mathrm{SiO}_{2}$ and $10 \mathrm{wt} \% \mathrm{Fe} / 1.0 \mathrm{wt} \% \mathrm{Pt} / 0.2$ $\mathrm{wt} \% \mathrm{~K} / \mathrm{SiO}_{2}$. Following are the steps of the preparation procedures:

\section{Preparation of $10 \mathrm{wt} \% \mathrm{Fe} / \mathrm{SiO}_{2}:$}

1. Dried desired amount of Davisil 644 support at $600{ }^{\circ} \mathrm{C}$ for $24 \mathrm{~h}$.

2. Dried desired amount of $\mathrm{Fe}\left(\mathrm{NO}_{3}\right)_{3} \cdot 9 \mathrm{H}_{2} \mathrm{O}$ in flowing air at $100{ }^{\circ} \mathrm{C}$ for $24 \mathrm{~h}$ to remove waters of hydration.

3. While the dried $\mathrm{Fe}\left(\mathrm{NO}_{3}\right)_{3}$ was still hot, $100 \mathrm{ml}$ of acetone was poured into the beaker and stirred until the solid dissolved.

4. Transferred the dried Davisil 644 support into a flask with a top mounted mechanical stirrer. Measured $200 \mathrm{ml}$ of acetone and poured into the flask washing the Davisil 644 on the wall of flask; stirred to form a slurry.

5. Bubbled He gas through the slurry at a rate of 100 SCCM.

6. Poured the $100 \mathrm{ml}$ dried iron nitrate into the slurry.

7. Continued bubbling of $\mathrm{He}$ and stirring until the acetone liquid was evaporated.

8. Dried the wet catalyst paste at $80^{\circ} \mathrm{C}$ for $24 \mathrm{~h}$ in a oven, put the dried catalyst (of dark orange color) in a sample vial and stored in a desiccator.

Preparation of $10 \mathrm{wt} \% \mathrm{Fe} / 1.0 \mathrm{wt} \% \mathrm{Pt} / \mathrm{SiO}_{2}:$ 
1. Dissolved suitable amount of Pt amine salt in $100 \mathrm{ml}$ of acetone to form a solution.

2. Measured the desired amount of dried $20 \mathrm{wt} \% \mathrm{Fe} / \mathrm{SiO}_{2}$ catalyst and added it to acetone to form a slurry. Transferred the slurry to the same mechanically stirred flask (as above).

3. Bubbled helium gas through the catalyst slurry.

4. Started the mechanical stirrer and slowly introduced the Pt salt solution.

5. Bubbled He and stirred until all acetone liquid was evaporated.

6. Dried the wet catalyst paste at $80^{\circ} \mathrm{C}$ in vacuum oven with flowing He for $24 \mathrm{~h}$.

7. Transferred the dried catalyst (of dark orange color) to a vial and stored it in a desiccator.

\section{Preparation of $10 \mathrm{wt} \% \mathrm{Fe} / 1.0 \mathrm{wt} \% \mathrm{Pt} / 0.2 \mathrm{wt} \% \mathrm{~K} / \mathrm{SiO}_{2}:$}

1. Dried desired amount of Davisil 644 support at $600{ }^{\circ} \mathrm{C}$ for $24 \mathrm{~h}$.

2. Dried desired amount of $\mathrm{Fe}\left(\mathrm{NO}_{3}\right)_{3} \cdot 9 \mathrm{H}_{2} \mathrm{O}$ in flowing air at $100{ }^{\circ} \mathrm{C}$ for $24 \mathrm{~h}$.

3. While the dried $\mathrm{Fe}\left(\mathrm{NO}_{3}\right)_{3}$ was still hot, $100 \mathrm{ml}$ of acetone was poured into the beaker and stirred until the solid dissolved.

4. Transferred the dried Davisil 644 support into a flask with a top mounted mechanical stirrer. Measured $200 \mathrm{ml}$ of acetone and poured into the flask washing the Davisil 644 on the wall of flask; stirred to form a slurry.

5. Bubbled He gas through the slurry.

6. While the slurry was bubbling, weighed the desired amount of $\mathrm{KNO}_{3}$ and dissolved it in about $4 \mathrm{ml}$ water in a small vial to form a solution.

7. Poured the $100 \mathrm{ml}$ dried iron nitrate into the slurry.

8. At the same time, poured the $\mathrm{KNO}_{3}$ solution into the slurry. 
9. Continued bubbling of $\mathrm{He}$ and stirring until the acetone liquid was evaporated.

10. Dried the wet catalyst paste at $80^{\circ} \mathrm{C}$ for $24 \mathrm{~h}$, put the dried catalyst (of dark orange color) in a sample vial and stored in a desiccator.

11. Took this $\mathrm{K}$ promoted catalyst out from desiccator and calcined it in $\mathrm{He}$ at $200^{\circ} \mathrm{C}$ for 3 h. Weighed desired amount of this catalyst and calculated the weight of Pt salt needed for $1.0 \mathrm{wt} \% \mathrm{Pt}$ in final catalyst, dissolved suitable amount of Pt amine salt in $100 \mathrm{ml}$ of acetone to form a solution.

12. Transferred the dried $\mathrm{Fe} / \mathrm{K} / \mathrm{SiO}_{2}$ support into a flask with a top mounted mechanical stirrer. Measured $200 \mathrm{ml}$ of acetone and poured into the flask; stirred to form a slurry.

13. Started the mechanical stirrer and slowly introduced the Pt salt solution.

14. Bubbled He and stirred until all acetone liquid was evaporated.

15. Dried the wet catalyst paste at $80^{\circ} \mathrm{C}$ in vacuum oven with flowing He for $24 \mathrm{~h}$.

16. Transferred the dried catalyst (of dark orange color) to a vial and stored it in a desiccator.

\section{BET Surface Area and Hydrothermal Stability Tests}

BET surface areas were obtained using a Gemini 2360 surface area analyzer. Approximately $0.15 \mathrm{~g}$ catalyst samples were degassed in $\mathrm{He}$ at $200^{\circ} \mathrm{C}$ for $2-3 \mathrm{~h}$ before test. The hydrothermal stability tests were performed in a $1 \mathrm{~cm}$ I.D. fixed-bed reactor with a temperature controller. The steam pressure was regulated using a high-pressure water pump. The steam partial pressure was in a range of 0 to 5 atm. Two grams of support (fresh or modified) was used in these tests. Each support was exposed to steam at $265^{\circ} \mathrm{C}$ for 72 hours. The steam treated catalyst was then removed from the fixed bed reactor and dried at $80^{\circ} \mathrm{C}$ in 
oven for 24 hours before BET measurements. For every support, the hydrothermal stability test was repeated once.

\section{TGA Studies}

A Perkin-Elmer TGA7 system was used in temperature-programmed studies of decomposition in $\mathrm{Ar}$ (TPAr), oxidation in $10 \% \mathrm{O}_{2}$ in $\mathrm{Ar}$ (TPO), and reduction in $10 \% \mathrm{H}_{2}$ in Ar (TPR) of fresh catalysts and catalysts after fixed bed activity runs. The catalysts were also exposed to a flow of syngas $\left(\mathrm{CO} / \mathrm{H}_{2}=1\right)$ during programmed linear heating to study the effects of syngas pretreatment.

\section{Mössbauer Spectroscopy}

Mössbauer spectra were obtained using an Austin S-600 spectrometer system with a laser absolute velocity calibrator that enables peak positions to be determined to within \pm 0.01 $\mathrm{mm} / \mathrm{s}$ [Stoker, 1999]. The gamma ray source was ${ }^{57} \mathrm{Co}$ in a rhodium matrix. Peak positions and isomer shifts of all spectra are reported with respect to metallic iron. Mössbauer spectra of the unpromoted and promoted catalyst were collected at 77 and $298 \mathrm{~K}$ to study iron phase transformations during synthesis in the fixed bed reactor.

Gamma ray counts were obtained as a function of radioactive source velocity and fitted to a series of sextets composed of six Lorentzian lines having equal widths and intensities with the ratios of 3:2:1:1:2:3 using a nonlinear least squares routine described elsewhere [Stoker, 1999]. Peak assignments were based on comparison of the fitted values of Mössbauer spectroscopy parameters with the reported values in the literature.

A $0.3 \mathrm{~g}$ sample of passivated catalyst was pressed to a 1-inch diameter wafer. The sample wafer was then placed in a plexiglass cell at $25^{\circ} \mathrm{C}$ or in an in-situ Mössbauer cell $\left(77^{\circ} \mathrm{C}\right.$ or in situ runs), which allows in-situ pretreatment in a controlled atmosphere from $77 \mathrm{~K}$ to $723 \mathrm{~K}$. 
For fresh catalyst and calcined catalysts, Mössbauer spectra were collected at room temperature (298 K). For reaction-aged (in fixed bed) and passivated catalysts, Mössbauer spectra were collected at $77 \mathrm{~K}$ and $298 \mathrm{~K}$ for each sample. Spectra of catalysts treated in situ in 1 atm of syngas $\left(\mathrm{CO} / \mathrm{H}_{2}=1\right)$ were obtained at $298 \mathrm{~K}$.

\section{Chemisorption}

Selective $\mathrm{H}_{2}$ chemisorption uptakes were measured by a flow desorption method using a custom flow system with a thermal conductivity detector (TCD). The details of this system and procedures are described elsewhere [Jones and Bartholomew, 1988]. In this study $1.0 \mathrm{~g}$ of iron catalyst was placed in a Pyrex flow cell and was reduced in a mixture of $\mathrm{Ar}$ and $\mathrm{H}_{2}$ $\left(40 \% \mathrm{H}_{2}\right)$ at a GHSV of 2000 . The sample temperature was increased at $1^{\circ} \mathrm{C} / \mathrm{min}$ to $300^{\circ} \mathrm{C}$ and held at $300^{\circ} \mathrm{C}$ for $16 \mathrm{~h}$; it was then cooled with dry ice/acetone to $-84^{\circ} \mathrm{C}$. At this temperature, the $\mathrm{H}_{2}$ flow was shut off and Ar was introduced to desorb physisorbed $\mathrm{H}_{2}$. The catalyst was then heated quickly to $300^{\circ} \mathrm{C}$ at $10-20^{\circ} \mathrm{C} / \mathrm{min}$ while the amount of desorbed $\mathrm{H}_{2}$ was measured by TCD.

\section{Activity Tests}

With the help of the BYU Statistics Consultation Lab, fixed bed test runs of $\mathrm{FePtK} / \mathrm{SiO}_{2}$ FTS catalysts were designed using an L18 orthogonal array of catalyst composition and pretreatment variables.

\section{$\underline{\text { Design factors }}$}

Design factors under investigation in the statistically designed experiments are listed in the following table along with their corresponding factor levels. The fixed bed reaction temperature consists of two levels, while catalyst composition, pretreatment gas and pretreatment temperature each have three levels. 
Table 1. Design Factors in Statistically Designed Experiments

\begin{tabular}{|l|l|l|}
\hline Factors & $\begin{array}{l}\text { Number of Factor } \\
\text { Levels }\end{array}$ & Factor Levels \\
\hline Catalyst composition & 3 & $10 \% \mathrm{Fe} / \mathrm{SiO}_{2}$ \\
& & $10 \% \mathrm{Fe}-1.0 \% \mathrm{Pt} / \mathrm{SiO}_{2}$ \\
& & $10 \% \mathrm{Fe}-1.0 \% \mathrm{Pt}-0.2 \mathrm{~K} / \mathrm{SiO}_{2}$ \\
& & \\
\hline Pretreatment gas composition & 3 & $\mathrm{H}_{2} / \mathrm{CO}=0.1$ \\
\cline { 3 - 3 } & & $\mathrm{H}_{2} / \mathrm{CO}=0.5$ \\
\cline { 2 - 3 } & $\mathrm{H}_{2} / \mathrm{CO}=1.0$ \\
\hline Pretreatment temperature & 3 & $250^{\circ} \mathrm{C}$ \\
\hline & & $280^{\circ} \mathrm{C}$ \\
\cline { 2 - 3 } & & $320^{\circ} \mathrm{C}$ \\
\hline \multirow{2}{*}{$\begin{array}{l}\text { Fixed bed reaction } \\
\text { temperature }\end{array}$} & $250^{\circ} \mathrm{C}$ \\
\cline { 2 - 3 } & & $265^{\circ} \mathrm{C}$ \\
\hline
\end{tabular}

\section{$\underline{\text { Response Variables }}$}

Table 2 lists the dependent variables of interest to this study, the units of measurement and the range of expected values. Study of these variables is expect to enable evaluation and correlation of catalyst preparation variables and physical and chemical properties with catalyst performance (activity, selectivity and stability).

Table 2. Dependent Variables in Statistically Designed Experiments

\begin{tabular}{|l|l|l|}
\hline Dependent Variable & Units & Range of values \\
\hline Conversion, $\mathrm{Xc0}$ & Vol\% & $0-1.0$ \\
\hline Selectivity of $\mathrm{C}_{5+}$ & Vol\% & $40-60$ \\
\hline Stability & $\% /$ hour & 100 \\
\hline Dispersion & $\%$ & $5.0-20.0$ \\
\hline BET surface area & $\mathrm{m}^{2} / \mathrm{g}$-cat & $0-300$ \\
\hline Phase composition & & $\mathrm{Fe}_{2.5} \mathrm{C}$ (I, II, III), $\mathrm{Fe}_{3} \mathrm{O}_{4}(\mathrm{SP}), \mathrm{Fe}^{2+}$ \\
\hline Morphology & & \\
\hline
\end{tabular}

Procedures

Activity tests were carried out in a $1 \mathrm{~cm}$ I.D. fixed-bed reactor with a three-zone furnace with a separate controller for each zone. Two grams of catalyst (100-150 mesh) was diluted with $4 \mathrm{~g}$ of quartz chips (70 mesh) to minimize the axial temperature gradient. The 
temperature inside the catalyst bed was measured by a thermocouple inserted into the catalyst bed.

The feed gas was purified using deoxygenation and zeolite traps and metered with calibrated mass flow controllers. The reactor pressure was regulated by an Mighty Mite backpressure regulator. Heavier waxy products were collected in a hot trap while lighter liquid products were collected at ambient pressure in a cold trap at ice temperature. The exit gas was then analyzed for $\mathrm{H}_{2}, \mathrm{CO}, \mathrm{CO}_{2}, \mathrm{CH}_{4}$ and $\mathrm{Ar}$ using an $\mathrm{HP} 5890$ gas chromatograph.

The iron catalyst was pretreated in-situ at atmospheric pressure before each activity test. Reactor temperature was increased at $1{ }^{\circ} \mathrm{C} / \mathrm{min}$ to $200^{\circ} \mathrm{C}$ and held at $200^{\circ} \mathrm{C}$ for $3 \mathrm{~h}$. A helium flow of $200 \mathrm{sccm}$ was used to decompose the iron nitrates. The temperature was then increased at $0.5^{\circ} \mathrm{C} / \mathrm{min}$ to $290^{\circ} \mathrm{C}$ and held for $16 \mathrm{~h}$ in a mixture of $\mathrm{CO}$ and $\mathrm{H}_{\mathbf{L}}\left(\mathrm{CO} / \mathrm{H}_{2}=1\right)$ flowing at $200 \mathrm{sccm}$. The reactor was then pressurized to $150 \mathrm{psi}$ with a gas mixture containing syngas and an argon tracer at a flow of $65 \mathrm{sccm}$. The reactor temperature was then adjusted to the desired value and the FT reaction was begun.

Calculations of $\mathrm{CO}$ conversion and consumption rates and of $\mathrm{CH}_{4}$ and $\mathrm{CO}_{2}$ selectivities were made using the following equations:

(1) CO conversion (fractional conversion):

$$
X_{C O}=\frac{(C O / A r)_{\text {product }}}{(C O / A r)_{\text {feed }}}
$$

(2) $\mathrm{CO}$ conversion rate $\left(\mathrm{mole} / \mathrm{g}_{\mathrm{cat}} \mathrm{s}\right)$ was calculated by assuming isothermal integral reaction (See details in APPENDIX).

$$
-r_{C O}=\eta k P_{C O}^{-0.24} P_{H_{2}}^{0.74}
$$

(3) $\mathrm{CH}_{4}$ selectivity (mole \%) 


$$
S_{\mathrm{CH}_{4}}=\frac{100 \times\left(\mathrm{CH}_{4} / \mathrm{Ar}\right)_{\text {product }}}{(\mathrm{CO} / \mathrm{Ar})_{\text {feed }} \times X_{C O}-S_{\mathrm{CO}_{2}} \times X_{C O}}
$$

(4) $\mathrm{CO}_{2}$ selectivity (mole \%)

$$
S_{\mathrm{CO}_{2}}=\frac{100 \times\left(\mathrm{CO}_{2} / \mathrm{Ar}\right)_{\text {product }}}{(\mathrm{CO} / \mathrm{Ar})_{\text {feed }} \times X_{c o}}
$$

\section{RESULTS AND DISCUSSION}

\section{Chemical Analysis of Catalysts}

Catalysts prepared in this study and their compositions determined by atomic absorption (AA) are tabulated in Table 3. Most catalysts have a Fe wt $\%$ of about $10 \%$ with deviation in reasonable range of instrument error. Three catalysts have been used for statistically designed fixed reactor tests: Fe-S-201, FePt-S220 and FePtK-S-218.

\section{BET Surface Area Measurements and Hydrothermal Stability Tests}

The thermal stability of Davisil 644 was tested by heating separate samples in air for $24 \mathrm{~h}$ at a temperature ranging from $200^{\circ} \mathrm{C}$ to $800^{\circ} \mathrm{C}$. BET surface area (SA) is plotted against furnace temperature in Fig 1. It is shown that the BET surface area first decreases sharply from $200^{\circ} \mathrm{C}$ to $400^{\circ} \mathrm{C}$, then levels off at 400,500 and $600^{\circ} \mathrm{C}$. After the furnace temperature exceeds $600^{\circ} \mathrm{C}$, the surface area starts to drop sharply again. The purpose of heating Davisil 644 support was to dehydroxylate the support; generally a temperature of $600-800^{\circ} \mathrm{C}$ is needed for substantial removal of hydroxyl groups. Hence a trade-off was to select $600^{\circ} \mathrm{C}$ as the support heating temperature.

Changes in BET surface area for impregnated iron catalysts after drying, calcination, and fixed bed reaction are shown in Table 4 . After drying at $80^{\circ} \mathrm{C}$ for $24 \mathrm{~h}$, both catalysts (Fe-S203, FePt-S-203) have BET surface areas of about $240 \mathrm{~m}^{2} /$ gcat $\left(244 \mathrm{~m}^{2} /\right.$ gcat and $241 \mathrm{~m}^{2} /$ gcat 
respectively). The unpromoted iron catalyst (Fe-S-206) appears to lose two-third of its surface area after a $55 \mathrm{~h}$ fixed bed run; i.e., it has a BET surface area of only $67 \mathrm{~m}^{2} /$ gcat. The reason for this low surface area may be due in part to the incomplete removal of wax formed during the fixed bed run, which is likely to block the pore structures of this catalyst. Similarly, FePt-S-206 only has a surface area of $45 \mathrm{~m}^{2} /$ gcat after $140 \mathrm{~h}$ fixed bed run. After fixed bed run and Soxhlet wax extraction at $110^{\circ} \mathrm{C}$, the "true" BET surface area of catalysts such as FePtK-S-215 and FePtK-S-216 can be measured, only a slight decrease in surface area are observed with two catalysts having a BET surface area of 236 and $225 \mathrm{~m}^{2} / \mathrm{gcat}$ respectively.

It is shown in Fig 2 that steam partial pressures for Fe and Co FTS catalysts under high conversion reaction condition are in the range of 0.5 to 3 atm. Fe FTS catalysts operate at significantly lower water partial pressures (0.5-0.8 atm) because of their high WGS activities. The hydrothermal stabilities of silica support and modified silica supports were tested at water partial pressures in a range of 0 to 5 atm $(0,1.0,2.0$ and $5.0 \mathrm{~atm})$. The results of hydrothermal stability tests in a fixed bed reactor are plotted in Fig 3 for three different silica supports (pure Davisil 644 silica, 3 wt $\% \mathrm{FeAl}_{2} \mathrm{O}_{4} / \mathrm{SiO}_{2}$ and $20 \mathrm{wt} \% \mathrm{CaAl}_{2} \mathrm{O}_{4} / \mathrm{SiO}_{2}$ modified support). Apparently fresh Davisil 644 support is not hydrothermally stable when exposed to steam partial pressures above 1 atm. Addition of iron aluminates or calcium aluminates improves the hydrothermal stability. At a water partial pressure of 5 atm, the calcium alumninate modified support maintains the highest BET surface area, while the iron aluminate modified support has the second largest BET surface area $\left(98 \mathrm{~m}^{2} / \mathrm{g}\right)$. Davisil 644 silica only has a BET surface area of $60 \mathrm{~m}^{2} / \mathrm{g}$ after similar exposure. 
The effect of K promoter effect on thermal stability of Davisil 644 is shown in Fig 4 in the form of BET surface area versus K level. BET surface area decreases with increasing K promoter level. The BET surface area of the $0.2 \mathrm{wt} \% \mathrm{~K}$ promoted support is $8.8 \%$ lower than the value of $285 \mathrm{~m}^{2} / \mathrm{g}$ for unpromoted silica. However, upon treatment at $800^{\circ} \mathrm{C}$ for 24 $\mathrm{h}$, the surface area of $3 \% \mathrm{~K} /$ Silica drops to essentially zero compared to $190 \mathrm{~m}^{2} / \mathrm{g}$ for unpromoted silica under the same conditions.

\section{Thermal Gravimetric Analysis (TGA)}

TGA studies including TPAr (temperature programmed heating in flowing argon), TPR (temperature programmed reduction in $\mathrm{H}_{2}$ ) and TPO (temperature programmed oxidation in $\mathrm{O}_{2}$ ) were carried out on dried unpromoted iron catalysts.

The TPAr spectrum of Fe-S-203 is illustrated in Fig 5. The low temperature peak around 50 to $100^{\circ} \mathrm{C}$ is attributed to loss of water from the supported iron catalyst. Two large overlapping peaks at $200-295^{\circ} \mathrm{C}$ are assigned to the decomposition of iron nitrates to iron oxides.

The TPR spectrum of Fe-S-207 after $24 \mathrm{~h}$ drying at $80^{\circ} \mathrm{C}$ is shown in Fig 6. Three peaks are observed during reduction. The first peak around $200^{\circ} \mathrm{C}$ is probably nitrate decomposition. The second peak around $280^{\circ} \mathrm{C}$ is probably due to reduction of $\mathrm{Fe}_{2} \mathrm{O}_{3}$ to $\mathrm{Fe}_{3} \mathrm{O}_{4}$. The last peak at $370^{\circ} \mathrm{C}$ could correspond to $\mathrm{FeO}$ being reduced to $\mathrm{Fe}$. An estimate of the degree of reduction of $>90 \%$ at $500^{\circ} \mathrm{C}$ can be obtained from this spectrum. It is evident that some species in the unpromoted iron catalyst (Fe-S-207) are difficult to reduce in $\mathrm{H}_{2}$ even at $370-400^{\circ} \mathrm{C}$. At less than $370^{\circ} \mathrm{C}$, the extent of reduction of is probably less than $75 \%$.

The effects of addition of a noble metal promoter Pt on extent of reduction of iron FTS catalyst are illustrated in Fig 7 and Fig 8. In Fig 7, a dramatic decrease in reduction 
temperature is observed for $\mathrm{FePt} / \mathrm{SiO}_{2}$ catalyst after calcination at $150^{\circ} \mathrm{C}$ and $200^{\circ} \mathrm{C}$ for 3 and $6 \mathrm{~h}$ respectively. It is evident that more than $90 \%$ of the iron is reduced to the metal at 400 $420^{\circ} \mathrm{C}$. A similar conclusion can be drawn after comparing the three spectra in Fig 8 , where both FePt-S-206 and FePtK-S-209 have lower reduction temperatures and higher extents of reduction relative to unpromoted Fe. This demonstrates that $\mathrm{Pt}$ significantly improves the reduction of $\mathrm{Fe} / \mathrm{SiO}_{2}$ catalyst prepared by evaporative deposition.

\section{Chemisorption Tests}

$\mathrm{H}_{2}$ chemisorption and dispersion were measured on calcined catalysts and several catalysts after statistically designed experiments and Soxhlet wax extraction (see Table 5). The average $\mathrm{H}_{2}$ uptake of the unpromoted iron catalyst Fe-S-201 (10.7 wt $\% \mathrm{Fe} / \mathrm{SiO}_{2}$ ) after calcination at $200^{\circ} \mathrm{C}$ and reduction in $\mathrm{H}_{2}$ at $300^{\circ} \mathrm{C}$ for $16 \mathrm{~h}$ is $44.5 \mu$ mole/gm-catalyst in three repeated measurements; dispersion is $7.7 \%$. After fixed bed reactor (FBR) run \#01 and Soxhlet wax extraction, dispersion unexpectedly increases to an average of $10.4 \%$. This small but significant increase could be due to formation of small crystallites of iron carbide. This phenomenon is not observed, however, for the same catalyst after FBR run \#08. Its dispersions are essentially the same as those for calcined Fe-S-201 before reaction with an average of $6.9 \%$. For calcined FePt-S-220 and FePtK-S-218, a trend of increases both in $\mathrm{H}_{2}$ uptake and dispersion after reaction were observed. The average $\mathrm{H}_{2}$ uptake for FePt-S-220 is $51.1 \mu \mathrm{mol} / \mathrm{gcat}$, while for FePtK-S-218 is $56.5 \mu \mathrm{mol} / \mathrm{gcat}$. Dispersions of promoted catalysts are based on an assumption that $80 \% \mathrm{Fe}$ and $100 \% \mathrm{Pt}$ is reduced; these assumptions are in turn based on TPR (in $\mathrm{H}_{2}$ ) data. The standard deviation of the uptakes for these two catalysts after statistically designed fixed bed runs were observed to increase, and unexpected increases in $\mathrm{H}_{2}$ uptakes and dispersions were observed. The larger deviation could be due to 
incomplete wax removal from the pores of these catalysts. But after the surface was cleaned by a few reductions, the apparent dispersions of these two catalysts after FBR runs are significantly lower. For FePt-S-220 after FBR run \#09, 4.9\%, while for FePtK-S-218 after FBR run $\# 07$, the dispersions in third and fourth measurements were $5.1 \%$, and $6.6 \%$ respectively.

\section{Mössbauer Spectroscopy}

A series of spectra collected after fixed bed runs is shown in Fig 9, 10 and 11. Corresponding Mössbauer parameters are listed in Table 6 and Table 7. The spectral areas of iron species of these spectra are summarized in Table 8. The spectral area of $\mathrm{Fe}_{2.5} \mathrm{C}$ in unpromoted catalyst Fe-S-206 is only $25.6 \%$, compared to $49.3 \%(298 \mathrm{~K})$ and $51.5 \%$ (77 K) for Pt promoted catalyst FePt-S-203. Thus, the Pt promoter significantly enhances formation of $\mathrm{Fe}_{2.5} \mathrm{C}$ as well as activity in fixed bed runs, suggesting that activity correlates with carbide content. The slightly higher spectral area for $\mathrm{Fe}_{2.5} \mathrm{C}$ and significantly lower area in small superparamagnetic $\mathrm{Fe}_{3} \mathrm{O}_{4}$ crystallites at liquid $\mathrm{N}_{2}$ temperature indicates that fractions of superparamagnetic $\mathrm{Fe}_{2.5} \mathrm{C}$ and $\mathrm{Fe}_{3} \mathrm{O}_{4}$ have become ferromagnetic at liquid $\mathrm{N}_{2}$ temperature.

Effects of pretreatment on iron phase transformations were studied in an in situ temperature-controlled reactor cell containing a 1-inch $0.3 \mathrm{~g}$ catalyst wafer of Fe-S-207. The Mössbauer spectrum collected at room temperature after in situ treatment with $\mathrm{H}_{2} / \mathrm{CO}=1$ is shown in Fig. 12; corresponding Mössbauer parameters are listed in Table 9. It is evident that iron phases were reduced during the $16 \mathrm{~h}$ pretreatment at $280^{\circ} \mathrm{C}$ in syngas $(\mathrm{H} / \mathrm{CO}=1)$, i.e., $\mathrm{Fe}_{2} \mathrm{O}_{3}$ was converted to a mixture of ferromagnetic $\mathrm{Fe}_{3} \mathrm{O}_{4}\left(10.3 \%\right.$ ), superparamagnetic $\mathrm{Fe}_{3} \mathrm{O}_{4}$

$(68.2 \%), \mathrm{Fe}^{2+}(7.5 \%)$ and $\chi-\mathrm{Fe}_{2.5} \mathrm{C}(14.0 \%)$. The peak of low intensity at about $0.89 \mathrm{~mm} / \mathrm{s}$ (Fig 12) has an isomer shift and quadruple splitting parameters matching these (Table 9) of 
$\mathrm{Fe}^{2+}$. Thus, for this unpromoted catalyst subjected to $16 \mathrm{~h}$ pretreatment in the Mössbauer cell at $280^{\circ} \mathrm{C}$ and $1 \mathrm{~atm}$, only $14 \% \chi-\mathrm{Fe}_{2.5} \mathrm{C}$ was formed. This lower than expected extent of reduction is to some degree a result of the abbreviated time and low pressure of treatment and in part an artifact of the cell design, i.e. gas flow around but not through the sample. We have redesigned the cell with the introduction of two hollow rings with holes directing gas towards the sample on both sides of the catalyst wafer and a provision for high-pressure treatment. With this improved Mössbauer cell, a series of in-situ pretreatment studies will be carried out.

Mössbauer spectra of three catalysts (Fe-S-210, FePt-S-220 and FePtK-S-218) collected at $25^{\circ} \mathrm{C}$ after $150 \mathrm{~h}$ statistically designed FBR runs are shown in Figs 13-21; corresponding Mössbauer parameters are listed in Table 10-18. The spectra areas of different iron phases are summarized in Table 19. A significant fraction (about 50\%) is present as magnetite $\left(\mathrm{Fe}_{3} \mathrm{O}_{4}\right)$ in all catalysts after reaction; However, the amount of $\mathrm{Fe}_{2.5} \mathrm{C}$ is significantly different for different catalysts. For example, after 150 h FBR run \#01 Fe-S-201 only contains 17.5\% Hagg carbide, while Pt promoted FePtK-S-218 is observed to contain $44.2 \% \mathrm{Fe}_{2.5} \mathrm{C}$ after run \#7. This difference is due in part to promoter effects as well as test run conditions, e.g. pretreatment and reaction temperatures.

Syngas conversion ( $\mathrm{CO}$ conversion) and iron carbide content $\left(\mathrm{Fe}_{2.5} \mathrm{C}\right)$ are plotted in Fig 22 for all catalysts after the statistically designed FBR runs. A fairly strong correlation is observed between iron carbide content and FT activity for catalysts after $150 \mathrm{~h}$ FBR reaction except run \#08. This observation agrees with the consensus that Hagg carbide $\left(\mathrm{Fe}_{2.5} \mathrm{C}\right)$ is the active phase. For example, Fe-S-201 at the end of run \#1 has the lowest activity (CO conversion 11\%), corresponding to lowest iron carbide content of $17.5 \%$ in spectra area. The 
loss of active phase surface area due to carbon deposition or graphitic carbon formation could also lead to deactivation, especially on the surface layer of the active iron carbide. A detailed statistical analysis will be done after all runs are finished.

\section{Activity Tests}

\section{Catalyst Activity and Stability}

Measurements of catalyst activities in terms of $\mathrm{CO}$ conversion were carried out in preliminary and statistically designed FBR runs. The purpose of these preliminary runs was to test the effects of Pt promoter and the repeatability of the fixed bed runs and to have preliminary information about the effects of pretreatment. Following these runs, $23,150 \mathrm{~h}$ statistically designed experiments were carried out on three catalysts (Fe-S-210, FePt-S-220 and FePtK-S-218).

The effects of Pt and K promoters on activity are shown by comparison for FePtK-S-215 and Fe-S-201 in Fig 23. Compared to the unpromoted catalyst which reaches a maximum CO conversion of about $84 \%$, the Pt and K promoted catalyst achieves a CO conversion of $97 \%$. But CO conversions for both catalysts level off at about $80 \%$ after 130 h FBR run. A remarkable repeatability was observed in Fig 24 for FePtK-S-215 and FePtK-S-216 (two separate batches). Both catalysts reached a maximum conversion of $97 \%$ at about the same time and underwent a similar decline in activity during $140 \mathrm{~h}$ FBR runs.

The effects of pretreatment on promoted catalysts are shown in Fig 25. Three different pretreatment atmospheres were used: syngas $\left(\mathrm{H}_{2} / \mathrm{CO}=1.0\right)$, pure $\mathrm{H}_{2}$ and pure $\mathrm{CO}$. The activity of the catalyst pretreated in syngas was initially low but increased to a maximum of $97 \%$, after which its activity declined significantly. On the contrary, the activity of the catalyst pretreated in $\mathrm{H}_{2}$ was initially about $80 \%$, then rapidly declined and stabilized at a 
conversion of about $70 \%$ after which little deactivation was observed. The $\mathrm{CO}$ conversion of the catalyst pretreated in $\mathrm{CO}$ increased very gradually to about $70 \%$ within $200 \mathrm{~h}$; moreover the activity was apparently still unvarying after 200 h. Further studies using in-situ Mössbauer spectroscopy and HRTEM are needed to understand these pretreatments effects at the nanoscale.

Before carrying out the statistically designed experiments, the effect of drying the catalyst before reaction was also studied. The result shown in Fig 26 clearly points to a higher activity for catalysts dried before activity testing. Based on these results we conclude that all catalysts should be stored in a desiccator and dried before FBR tests.

Steady-state activities and selectivities for selected unpromoted and promoted catalysts are summarized in Table 20. The promotional effect of $\mathrm{Pt}(0.5 \mathrm{wt} \%)$ may explain the higher activity of FePt-S-206. However, because FePt-S-203 was run at $265^{\circ} \mathrm{C}$ (lower than $270^{\circ} \mathrm{C}$ for the unpromoted iron catalyst fixed bed run), the conversion activity is not a great deal higher that that of unpromoted catalyst (Fe-S-206). While the promotional effect of Pt in iron FT catalysts still needs further study, the higher activity of Pt is likely due to improved reduction of iron oxide to active carbide. The higher activity stability may be due to the ability of noble metal to decompose coke precursors [Iglesia et al., 1993; Huber and Bartholomew, 2000] and prevent oxidation of the carbides.

\section{$\mathrm{CH}_{4}$ and $\mathrm{CO}_{2}$ Selectivities}

Methane and $\mathrm{CO}_{2}$ selectivities are also tabulated in Table 20. $\mathrm{CH}_{4}$ selectivities of $\mathrm{Pt}$ promoted catalysts are higher than for unpromoted catalysts $(9.5 \%$ and $10.5 \%$ compared to 2.6\%). $\mathrm{CO}_{2}$ selectivity for FePt-S-203 is lower than Fe-S-206 (33.3\% vs. 36.2), while for 
FePt-S-206, $\mathrm{CO}_{2}$ selectivity is higher than that of unpromoted catalyst (38.1\% vs. $36.2 \%$ ). The higher $\mathrm{CH}_{4}$ selectivity for Pt promoted Fe catalyst may be due to a higher hydrogenation activity, which is important in maintaining a clean metal surface and thus preventing fast deactivation. In terms of $\mathrm{CO}_{2}$ selectivities, the catalyst with $0.5 \mathrm{wt} \% \mathrm{Pt}$ has the lowest value of about $33 \%$ from $20 \mathrm{~h}$ to $60 \mathrm{~h}$ of run time, while the value for unpromoted and $1 \mathrm{wt} \% \mathrm{Pt}$ promoted catalyst are $35 \%$ and $38 \%$ respectively.

\section{CONCLUSIONS}

A rationally designed high activity FePtK catalyst supported on attrition-resistant silica was prepared using a non-aqueous (acetone) evaporative deposition technique. Preliminary study of pretreatment, drying effects on catalyst performance and repeatability has been done. 14 statistically designed FBR runs have been finished, room temperature Mössbauer spectra have been collected on 11 samples after run. Conclusions from the present work include the following:

1. Silica support collapse only happens at above 1 atm water partial pressure, with $\mathrm{FeAl}_{2} \mathrm{O}_{4}$ and $\mathrm{CaAl}_{2} \mathrm{O}_{4}$ coated silica support showing improved hydrothermal stability.

2. TPR results show an extent of reduction of $75 \%$ is achieved for $\mathrm{Fe} / \mathrm{SiO}_{2}$ at less than $370^{\circ} \mathrm{C}$. For Pt promoted catalysts, a marked decrease in reduction temperature is observed and $90 \%$ reduction of iron metal is possible at $400^{\circ} \mathrm{C}$.

3. Using in situ Mössbauer analysis, the following iron phase transformations are observed after a $16 \mathrm{~h}$ pretreatment at $280^{\circ} \mathrm{C}$ in syngas $(\mathrm{H} / \mathrm{CO}=1)$ at $1 \mathrm{~atm}: \mathrm{Fe}_{2} \mathrm{O}_{3}$ is converted to a mixture of ferromagnetic $\mathrm{Fe}_{3} \mathrm{O}_{4}(10.29 \%)$, superparamagnetic $\mathrm{Fe}_{3} \mathrm{O}_{4}(68.24 \%), \mathrm{Fe}^{2+}$ (7.49\%) and $\chi-\mathrm{Fe}_{2.5} \mathrm{C}(14 \%)$. The lower than expected extent of reduction is possibly due 
to the abbreviated time and low pressures of treatment and in part an artifact of the cell design leading to poor gas/solid contact.

4. The Pt promoter significantly improves the dispersion of iron particles on the silica support during reduction in $\mathrm{H}_{2}$ at $300^{\circ} \mathrm{C}$. During the FBR runs, dispersions of all catalysts decrease significantly.

5. After reacting for about 60 hours at $265^{\circ} \mathrm{C}$ and 10 atm followed by passivation, Ptpromoted iron $(0.5 \mathrm{wt} \% \mathrm{Pt})$ contains a greater percentage of $\chi-\mathrm{Fe}_{2.5} \mathrm{C}$ and a smaller percentage of superparamagnetic $\mathrm{Fe}_{3} \mathrm{O}_{4}$ relative to the unpromoted iron catalyst. Thus, Pt substantially enhances reduction of iron oxides to $\chi-\mathrm{Fe}_{2.5} \mathrm{C}$ while significantly reducing iron-silica support interactions. FePt-S-206 (containing $1 \% \mathrm{Pt}$ ) after testing at $265^{\circ} \mathrm{C}$ and $10 \mathrm{~atm}$ for a total of $140 \mathrm{~h}$ and careful passivation contains more superparamagnetic $\mathrm{Fe}_{3} \mathrm{O}_{4}(59.9 \%$ vs. $48.6 \%)$ and less $\mathrm{Fe}_{2.5} \mathrm{C}(40.2$ vs. 51.5\%) than that of FePt-S-203 (0.5 wt $\% \mathrm{Pt}, 60 \mathrm{~h}$ fixed bed run). This difference in phases distribution may be explained by the longer FTS reaction time for the $1 \mathrm{wt} \%$ Pt promoted iron catalyst in which more iron carbides are probably converted to superparamagnetic $\mathrm{Fe}_{3} \mathrm{O}_{4}$ during exposure to an oxidizing environment of product steam and $\mathrm{CO}_{2}$. No $\mathrm{Fe}^{2+}$ is observed too, which confirms that $\mathrm{Pt}$ promotes iron oxides reduction and inhibits the iron-silica support interaction.

6. The activity of Pt-promoted iron is higher than unpromoted iron. This higher activity of $\mathrm{Pt}$ is probably due to improved reduction of iron oxide to active carbide. The higher activity stability may be due to the ability of noble metal to decompose coke precursors and moderate oxidation of the carbides. 
7. A catalyst pretreated in syngas $\left(\mathrm{H}_{2} / \mathrm{CO}=1.0\right)$ has low initial activity and maximum activity, but deactivates after reaching peak activity; the activity of a catalyst pretreated in $\mathrm{H}_{2}$ is initially high and quickly levels off to a moderate steady-state activity; activity of a CO pretreated catalyst is initially low but increases gradually to a moderately high value; the activity of this catalyst continues to increase after 200 hours of testing.

8. The $\mathrm{CH}_{4}$ selectivity of the unpromoted iron catalyst is unexpectedly the lowest among the three catalysts tested. The higher $\mathrm{CH}_{4}$ selectivities for Pt promoted Fe catalyst may be due to a higher hydrogenation activity, which is important in maintaining a clean metal surface and thus preventing fast deactivation 


\section{REFERENCES}

Bukur, D. B., Lang, X., A precipitated iron Fischer-Tropsch catalyst for synthesis gas conversion to liquid fuels, Studies in Surface Science and Catalysis, 119 (1998), 113-118.

Bukur, D. B., Lang, X., Ding, Y., Pretreatment effect studies with a precipitated iron FischerTropsch catalyst in a slurry reactor, Applied Catalysis, 4683 (1999), 1-21.

Huber, G., W., Bartholomew, C. H., Conrad, T. L., Woolley, K. W., Guymon, C. G., Pt promotion of $\mathrm{Co} / \mathrm{SiO}_{2}$ Fischer-Tropsch synthesis catalysis, presented at American Chemical Society $219^{\text {th }}$ National Meeting, San Francisco, March 26-30, 2000.

Iglesia, E., Soled, S. L., Fiato, R. A., Via, G. H., Bimetallic Synergy in Cobalt-Ruthenium Fischer-Tropsch Synthesis Catalysts, Journal of Catalysis, 143 (1993), 345-368.

Pham, H., Attrition and SEM data, Unpublished Report, August 18, 1999.

Pham, H., Personal Communication, Feb 2000. 
Table 3. Catalyst codes and compositions determined by atomic absorption

\begin{tabular}{|c|c|c|c|c|c|}
\hline Catalyst Code $^{\mathrm{a}}$ & Support & $\mathrm{Fe}$ wt $\%$ & K wt $\%$ & $\mathrm{Pt}$ wt $\%$ & $\mathrm{Al} \mathrm{wt} \%$ \\
\hline Fe-S-201 & Davisil 644 & 10.7 & - & - & - \\
\hline Fe-S-202 & Davisil 635 & & - & - & - \\
\hline FePt-S-203 & Davisil 635 & - & - & $0.5^{\mathrm{a}}$ & - \\
\hline Fe-S-206 & Davisil 644 & 10.05 & - & - & - \\
\hline FePt-S-206 & Davisil 644 & - & - & - & - \\
\hline Fe-S-207 & \multirow{8}{*}{ Davisil 644} & - & - & - & - \\
\hline FePtK-S-209 & & 11.11 & 0.21 & 1.53 & - \\
\hline FePtKAl-S-212 & & 10.36 & 0.46 & 0.38 & - \\
\hline $\begin{array}{l}\text { FePtK-215 after fixed bed } \\
\text { run }^{\text {b }}\end{array}$ & & 6.82 & 0.53 & 0.45 & - \\
\hline FePtK-S-216 & & 11.4 & 0.93 & 1.01 & - \\
\hline FePtK-S-217 & & 11.1 & 0.88 & 0.90 & - \\
\hline $\begin{array}{l}\text { FePtK-216 after fixed bed } \\
\text { run }^{\mathrm{b}}\end{array}$ & & 6.39 & 0.38 & 0.48 & - \\
\hline FePtK-S-218 & & 9.25 & - & - & - \\
\hline FePt-S-220 & & 11.54 & - & - & - \\
\hline
\end{tabular}

${ }^{\mathrm{a}}$ Calcined catalysts contain about $10-12 \% \mathrm{Fe}, 0.2-0.9 \% \mathrm{~K}, 0.5-1.0 \% \mathrm{Pt}$, calcined at $200^{\circ} \mathrm{C}$ for $3 \mathrm{~h}$ in flowing $\mathrm{He}$

${ }^{\mathrm{b}}$ After reaction, wax removed

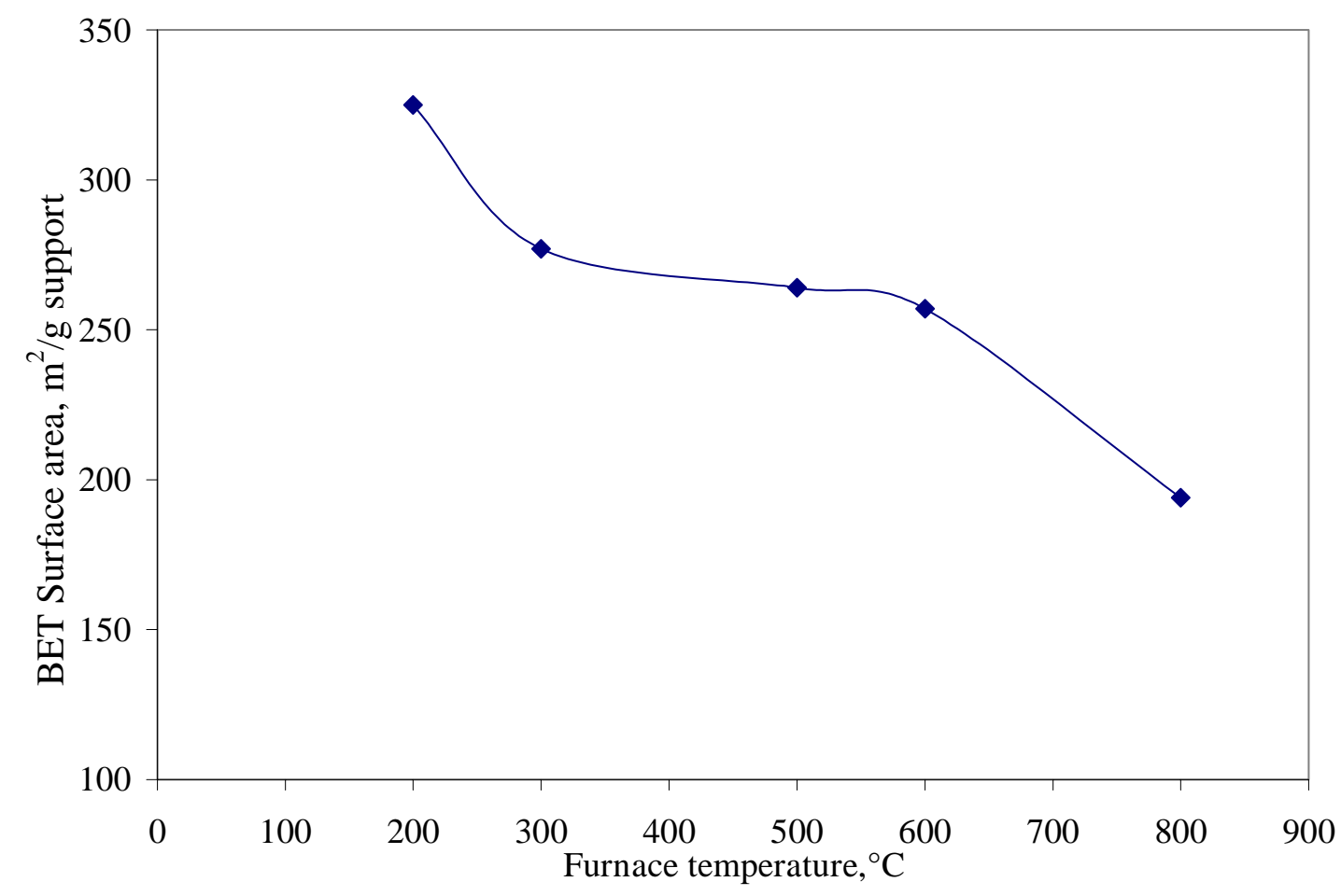

Fig 1. Thermal stability of Davisil 644 support after heating in air for $24 \mathrm{~h}$ at different temperatures. 
Table 4. BET surface area of catalysts Davisil supported on $635^{\mathrm{a}}$ and Davisil $644^{\mathrm{b}}$

\begin{tabular}{|c|c|c|c|}
\hline \multirow[t]{2}{*}{ Catalyst Code } & \multirow[t]{2}{*}{ Treatment or Test Runs } & \multicolumn{2}{|c|}{$\begin{array}{l}\text { BET Surface Area } \\
\mathrm{m}^{2} / \mathrm{g}\end{array}$} \\
\hline & & Run \#1 & Run \#2 \\
\hline $\mathrm{Fe}-\mathrm{S}-203^{\mathrm{a}}$ & Afterdried @80², 24 h & 244 & - \\
\hline FePt-S-203 ${ }^{\mathrm{a}}$ & Afterdried @ $80^{\circ} \mathrm{C}, 24$ h, & 241 & - \\
\hline Fe-S-206 ${ }^{b}$ & $\begin{array}{l}\text { After } 55 \mathrm{~h} \text { fixed bed run } \mathrm{T}=270^{\circ} \mathrm{C} \\
\mathrm{P}=150 \mathrm{psi} \text {, wax not removed }\end{array}$ & 67 & - \\
\hline FePt-S-206 ${ }^{b}$ & After $140 \mathrm{~h}$ fixed bed run, wax not removed & 45 & - \\
\hline FePt-S-209b & Fresh catalyst & 266 & - \\
\hline FePt-S-209b & After fixed bed run and wax not removed & 7.5 & - \\
\hline FePtK-S-213 ${ }^{b}$ & $\begin{array}{l}\text { After fixed bed run and wax removed in toluene } \\
\text { solvent }\end{array}$ & 240 & 208 \\
\hline FePtK-S-215 & Fixed Bed Run and Wax not removed & 145 & - \\
\hline FePtK-S-215 & Fixed Bed Run and Soxhlet Wax Removal & 236 & 222 \\
\hline FePtK-S-216 & Fresh catalyst calcined in $\mathrm{He} @ 200^{\circ} \mathrm{C}$ & 296 & - \\
\hline FePtK-S-216 ${ }^{b}$ & Fixed Bed Run and Soxhlet Wax Removal & 225 & - \\
\hline
\end{tabular}




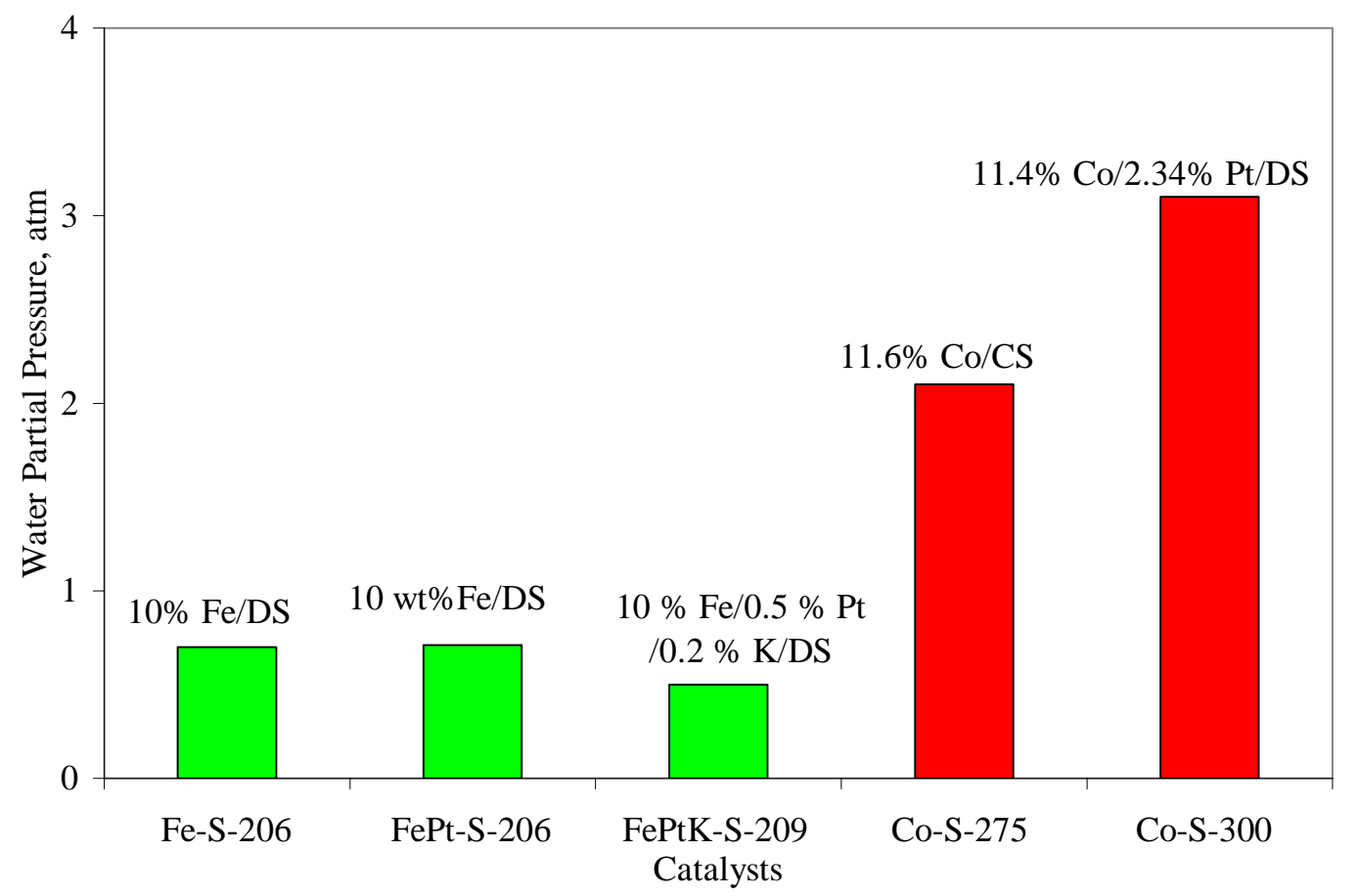

Fig 2. Calculated Water Partial Pressures at Fixed Bed Run Conditions (DS = Davisil 644, $\mathrm{CS}=\mathrm{Cab}-\mathrm{O}-\mathrm{Sil})$

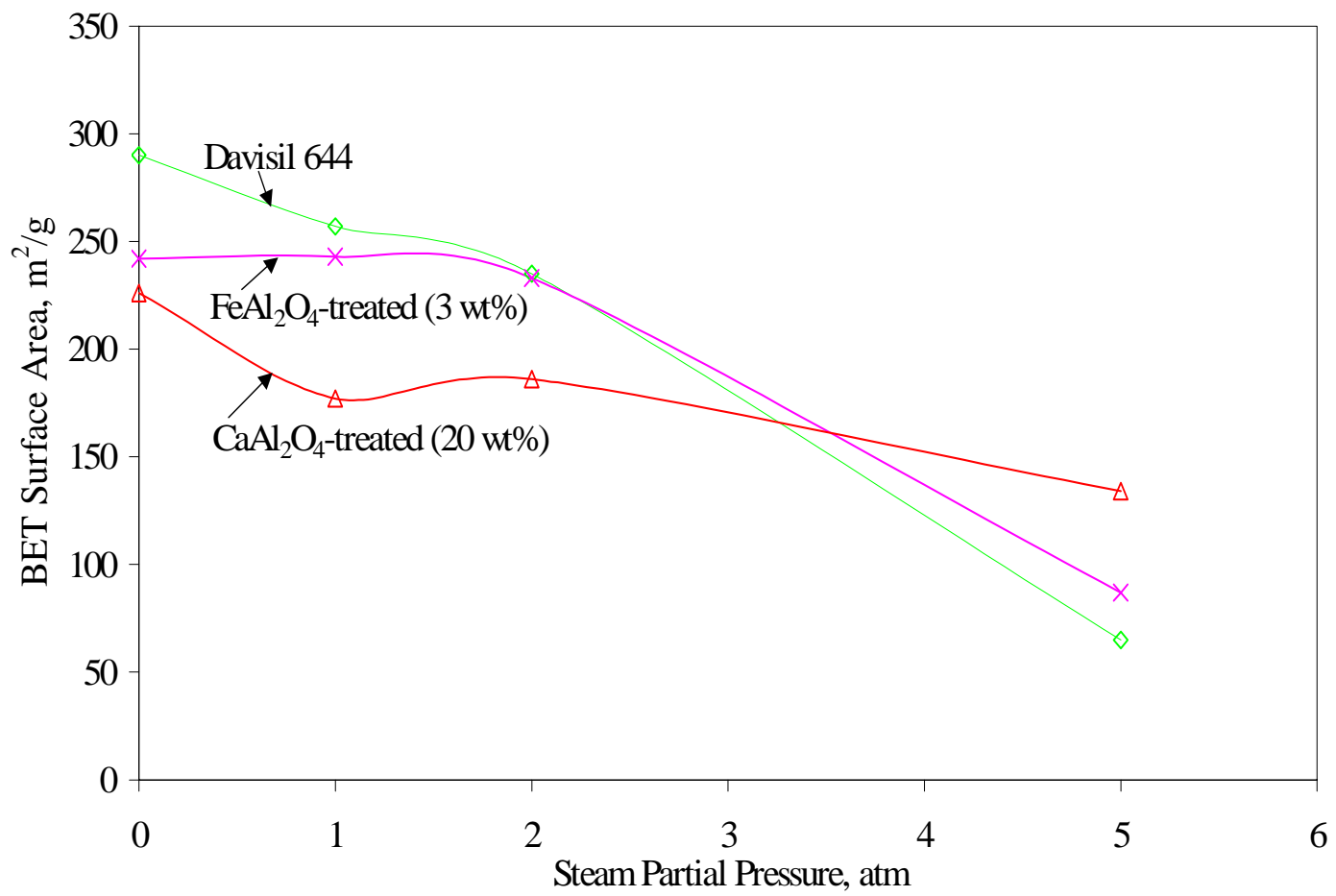

Fig 3. Hydrothermal Stability of Davisil 644 Silica support and $\mathrm{FeAl}_{2} \mathrm{O}_{4}$ Modified Davisil 644 Support ( $72 \mathrm{~h}$ steam treatment at $\mathrm{P}_{\text {total }}=10 \mathrm{~atm}, \mathrm{~T}=265^{\circ} \mathrm{C}$, repeat every run) BET Surface Area Thermal Stability of Davisil 644 


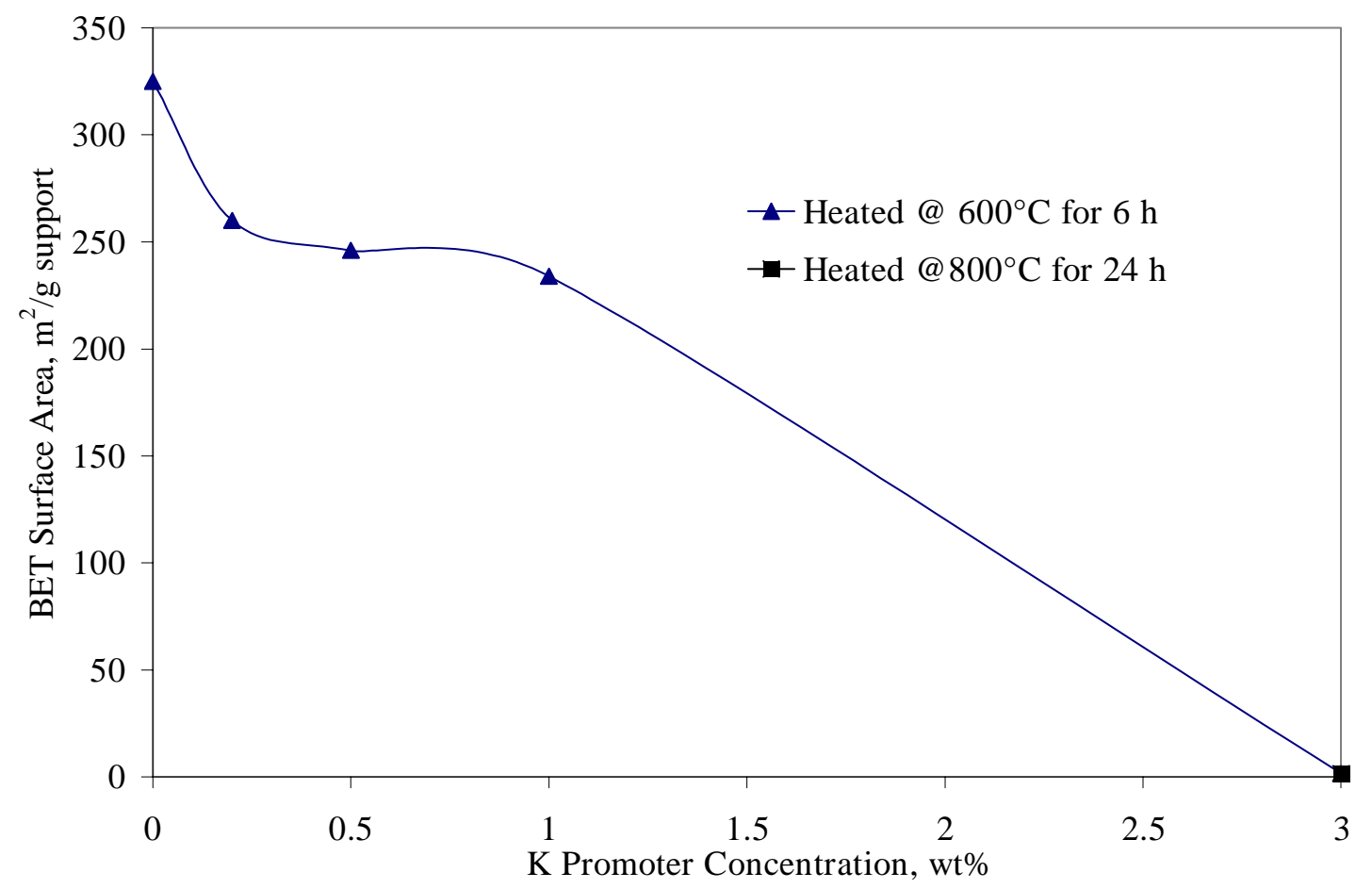

Fig 4. K Promoter Effects on BET Thermal Stability of Davisil 644

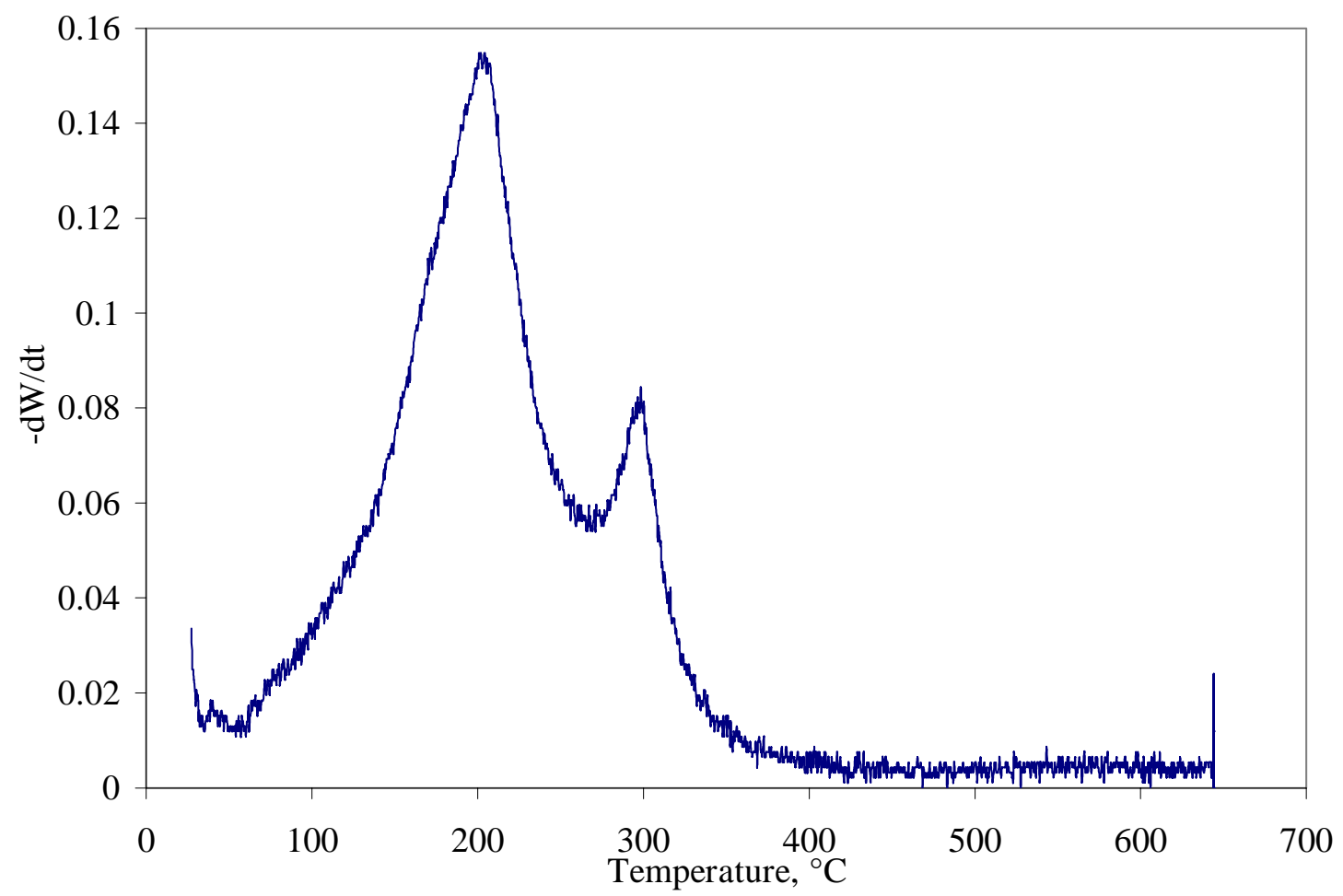

Fig 5. TPAr of Fe-S-207 after drying at $80^{\circ} \mathrm{C} 24 \mathrm{~h}$ 


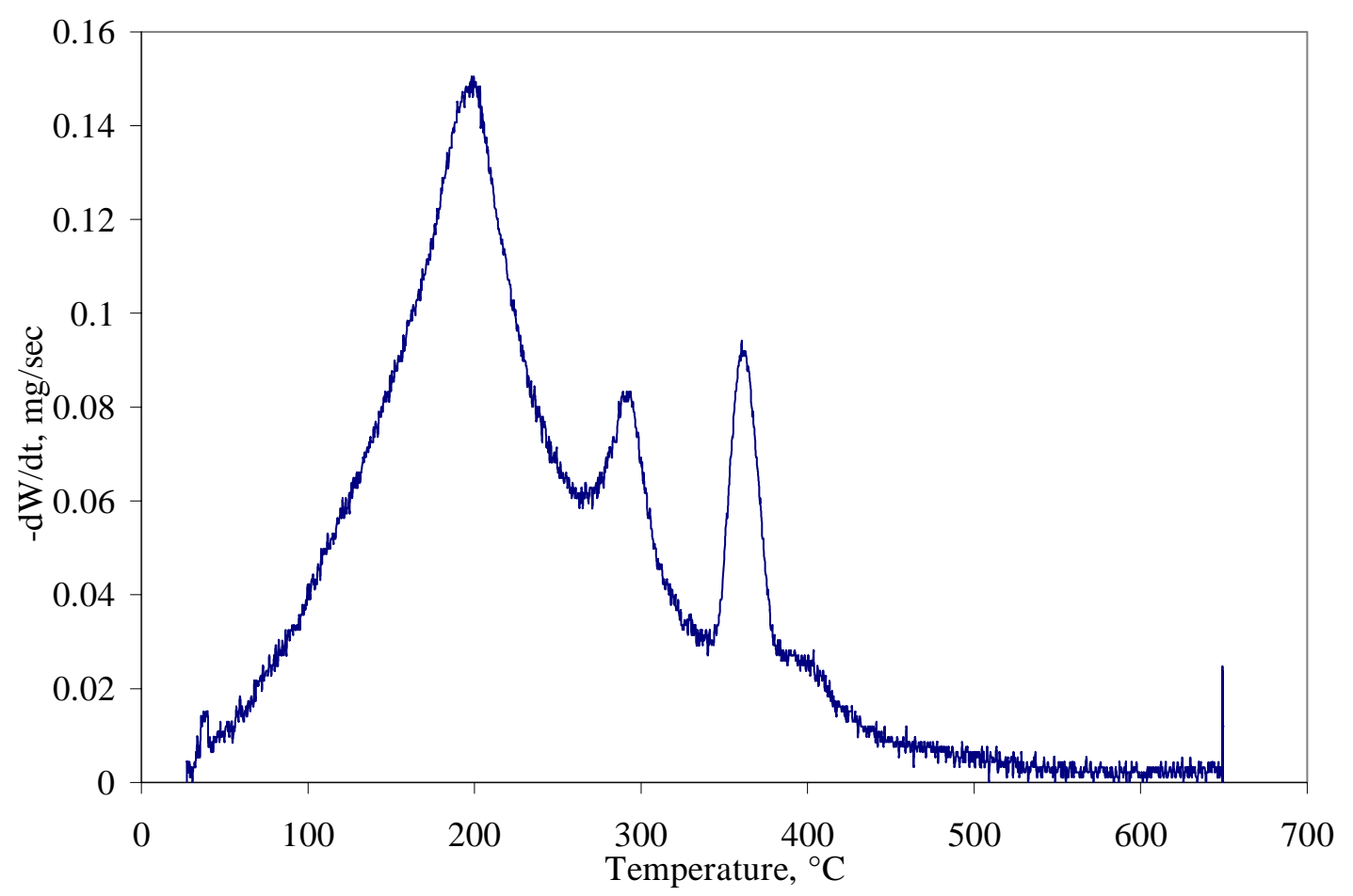

Fig 6. TPR of Fe-S-207 fresh catalyst after drying at $80^{\circ} \mathrm{C}$ for $24 \mathrm{~h}$

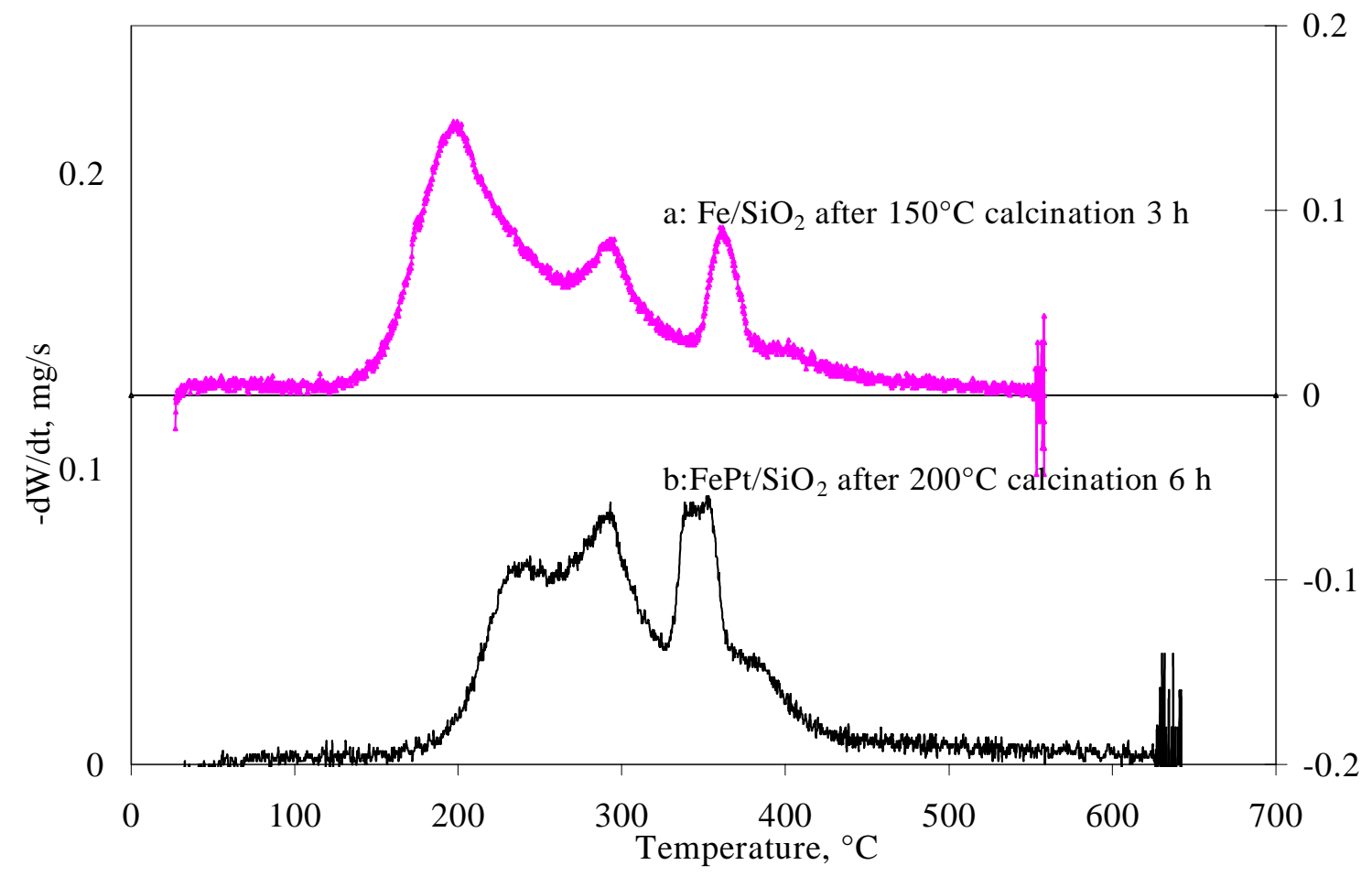

Fig 7. TPR of calcined Fe-S-207 and FePt-S-207 


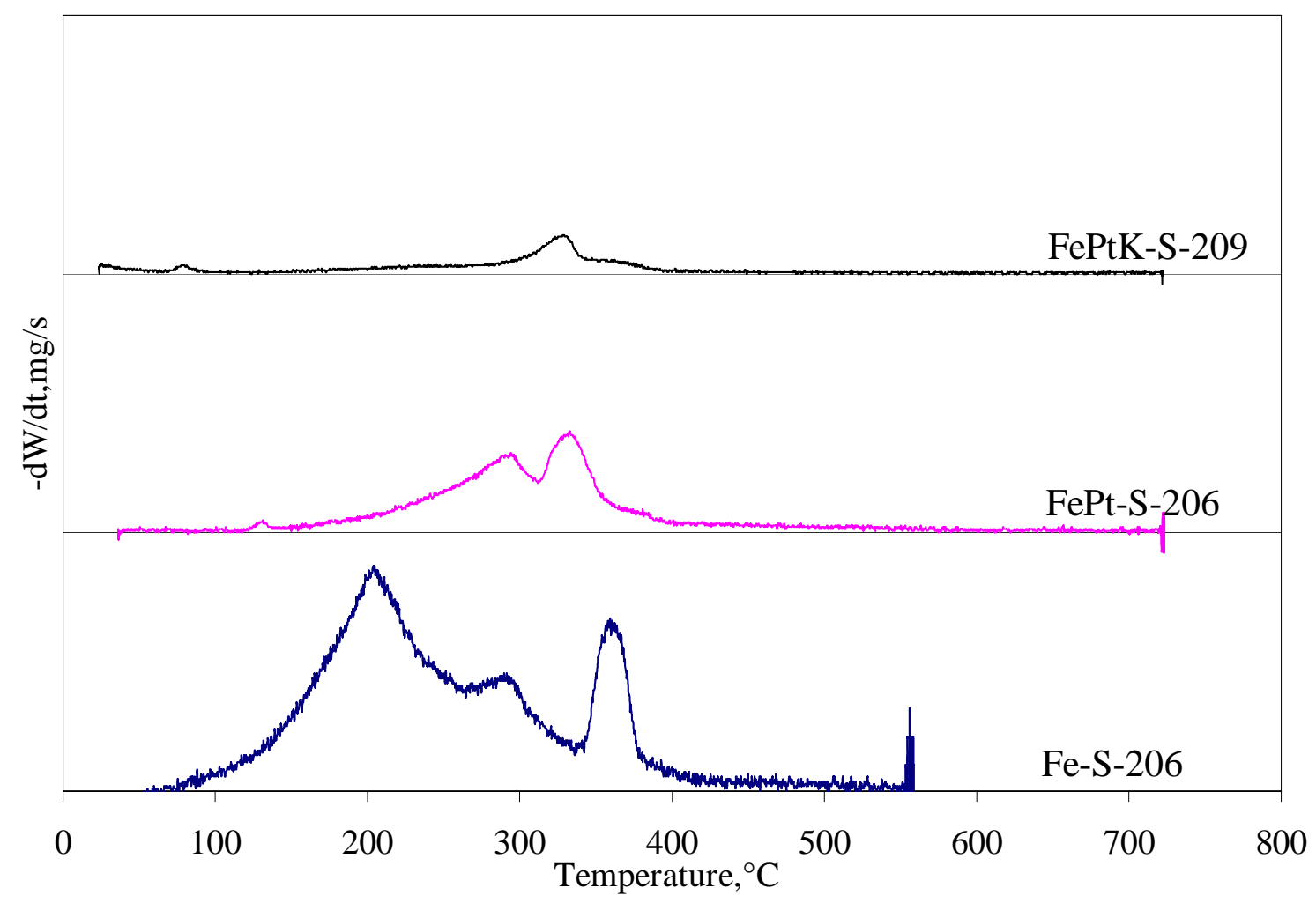

Fig 8. TPR of Unpromoted and Promoted Fe Catalysts after $150^{\circ} \mathrm{C} 3 \mathrm{~h}$ calcinations 
Table 5. $\mathrm{H}_{2}$ Chemisorption and Dispersion Measurements

\begin{tabular}{|c|c|c|c|}
\hline Catalyst Code & $\begin{array}{l}\text { Extent of Reduction at } 300^{\circ} \mathrm{C} \\
(\%)^{\mathrm{a}}\end{array}$ & $\begin{array}{l}\mathrm{H}_{2} \text { Uptake } \\
(\mu \text { mole/gm catalyst })\end{array}$ & $\begin{array}{l}\text { Dispersion } \\
(\%)\end{array}$ \\
\hline \multirow[t]{3}{*}{ Fe-S-201 (calcined ${ }^{\mathrm{b}}$ ) } & \multirow[t]{4}{*}{80} & 41.5 & 7.2 \\
\hline & & 44.1 & 7.7 \\
\hline & & 47.9 & 8.3 \\
\hline Average/Standard Deviation & & $44.5 \pm 3.2$ & $7.7 \pm 0.6$ \\
\hline \multirow{4}{*}{$\begin{array}{l}\text { Fe-S-201 after FBR run } 01 \\
\text { and wax extraction }\end{array}$} & \multirow[t]{5}{*}{80} & 71.3 & 12.4 \\
\hline & & 50.3 & 8.8 \\
\hline & & 69.2 & 12.0 \\
\hline & & 47.5 & 8.3 \\
\hline Average/Standard Deviation & & $59.6 \pm 12.4$ & $10.4 \pm 2.1$ \\
\hline \multirow{4}{*}{$\begin{array}{l}\text { Fe-S-201 after FBR run } 08 \\
\text { and wax extraction }\end{array}$} & \multirow[t]{5}{*}{80} & 52.8 & 7.4 \\
\hline & & 52.9 & 7.4 \\
\hline & & 36.4 & 5.1 \\
\hline & & 54.5 & 7.6 \\
\hline Average/Standard Deviation & & $49.1 \pm 8.5$ & $6.9 \pm 1.2$ \\
\hline \multirow[t]{3}{*}{ FePt-S-220 (calcined ${ }^{\mathrm{b}}$ ) } & \multirow[t]{4}{*}{$80(\mathrm{Fe}), 100(\mathrm{Pt})$} & 67.7 & 8.6 \\
\hline & & 46.9 & 5.9 \\
\hline & & 38.7 & 4.9 \\
\hline Average/Standard Deviation & & $51.1 \pm 14.9$ & $6.5 \pm 1.9$ \\
\hline \multirow{3}{*}{$\begin{array}{l}\text { FePt-S-220 after FBR run } 09 \\
\text { and wax extraction }\end{array}$} & \multirow[t]{4}{*}{$80(\mathrm{Fe}), 100(\mathrm{Pt})$} & 71.0 & 9.0 \\
\hline & & 116.8 & 14.8 \\
\hline & & 38.7 & 4.9 \\
\hline Average/Standard Deviation & & $75.5 \pm 39.2$ & $9.6 \pm 5.0$ \\
\hline \multirow[t]{3}{*}{ FePtK-S-218 calcined $^{\mathrm{b}}$ ) } & \multirow[t]{4}{*}{$80(\mathrm{Fe}), 100(\mathrm{Pt})$} & 64.1 & 8.1 \\
\hline & & 67.0 & 8.5 \\
\hline & & 38.4 & 4.9 \\
\hline Average/Standard Deviation & & $56.5 \pm 15.7$ & $7.2 \pm 2.0$ \\
\hline FePtK-S-218 after FBR run & \multirow[t]{4}{*}{$80(\mathrm{Fe}), 100(\mathrm{Pt})$} & 173.2 & 22.0 \\
\hline \multirow[t]{2}{*}{05 and wax extraction } & & 48.3 & 6.1 \\
\hline & & 92.6 & 11.8 \\
\hline Average/Standard Deviation & & $104.7 \pm 63.3$ & $13.3 \pm 8.0$ \\
\hline FePtK-S-218 after FBR run & $80(\mathrm{Fe}), 100(\mathrm{Pt})$ & 180.1 & 25.1 \\
\hline \multirow[t]{3}{*}{07 and wax extraction } & & 218.0 & 30.4 \\
\hline & & 36.4 & 5.1 \\
\hline & & 47.1 & 6.6 \\
\hline Average/Standard Deviation & & $120.4 \pm 92.2$ & $16.8 \pm 12.9$ \\
\hline
\end{tabular}

${ }^{a}$ Estimated value measured by TPR.

${ }^{\mathrm{b}}$ Catalyst calcined at $200^{\circ} \mathrm{C}$ in $\mathrm{He}$ for $3 \mathrm{~h}$.

${ }^{c} \mathrm{H}_{2}$ reduction profile: increase at $1^{\circ} \mathrm{C} / \mathrm{min}$ from room temperature to $300^{\circ} \mathrm{C}$ and keep $16 \mathrm{~h}$. 


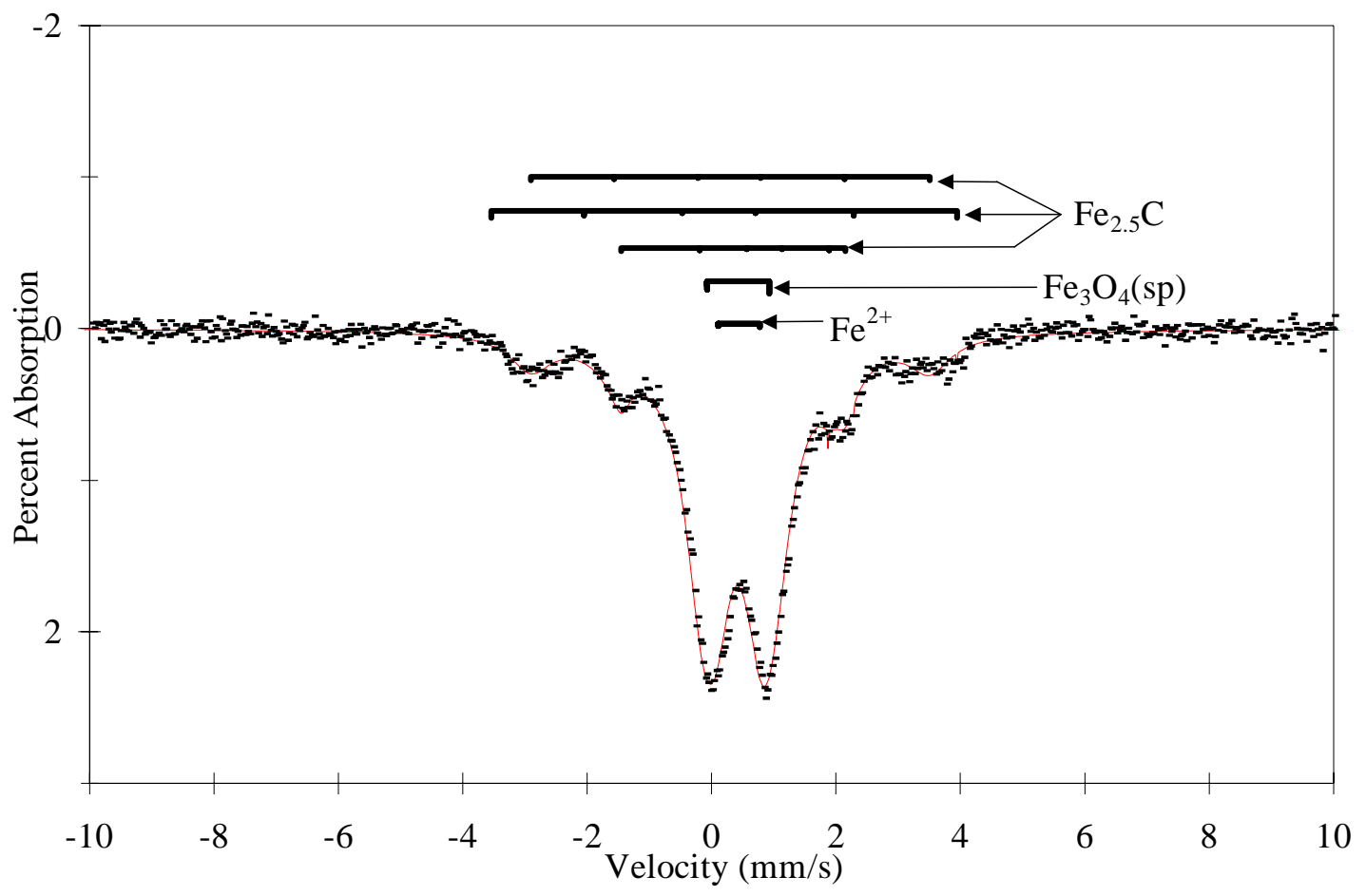

Fig 9. Fe-S-206 After 55hrs fixed bed test run

Table 6. Mössbauer spectroscopy parameters of Fe-S-206 after $55 \mathrm{~h}$ fixed bed run at $270^{\circ} \mathrm{C}, 10 \mathrm{~atm}, \mathrm{H}_{2} / \mathrm{CO}=1$.

\begin{tabular}{|c|c|c|c|c|c|c|}
\hline Species & $\begin{array}{r}\text { Iron } \\
\text { site } \\
\end{array}$ & $\begin{array}{l}\mathrm{IS}^{\mathrm{a}} \\
\mathrm{mm} / \mathrm{s}\end{array}$ & $\begin{array}{l}\Delta \mathrm{E}_{\mathrm{Q}}^{\mathrm{b}} \\
\mathrm{mm} / \mathrm{s}\end{array}$ & $\begin{array}{l}\text { HFS } \\
\text { KOe }\end{array}$ & $\begin{array}{l}\% \text { Area } \\
298 \mathrm{~K}\end{array}$ & $\begin{array}{l}\% \text { Area } \\
77 \mathrm{~K}\end{array}$ \\
\hline \multicolumn{7}{|c|}{$\underline{10 \mathrm{wt} \% \mathrm{Fe} / \mathrm{SiO}_{2}} \underline{2}_{2}$ Davisil 635 ) after $55 \mathrm{~h}$ fixed } \\
\hline \multicolumn{7}{|c|}{ bed test at $280^{\circ} \mathrm{C} \mathrm{P}=1 \mathrm{~atm}, \mathrm{H}_{2} / \mathrm{CO}=1$. } \\
\hline \multicolumn{7}{|c|}{ (spectra collected at $298 \mathrm{~K}$ for $24 \mathrm{~h}$ ) } \\
\hline \multirow[t]{2}{*}{$\mathrm{Fe}_{3} \mathrm{O}_{4}(\mathrm{sp})^{\mathrm{c}}$} & & 0.43 & 0.99 & --- & 63.5 & \\
\hline & & 0.44 & 0.67 & --- & 10.9 & \\
\hline \multirow[t]{3}{*}{$\chi-\mathrm{Fe}_{2.5} \mathrm{C}$} & I & 0.29 & 0.02 & 198 & 18.0 & \\
\hline & II & 0.16 & 0.09 & 232 & 0.05 & \\
\hline & III & 0.60 & -0.50 & 111 & 7.6 & \\
\hline $\mathrm{Fe}^{2+}$ & & 0.68 & 2.39 & --- & 0.06 & \\
\hline
\end{tabular}

${ }^{\mathrm{a}}$ Relative to $\alpha-\mathrm{Fe}$.

${ }^{b}$ For magnetically split spectra this value is $2 \varepsilon^{\prime}, \Delta \mathrm{E}_{\mathrm{Q}}=2 \varepsilon$ ' if $\phi=0$.

${ }^{\mathrm{c}}$ Superparamagnetic $\mathrm{Fe}_{3} \mathrm{O}_{4}$. 


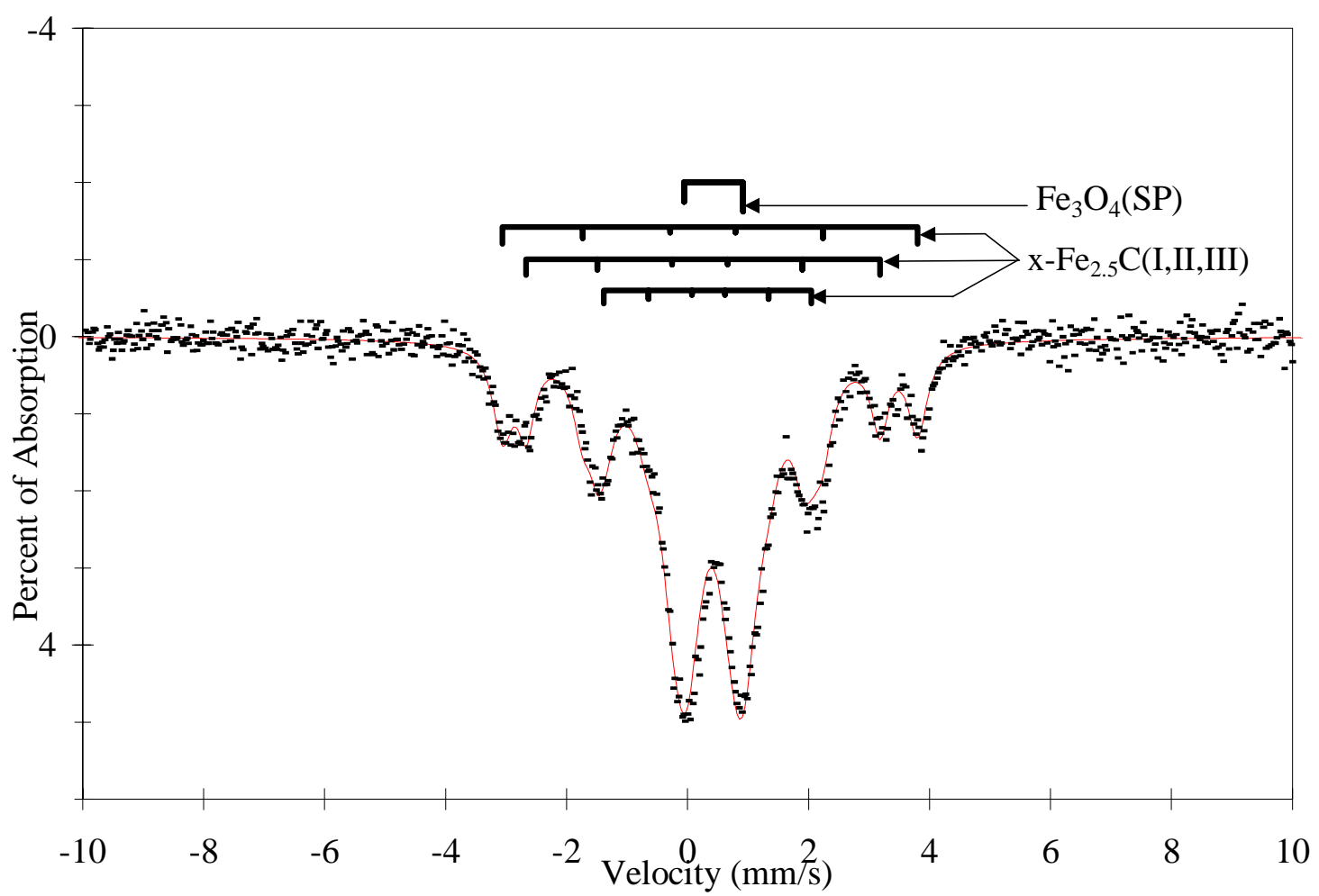

Fig 10. FePt-S-203 after fixed bed run (spectra collected at $298 \mathrm{~K}$ )

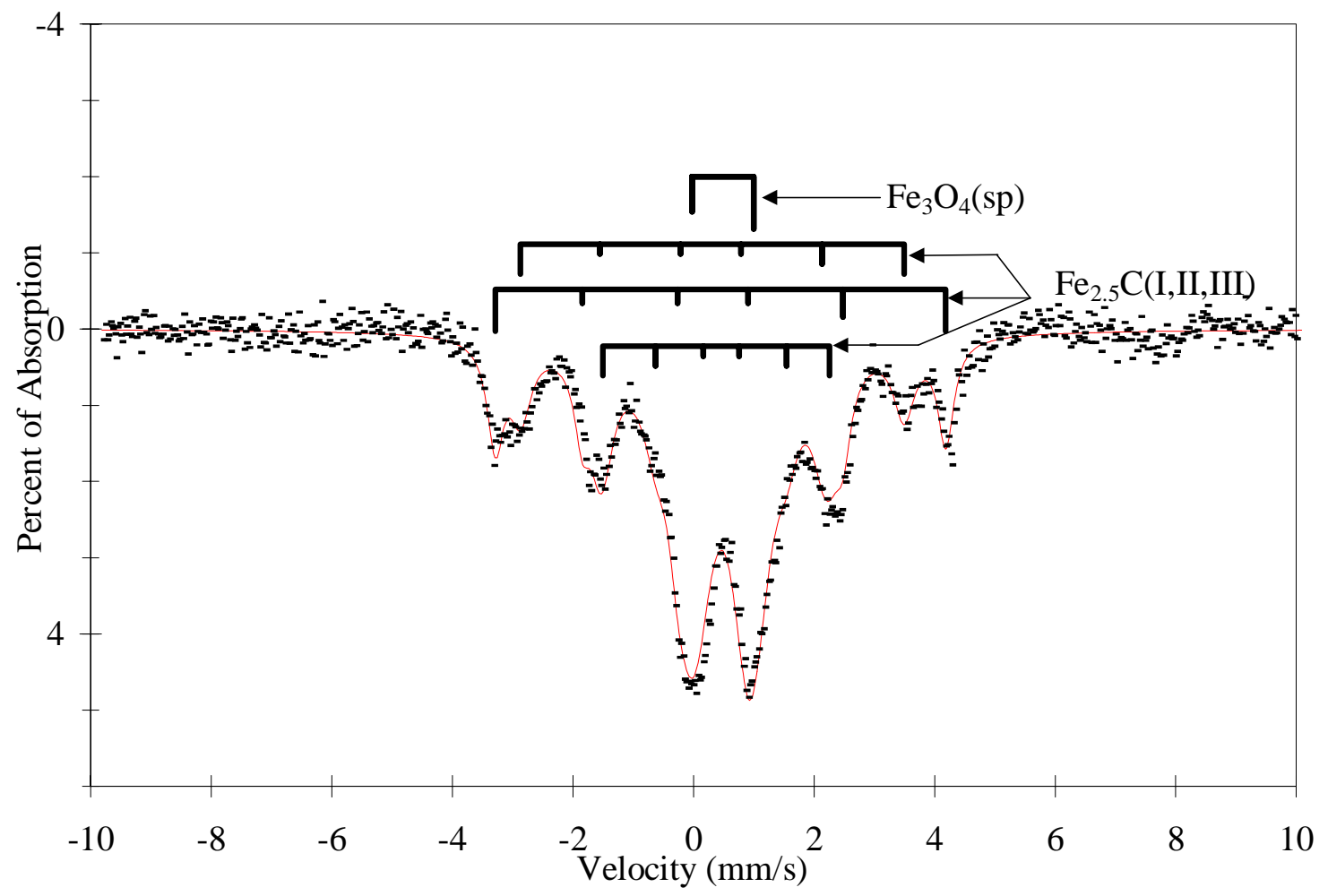

Fig 11. FePt-S-203 after fixed bed run (spectra collected at 77K) 
Table 7. Room Temperature and Liquid $\mathrm{N}_{2}$ Temperature Mössbauer spectroscopy parameters of FePt-S-203 catalyst after fixed bed run at $270^{\circ} \mathrm{C}, 10$ atm, $\mathrm{H}_{2} / \mathrm{CO}=1$

\begin{tabular}{|c|c|c|c|c|c|c|}
\hline Species & $\begin{array}{r}\text { Iron } \\
\text { site } \\
\end{array}$ & $\begin{array}{l}\mathrm{IS}^{\mathrm{a}} \\
\mathrm{mm} / \mathrm{s}\end{array}$ & $\begin{array}{l}\Delta \mathrm{E}_{\mathrm{Q}}^{\mathrm{b}} \\
\mathrm{mm} / \mathrm{s}\end{array}$ & $\begin{array}{l}\text { HFS } \\
\text { KOe }\end{array}$ & $\begin{array}{l}\% \text { Area } \\
298 \mathrm{~K} \\
\end{array}$ & $\begin{array}{l}\% \text { Area } \\
77 \mathrm{~K}\end{array}$ \\
\hline \multicolumn{7}{|c|}{$10 \mathrm{wt} \% \mathrm{Fe} / 0.5 \mathrm{wt} \% \mathrm{Pt} / \mathrm{SiO}_{2}$ (Davisil 644) } \\
\hline \multicolumn{7}{|c|}{ after $60 \mathrm{~h}$ fixed bed test } \\
\hline \multicolumn{7}{|c|}{ (spectra collected at $298 \mathrm{~K}$ for $24 \mathrm{~h}$ ) } \\
\hline $\mathrm{Fe}_{3} \mathrm{O}_{4}(\mathrm{sp})^{\mathrm{c}}$ & & 0.43 & 0.97 & --- & 50.6 & \\
\hline \multirow[t]{3}{*}{$\chi-\mathrm{Fe}_{2.5} \mathrm{C}$} & I & 0.23 & 0.05 & 181 & 14.7 & \\
\hline & II & 0.31 & 0.12 & 212 & 17.8 & \\
\hline & III & 0.34 & -0.02 & 106 & 16.8 & \\
\hline \multicolumn{7}{|c|}{$10 \mathrm{wt} \% \mathrm{Fe} / 0.5 \mathrm{wt} \% \mathrm{Pt} / \mathrm{SiO}_{2}$ (Davisil 644) } \\
\hline \multicolumn{7}{|c|}{ after $60 \mathrm{~h}$ fixed bed test } \\
\hline \multicolumn{7}{|c|}{ (spectra collected at $77 \mathrm{~K}$ for $24 \mathrm{~h}$ ) } \\
\hline \multicolumn{7}{|l|}{$\mathrm{Fe}_{3} \mathrm{O}_{4}(\mathrm{sp})^{\mathrm{c}}$} \\
\hline \multirow[t]{4}{*}{$\chi-\mathrm{Fe}_{2.5} \mathrm{C}$} & & 0.49 & 1.02 & --- & & 48.6 \\
\hline & I & 0.30 & 0.02 & 197 & & 16.5 \\
\hline & II & 0.39 & 0.13 & 231 & & 17.6 \\
\hline & III & 0.42 & -0.08 & 117 & & 17.4 \\
\hline
\end{tabular}

${ }^{\mathrm{a}}$ Relative to $\alpha-\mathrm{Fe}$.

${ }^{\mathrm{b}}$ For magnetically split spectra this value is $2 \varepsilon^{\prime}, \Delta \mathrm{E}_{\mathrm{Q}}=2 \varepsilon$ ' if $\phi=0$.

${ }^{\mathrm{c}}$ Superparamagnetic $\mathrm{Fe}_{3} \mathrm{O}_{4}$. 
Table 8. Iron phases of unpromoted (Fe-S-206) and promoted (FePt-S-203, FePtK-S-218) catalysts (room temperature and liquid $\mathrm{N}_{2}$ Mössbauer Spectra)

\begin{tabular}{|l|c|c|c|c|c|}
\hline \multicolumn{1}{|c|}{ Catalyst } & $\begin{array}{c}\text { Temp } \\
\end{array}$ & $\mathrm{K}$ & \multicolumn{4}{|c|}{$\begin{array}{c}\text { Iron species } \\
\text { \% Area }\end{array}$} \\
\cline { 3 - 6 } & & $\mathrm{Fe}_{3} \mathrm{O}_{4}(\mathrm{FiM})^{\mathrm{b}}$ & $\mathrm{Fe}_{2.5} \mathrm{C}^{\mathrm{c}}$ & $\mathrm{Fe}^{2+}$ & $\mathrm{Fe}_{3} \mathrm{O}_{4}(\mathrm{sp})$ \\
\hline $\mathrm{Fe}-\mathrm{S}-206$ & 298 & - & 25.6 & 0.1 & 74.3 \\
\hline FePt-S-203 & 298 & - & 49.3 & - & 50.6 \\
\hline FePt-S-203 & 77 & - & 51.5 & - & 48.6 \\
\hline
\end{tabular}

${ }^{\mathrm{a}}$ : Temperatures at which Mössbauer Spectra are collected

b. Ferrimagnetic $\mathrm{Fe}_{3} \mathrm{O}_{4}$

${ }^{c}$ : Haag or $\chi$-carbides $\left(\mathrm{Fe}_{2.5} \mathrm{C}\right)$ 


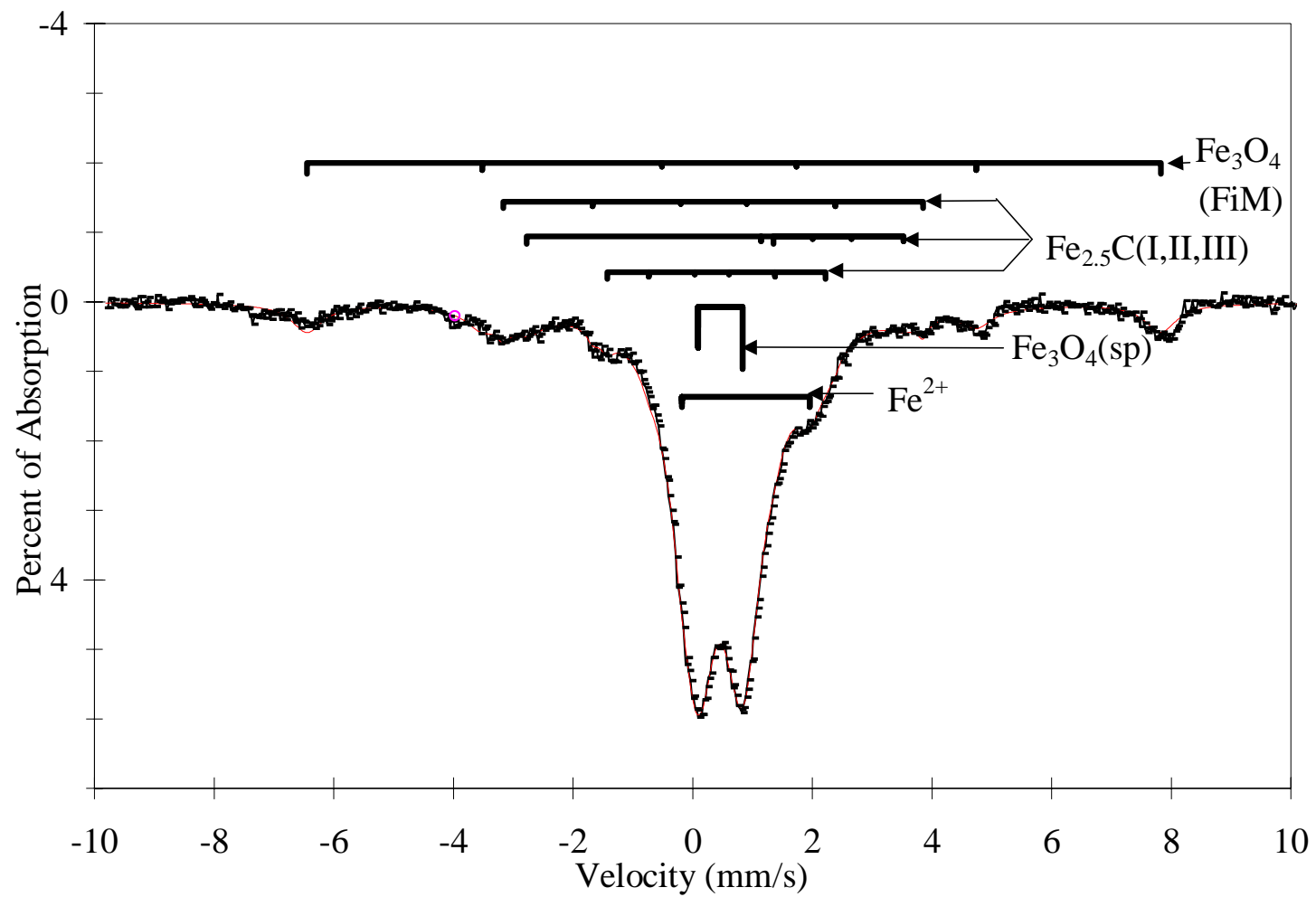

Fig 12. In-situ Mössbauer spectrum of Fe-S-207 after pretreated at $280^{\circ} \mathrm{C}$, 1atm and $\mathrm{H}_{2} / \mathrm{CO}=1$. 
Table 9. Mössbauer spectroscopy parameters of Fe-S-207 after $16 \mathrm{~h}$ in-situ pretreatment at $280^{\circ} \mathrm{C}$ (spectra collected at $298 \mathrm{~K}$ for $24 \mathrm{~h}$ ).

\begin{tabular}{|c|c|c|c|c|c|}
\hline Species & $\begin{array}{l}\text { Iron } \\
\text { site }\end{array}$ & $\begin{array}{l}\mathrm{IS}^{\mathrm{c}} \\
(\mathrm{mm} / \mathrm{s})\end{array}$ & $\begin{array}{l}\Delta \mathrm{E}_{\mathrm{Q}}^{\mathrm{d}} \\
(\mathrm{mm} / \mathrm{s})\end{array}$ & $\begin{array}{l}\text { HFS } \\
\text { KOe }\end{array}$ & $\%$ Area \\
\hline \multicolumn{6}{|c|}{$10 \mathrm{wt} \% \mathrm{Fe} / \mathrm{SiO}_{2}$ pretreated in $\mathrm{H}_{2}=\underline{\mathrm{CO} 16 \mathrm{~h}}$} \\
\hline $\mathrm{Fe}_{3} \mathrm{O}_{4}\left(\mathrm{FiM}^{\mathrm{e}}\right)$ & & 0.65 & 0.08 & 442 & 10.3 \\
\hline \multirow[t]{3}{*}{$\chi-\mathrm{Fe}_{2.5} \mathrm{C}(295 \mathrm{~K})$} & I & 0.81 & -0.01 & 128 & 8.1 \\
\hline & II & 0.35 & -3.04 & 217 & 2.3 \\
\hline & III & 0.36 & 0.08 & 113 & 3.6 \\
\hline $\mathrm{Fe}^{2+}(295 \mathrm{~K})$ & & 0.89 & 2.14 & --- & 7.5 \\
\hline $\mathrm{Fe}_{3} \mathrm{O}_{4}(\mathrm{sp})^{\mathrm{f}}$ & & 0.46 & 0.74 & --- & 68.2 \\
\hline
\end{tabular}

${ }^{\mathrm{a} C a t a l y s t}$ preparation and composition similar to Fe-S-206

${ }^{\mathrm{b}}$ In-situ treatment was conducted at $1 \mathrm{~atm}$; gas largely bypassed the sample leading to low extent of carbide formation

${ }^{\mathrm{c}}$ Relative to $\alpha-\mathrm{Fe}$.

${ }^{\mathrm{d}}$ For magnetically split spectra this value is $2 \varepsilon^{\prime}, \Delta \mathrm{E}_{\mathrm{Q}}=2 \varepsilon$ ' if $\phi=0$.

${ }^{\mathrm{e}}$ Ferrimagnetic $\mathrm{Fe}_{3} \mathrm{O}_{4}$.

${ }^{\mathrm{f}}$ Superparamagnetic $\mathrm{Fe}_{3} \mathrm{O}_{4}$. 


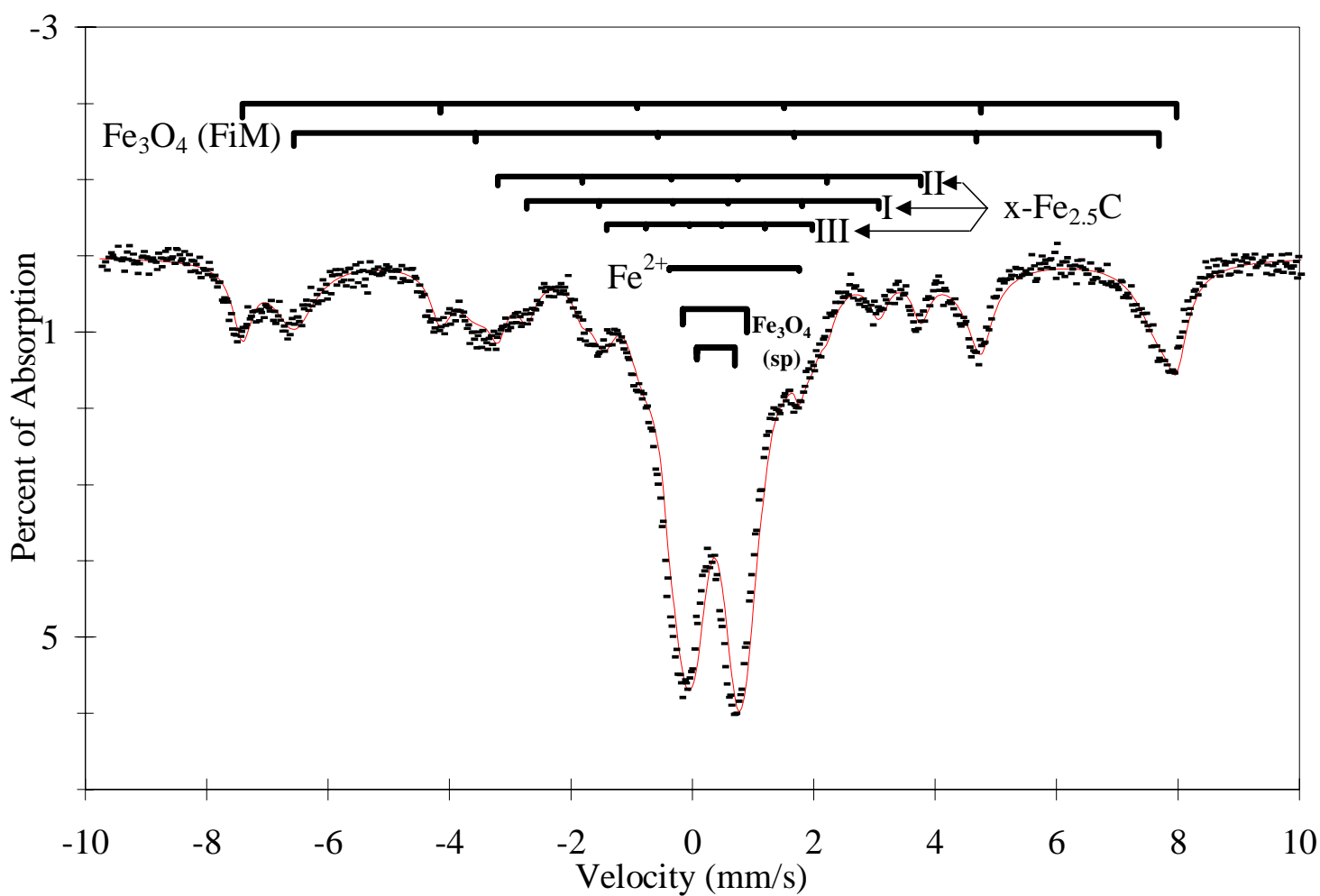

Fig 13. Mossbauer Spectrum of Fe-S-201 $\left(10.7 \% \mathrm{Fe} / \mathrm{SiO}_{2}\right)$ after statistically designed experiments run \#01

SCA settings:

Window: 0.8 volts

Lower level: 5.6 volts

Course gain: $1 \mathrm{~K}$

Fine gain: 0.532
Source to Counter distance: 7 inch Count rate: 15,616 counts/sec

Data collected at room temperature for $24 \mathrm{~h}$ 
Table 10. Mössbauer spectroscopy parameters of $10.7 \mathrm{wt} \% \mathrm{Fe} / \mathrm{SiO}_{2}$ catalyst after statistically designed fixed bed run $\# 01$ at $250^{\circ} \mathrm{C}, 10 \mathrm{~atm}, \mathrm{H}_{2} / \mathrm{CO}=1$

\begin{tabular}{|c|c|c|c|c|c|c|}
\hline Species & $\begin{array}{r}\text { Iron } \\
\text { site }\end{array}$ & $\begin{array}{l}\mathrm{IS}^{\mathrm{a}} \\
\mathrm{mm} / \mathrm{s}\end{array}$ & $\begin{array}{l}\Delta \mathrm{E}_{\mathrm{Q}}^{\mathrm{b}} \\
\mathrm{mm} / \mathrm{s}\end{array}$ & $\begin{array}{l}\text { HFS } \\
\text { KOe }\end{array}$ & $\begin{array}{l}\% \\
\text { Area } \\
(298 \mathrm{~K})\end{array}$ & $\begin{array}{l}\% \\
\text { Area } \\
(77 \mathrm{~K})\end{array}$ \\
\hline \multicolumn{7}{|l|}{$\underline{10.7 \mathrm{wt} \% \mathrm{Fe} / \mathrm{SiO}_{2}} \underline{\text { after } 150 \mathrm{~h}}$} \\
\hline \multicolumn{7}{|l|}{ fixed bed test at $280^{\circ} \mathrm{C} \mathrm{P}=1 \mathrm{~atm}, \mathrm{H}_{2} / \mathrm{CO}=1$} \\
\hline \multicolumn{7}{|l|}{ (spectra collected at $298 \mathrm{~K}$ for $24 \mathrm{~h}$ ) } \\
\hline \multirow[t]{2}{*}{$\mathrm{Fe}_{3} \mathrm{O}_{4}\left(\mathrm{FiM}^{\mathrm{c}}\right)$} & & 0.29 & -0.02 & 477 & 11.2 & \\
\hline & & 0.56 & 0.01 & 441 & 22.1 & \\
\hline \multirow[t]{3}{*}{$\chi-\mathrm{Fe}_{2.5} \mathrm{C}$} & I & 0.15 & 0.04 & 179 & 6.3 & \\
\hline & II & 0.24 & 0.08 & 216 & 6.6 & \\
\hline & III & 0.25 & 0.07 & 105 & 4.6 & \\
\hline $\mathrm{Fe}^{2+}$ & & 0.69 & 2.14 & --- & 0.8 & \\
\hline \multirow[t]{2}{*}{$\mathrm{Fe}_{3} \mathrm{O}_{4}(\mathrm{sp})^{\mathrm{d}}$} & & 0.37 & 1.1 & --- & 28.4 & \\
\hline & & 0.39 & 0.6 & --- & 20.0 & \\
\hline
\end{tabular}

${ }^{\mathrm{a}}$ Relative to $\alpha-\mathrm{Fe}$.

${ }^{b}$ For magnetically split spectra this value is $2 \varepsilon^{\prime}, \Delta \mathrm{E}_{\mathrm{Q}}=2 \varepsilon$ ' if $\phi=0$.

${ }^{c}$ Ferrimagnetic $\mathrm{Fe}_{3} \mathrm{O}_{4}$.

${ }^{\mathrm{d}}$ Superparamagnetic $\mathrm{Fe}_{3} \mathrm{O}_{4}$. 


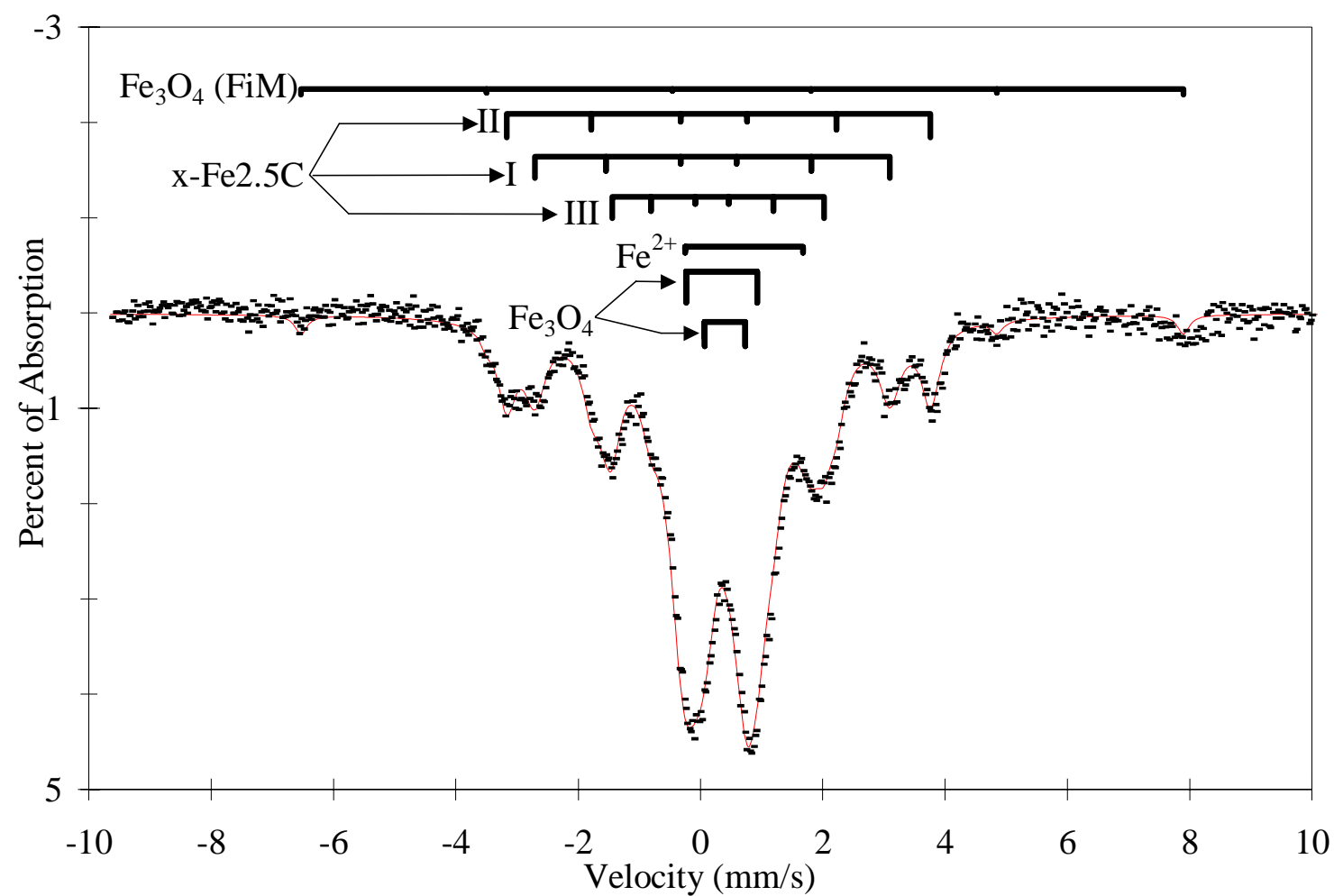

Fig 14. Mossbauer Spectrum of Fe-S-201 $\left(10.7 \% \mathrm{Fe} / \mathrm{SiO}_{2}\right)$ after statistically designed experiments run \#02

SCA settings:

Window: 0.8 volts

Lower level: 5.6 volts

Course gain: $1 \mathrm{~K}$

Fine gain: 0.532
Source to Counter distance: 7 inch Count rate: 17,932 counts/sec

Data collected at room temperature for $24 \mathrm{~h}$ 
Table 11. Mössbauer spectroscopy parameters of $10.7 \mathrm{wt} \% \mathrm{Fe} / \mathrm{SiO}_{2}$ catalyst after statistically designed fixed bed run $\# 02$ at $265^{\circ} \mathrm{C}, 10 \mathrm{~atm}, \mathrm{H}_{2} / \mathrm{CO}=1$

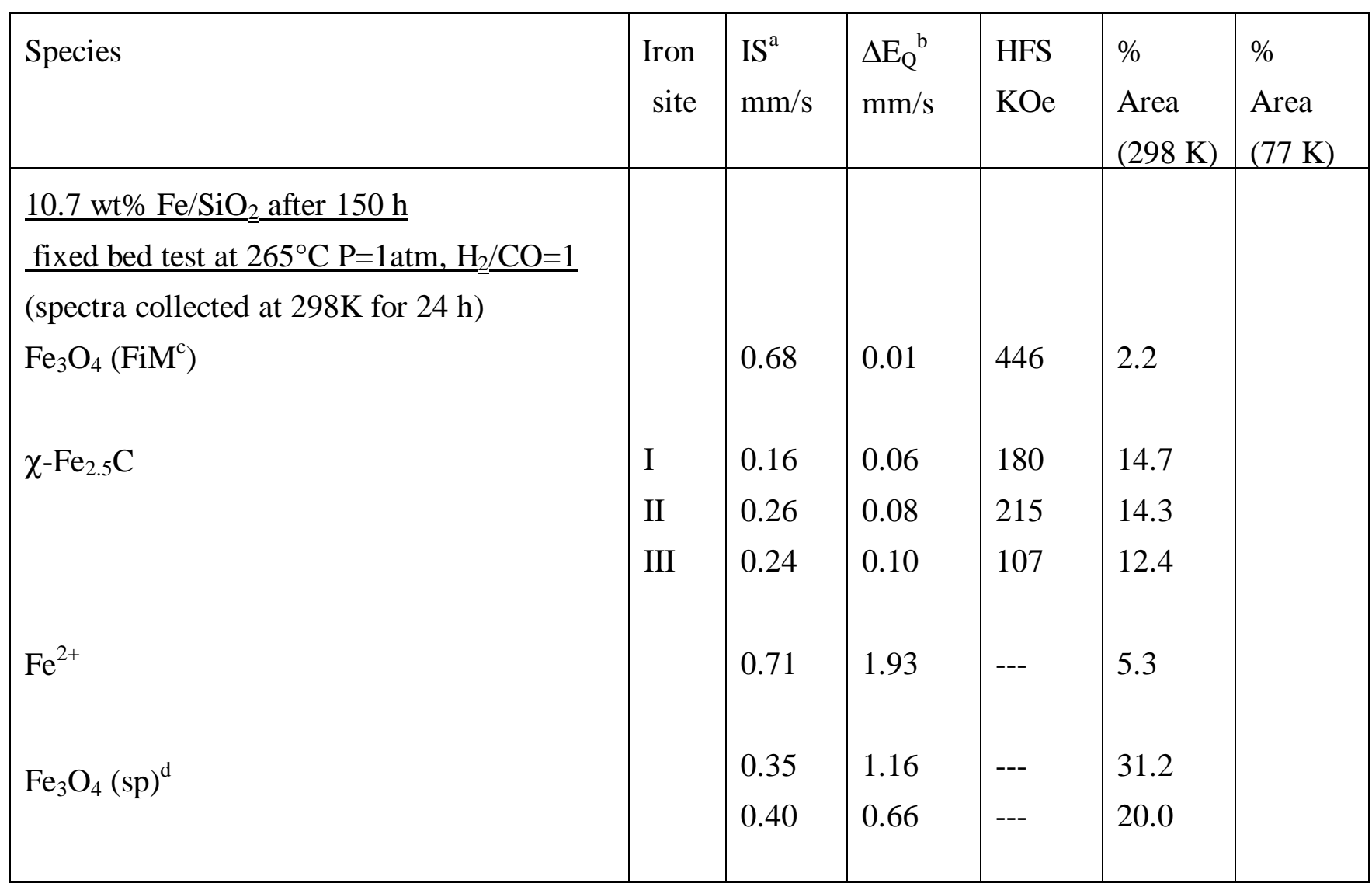

${ }^{\mathrm{a}}$ Relative to $\alpha-\mathrm{Fe}$.

${ }^{b}$ For magnetically split spectra this value is $2 \varepsilon^{\prime}, \Delta \mathrm{E}_{\mathrm{Q}}=2 \varepsilon$ ' if $\phi=0$.

${ }^{\mathrm{c}}$ Ferrimagnetic $\mathrm{Fe}_{3} \mathrm{O}_{4}$.

${ }^{\mathrm{d}}$ Superparamagnetic $\mathrm{Fe}_{3} \mathrm{O}_{4}$. 


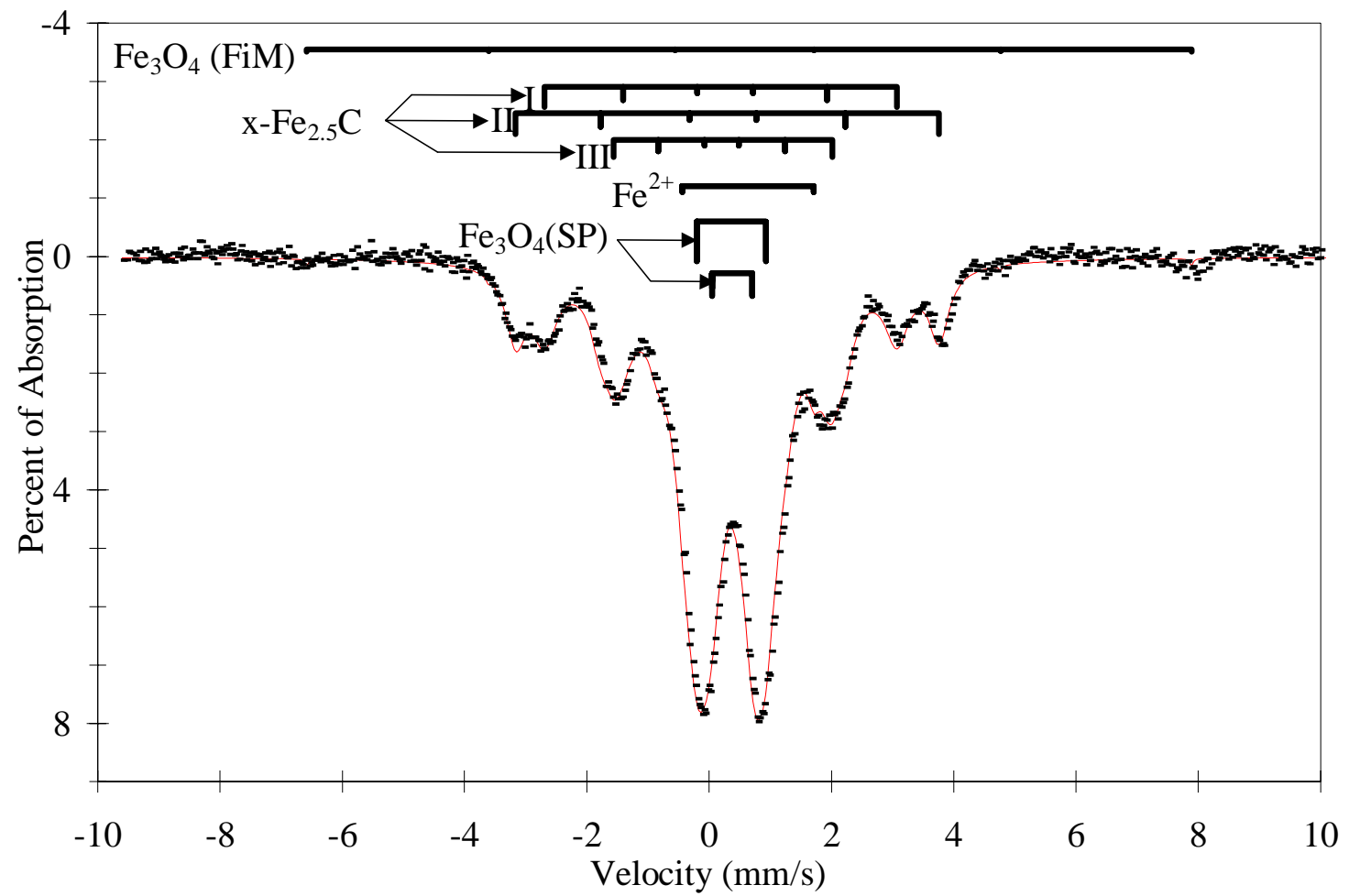

Fig 15. Mossbauer Spectrum of Fe-S-201 $\left(10.7 \% \mathrm{Fe} / \mathrm{SiO}_{2}\right)$ after statistically designed experiments run \#03

SCA settings:

Window: 0.8 volts

Lower level: 5.6 volts

Course gain: $1 \mathrm{~K}$

Fine gain: 0.532
Source to Counter distance: 7 inch Count rate: 14,300 counts/sec

Data collected at room temperature for $24 \mathrm{~h}$ 
Table 12. Mössbauer spectroscopy parameters of $10.7 \mathrm{wt} \% \mathrm{Fe} / \mathrm{SiO}_{2}$ catalyst after statistically designed fixed bed run $\# 03$ at $250^{\circ} \mathrm{C}, 10 \mathrm{~atm}, \mathrm{H}_{2} / \mathrm{CO}=1$

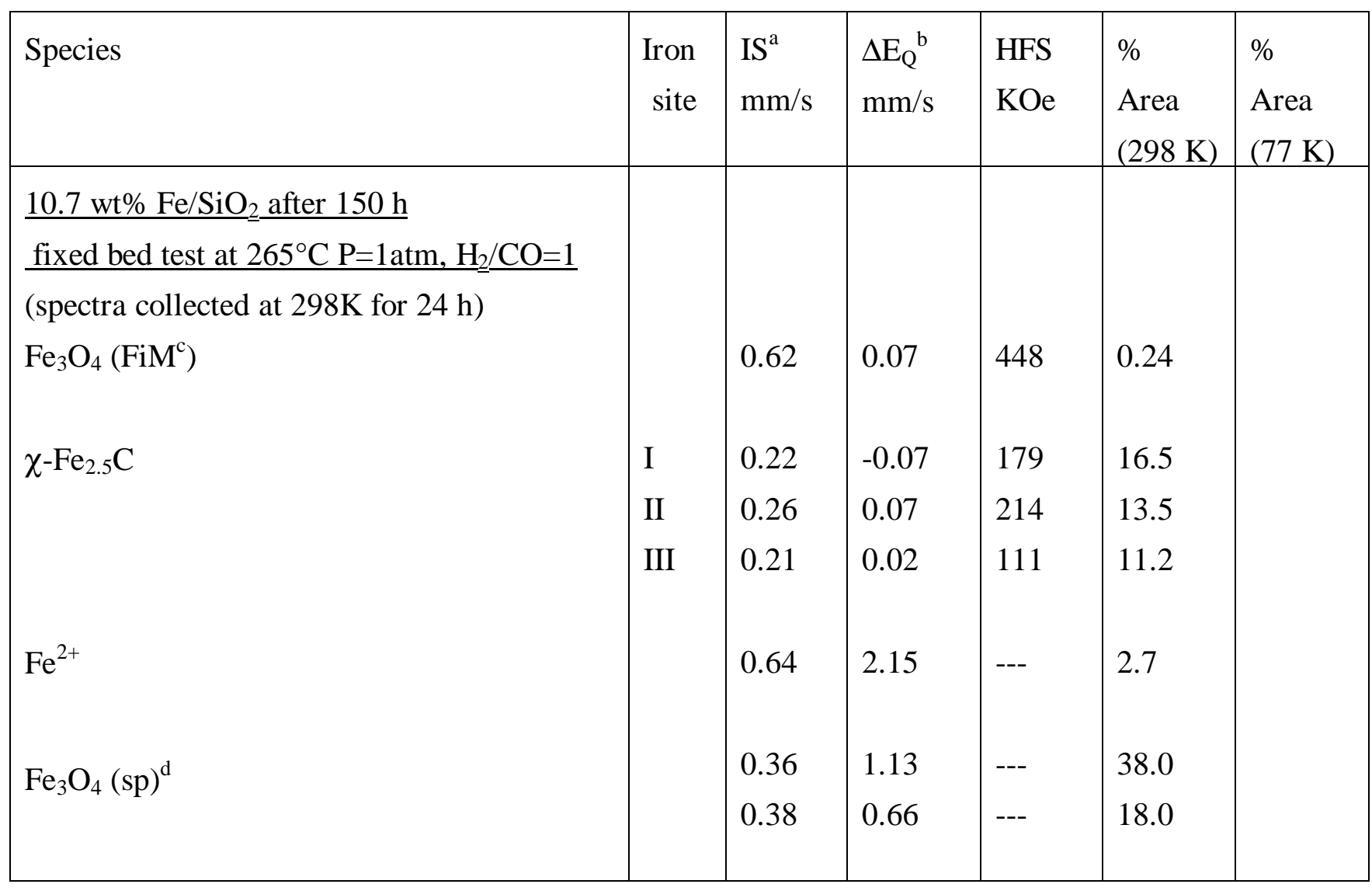

${ }^{\mathrm{a}}$ Relative to $\alpha-\mathrm{Fe}$.

${ }^{b}$ For magnetically split spectra this value is $2 \varepsilon^{\prime}, \Delta \mathrm{E}_{\mathrm{Q}}=2 \varepsilon$ ' if $\phi=0$.

${ }^{c}$ Ferrimagnetic $\mathrm{Fe}_{3} \mathrm{O}_{4}$.

${ }^{\mathrm{d}}$ Superparamagnetic $\mathrm{Fe}_{3} \mathrm{O}_{4}$. 


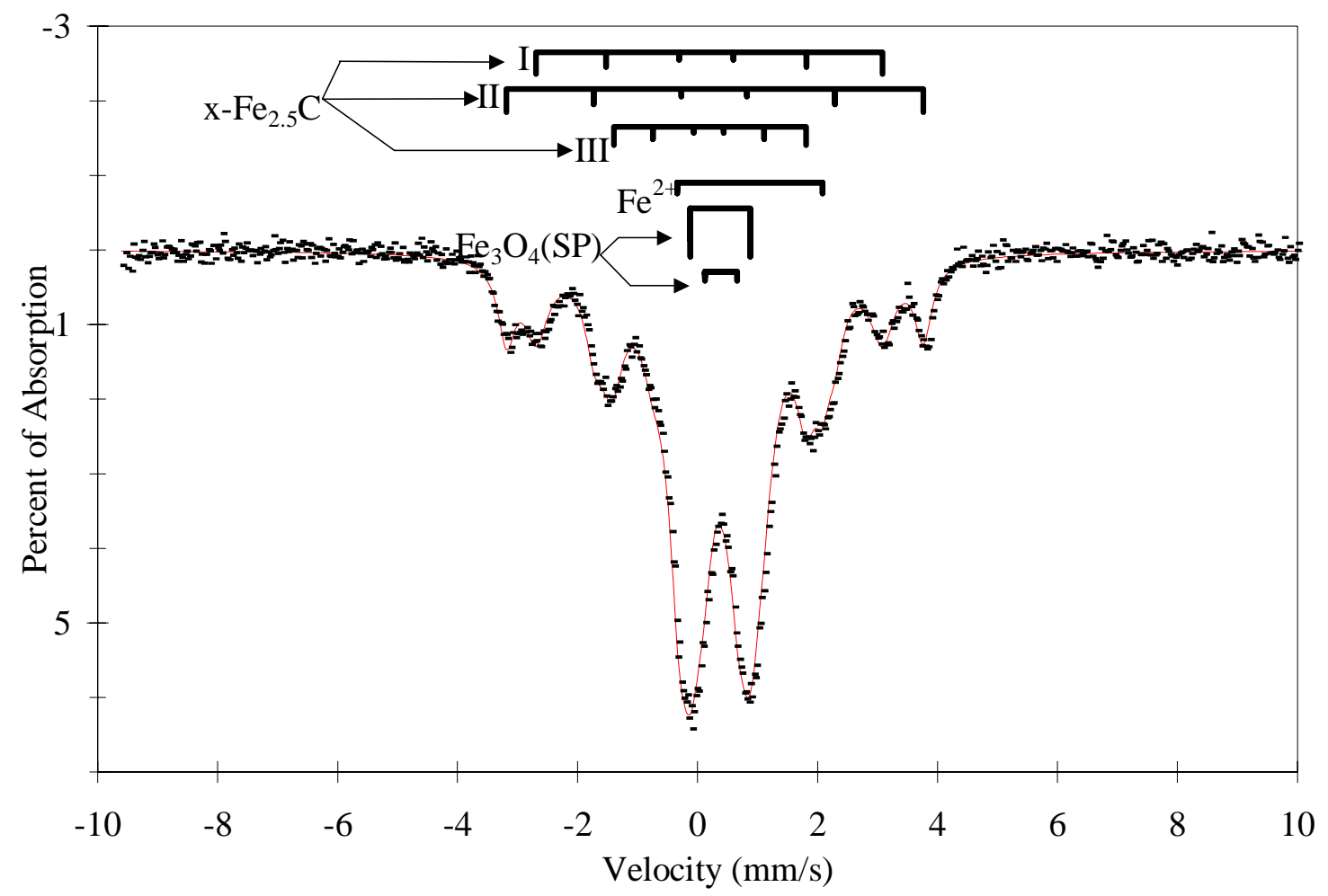

Fig 16. Mossbauer Spectrum of FePt-S-220 after statistically designed experiments run \#04

SCA settings:

Window: 0.8 volts

Lower level: 5.6 volts

Course gain: $1 \mathrm{~K}$

Fine gain: 0.532
Source to Counter distance: 7 inch Count rate: 15,640 counts/sec Data collected at room temperature for $24 \mathrm{~h}$ 
Table 13. Mössbauer spectroscopy parameters of FePt-S-220 catalyst after statistically designed fixed bed run \# 04 at $250^{\circ} \mathrm{C}, 10$ atm, $\mathrm{H}_{2} / \mathrm{CO}=1$; Catalyst pretreated in $\mathrm{H} 2 / \mathrm{CO}=0.1$, $280^{\circ} \mathrm{C}$ for $16 \mathrm{~h}$

\begin{tabular}{|c|c|c|c|c|c|c|}
\hline Species & $\begin{array}{l}\text { Iron } \\
\text { site }\end{array}$ & $\begin{array}{l}\mathrm{IS}^{\mathrm{a}} \\
\mathrm{mm} / \mathrm{s}\end{array}$ & $\begin{array}{l}\Delta \mathrm{E}_{\mathrm{Q}}{ }^{\mathrm{b}} \\
\mathrm{mm} / \mathrm{s}\end{array}$ & $\begin{array}{l}\text { HFS } \\
\text { KOe }\end{array}$ & $\begin{array}{l}\% \\
\text { Area } \\
(298 \mathrm{~K})\end{array}$ & $\begin{array}{l}\% \\
\text { Area } \\
(77 \mathrm{~K})\end{array}$ \\
\hline $\begin{array}{l}\text { FePt-S-220 after } 150 \mathrm{~h} \\
\text { fixed bed test at } 250^{\circ} \mathrm{C} P=1 \mathrm{~atm}, \mathrm{H}_{2} / \mathrm{CO}=1 \\
\text { (spectra collected at } 298 \mathrm{~K} \text { for } 24 \mathrm{~h} \text { ) }\end{array}$ & & & & & & \\
\hline$\chi-\mathrm{Fe}_{2.5} \mathrm{C}$ & $\begin{array}{l}\text { I } \\
\text { II } \\
\text { III }\end{array}$ & $\begin{array}{l}0.17 \\
0.28 \\
0.20\end{array}$ & $\begin{array}{l}0.05 \\
0.01 \\
0.03\end{array}$ & $\begin{array}{l}179 \\
215 \\
99\end{array}$ & $\begin{array}{l}16.6 \\
12.7 \\
11.8\end{array}$ & \\
\hline $\begin{array}{l}\mathrm{Fe}^{2+} \\
\mathrm{Fe}_{3} \mathrm{O}_{4}(\mathrm{sp})^{\mathrm{c}}\end{array}$ & & $\begin{array}{l}0.87 \\
0.38 \\
0.39\end{array}$ & $\begin{array}{l}2.42 \\
0.99 \\
0.54\end{array}$ & $\begin{array}{l}--- \\
--- \\
---\end{array}$ & $\begin{array}{l}5.8 \\
48.4 \\
4.6\end{array}$ & \\
\hline
\end{tabular}

${ }^{\mathrm{a}}$ Relative to $\alpha-\mathrm{Fe}$.

${ }^{\mathrm{b}}$ For magnetically split spectra this value is $2 \varepsilon^{\prime}, \Delta \mathrm{E}_{\mathrm{Q}}=2 \varepsilon$ ' if $\phi=0$.

${ }^{\mathrm{c}}$ Superparamagnetic $\mathrm{Fe}_{3} \mathrm{O}_{4}$. 


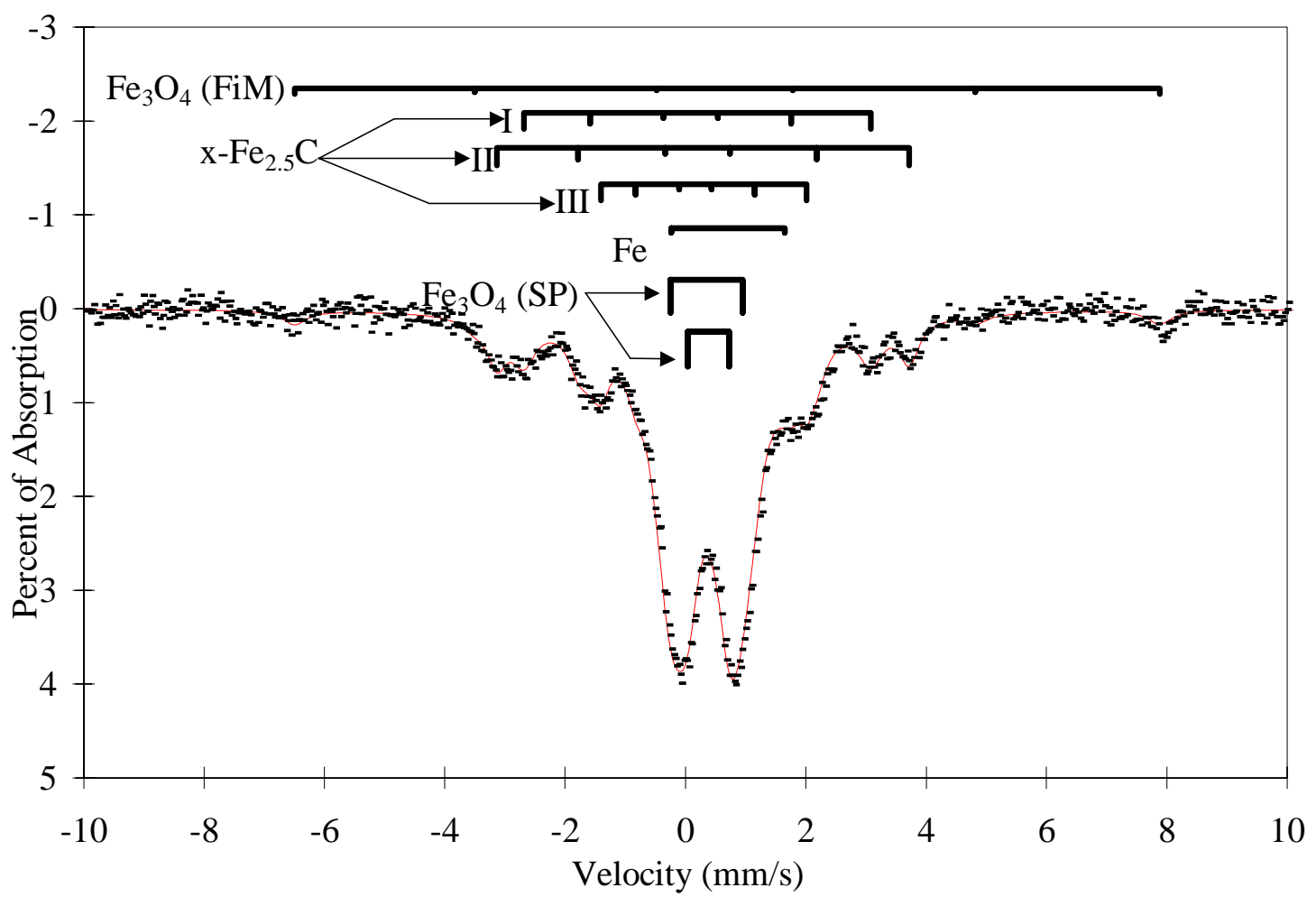

Fig 17. Mossbauer Spectrum of FePtK-S-218 after statistically designed experiments run \#05

SCA settings:

Window: 0.8 volts

Lower level: 5.6 volts

Course gain: $1 \mathrm{~K}$

Fine gain: 0.532
Source to Counter distance: 7 inch Count rate: 18,253 counts/sec Data collected at room temperature for $24 \mathrm{~h}$ 
Table 14. Mössbauer spectroscopy parameters of FePtK-S-218 catalyst after statistically designed fixed bed run $\# 05$ at $265^{\circ} \mathrm{C}, 10 \mathrm{~atm}, \mathrm{H}_{2} / \mathrm{CO}=1$

\begin{tabular}{|c|c|c|c|c|c|c|}
\hline Species & $\begin{array}{l}\text { Iron } \\
\text { site }\end{array}$ & $\begin{array}{l}\mathrm{IS}^{\mathrm{a}} \\
\mathrm{mm} / \mathrm{s}\end{array}$ & $\begin{array}{l}\Delta \mathrm{E}_{\mathrm{Q}}^{\mathrm{b}} \\
\mathrm{mm} / \mathrm{s}\end{array}$ & $\begin{array}{l}\text { HFS } \\
\text { KOe }\end{array}$ & $\begin{array}{l}\% \\
\text { Area } \\
(298 \mathrm{~K})\end{array}$ & $\begin{array}{l}\% \\
\text { Area } \\
(77 \mathrm{~K})\end{array}$ \\
\hline \multicolumn{7}{|l|}{$\underline{\text { FePtK-S-218 after } 150 \mathrm{~h}}$} \\
\hline \multicolumn{7}{|l|}{ fixed bed test at $265^{\circ} \mathrm{C} \mathrm{P}=1 \mathrm{~atm}, \mathrm{H}_{2} / \mathrm{CO}=1$} \\
\hline \multicolumn{7}{|l|}{ (spectra collected at $298 \mathrm{~K}$ for $24 \mathrm{~h}$ ) } \\
\hline $\mathrm{Fe}_{3} \mathrm{O}_{4}\left(\mathrm{FiM}^{\mathrm{c}}\right)$ & & 0.67 & 0.04 & 445 & 4.0 & \\
\hline \multirow[t]{3}{*}{$\chi-\mathrm{Fe}_{2.5} \mathrm{C}$} & I & 0.14 & 0.11 & 179 & 12.6 & \\
\hline & II & 0.25 & 0.09 & 212 & 10.6 & \\
\hline & III & 0.23 & 0.14 & 106 & 8.6 & \\
\hline $\mathrm{Fe}^{2+}$ & & 0.71 & 1.89 & --- & 4.8 & \\
\hline \multirow{2}{*}{$\mathrm{Fe}_{3} \mathrm{O}_{4}(\mathrm{sp})^{\mathrm{d}}$} & & 0.35 & 1.20 & --- & 30.4 & \\
\hline & & 0.38 & 0.69 & --- & 29.0 & \\
\hline
\end{tabular}

${ }^{\mathrm{a}}$ Relative to $\alpha-\mathrm{Fe}$.

${ }^{b}$ For magnetically split spectra this value is $2 \varepsilon$ ', $\Delta \mathrm{E}_{\mathrm{Q}}=2 \varepsilon$ ' if $\phi=0$.

${ }^{\mathrm{c}}$ Ferrimagnetic $\mathrm{Fe}_{3} \mathrm{O}_{4}$.

${ }^{\mathrm{d}}$ Superparamagnetic $\mathrm{Fe}_{3} \mathrm{O}_{4}$. 


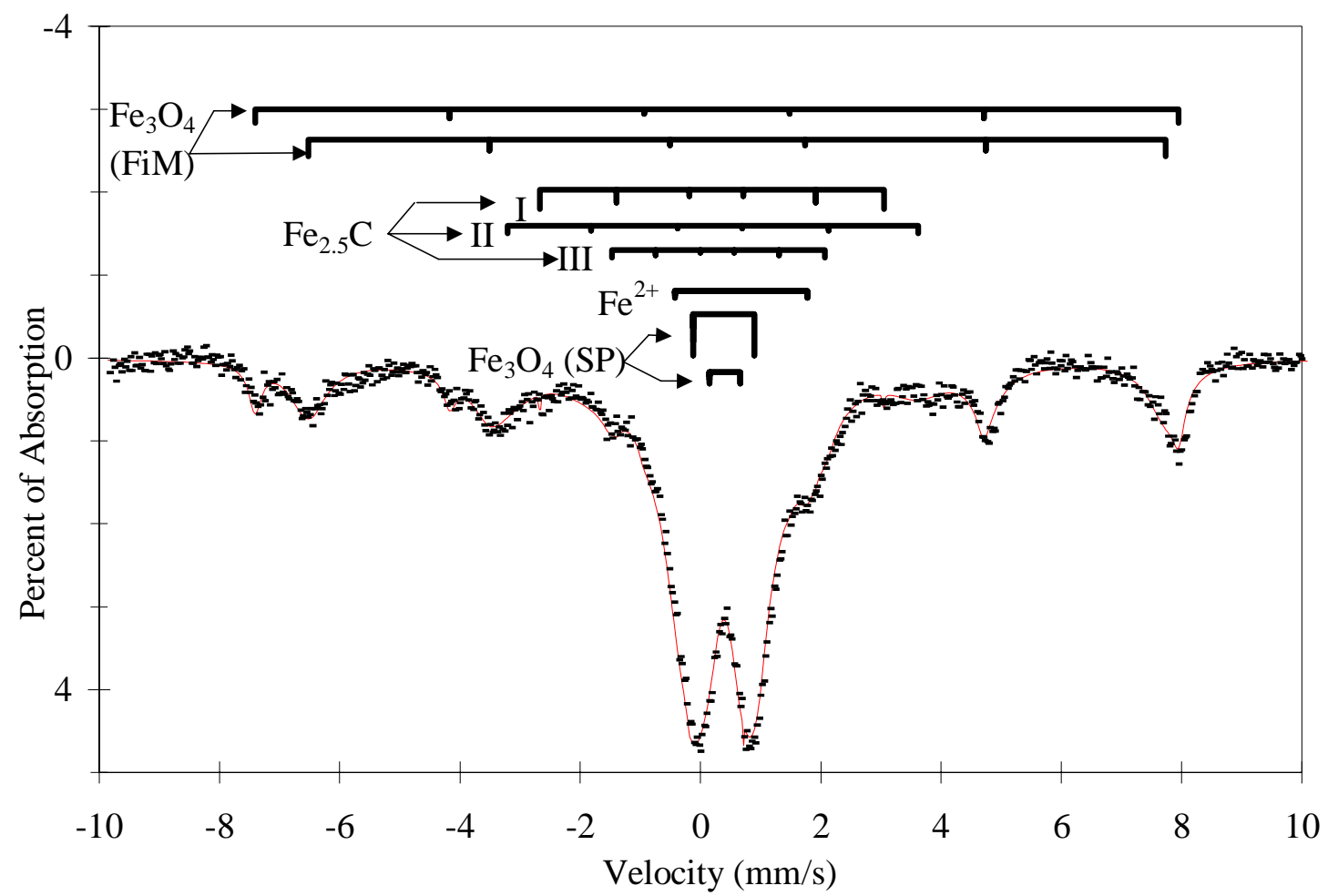

Fig 18. Mossbauer Spectrum of Fe-S-201 after statistically designed experiments run \#06

SCA settings:

Window: 0.8 volts

Lower level: 5.6 volts

Course gain: $1 \mathrm{~K}$

Fine gain: 0.532
Source to Counter distance: 7 inch Count rate: 16,620 counts/sec Data collected at room temperature for $24 \mathrm{~h}$ 
Table 15. Mössbauer spectroscopy parameters of Fe-S-201 catalyst after statistically designed fixed bed run $\# 06$ at $265^{\circ} \mathrm{C}, 10 \mathrm{~atm}, \mathrm{H}_{2} / \mathrm{CO}=1$

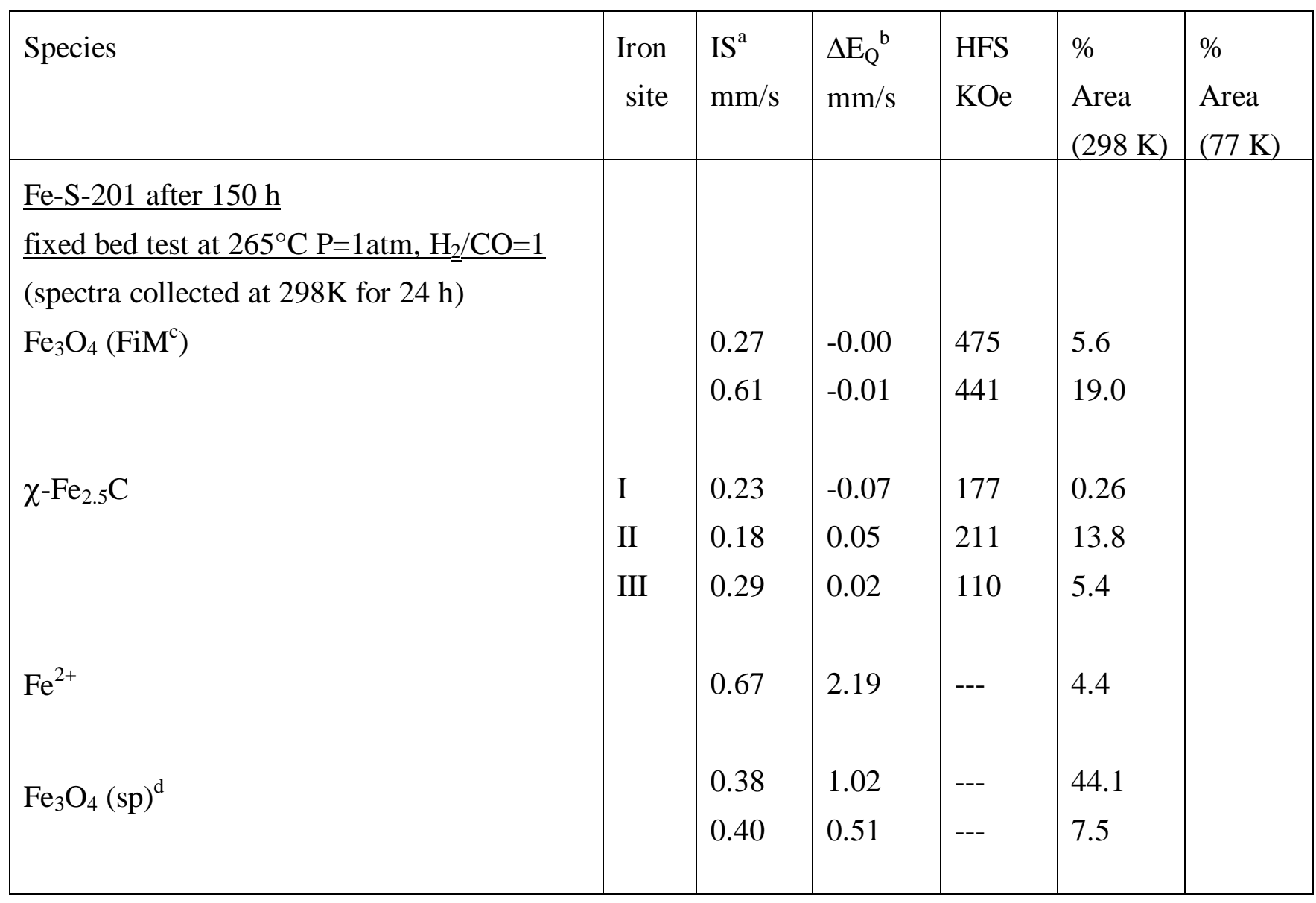

${ }^{\mathrm{a}}$ Relative to $\alpha-\mathrm{Fe}$.

${ }^{\mathrm{b}}$ For magnetically split spectra this value is $2 \varepsilon^{\prime}, \Delta \mathrm{E}_{\mathrm{Q}}=2 \varepsilon$ ' if $\phi=0$.

${ }^{\mathrm{c}}$ Ferrimagnetic $\mathrm{Fe}_{3} \mathrm{O}_{4}$.

${ }^{\mathrm{d}}$ Superparamagnetic $\mathrm{Fe}_{3} \mathrm{O}_{4}$. 


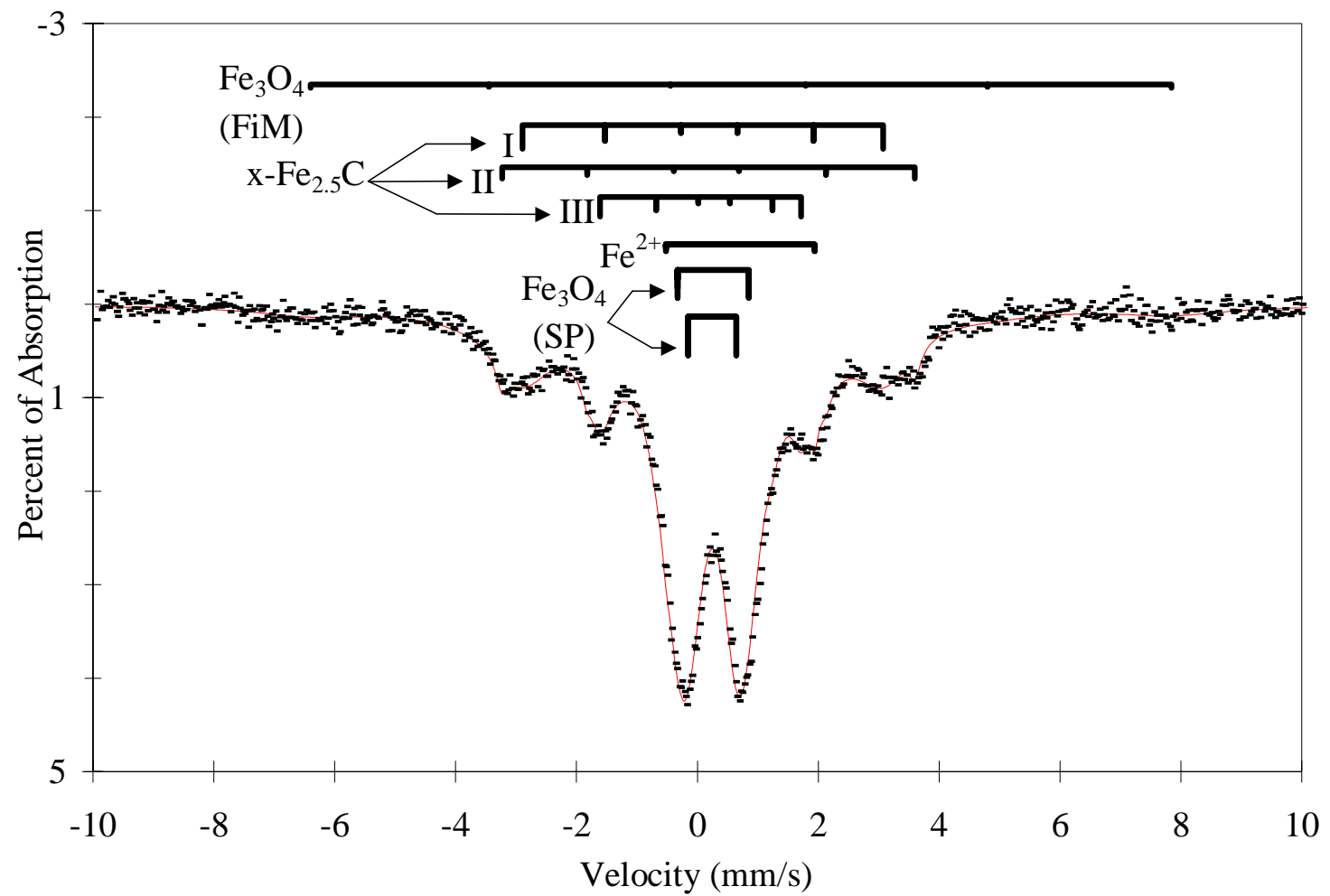

Fig 19. Mossbauer Spectrum of FePtK-S-218 after statistically designed experiments run \#07

SCA settings:

Window: 0.8 volts

Lower level: 5.6 volts

Course gain: $1 \mathrm{~K}$

Fine gain: 0.532
Source to Counter distance: 7 inch

Count rate: 19,489 counts/sec

Data collected at room temperature for $24 \mathrm{~h}$ 
Table 16. Mössbauer spectroscopy parameters of FePtK-S-218 catalyst after statistically designed fixed bed run $\# 07$ at $265^{\circ} \mathrm{C}, 10 \mathrm{~atm}, \mathrm{H}_{2} / \mathrm{CO}=1$

\begin{tabular}{|c|c|c|c|c|c|c|}
\hline Species & $\begin{array}{l}\text { Iron } \\
\text { site }\end{array}$ & $\begin{array}{l}\mathrm{IS}^{\mathrm{a}} \\
\mathrm{mm} / \mathrm{s}\end{array}$ & $\begin{array}{l}\Delta \mathrm{E}_{\mathrm{Q}}^{\mathrm{b}} \\
\mathrm{mm} / \mathrm{s}\end{array}$ & $\begin{array}{l}\text { HFS } \\
\text { KOe }\end{array}$ & $\begin{array}{l}\% \\
\text { Area } \\
(298 \mathrm{~K})\end{array}$ & $\begin{array}{l}\% \\
\text { Area } \\
(77 \mathrm{~K})\end{array}$ \\
\hline \multicolumn{7}{|l|}{$\underline{\text { FePtK-S-218 after } 150 \mathrm{~h}}$} \\
\hline \multicolumn{7}{|l|}{ fixed bed test at $265^{\circ} \mathrm{C} \mathrm{P}=1 \mathrm{~atm}, \mathrm{H}_{2} / \mathrm{CO}=1$} \\
\hline \multicolumn{7}{|l|}{ (spectra collected at $298 \mathrm{~K}$ for $24 \mathrm{~h}$ ) } \\
\hline $\mathrm{Fe}_{3} \mathrm{O}_{4}\left(\mathrm{FiM}^{\mathrm{c}}\right)$ & & 0.70 & 0.05 & 441 & 7.7 & \\
\hline \multirow[t]{3}{*}{$\chi-\mathrm{Fe}_{2.5} \mathrm{C}$} & I & 0.14 & -0.11 & 185 & 32.3 & \\
\hline & II & 0.17 & 0.04 & 212 & 3.1 & \\
\hline & III & 0.17 & 0.14 & 103 & 8.8 & \\
\hline $\mathrm{Fe}^{2+}$ & & 0.71 & 1.89 & --- & 1.3 & \\
\hline \multirow{2}{*}{$\mathrm{Fe}_{3} \mathrm{O}_{4}(\mathrm{sp})^{\mathrm{d}}$} & & 0.26 & 1.20 & --- & 18.6 & \\
\hline & & 0.25 & 0.69 & --- & 28.2 & \\
\hline
\end{tabular}

${ }^{\mathrm{a}}$ Relative to $\alpha-\mathrm{Fe}$.

${ }^{b}$ For magnetically split spectra this value is $2 \varepsilon$ ', $\Delta \mathrm{E}_{\mathrm{Q}}=2 \varepsilon$ ' if $\phi=0$.

${ }^{\mathrm{c}}$ Ferrimagnetic $\mathrm{Fe}_{3} \mathrm{O}_{4}$.

${ }^{\mathrm{d}}$ Superparamagnetic $\mathrm{Fe}_{3} \mathrm{O}_{4}$. 


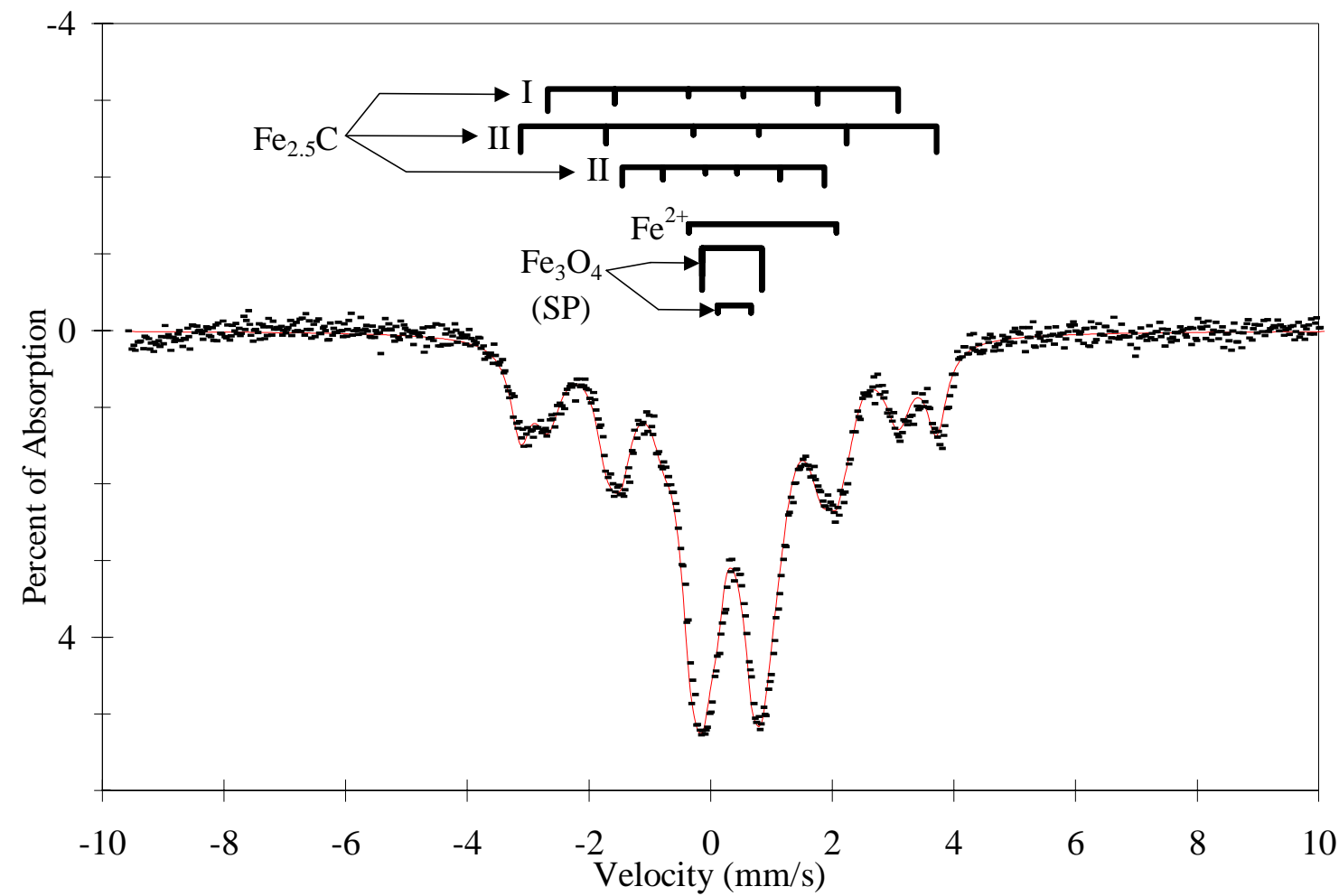

Fig 20. Mossbauer Spectrum of Fe-S-201 after statistically designed experiments run \#08

SCA settings:

Window: 0.8 volts

Lower level: 5.6 volts

Course gain: $1 \mathrm{~K}$

Fine gain: 0.532
Source to Counter distance: 7 inch Count rate: 16,809 counts/sec Data collected at room temperature for $24 \mathrm{~h}$ 
Table 17. Mössbauer spectroscopy parameters of Fe-S-201 catalyst after statistically designed fixed bed run $\# 08$ at $265^{\circ} \mathrm{C}, 10 \mathrm{~atm}, \mathrm{H}_{2} / \mathrm{CO}=1$

\begin{tabular}{|c|c|c|c|c|c|c|}
\hline Species & $\begin{array}{l}\text { Iron } \\
\text { site }\end{array}$ & $\begin{array}{l}\mathrm{IS}^{\mathrm{a}} \\
\mathrm{mm} / \mathrm{s}\end{array}$ & $\begin{array}{l}\Delta \mathrm{E}_{\mathrm{Q}}^{\mathrm{b}} \\
\mathrm{mm} / \mathrm{s}\end{array}$ & $\begin{array}{l}\text { HFS } \\
\text { KOe }\end{array}$ & $\begin{array}{l}\% \\
\text { Area } \\
(298 \mathrm{~K})\end{array}$ & $\begin{array}{l}\% \\
\text { Area } \\
(77 \mathrm{~K})\end{array}$ \\
\hline \multirow{5}{*}{$\begin{array}{l}\frac{\text { Fe-S- } 201 \text { after } 150 \mathrm{~h}}{\text { fixed bed test at } 265^{\circ} \mathrm{C} \mathrm{P}=1 \mathrm{~atm}, \mathrm{H}_{2}} / \mathrm{CO}=1 \\
(\text { spectra collected at } 298 \mathrm{~K} \text { for } 24 \mathrm{~h}) \\
\mathrm{Fe}_{3} \mathrm{O}_{4}\left(\mathrm{FiM}^{\mathrm{c}}\right)\end{array}$} & \multirow{11}{*}{\begin{tabular}{|l} 
I \\
II \\
III
\end{tabular}} & & & & & \\
\hline & & & & & & \\
\hline & & & & & & \\
\hline & & --- & --- & --- & --- & \\
\hline & & --- & --- & --- & --- & \\
\hline \multirow[t]{3}{*}{$\chi-\mathrm{Fe}_{2.5} \mathrm{C}$} & & 0.15 & 0.11 & 178 & 19.4 & \\
\hline & & 0.28 & 0.04 & 212 & 17.1 & \\
\hline & & 0.19 & 0.03 & 103 & 12.9 & \\
\hline $\mathrm{Fe}^{2+}$ & & 0.86 & 2.42 & --- & 4.1 & \\
\hline \multirow{2}{*}{$\mathrm{Fe}_{3} \mathrm{O}_{4}(\mathrm{sp})^{\mathrm{d}}$} & & 0.35 & 0.98 & --- & 43.7 & \\
\hline & & 0.39 & 0.55 & --- & 2.9 & \\
\hline
\end{tabular}

${ }^{\mathrm{a}}$ Relative to $\alpha-\mathrm{Fe}$.

${ }^{\mathrm{b}}$ For magnetically split spectra this value is $2 \varepsilon^{\prime}, \Delta \mathrm{E}_{\mathrm{Q}}=2 \varepsilon$ ' if $\phi=0$.

${ }^{\mathrm{c}}$ Ferrimagnetic $\mathrm{Fe}_{3} \mathrm{O}_{4}$.

${ }^{\mathrm{d}}$ Superparamagnetic $\mathrm{Fe}_{3} \mathrm{O}_{4}$. 


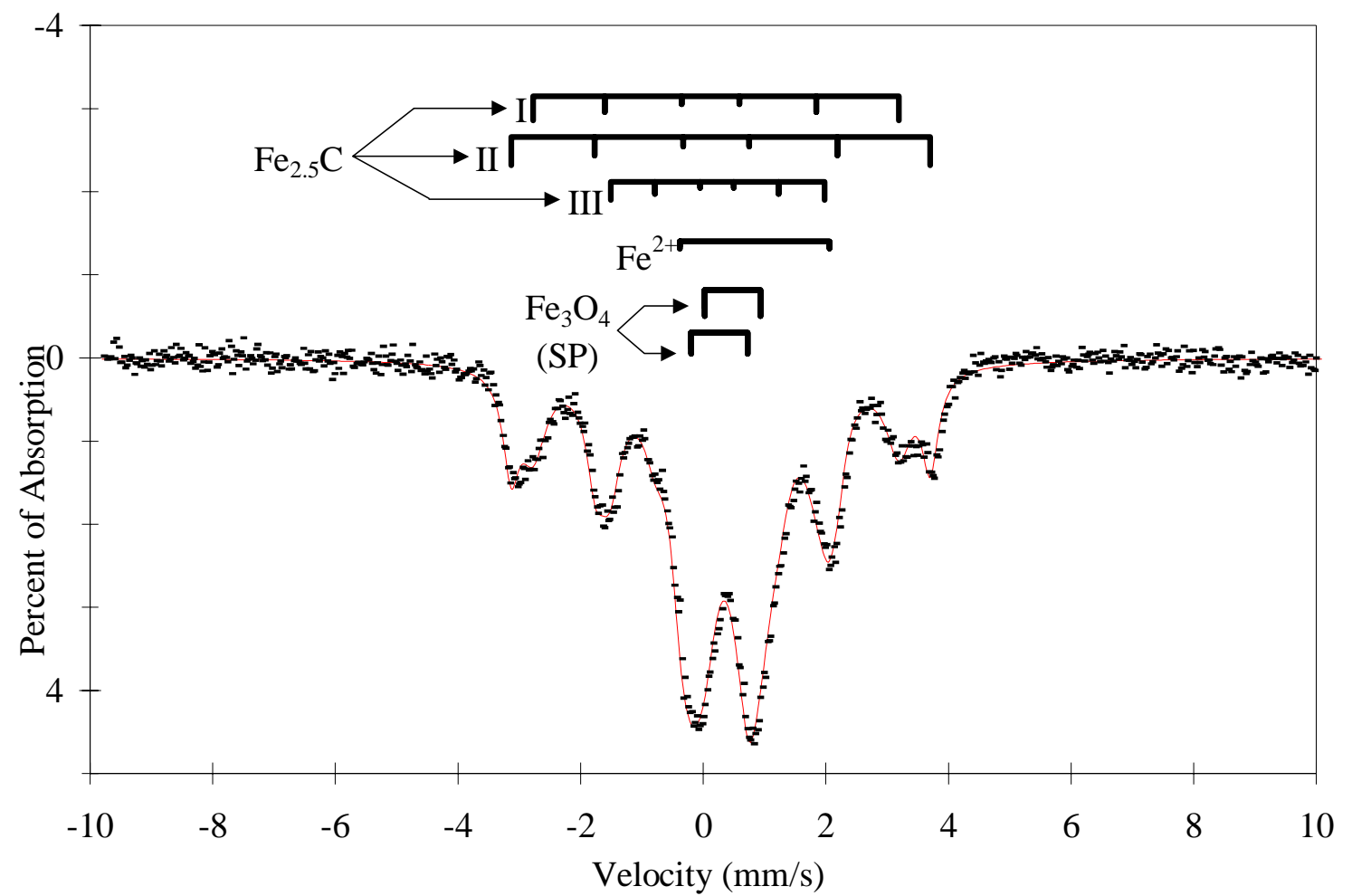

Fig 21. Mossbauer Spectrum of FePt-S-220 after statistically designed experiments run \#09

SCA settings:

Window: 0.8 volts

Lower level: 5.6 volts

Course gain: $1 \mathrm{~K}$

Fine gain: 0.532
Source to Counter distance: 7 inch

Count rate: 15,640 counts/sec

Total Counts:1,348,976

Data collected at room temperature for $24 \mathrm{~h}$ 
Table 18. Mössbauer spectroscopy parameters of FePt-S-220 catalyst after statistically designed fixed bed run \# 09 at $265^{\circ} \mathrm{C}, 10 \mathrm{~atm}, \mathrm{H}_{2} / \mathrm{CO}=1$; Catalyst pretreated in $\mathrm{H}_{2} / \mathrm{CO}=0.5$, $320^{\circ} \mathrm{C}$ for $16 \mathrm{~h}$

\begin{tabular}{|c|c|c|c|c|c|c|}
\hline Species & $\begin{array}{l}\text { Iron } \\
\text { site }\end{array}$ & $\begin{array}{l}\mathrm{IS}^{\mathrm{a}} \\
\mathrm{mm} / \mathrm{s}\end{array}$ & $\begin{array}{l}\Delta \mathrm{E}_{\mathrm{Q}}^{\mathrm{b}} \\
\mathrm{mm} / \mathrm{s}\end{array}$ & $\begin{array}{l}\text { HFS } \\
\text { KOe }\end{array}$ & $\begin{array}{l}\% \\
\text { Area } \\
(298 \mathrm{~K})\end{array}$ & $\begin{array}{l}\% \\
\text { Area } \\
(77 \mathrm{~K})\end{array}$ \\
\hline $\begin{array}{l}\text { FePt-S-220 after } 150 \mathrm{~h} \\
\text { fixed bed test at } 250^{\circ} \mathrm{C} P=1 \mathrm{~atm}, \mathrm{H}_{2} / \mathrm{CO}=1 \\
\text { (spectra collected at } 298 \mathrm{~K} \text { for } 24 \mathrm{~h} \text { ) }\end{array}$ & & & & & & \\
\hline$\chi-\mathrm{Fe}_{2.5} \mathrm{C}$ & $\begin{array}{l}\text { I } \\
\text { II } \\
\text { III }\end{array}$ & $\begin{array}{l}0.16 \\
0.25 \\
0.23\end{array}$ & $\begin{array}{l}0.09 \\
0.07 \\
0.01\end{array}$ & $\begin{array}{l}185 \\
212 \\
108\end{array}$ & $\begin{array}{l}21.7 \\
15.5 \\
12.7\end{array}$ & \\
\hline $\begin{array}{l}\mathrm{Fe}^{2+} \\
\mathrm{Fe}_{3} \mathrm{O}_{4}(\mathrm{sp})^{\mathrm{c}}\end{array}$ & & $\begin{array}{l}0.84 \\
0.48 \\
0.26\end{array}$ & $\begin{array}{l}2.44 \\
0.91 \\
0.93\end{array}$ & $\begin{array}{l}--- \\
--- \\
---\end{array}$ & $\begin{array}{l}3.6 \\
28.5 \\
17.9\end{array}$ & \\
\hline
\end{tabular}

${ }^{\mathrm{a}}$ Relative to $\alpha-\mathrm{Fe}$.

${ }^{\mathrm{b}}$ For magnetically split spectra this value is $2 \varepsilon^{\prime}, \Delta \mathrm{E}_{\mathrm{Q}}=2 \varepsilon$ ' if $\phi=0$.

${ }^{\mathrm{c}}$ Superparamagnetic $\mathrm{Fe}_{3} \mathrm{O}_{4}$. 
Table 19. Iron phases of unpromoted (Fe-S-201) and promoted (FePt-S-220, FePtK-S-218) catalysts after statistically designed fixed bed runs (room temperature Mössbauer)

\begin{tabular}{|l|c|c|c|c|c|}
\hline \multicolumn{1}{|c|}{ Catalyst } & \multirow{2}{*}{$\begin{array}{c}\text { Run } \\
\text { number }\end{array}$} & \multicolumn{4}{|c|}{$\begin{array}{c}\text { Iron species } \\
\text { \% Area }\end{array}$} \\
\cline { 3 - 6 } & & $\mathrm{Fe}_{3} \mathrm{O}_{4}(\mathrm{FiM})^{\mathrm{a}}$ & $\mathrm{Fe}_{2.5} \mathrm{C}^{\mathrm{b}}$ & $\mathrm{Fe}^{2+}$ & $\mathrm{Fe}_{3} \mathrm{O}_{4}(\mathrm{sp})$ \\
\hline Fe-S-201 & 1 & 33.3 & 17.5 & 0.8 & 48.4 \\
\hline Fe-S-201 & 2 & 2.2 & 41.4 & 5.3 & 51.2 \\
\hline Fe-S-201 & 3 & 0.2 & 41.2 & 2.7 & 56.0 \\
\hline FePt-S-220 & 4 & - & 41.1 & 5.8 & 53.0 \\
\hline FePtK-S-218 & 5 & 4.0 & 31.8 & 4.8 & 59.4 \\
\hline Fe-S-201 & 6 & 24.6 & 19.5 & 4.4 & 51.6 \\
\hline FePtK-S-218 & 7 & 7.7 & 44.2 & 1.3 & 46.8 \\
\hline Fe-S-201 & 8 & - & 49.4 & 4.1 & 46.6 \\
\hline FePt-S-220 & 9 & - & 49.9 & 3.6 & 46.4 \\
\hline
\end{tabular}

${ }^{\mathrm{a}}$ :Ferrimagnetic $\mathrm{Fe}_{3} \mathrm{O}_{4}$

b:Haag or $\chi$-carbides $\left(\mathrm{Fe}_{2.5} \mathrm{C}\right)$

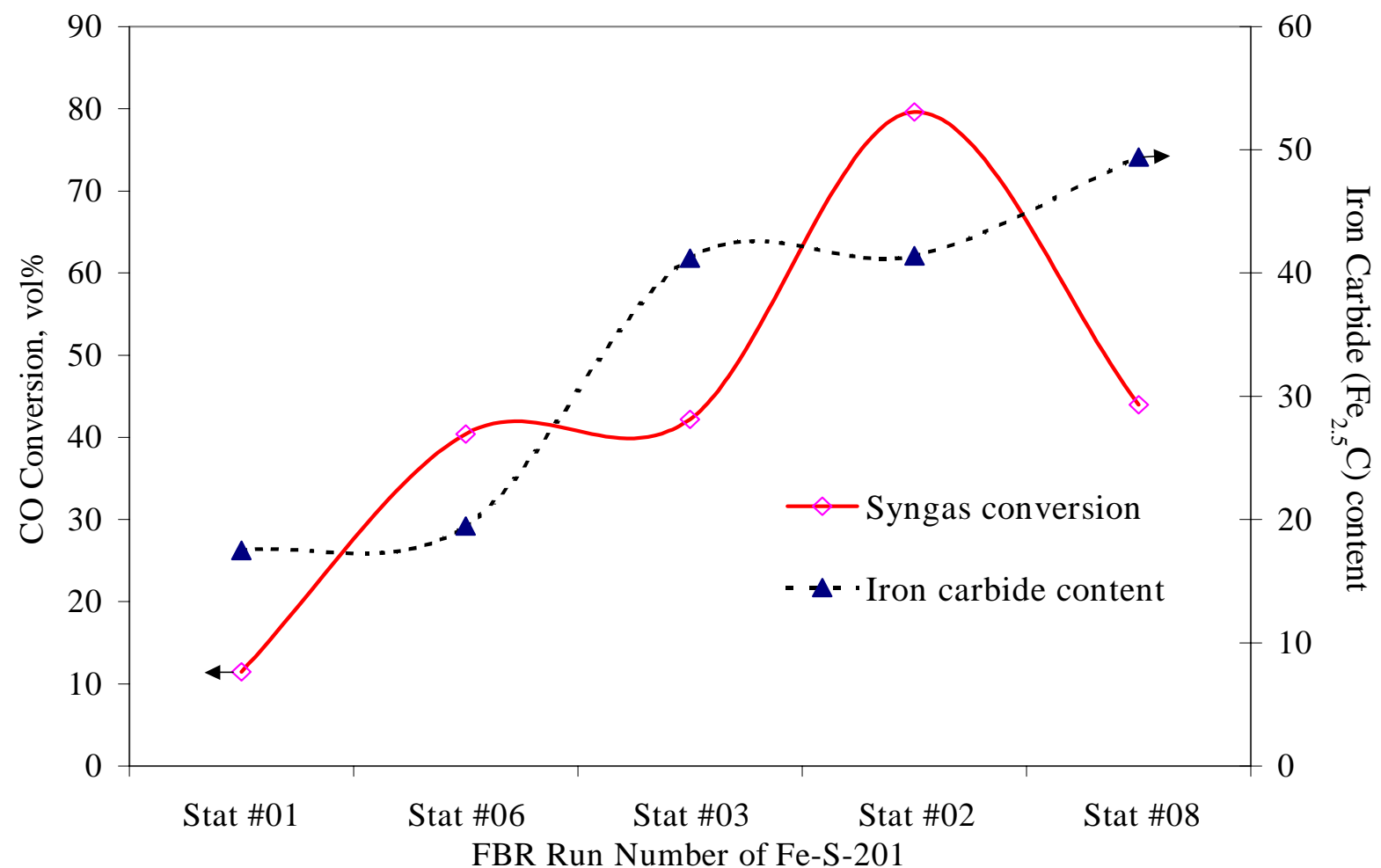

Fig 22. Syngas Conversion and Iron Carbide Content Correlation of Fe-S-201 


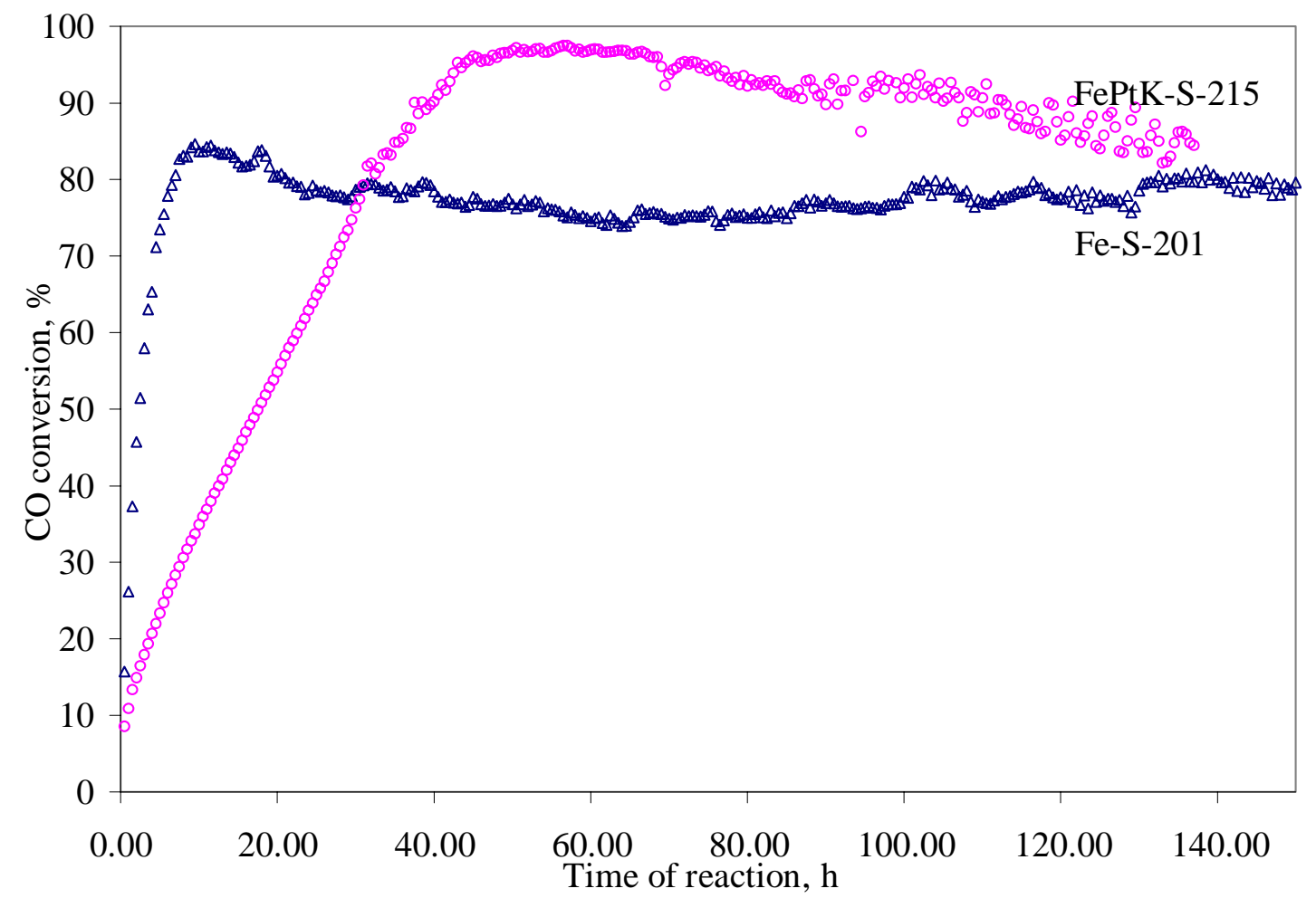

Fig 23. CO conversion of FePtK-S-215 compared with Fe-S-201 at $265^{\circ} \mathrm{C}, 10 \mathrm{~atm}, \mathrm{H}_{2} / \mathrm{CO}=1$

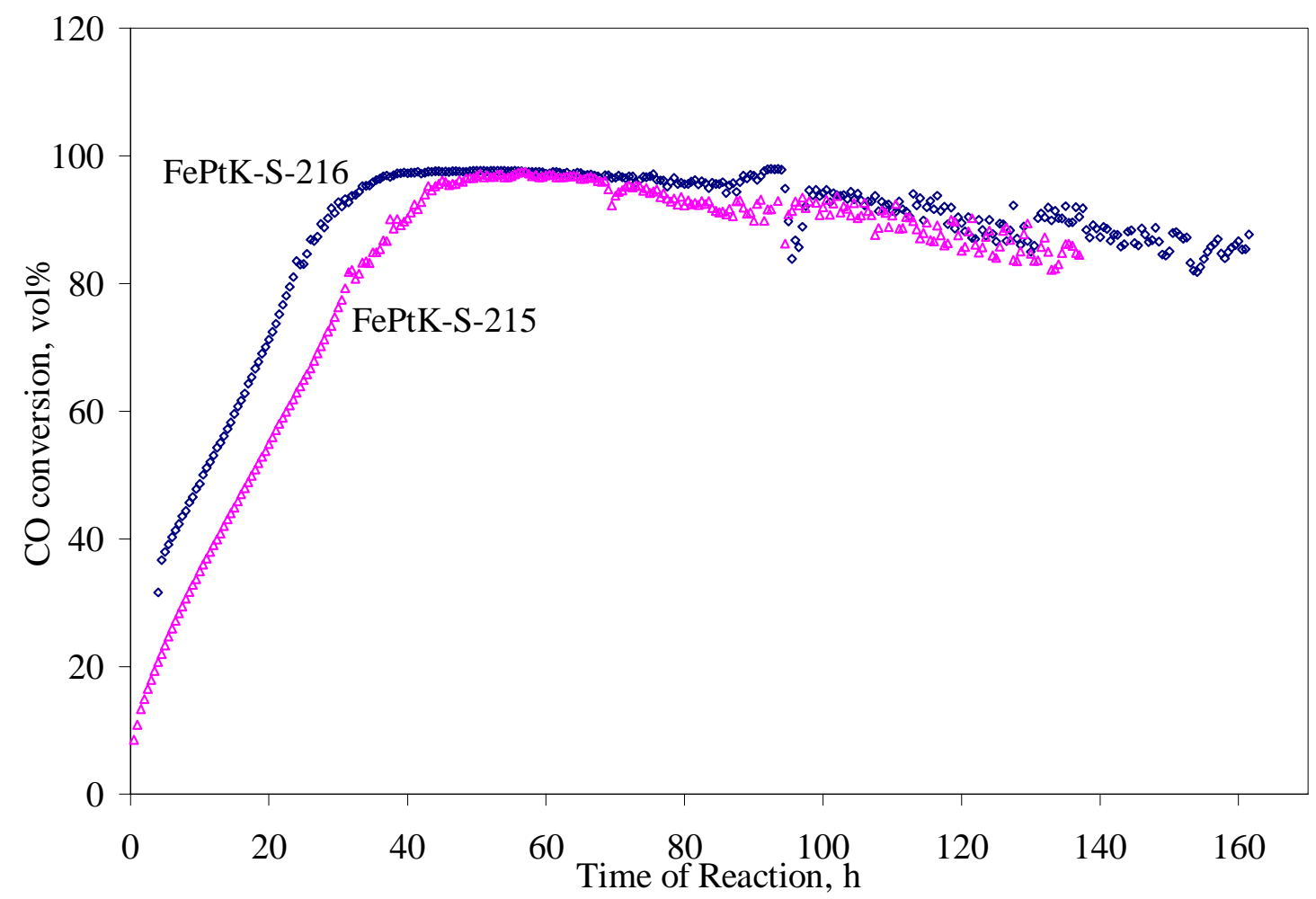

Fig 24. Repeatability of FePtK-S-215 and FePtK-S-216 fixed bed runs $\mathrm{T}=265^{\circ} \mathrm{C}, \mathrm{P}=10 \mathrm{~atm}$, Total Flow=64 sccm, $\mathrm{H}_{2} / \mathrm{CO}=1$ 


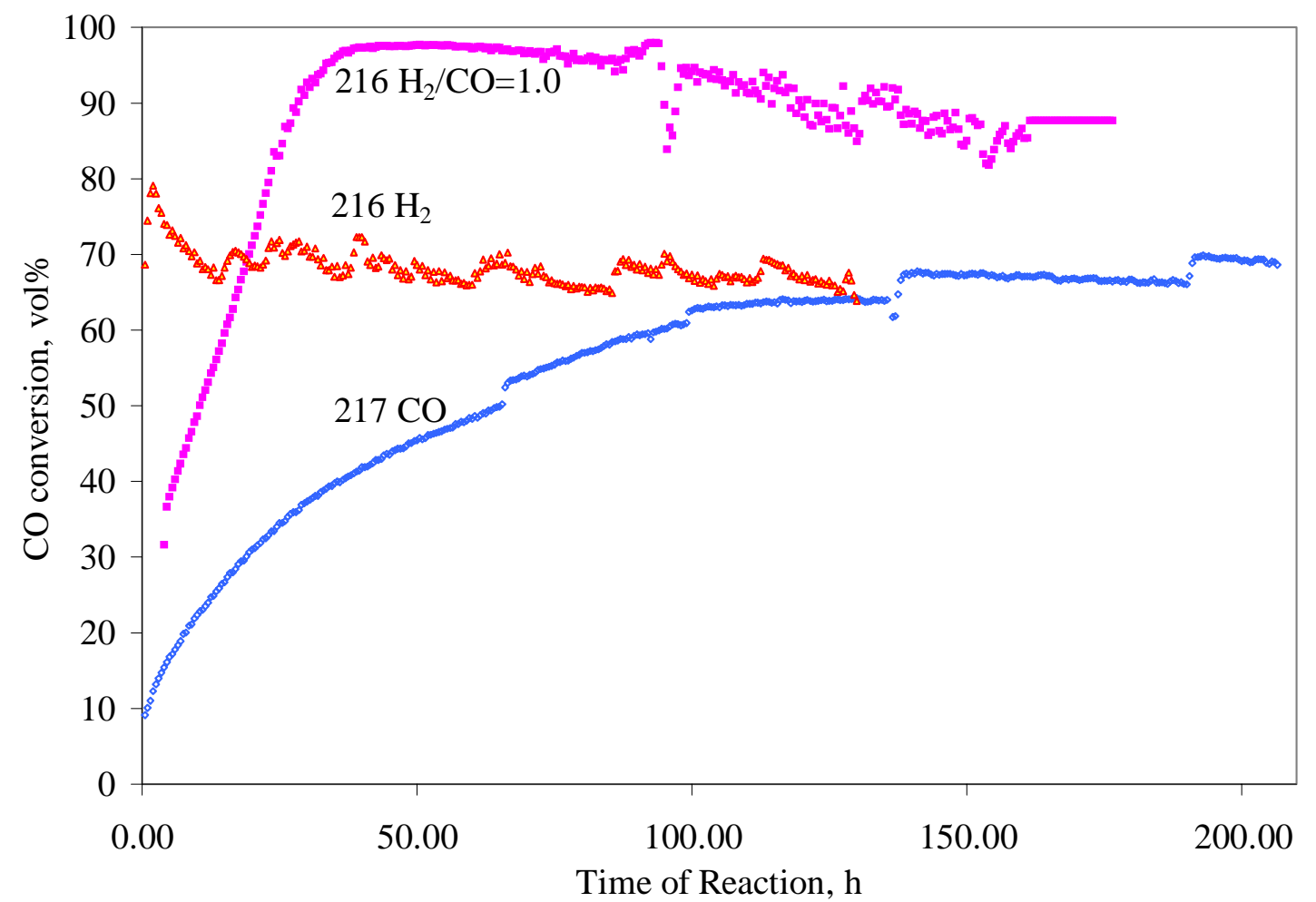

Fig 25. Pretreatment effects on FePtK-S-216 and FePtK-S-217

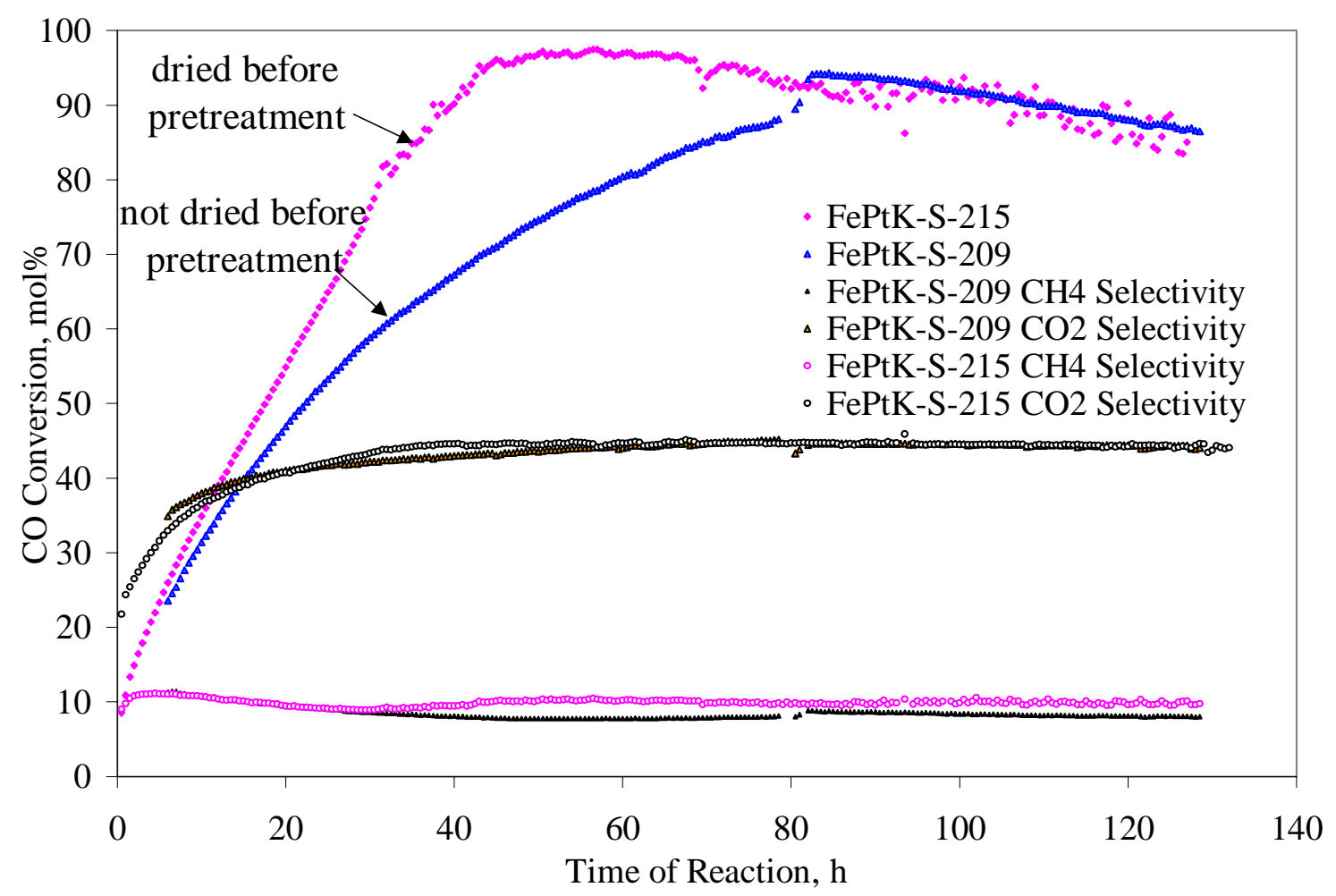

Fig 26. Fixed Bed Activity Comparision of FePtK-S-209 and FePtK-S-215 
Table 20. Steady-state activity and selectivity for unpromoted (Fe-S-203, Fe-S-206) and promoted (FePt-S-203, FePt-S-206) catalysts ${ }^{\text {a }}$.

\begin{tabular}{ccccccccc}
\hline Catalyst & $\begin{array}{c}\text { TOS } \\
(\mathrm{h})\end{array}$ & $\begin{array}{c}\text { Temp } \\
\left({ }^{\circ} \mathrm{C}\right)\end{array}$ & $\begin{array}{c}\text { Xco } \\
(\%)\end{array}$ & $\begin{array}{c}-\mathrm{r}_{\mathrm{CO} 10} 10^{6} \\
(\mathrm{~mol} / \mathrm{g}-\mathrm{s})\end{array}$ & $\begin{array}{c}\eta \mathrm{k} \mathrm{x} \mathrm{10} \\
\left(\mathrm{mol} / \mathrm{g}-\mathrm{s}-\mathrm{Pa}^{0.5}\right)\end{array}$ & $\begin{array}{c}\text { TOF } \\
\left(\mathrm{s}^{-1}\right)\end{array}$ & $\begin{array}{c}\mathrm{S}_{\mathrm{CH} 4} \\
(\%)\end{array}$ & $\begin{array}{c}\mathrm{S}_{\mathrm{CO} 2} \\
(\%)\end{array}$ \\
\hline Fe-S-206 $^{\mathrm{b}}$ & 30 & 270 & 52.2 & 6.4 & 9.0 & 2.6 & 8.7 & 36.2 \\
& 35 & 270 & 51.1 & 6.3 & 8.8 & 2.6 & 8.7 & 35.6 \\
& 40 & 270 & 50.1 & 6.2 & 8.7 & 2.5 & 8.8 & 35.5 \\
& 49 & 270 & 48.5 & 6.0 & 8.4 & 2.4 & 8.9 & 34.9 \\
\hline FePt-S-203 $^{\mathrm{c}}$ & 25 & 265 & 44.8 & 5.5 & 7.8 & 1.6 & 9.5 & 33.3 \\
& 35 & 265 & 43.4 & 5.3 & 7.5 & 1.6 & 9.5 & 32.8 \\
& 45 & 265 & 42.1 & 5.2 & 7.3 & 1.5 & 9.6 & 32.3 \\
FePt-S-206 $^{\mathrm{d}}$ & 61 & 265 & 40.3 & 5.0 & 7.0 & 1.5 & 9.7 & 31.9 \\
\hline & 35 & 266 & 54.4 & 6.7 & 9.4 & 2.0 & 10.5 & 38.1 \\
& 45 & 265 & 58.0 & 7.1 & 10.0 & 2.1 & 10.2 & 38.7 \\
& 61 & 265 & 55.5 & 6.8 & 9.6 & 2.0 & 10.1 & 38.0 \\
\hline
\end{tabular}

a Catalyst loading: $2 \mathrm{~g}$

Reaction conditions: $10 \mathrm{~atm}, \mathrm{H}_{2} / \mathrm{CO}=1$, GHSV=1.92 NL/h/g $/ \mathrm{g}_{\text {cat }}$

PFR reactor assumed

b Fe-S-206 (10 wt\% Fe); assume 6.8\% dispersion; Davisil 644 supported

${ }^{c}$ FePt-S-206 (10 wt\% Fe, $0.5 \mathrm{wt} \% \mathrm{Pt}$ ); assume 9.5\% dispersion; Davisil 644 supported

d FePt-S-206 (10 wt\% Fe, 1wt\% Pt); assume 9.5\% dispersion; Davisil 644 supported 


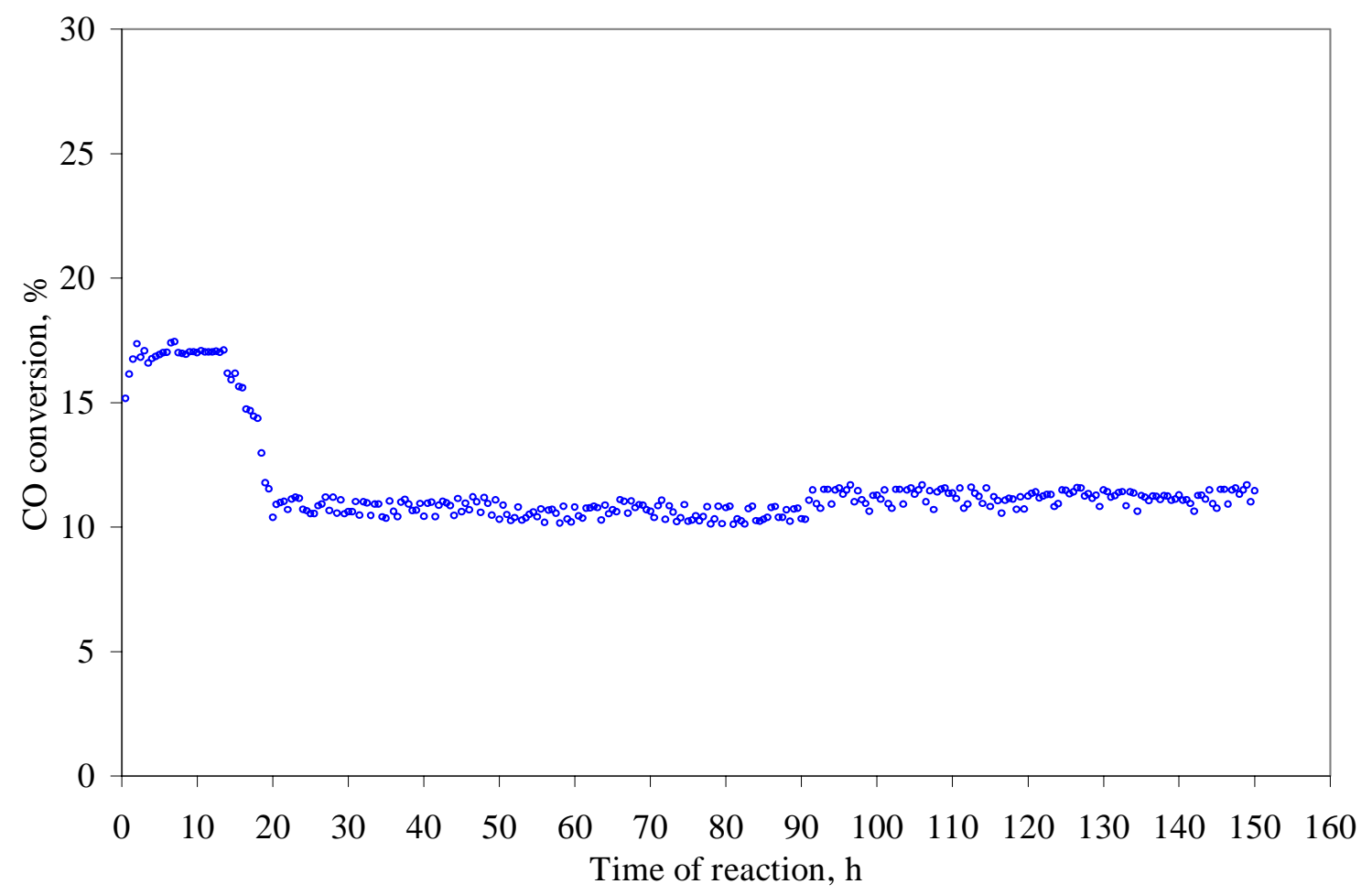

Fig 27. Statistically Designed Fixed Run 1 of Fe-S-201 Fixed Bed Run; Pretreated in $\mathrm{H}_{2} / \mathrm{CO}=1,250^{\circ} \mathrm{C}, 16 \mathrm{~h}$ Reaction conditions: $\mathrm{T}=250^{\circ} \mathrm{C}, \mathrm{P}=10 \mathrm{~atm}$, Total Flow $=64 \mathrm{SCCM}$

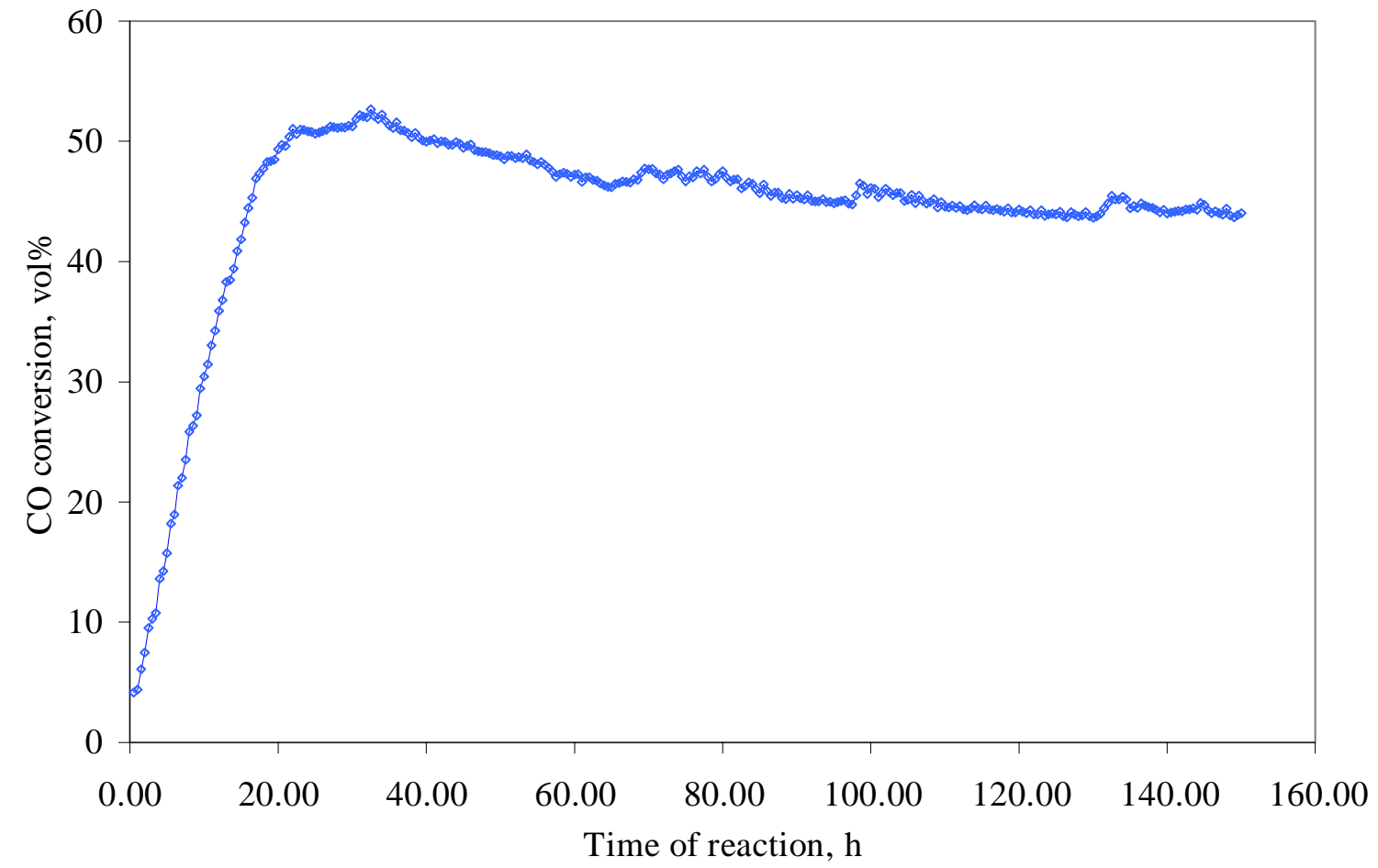

Fig 28. Statistically Designed Fixed Run 4 of FePt-S-220 Fixed Bed Run; Pretreated in $\mathrm{H}_{2} / \mathrm{CO}=0.1,280^{\circ} \mathrm{C}, 16 \mathrm{~h}$ Reaction conditions: $\mathrm{T}=250^{\circ} \mathrm{C}, \mathrm{P}=10 \mathrm{~atm}$, Total Flow $=64 \mathrm{SCCM}$ 


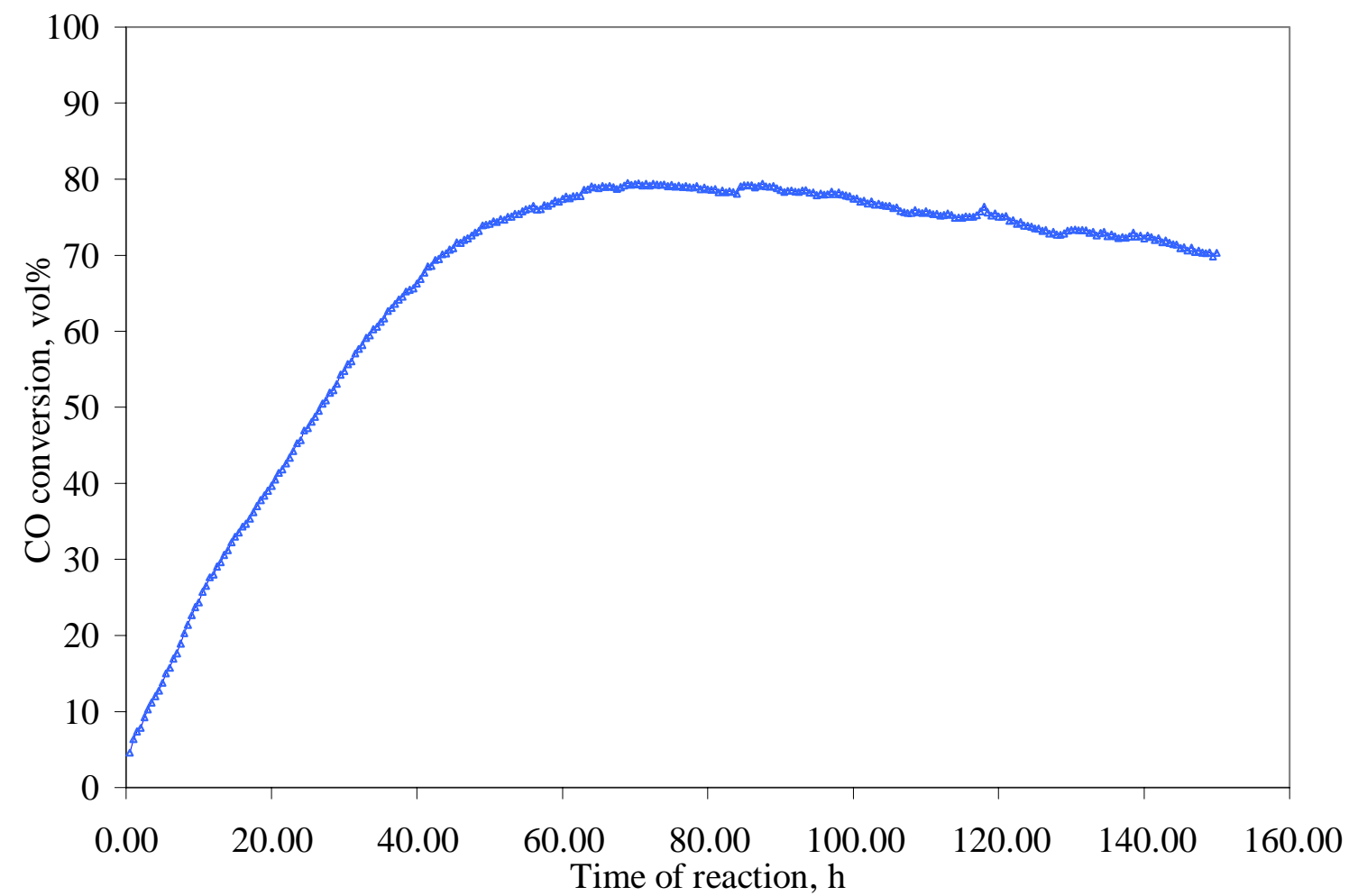

Fig 29. Statistically Designed Fixed Run 7 of FePtK-S-218 Fixed Bed Run; Pretreated in $\mathrm{H}_{2} / \mathrm{CO}=1,320^{\circ} \mathrm{C}$, 16h Reaction conditions: $\mathrm{T}=265^{\circ} \mathrm{C}, \mathrm{P}=10 \mathrm{~atm}$, Total Flow $=64 \mathrm{SCCM}$ 
Table 21. Steady-state activity and selectivity for unpromoted (Fe-S-201) and promoted (FePt-S-220, FePtK-S-218) catalysts ${ }^{a}$ in statistically designed fixed bed runs

\begin{tabular}{|l|c|c|c|c|c|c|c|}
\hline \multicolumn{1}{|c|}{ Catalyst } & $\begin{array}{c}\text { Run } \\
\text { number }\end{array}$ & $\begin{array}{c}\text { TOS } \\
(\mathrm{h})\end{array}$ & $\begin{array}{c}\text { Reaction Temp } \\
\left({ }^{\circ} \mathrm{C}\right)\end{array}$ & $\begin{array}{c}\text { Xco } \\
(\%)\end{array}$ & $\begin{array}{c}\mathrm{S}_{\mathrm{CH} 4} \\
(\%)\end{array}$ & $\begin{array}{c}\mathrm{S}_{\mathrm{CO} 2} \\
(\%)\end{array}$ & $\begin{array}{c}\text { Deactivation } \\
\text { Rate }(\% / \mathrm{h})\end{array}$ \\
\hline Fe-S-201 & 1 & 40 & 250 & 10.4 & 0.0 & 13.8 & \\
& & 150 & & 11.5 & 0.0 & 14.0 & 0.01 \\
\hline Fe-S-201 & 2 & 40 & 265 & 78.5 & 12.7 & 49.5 & \\
& & 150 & & 79.6 & 12.5 & 50.1 & 0.01 \\
\hline Fe-S-201 & 3 & 40 & 250 & 45.4 & 8.3 & 34.3 & \\
& & 150 & & 42.2 & 8.6 & 32.8 & -0.029 \\
\hline FePt-S-220 & 4 & 40 & 250 & 45.0 & 8.9 & 37.2 & \\
& & 150 & & 44.0 & 7.4 & 33.3 & -0.009 \\
\hline FePtK-S-218 & 5 & 40 & 265 & 74.4 & 10.6 & 52.1 & \\
& & 150 & & 74.9 & 8.7 & 49.9 & 0.0046 \\
\hline Fe-S-201 & 6 & 40 & 265 & 40.6 & 9.6 & 33.4 & \\
& & 150 & & 40.4 & 8.7 & 33.4 & -0.0018 \\
\hline FePtK-S-218 & 7 & 40 & 250 & 66.3 & 9.8 & 49.5 & \multirow{2}{*}{0.036} \\
\hline Fe-S-201 & 8 & 40 & 250 & 31.4 & 9.5 & 25.6 & \\
& & 150 & & 44.0 & 8.8 & 33.2 & 0.115 \\
\hline
\end{tabular}

a Catalyst loading: $2 \mathrm{~g}$

Reaction conditions: $10 \mathrm{~atm}, \mathrm{H}_{2} / \mathrm{CO}=1$, GHSV=1.92 NL/h/g $/ \mathrm{g}_{\text {cat }}$

PFR reactor assumed

b Assume linear deactivation 